\title{
COMPONENT DEVELLOPMENT
}

\section{DOE/ET/27/25-T2-VOLS $S R C-C R-81-7 S-V_{0} 1 . S$}

\author{
Claude Harvey, Warren NcBee and Hugh B. Matthews \\ Sperry Research Center, Sudbury, MA 01776
}

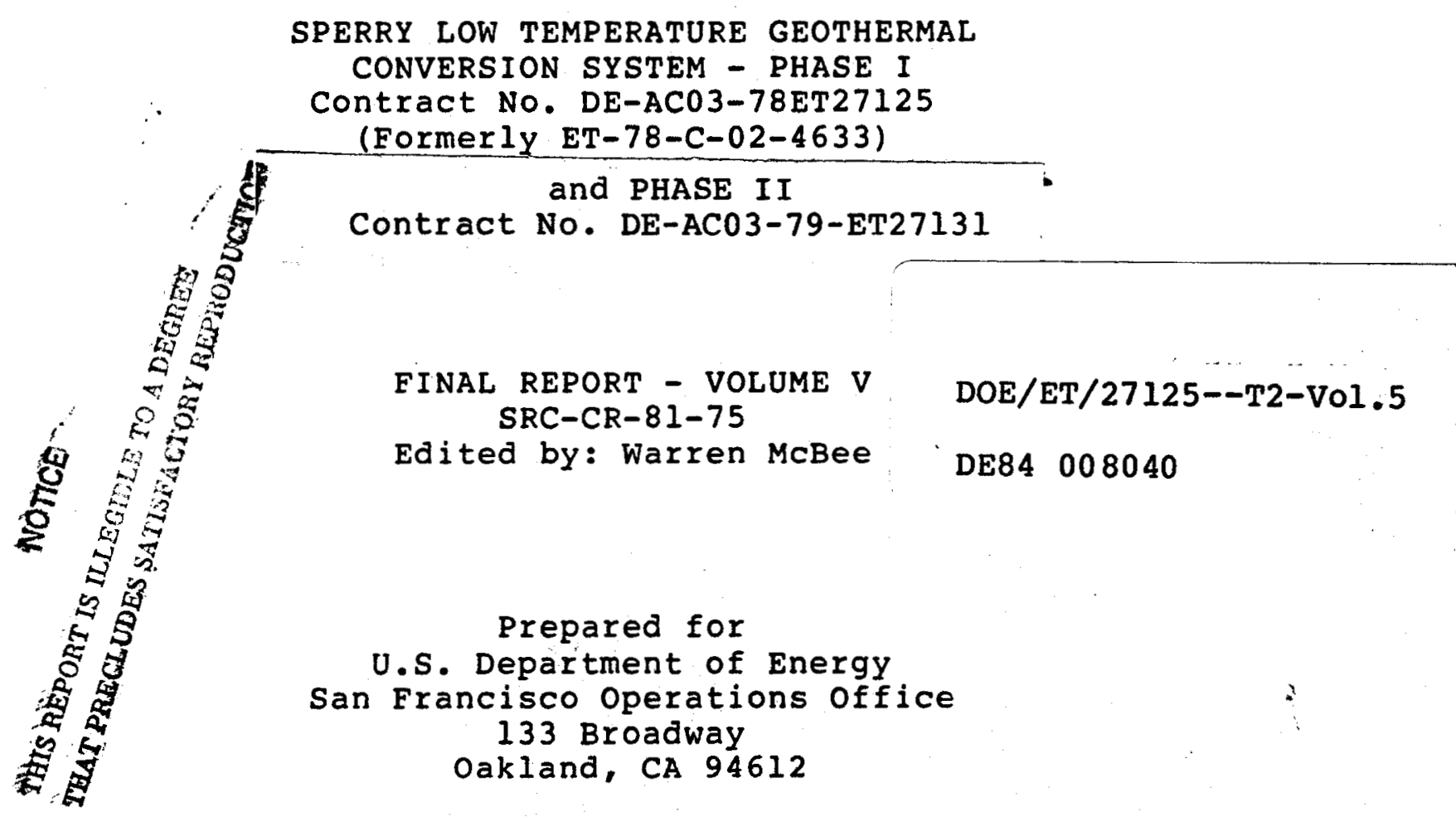

\section{DISCLAIMER}

This report was prepared as an account of work sponsored by an agency of the United States Government. Neither the United States Government nor any agency thereof, nor any of their employees, makes any warranty, express or implied, or assumes any legal liability or responsibility for the accuracy, completeness, or usefulness of any information, apparatus, product, or process disclosed, or represents that its use would not infringe privately owned rights. Reference herein to any specific commercial product, process, or service by trade name, trademark, manufacturer, or otherwise does not necessarily constitute or imply its endorsement, recommendation, or favoring by the United States Government or any agency thereof. The views and opinions of authors expressed herein do not necessarily state or reflect those of the United States Government or any agency thereof. 


\section{DISCLAIMER}

This report was prepared as an account of work sponsored by an agency of the United States Government. Neither the United States Government nor any agency Thereof, nor any of their employees, makes any warranty, express or implied, or assumes any legal liability or responsibility for the accuracy, completeness, or usefulness of any information, apparatus, product, or process disclosed, or represents that its use would not infringe privately owned rights. Reference herein to any specific commercial product, process, or service by trade name, trademark, manufacturer, or otherwise does not necessarily constitute or imply its endorsement, recommendation, or favoring by the United States Government or any agency thereof. The views and opinions of authors expressed herein do not necessarily state or reflect those of the United States Government or any agency thereof. 


\section{DISCLAIMER}

Portions of this document may be illegible in electronic image products. Images are produced from the best available original document. 


\section{LEGIBILITY NOTICE}

A major purpose of the Technical Information Center is to provide the broadest possible dissemination of information contained in DOE's Research and Development Reports to business, industry, the academic community, and federal, state, and local governments. Non-DOE originated information is also disseminated by the Technical Information Center to support ongoing DOE programs.

Although large portions of this report are not reproducible, it is being made available only in paper copy form to facilitate the availability of those parts of the document which are legible. Copies may be obtained from the National Technical Information Service. Authorized recipients may obtain a copy directly from the Department of Energy's Technical Information Center. 
DISCLAIMER

This report was prepared as an account of work sponsored by an agency of the United States Government. Neither the United States Government nor any of their employees, makes any warranty, express or implied, or assumes any legal liability or responsibility for the accuracy, completeness, or usefulness of any information, apparatus, product, or process disclosed, or represents that its use would not infringe privately owned rights. Reference herein to any specific commercial product, process, or service by trade name, trademark, manufacturer, or otherwise, does not necessarily constitute or imply its endorsement, recommendation, or favoring by the United States Government or any agency thereof. The views and opinions of authors expressed herein do not necessarily state or reflect those of the United States Government or any agency thereof. 
FOREWORD

This final report covers the work performed under the "Sperry Low Temperature Geothermal Conversion system" project, both Phase I under Contract No. DE-AC03-78-ET27125 (formerly ET-78-C-02-4633) and Phase II under Contract No. DE-AC03-79-ET27131.

Vols. I and II, submitted in 1982 covered a portion of the work accomplished under Phase I. Vols. III, IV, V, and VI submitted at this time cover the balance of work performed. under Phase I and work performed under Phase II. 


\section{VOLUME TABLE OF CONTENTS}

I ORGANIC WORKING FLUID FROPERTIES

II SISTEM COMPONENT COMPATIBILITY \& R-114 STABILITY

III SYSTEMS DESCRIPTION

IV FIEID ACTIVITIES

$\mathrm{V}$ COMPONENT DEVELOPMENT

VI ECONOMIC STUDIES 
VOLTME V

TABLE OF CONTENTS

INTRODUCTION 1

5.0

5.1

INSTRUMENTATION AND CONTROL

5.1 .1

5.1 .2

5.1 .3

5.1 .4

5.1 .5

Introduction

Down-Well Data Acquisition System

Surface I \& C System

Scientific Data

Gravity Head I \& C System

2

2

2

3

3

3

5.2

DOWN-WELL CONDUITS \& SEALS 5

5.2 .1

$5 \cdot 2.2$

5.2 .3

Introduction

Conduit Welded Connections

5

Packers and Sliding Seals

$5.2 \cdot 3.1$

$5.2 \cdot 3 \cdot 2$

$5 \cdot 2 \cdot 3 \cdot 2.1$

$5 \cdot 2 \cdot 3 \cdot 2.2$

$5 \cdot 2 \cdot 3 \cdot 2 \cdot 3$

$5 \cdot 2 \cdot 3 \cdot 2 \cdot 4$

Introduction

Sliding Packer

Packer Formulation

Development

Packer Cup Test Procedure $\quad 11$

Packer Cup Design

Cup Test Results

12

13

$5 \cdot 2 \cdot 3 \cdot 3$

$5 \cdot 2 \cdot 3 \cdot 4$

5.2 .3 .5

Fixed Packer Approach

Riser Sliding Seal

Pump System Downcomer Seal

13

13

14

5.2 .4

Lube \& Instrument Lines

14

TURBINE-PUMP-UNIT DEVELOPMENT

15

Introduction

15

FRANCIS TURBINE DESIGN STUDY

16

5.4

$5 \cdot 3 \cdot 1$

HEAT EXCHANGER DEVELOPMENT 17

Introduction $\quad 17$

Ten-Pound Loop 17

5.5 .2

$5 \cdot 5 \cdot 3$

$5 \cdot 5 \cdot 4$

Tube Bundle Geometry

23

Tube Sheet Seals

24

5.6

ENTHALPY RECOVERY UNIT

25 
TABLE OF CONTENTS (Cont'd)

APPENDIX A

APPENDIX B

APPENDIX C

APPENDIX D

APPENDIX E

APPENDIX F

APPENDIX G

APPENDIX H
Operating Instructions for Scientific Instrumentation System

Report on Test for 1/2" Tube (Lube Iine)

Report on Pressure/Temperature Test of Stabbing Fixture Seals

Design and Predicted Performance of Sperry Stand-Alone TurbinePump Unit

Turbine-Pump Unit Test Programs

Gravity-Head Turbine-Pump Unit Sizing Study

Micro Motion Mass Flow Meter

Double Tubesheet Leak Tests 
1. Downwell Data Acquisition 26

2. Block Flow Diegram, Down Well Data Acquisition 27

3. Hoisting Drum for Lube/Signal Line 28

4. Pump Test System P \& I Diagram 29

5. Organic Pump System Control Schematic 30

6. Mimic Board Layout 31

7. Pump System Control Panel 32

8. Geothermal. Pump Instrumentation System 33

9. Surface Data Acquisition - Block Diagram 34

10. Data Storage and Control - Block Diagram 35

11. Gravity Head System Control Schematic 36

12. G. H. Mimic Board Layout 37

13. G. H. Main Single Line Diagram 38

14. Gravity Head System Schematic 39

15. Typical Tabuler Heat Exchanger Section 40

16. Automated Welding Lathe 41

17. Photomicrograph of Welded Section of Casing 42

18. Higher Magnification of Portion of Fig. 1742

19. Packer Cup Test Facility 43

20. Initial Packer Cup Design 44

21. T-Bar Fingers for Packer Cup 45

22. Modified Cup Design Cross-Section 46

23. Fixed Baker Packer 47

24. Well-Head Sliding Seal Assembly 48

25. Well-Head Sliding Seal Detail 49

26. Down-well Heat Exchanger Coupling 50

27. R-114 Downcomer Seal 51

28. Lube 0il/Electricsl Stabbing Fixture 52

29. Pump System TPU Layout 53

30. G. H. TPU Francis Turbine Machining Assy. $\quad 54$

31. Francis Turbine Blade Design 55

32. Fluid Test Apparatus (Ten Pound Loop) 56

33. Photograph of Ten Pound Loop 57

34. Typical Tube Bundle Layout 58

35. Enthalpy Recovery Unit 59 


\subsection{INTRODUCTION}

The fundamental inventions which motivate this program are system concepts centered on a novel heat engine cycle and the use of down-well heat exchange. However, the implementation of these system concepts required development of new components and subsystems, and research in materials and fluid dynamics. A major research topic was organic working fluid properties, reported in vol. I of this Final Report. Another major research topic was compatibility between the three fluids involved in the system (R-114, geothermal brine, lubricating oil) and between these fluids and the materials of construction, especially elastomers, used in

- seals. This topic is reported in Vol. II. The remaining component and material development efforts are reported in this volume. As would be expected, the primary emphasis is on down-well hardware. The only surface equipment included is the surface portion of the instrumentation and control systems covered in sections $5.1 .3,5.1 .4$ and 5.1 .5 . Downwell instrumentation is reported in section 5.1 .2 .

Down-well conduits and techniques for installing, connecting and sealing them are covered in section 5.2 .

The downwell turbine-pump unit (TPU) is a critical component since it is relatively inaccessible and operates in a hostile environment. Its development is reported in section 5.3. The TPU for the gravity-head system requires a different type of turbine because of the large flowrate through it and the small pressure difference across it. The design study for a Francis turbine to meet these requirements is reported in section 5.4 .

A feature of these systems is use of a down-well heat exchanger. There were extensive studies, described in section 5.5, of tube-bundle configuration, tube-sheet seals, structural integrity, and flow and heat transfer, as well as the research on welded connections and sliding elastomeric seals described in section 5.2 .

Another innovative component in these systems is the enthalpy recovery unit (ERU). This direct-contact heat exchanger compensates for under-cooling in the condenser and superheat in the main turbine exhaust. It is described in section 5.6 . 


\section{1 .1 Introduction}

The instrumentation and control systems for the pump system were completed and installed at the $E$. Mesa test site and were ready for operation in June, 1981, when the well was lost. These I\&C systems consisted of three subsystems: 1) a down-well data acquisition and

transmission system, 2) an operation surface system and 3) a scientific data surface system. These subsystems are described in sections 5.1.2, 5.1 .3 and 5.1 .4 below.

The instrumentation and control system for the gravity head system was not fabricated per se, but it would have been derived from the pump I\&C system for the most part. The principal addition would have been associated with the turbine-generator controls and output electric power switchgear. The plan for these additions is described briefly in section 5.1 .5 below.

\subsubsection{Down-well Data Acquisition Subsystem}

The functional schematic of this subsystem is shown in Figure 1 . Its function is to sense and transmit the following data:

- Pump Inlet \& Outlet Pressures

- Turbine Inlet \& Outlet Pressures

- Lubrication oil pressure

- Pump outlet Temperature

- Turbine Inlet \& Outlet Temperatures

- Heat Exchanger Inlet \& Outlet

Temperatures

- (Both Brine \& Working Fluid)

- Transducer Manifold Temperatures

- Instrument Cannister Temperatures

- Turbine-Pump RPM (2 Channels)

- Zero \& Full-scale Calibration signals

The block flow diagram of the down-well package is shown in Figure 2. This portion of the system is located in a sealed canister inside the turbine exhaust pipe just above the turbine. Electrical connection to the surface is by means of a coaxial logging cable which was threaded through the lubrication oil tube. The instrumentation cable and lube oil tube are continuous and are stabbed into the turbine exhaust pipe by means of a special fitting above the oil cooler. This is done after the TPU and its RIl4 conduits have been installed in the well. Due to loss of the well this installation operation was never tried. However, many tests were made in the lab of the stabbing connection and it went through several design modifications as a result of these tests. The hydraulically operated lowering and hoisting drum for the combined lube oil tube and instrumentation cable is shown in Figure 3 . 
The electronic components and sensors for the down-well instrument package were tested separately for satisfactory performance under the severe down-well conditions, particularly the soak at maximum brine temperature when the TPU is not operating and there is no cooling by the turbine exhaust. The complete down-well instrument package was operated successfully in the turbine exhaust line during laboratory testing of the TPU.

\section{1 .3 Surface I\&C System}

The complete piping and instrumentation diagram for the pump system is shown in Figure 4. The items in a double circle are associated with the scientific data system. All other I\&C items in this figure are part of the independent operating subsystem. The primary control system is very simple. The primary controlled parameters are brine flow and organic working fluid flow via feed pump control. There is also a system for automatically transferring from external power supply to an emergency generator with a battery-powered uninterruptable instrument power supply to bridge the switchover time gap. Figure 5. is a control schematic. The system control panel is a mimic board. A layout drawing is shown in Figure 6 and a photograph of the installed panel in Figure 7 .

All surface instrumentation and control components were installed, wired and checked out. A complete set of instrumentation loop diagrams was prepared and is in the drawing file.

\section{1 .4 Scientific Data System}

This system was designed to acquire, display and record all data required to define performance and compare with theoretical predictions. The overall system configuration is shown in Figure 8 . The processor is a Sperry UNIVAC V70-600. The multiplexed surface data acquisition system block diagram is shown in Figure 10. The multiplexer was procured from Honeywell. A block diagram of the data storage and control portion of the system is shown in Figure 11. A complete operating software package was written and debugged. The system was operational on the E. Mesa site in its own van at the time the well was lost. The operating instructions for the system are contained in Appendix A.

\section{1 .5 Gravity Head I\&C System}

The instrumentation and control system for the pump system was to be used for the gravity head system also. For example, all I\&C associated with the brine-handing system would be identical except for adjustments in sensor ranges to match different parameter values. The pump surface data system was designed to accommodate the additional sensors needed for the gravity-head system because of the additional evaporative condensers and the surface turbine.

The principal change would be in the control system, which would include the main turbine-generator controls and output electric power switchgear. The gravity-head system control schematic is shown in Figure 11. The basic control function is to sense generator load conditions and condenser status and to adjust the brine flow, turbine throttle, turbine 
by-pass, and R-114 flow, and/or valves to accommodate changes in load and wet-bulb temperature, or an emergency shut-down. The same system would execute a normal start-up or shut-down procedure.

The operating panel mimic board layout is shown in Figure 12 . It was lanned to be even simpler than the one for the pump system. The main single line diagram is shown in Figure 13. The system was to have been capable of exercising fully automatic control under the supervision of - the scientific data system processor to demonstrate the feasibility of unattended or remote operation. 


\subsection{DOWNWELL CONDUITS AND SEALS}

\section{2 .1 Introduction}

A schematic drawing of the gravity-head system is shown in Figure 14. Unique features of the system are the down-well heat exchanger, turbinepump unit (TPU) and insulated riser. Also required is a small conduit to

- supply lubrication oil and a coaxial cable for instrumentation from the surface to the TPU. The upper portion of the down-well heat exchanger consists of tube bundle sections as shown in Figure 15. in order to provide the required heat exchange area per foot of length. The design installation, connection and sealing of these conduits pose engineering - problems not encountered previously in down-well equipment design and operation. An extensive development effort was carried out to address and solve these problems.

The reporting of this effort is divided into four sections: section 5.2 .2 treats the development of welded connections between heat exchanger sections, section 5.2 .3 . covers the elastomeric sliding seals, section 5.2.4 discusses the lubrication and instrument 1 ines and section 5.5 covers the tube sheet seal development as well as other aspects of heat exchanger development.

\subsubsection{Conduit Welded Connections}

The design of the connections between sections of the down-well conduits is driven by three primary requirements:

(1) structural integrity

(2) negligible leakage

(3) rapid, low-cost installation and removal with several workover cycles.

The proposed automatic welding and de-welding (cutting) procedures were developed at Sperry Research Center to offset disadvantages experienced when joining large down-hole pipe or casing with threaded couplings. In spite of high cost, "leakproof" designs, and use of a variety of sealants, large threaded joints typically leaked and were difficult to unscrew when coming out of the well because of thread corrosion by brine. Sealing welds have been applied to threaded couplings by machine with an $H$ and $M$ Pipe Beveling Machine Company pipe lathe which has been split and hinged to permit clamping around the pipe rather than slipping over the end. The lathe holds, positions, and transports the torch during welding and has been proven reliable in ine pipe operations which are in many ways as difficult as rig operations. The pipe lathe is also used for cutting if removal of a section is required. The lathe production model was not precise or sturdy enough for this application and was enhanced by several changes, including:

1. Heavy base plates were attached to the carriage rings. 
2. Inter-ring struts were enlarged in cross section.

3. Hinges for frame and ring gear were made heavier and more precise.

4. Clamps and alignment means for the carriage and ring gear separation were improved.

5. Carriage-to-pipe clamping means were enlarged and improved.

6. Means were developed to locate the frame on the pipe so that the ring gear rotates in a plane parallel to the weld face when welding and yet perpendicular to the pipe axis when Arcairing. This is to prevent cumulative increase in error of weld plane-topipe axis after repeated weld/de-weld operations.

7. A larger and more rugged drive motor with integral gear box rotates the ring gear directly through a fiber gear. It delivers a 7-fold increase in torque in the operating range to give a constant speed even if the ring binds because of dirt or misalignment. In addition, a remotely located power supply with IR compensation was added which yields a 998 speed regulation over the torque range.

A photograph of the modified welding lathe set-up for 8 " tests is shown in Figure 16.

Welding is done by the MIG (metal inert gas) process which is also referred to as GMAW (gas-metal-arc welding), while de-welding or cutting is done by arc gouging using an Arcair torch. Currently both procedures have been used successfully on hundreds of test runs on 8-, 13-, and 16inch diameter pipe with wall thicknesses of $1 / 2-i n c h$ in both bench and field tests. For example this process and equipment were used to weld the threaded couplings on one end of all the down well conduit sections fabricated for the pump system test. Welding rates of about $10 \mathrm{inch} / \mathrm{min}$ and cutting rates of $20 \mathrm{inch/min}$ have been demonstrated. Weld quality has been reported consistently high as determined by:

- Visual inspection

- Metallographic sections

$\therefore$ Pressurization with water to 5000 psi

The welding procedure is easily learned by an experienced welder and satisfactory welds with rusted and greasy, as well as clean, pipe have been achieved.

$V$ isual inpection of finished welds for a smooth uniform surface has proved adequate to identify satisfactory welds. The metallographic section of welded casing shown in Figures 17 and 18 illustrates that the welded joints are of high quality with no porosity or slag in the weld 
zone. Rewelded sections previously cut by arc gouging also exhibit high quality.

An important aspect of the experience to date with all conduit welds is that they are seal welds on threaded joints. Full structural in combination with sealing aspects of the welds have not been tested. However, a properly made weld should withstand expected stresses and seal properly. The highest stresses expected will be generated by the pulling capability of the rig and will be exerted along the axis of the conduit.

- If a 1/2-inch fillet weld is made with $E 60$ weld metal in a $1 / 2-i n c h$ wall thickness conduit, the American Welding Society code allows $6.37 \times 10^{3}$ lbf/inch of weld. For a 24-inch casing, the total load which could be supported without failure is

5

$$
W=6.37 \times 103()(24)=480 \times 1031 \mathrm{bf} .
$$

This represents $10,000 \mathrm{lb}$ more than the yielding load of the pipe, based on a yield strength of $25 \mathrm{ksi}$ ( $1000 \mathrm{lbf} / \mathrm{inch}$ squared of cross section), and should be safe. On larger and thicker casing, such as the 30-inch OD casing with a $3 / 4$-inch wall thickness, the allowed load is $9.55 \times 103$ $1 \mathrm{bf} /$ inch for a $3 / 4$ inch fillet. The weld can support

$$
W=9.55 \times 10^{3}()(30)=0.9 \times 10^{3} 1 \mathrm{bf} \text {, }
$$

which is 160,000 lbs more than the yield load of the pipe, again based on a yield strength of $25 \mathrm{ksi}$. Properly made welds are essentially as strong as the conduit with a nominal yield strength of $25 \mathrm{ksi}$.

The scale-up required to handle up to 30 -inch diameter with $3 / 4$-inch wall pipe or casing should be feasible based on equipment availability and current knowledge. Larger pipe lathes are commercially available and could be modified as described earlier. The preferred approach to minimize scale-up difficulty would be the use of threaded couplings with a weld for sealing. The threaded couplings need not be of the sealing type but would provide alignment and support prior to welding as well as structural integrity in the eventof poor weld quality. As welding expertise and confidence improves, consideration could be given to all welded joint construction (i.e.. no threads).

Corrosion rates in weld regions should not be significantly different than for the base metal because severe compositional gradients are not generated in the weld area. The $E 60$ weld rod employed does not vary appreciably from the nominal composition of the base metal.

\subsubsection{Packers and sliding seals}

\section{2 .3 .1 Introduction}

As can be seen by referring back to Figure 14 . there are three large down-well fluid flows: 1) upward flow of geothermal brine between the well casing and the heat exchanger, 2) downward flow of R-114 in the heat exchanger, and 3) upward flow of R-115 inside the riser. These flows are contained by three large conduits which are at different temperatures at different times, therefore there must be at least two sliding seals to accommodate differential thermal expansion. Also, there must be a seal 
between the pump and the well casing, across which the pump added pressure appears. This packer can be fixed, in which case there must be a sliding seal somewhere else in the down-comer (heat exchanger) conduit, or the packer can perform this function also by making a sliding seal to the well casing. Both approaches were studied and are discussed in sections 5.2 .3 .2 and 5.2 .3 .3 below. The other sliding seal is in the $R-$ 114 riser. This is discussed in section 5.2.3.4 below.

เ

\section{2 .3 .2 sliding Packer}

Since there must be an elastomeric packer seal to the well at the - pump casing, it is an attractive approach to make this packer a sliding seal as well to accommodate differential thermal expansion between the down-well heat exchanger and the well casing. In this approach, the down-well hardware is suspended from the well-head. Such a sliding packer is not an off-the-shelf component. There are fixed packers available with a sliding-seal bore. In fact, such an asembly was used for the earlier sperry pump test at Heber and proved unsatisfactory because of jamming of the close-tolerance sliding-seal assembly by sand and debris falling from above. If a fixed packer is used, it is believed better to locate the sliding-seal at well-head where it is not susceptible to such sources of jamming. This approach was studied and is reported below in section 5.2.3.3. Thus, development of a packer which can provide a sliding-seal against the well casing was a task objective. The approach taken was to modify oil-well swab cup designs and materials to meet the larger-size, higher-temperature, higher-pressure, corrodedcasing requirements of the geothermal application.

The configuration selected for development consisted of three redundant packer cups to be attached to the pump inlet tube to form a sliding seal against the $13-3 / 8$ inch casing string. Each cup was to have the approximate shape of an inverted bell. The bell lip would form an initial seal with the pump off. After pump start-up the differential pressure would expand the cup and increase the sealing contact area. Maximum design differential pressure would be 625 psid. The rated operating brine temperature was $3500 \mathrm{~F}$.

Regal International was contracted to assist in the sliding packer design and to fabricate the experimental packer cups. A test facility was constructed at Barber-Nichols Company to test the cups both statically and dynamically in brine at $3500 \mathrm{~F}$. Six generations of experimental cups were designed and fabricated before a successful combination of design, materials, and manufacturing technique was established.

The early designs failed to establish an initial seal properly. Later versions sealed initially, but failed structurally at higher differential pressures. When the cups were strengthened with metal reinforcing fingers, to overcome the strength of material problems, material bonding problems developed which again resulted in structural failures. Ultimately, the proper combination of bonding agents and 
manufacturing techniques was established which resulted in a successful test of three sets of cuts in the Barber-Nichols test jig at full temperature and pressure.

\subsection{Packer Formulation Development}

This section concerns the development of the elastomer compound to be used in the cup type packing unit. Existing elastomer formulations were - known to be incapable of lasting in the geothermal environment. The development of a new elastomer was begun on 1-9-79. The parameters for development of the new formulation are shown in Table I.

F The first task was to research available literature and consult with suppliers' technical personnel in an effort to identify polymers with the greatest potential for development. A great deal of research was performed and several possibilities were defined for elastomer candidates as well as some promising methods for formulation development. One thing we quickly found was that very little information exists relating directly to geothermal work. However, related work on formulations to be used in steam was found to be helpful. EPDM or Fluorocarbon elastomers were found to be promising and were chosen for development work.

In order to evaluate the suitability of these formulations for the end use, a test media similar to the actual working media was needed. This media, which had been used in other geothermal development work, was formulated as an aqueous solution of $\mathrm{H}_{2} \mathrm{~S}(300 \mathrm{ppm}), \mathrm{CO}_{2}(1,000 \mathrm{ppm})$ and $\mathrm{NaCl}(25,000 \mathrm{ppm})$. All tests were run at $2040^{\circ} \mathrm{C}$ for varying durations. Initial tests were conducted for 22 hours and established three of eighteen formulations as candidates for further development (Table II). The 22 hour tests proved to be a disaster for 2 fluoroelastomer

formulations which had been compounded for steam resistance. Due to time limitations and the fact that the EPDM formulations worked so well, further development of fluoroelastomer formulations was suspended.

As the program progressed, the duration of the tests was expanded from the initial 22 hours to 48 hours, 70 hours, 120 hours and finally 576 hours. The most hydrothermal chemically stable formulations from each group were selected for further work with the goal being to achieve a percentage change of unaged to aged physical properties of $15 \%$ or less in any category. A total of 39 EPDM and 2 fluoroelastomer formulations were designed and tested before the desired results were obtained. These results are shown in Table III.

Field experience with elastomer packers indicated a problem of casing cure, a situation in which an elastomer seal under heat and pressure will adhere to the casing wall. To determine if this might be a problem with the formulation developed, we clamped a sample between two pieces of steel plate. One plate was placed in a pan of synthetic brine solution at $70^{\circ} \mathrm{C}$ for 24 hours and allowed to rust. Half of this plate was then bead blasted and cleaned and a sample of the compound was clamped over both the rusty and clean areas. The clamped arrangement was aged in the brine solution for 24 days at $204^{\circ} \mathrm{C}$ and showed no adhesion of rubber to 
metal in any area. Consequently, we do not feel that casing cure will be a severe problem, if anything, considering the desired one-year lifetime.

During our development work, we found that this same formulation also horks very well in a standard compressive seal ring configuration holding water at $1000 \mathrm{psi}$ and $175^{\circ} \mathrm{C}$ for 24 hours. A seal of this type is needed in the same geothermal conversion system although it will be used in a *slightly different environment. The environmental requirements for this compressive seal are good aging resistance to the brine solution plus resistance to R-114, 1,2 dichlorotetrafluoreothane.

F

TABLE I

Temperature Range: $1600-1800^{\circ} \mathrm{C}$

Fluid Composition: Brine solution consisting of chlorides (Na, Ca), $\mathrm{H}_{2} \mathrm{~S}$, $\mathrm{CO}_{2}, \mathrm{CO}_{3},=$ very 1 ittle dissolved $\mathrm{O}_{2}$.

Pressure Differential: 1000 psi

Life Expectancy: 1 year

TABLE II

\section{CHANGE*}

$\# 17$

Tensile

19.7

Ultimate Elongation

$+13.8$

Modulus, $100 \%$

5.3

16.4

Tear, die $C$

$+6.0$

Haraness

*Aged 24 Hours at $204{ }^{\circ}$, synthetic Brine.

\section{UNITS}

psi

웅

psi

psi

pli

Shore A

TABLE III
Tensile

Ultimate Elongation

Modulus, $100 \%$ $200 \%$

Tear, die C

Hardness

*Aged 576 hours at 2040C, Synthetic Brine.
8

$$
\begin{array}{ll}
\# 3 & \# 10 \\
+2 & -8.6 \\
+18.4 & +22.0 \\
-1.2 & -19.3 \\
-6.4 & -23.0 \\
+.6 & -1.1
\end{array}
$$

$0 \quad-3$

0
UNITS

$$
\begin{array}{r}
\text { psi } \\
\text { q } \\
\text { psi } \\
\text { psi } \\
\text { pli }
\end{array}
$$

Shore A

\section{\& CHANGE*}

$-6.3$

$+15.2$

$-7.1$

$-7.7$

$+5.0$

$+1$ 
(1) Baldwin, F.P. and Ver Strate, G., Rubber Chem. Technol. 45,709 (1972).

(2) Dunn, J. R., Rubber Chem. Technol. 41,304 (1968).

(3) Hirasuna, A. R., et. al., December 1977 "Geothermal Elastomeric Materials - Twelve-Months Progress Report, October 1, 1976September 30, 1977), L'Garde, Inc.. Newport Beach, Calif. 92663, SAN/1308-2, U.S. Department of Energy, Geothermal Energy. (4) Murray, K., Rubber Chem. Technol., 44,1441 (1971).

(5) Ranney, M.W. and Pagano, C.A., Rubber Chem. Technol.44, 1080 (1971).

(6) Sperry Research Center, February 21, 1978, "Low Temperature

Geothermal Conversion Systems", SCRC-317-16C, sudbury, Mass 01776.

f

\subsection{Packer Cut Test Procedure}

A test facility was designed and constructed by Barber-Nichols Engineering $C o$. to test packer cups under realistic conditions. A photo is shown in Figure 19.

The objective was to operate the packer cups under simulated well conditions to verify performance in terms of: 1 ) leakage before and after experiencing cyclical operating conditions, 2) the forces involved in moving the cups, and 3 ) the abililty to seal and reseal.

The approach was to: 1) install packer cups in a section of waterfilled, unconditioned well casing, 2) maintain the water temperature, water differential pressure, and the presence of well sand that simulates well conditions, and 3) put the cups through the cyclical motion typical of system startup, operation, and restart. During the tests, which were accelerated greatly relative to actual field-test time variations, the temperature, pressure, leakage, and forces were monitored. The differential pressure was maintained constant during cup motion, which was imposed by an independent hydraulic system. Two cups were mounted on a shaft, opposing each other, so that the differential pressure across the cups would not transmit a force to the hydraulic system.

The test fixture was oriented vertically. The water within the fixture was heated by electrical band heaters around the outside of the fixture and wrapped with blanket insulation to retain the heat. The temperature was maintained at $3500^{\circ}$ for all tests.

The tests were done in two parts, one with sand, and one without sand. The test procedures were as follows.

Tests Without sand

Set the pressure in the cavity between the two cups at 1050 psig. Set the pressure on the opposite sides of the cups at 425 psig (for a nominal design pressure across the cups of $625 \mathrm{psi}$ ). Go through the following steps.

1) Leave packer in initial position for five minutes, compensating for any leakage to the low pressure sides by manually bleeding off water 
to maintain the set pressure of 425 psig. To determine leakage rates, collect bleed water and record the times involved.

2) Move packer approximately one inch to a new position by using the hydraulic system to slowly increase the force on the packer assembly until it moves. Record the peak pressure at which movement occurs. Repeat step 1 .

At each step, record water temperature, all pressures, times, packer position, peak hydraulic pressure at which packer moves, and volumes of bleed water. Note any irregularities that occur.

3) Repeat step 2 three times.

4) Repeat step 2 three times, but using 2-inch instead of 1-inch displacements.

5) Repeat step 2 three times using 3-inch displacements.

6) Repeat step 2 one time using 10-inch displacement.

7) Repeat steps 3 through 6 ten times.

8) Repeat steps 1 through 7 for a low-pressure setting of 750 psig, corresponding to a pressure across the cups of 300 psi.

9) Move packer approximately 2 inches, reduce all pressures to zero psig, wait for five minutes, then repressurize to the original 625 psid conditions of step 1 . Check leakage rates for five minutes.

10) If leakage rates not excessive in step 9, leave in position for one week. Maintain presures and monitor regularly. After one week, repeat steps 3 through 6 one time. Disassemble and inspect.

Tests With Sand

Cover bottom cup with special well sand to a depth of approximately 2 inches and reassemble. Repeat steps 1 through 10 .

\section{$5.2 .3 \cdot 2.3$ Packer Cup Design}

The initial packer cup design is shown in Figure 20. This design failed in Laboratory Testing because of inelastic deformation of the spring-wire fingers and separation of elastomer from the fingers. Attempts to use tube-reinforced wire fingers also failed and ultimately the design of the fingers was changed to the much stronger $T$-bars shown in Figure 21. These were placed in the cup as shown in Figure 22. 
Approximately 12 packer cups were tested. These represented three different structural design approaches for the support fingers: 1 ) the jnitial spring-wire fingers which failed at 300 psid 2) tube-reinforced spring-wire fingers which failed at 500 psid and 3) T-Bar fingers which passed the test procedure in at least 4 cups. There was also an early problem in establishing an initial seal, which was solved by changed lip -design and the fit of the cup in the casing. There was also an interim problem with elastomer bonding to the base-plate and the fingers, which was solved by a process change instituted by Regal.

- Three different cups passed the total test procedure and were assembled into a three-cup assembly, which was at well-site for use in the initial pump test at the time the well liner collapsed.

\subsubsection{Fixed Packer Approach}

Because the sliding packer cups were still failing tests in the fall of 1980, it was decided to pursue a back-up approach to achieving the seal to the well-casing at the pump and the sliding seal to accommodate differential expansion between the well casing and the heat exchanger.

The design of the fixed Baker packer is shown in Figure 23 . This packer rests on the tapered transition between the 20 " and 13-3/8" well casings. It extends into the 13-3/8" casing and makes a fixed seal to the I.D. of that casing. The seal is established by a limited compression of an elastomer ring produced by the weight of the down-well equipment. The production tube hangs from the packer assembly. A fixed packer was fabricated and available for the pump test if needed.

Because the packer is fixed, there must be a sliding seal somewhere in the heat exchanger conduit. The preferred location is at wellhead. There are several reasons for this choice. The full weight of the downwell equipment then rests on the fixed packer assembly to set it. The sliding seal can be replaced easily without removing any other down-well hardware. The sliding seal is located where sand and debris will not settle into it causing jamming and leaks. A sketch of this well-head sliding seal assembly is shown in Figure 24. The 18" 0.D., 0.938 " wall tube is welded to the top heat exchanger section and has a polished bore to receive the seal assembly. The seal assembly is shown in more detail in Figure 25. This is captured between the casing flange and the next wellhead spool lower flange. EPDM seal rings are bonded into the six grooves. The vent between the upper and lower groups of three seal rings provides leak detection and is a positive protection against brine leakage into the $R-114$ system. A seal was fabricated and pressure-tested and was available for the pump test if needed.

\section{2 .3 .4 Riser sliding seal}

The other large sliding seal is in the riser pipe. For practicality of installation there is one such seal for each heat exchanger section. Since these seals separate $R-114$ at low pressure from $R-114$ at high 
pressure, leakage is not a source of fluid contamination and slow leakage can be tolerated. High leakage would degrade system performance however, so a positive seal is required. A drawing of the downwell heat exchanger coupling is shown in Figure 26. The sliding seal need accommodate only the differential expansion of one section. sliding seals of this type Were fabricated and tested successfully by Regal Tool and Rubber Co. only one was needed for the pump test since it used a one-section heat exchanger. It was located just above the turbine pump unit. The EPDM velastomer was used here also.

\subsubsection{Pump System Down-Comer seal}

F For the pump system only, there was a requirement for a stabbled "sliding seal at the bottom end of the R-114 4" down-comer. The receptacle for this is above the one-section heat exchanger. A seal assembly was designed, fabricated and tested by Regal and was available for the pump system test. A sketch is shown in Figure 27. 5.2 .4 Lube and Instrument Lines

Both systems require make-up lubrication oil conduit and a oneconductor electrical lead for instrumentation from the surface to the down-well TPU. The design approach taken was to thread the electrical cable (a small standard l-conductor, teflon-insulated, armored logging cable) through a $1 / 2 "$ OD X $0.035^{\prime \prime}$ Wall stainless steel tube of sufficient length to extend from wellhead to TPU. A combined electrical and lubricating oil stabbing fixture and weight are affixed to the lower end and a feed-through is on center-line at the top of the wellhead. oil line and cable is run-in as a unit after all other down-well hardware is in place.

One question with this approach was the practicality of threading the electrical cable through the tubing. By laying the tubing out straight on the ground it was found to be easy to blow a pig with a light line through a $2300^{\prime}$ ' long tube and to pull the logging cable through.

Another question was the potential failure of the tube after several installations with repeated spooling and unspooling from a storage and installation drum. Tests to check this were made by Mustang and are reported in Appendix $B$.

Another design problem was the downwell stabbing fixture. The version of this fixture for the pump system is shown in Figure 28. . Pressure and temperature tests were conducted by Mustang Engineering on the elastomer seal/electrical connection portion of this assembly. Their report is attached as Appendix $C$. 


\subsection{TURBINE-PUMP-UNIT DEVELOPMENT}

\section{3 .1 Introduction}

A key component of the gravity-head and pump system is the down-well turbine-pump unit (TPU). The TPU performance requirements must be tailored to the system parameters. Also, the cost of retrieval for maintenance dictates extreme reliability.

- The development of the TPU was subcontracted to Barbher-Nichols Engineering $\mathrm{Co}$., who had developed the similar, steam-driven TPU used successfully in the earlier down-well pump system test at Heber, CA.

- Two technical reports submitted under this contract by Barber-Nichols are attached as Appendices $D$. and $D$. Appendix $D$. covers the design and predicted performance of the TPU. Appendix $E$. covers the test programs conducted on both components of the TPU and a complete TPU. Figure 29 is a layout drawing of the TPU which was fabricated and tested in the laboratory and was available at field test site for the pump system field layout. 


\subsection{FRANCIS TURBINE DESIGN STUDY}

The down-well turbine-pump unit (TPU) for the gravity-head system has many operating parameters and constraints in common with the TPU for the pump system. For example, the pressure-added, flow-rate and, therefore, the power required of the pump are nearly the same and the overall

Giameter and required reliability are the same. Therefore, many design

features of the pump system TPU can be carried over to the gravity-head system, such as pump design, bearings, shaft seals, static seals,

- lubrication system, materials selection, etc. However, there is an essential difference in the turbine design parameters. Compared with the pump system the gravity-head system requires a much larger working fluid flow-rate through the TPU turbine and a much smaller difference across the TPU turbine in working fluid pressure and enthalpy. These

differences dictate an entirely different design approach to the gravityhead system TPU turbine. Questions of compatibility with the pump speed, the rotating group design and the diameter constraint must be addressed.

Fortunately, choice of a Francis-type turbine resluted in favorable answers to all these questions. In fact, it leads to an even better match between the desired operating speeds of turbine and pump than was possible for the pump-system TPU.

A design study for a Francis turbine for the gravity-head TPU was completed by Barber-Nichols Engineering Co. Their study report is attached as Appendix F. Figure 30. is a Machine Assembly drawing of the Francis turbine and Figure 31. is a drawing of a single blade. 


\subsection{HEAT EXCHANGER DEVELOPMENT}

\subsubsection{INTRODUCTION}

The downwell heat exchanger is perhaps the most characteristic novel feature of the gravity head system. There were several study topics in the program aimed at generating design information for the downwell heat

exchanger. Same of these have been covered earlier in this report. These include R-114 properties in Vol. I, the stability of R-114 and its compatibility with other materials in Vol. II, calculation of heat exchange requirements in Vol. III and welded connections and sliding seals in Section 5.2 of this volume. In attempting to calculate heat transfer in the supercritical region it became apparent that empirical data were required and an experimental task was planned to obtain data on heat transfer from brine to R-114 and transport properties of R-114 for the complete range of pressure, temperature and density to be encountered in the heat exchanger. The experimental apparatus designed and built for this purpose was called a "ten-pound loop" because its charge of R-114 weighed about ten pounds and it involved closed-loop flow of R-114 with both heating and cooling. This task is reported in section 5.5 .2 below.

The configuration of the downwell heat exchanger has two distinct portions. There is a lower portion consisting simply of two concentric tube strings. Other than the welded and sliding seal connections reported on in Section 5.2 above, this portion has no unusual design problems. The upper portion however consists of an annular tube bundle in the space between well casing and R-114 riser as shown in Fig. 1.5. This poses two interesting problems. One, how can roughly uniform brine flow be achieved throughout the tube bundle, and, two, how can one prevent any leakage at the joints between tubes and tube sheets? These tasks are reported in sections 5.5.3 and 5.5.4 below.

\subsubsection{TEN-POUND LOOP}

An experimental apparatus called a "ten-pound loop" was designed and built to obtain fluid transport property and het transfer data on R-114. A schematic diagram is shown in Fig. 32. A photograph of the completed apparatus is shown in Fig. 33. The long structure in the photograph contains the concentric tube heat exchanger portion of the apparatus. It is about 25 feet long and can be positioned horizontally or vertically to vary the gravity-head of the fluid over the length of the exchanger from zero to a maximum value. This feature permits separation of pressure differences due toflow loss and gravity-head (density). Another feature of the apparatus is use of flow meters for both R-114 and water which measure mass flow rate directly to avoid the assumption of viscosity values necessry in an aperture-type flow meter. A description of the flow meter used is given in Appendix G. 
The design parameters for the ten-pound loop were as follows:

- Inner HX Tube: 0.5" O.D. X 0.049" Wall, SS

- Outer HX Tube: $0.75 "$ O.D. X 0.050" Wall, SS

- Length of HX Between Sensers: $20 \mathrm{Ft}$.

- Naminal HX DT: $200^{\circ}$.

- Nominal Heat Exchanger Rate: 210 BTU/Min.

- End Loss Heat Rate: 0.003 BTU/Min.

- $p=R-114:$ Naminal 3.48 psi e $5 \% / \mathrm{sec}$.

- Water: Nominal $0.78 \mathrm{psi}$ e $3.5 \%$ sec.

Two approaches to obtaining thermal conductivity measurements were considered. The first involves directly calculating $k$ from the overall heat duty of the annular test section. These calculations, which are explained in detail later, are the primary data reduction means since a single experiment provides all of the necessary input data. As a check on these measurements, the wilson plot technique is proposed as a secondary means of data reduction. The technique involves performing a series of experiments at a constant heat flux, operating pressure, and temperatur ein the organic loop; but at a series of mass flow rates in the "brine" loop. Only one thermal conductivity calculation is performed on this data set. The technique is useful in that data taken for the primary calculation scheme can be sued as input for the wilson plot technique after it has been categorized appropriately. A wilson plot also provides an estimate of the degree of scatter in a given data set.

DIRECT THERMAL CONDUCTIVITY CALCULATIONS:

Measured Parameters: $\mathrm{T}_{114}$ in, $\mathrm{T}_{114}$ out, $\mathrm{T}_{\mathrm{B}}$ in $\mathrm{T}_{\mathrm{B} \text { out }} \dot{\mathrm{m}}_{114}, \dot{\mathrm{m}}_{\mathrm{B}}$

System Constants: $\quad A_{C}, C, A_{B}, A_{114}, A_{W}, R_{W}$

Parameters determined fram the above information:

$$
\text { LMID, } \Delta \mathrm{T}_{114}, \mathrm{C}_{\mathrm{pl14}}, \mathrm{H}_{\mathrm{B}^{\prime}} \mathrm{H}_{114}
$$

The heat exchanger log-mean temperature difference and the heat transfer coefficient on the R-114 side of the loop are determined by:

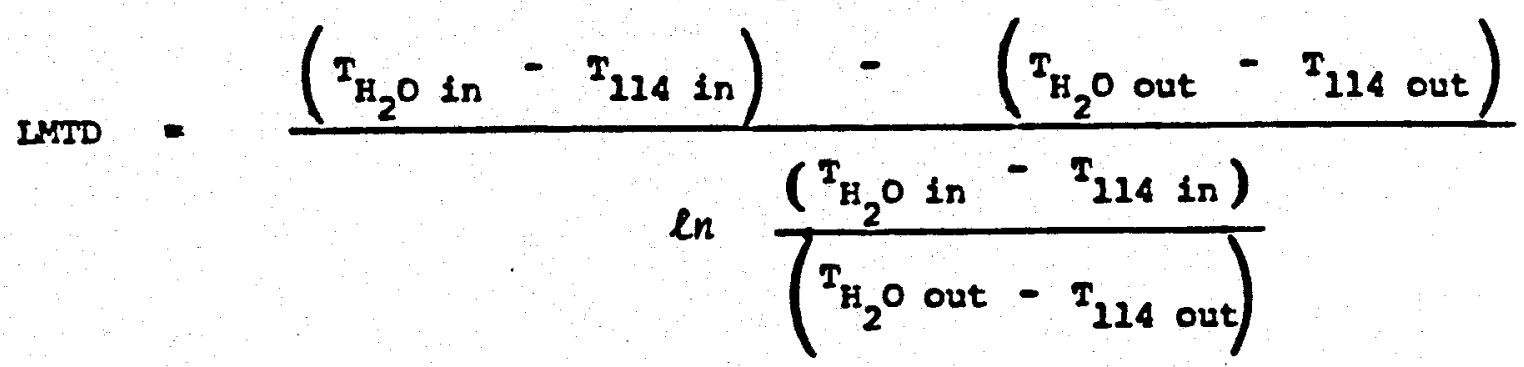




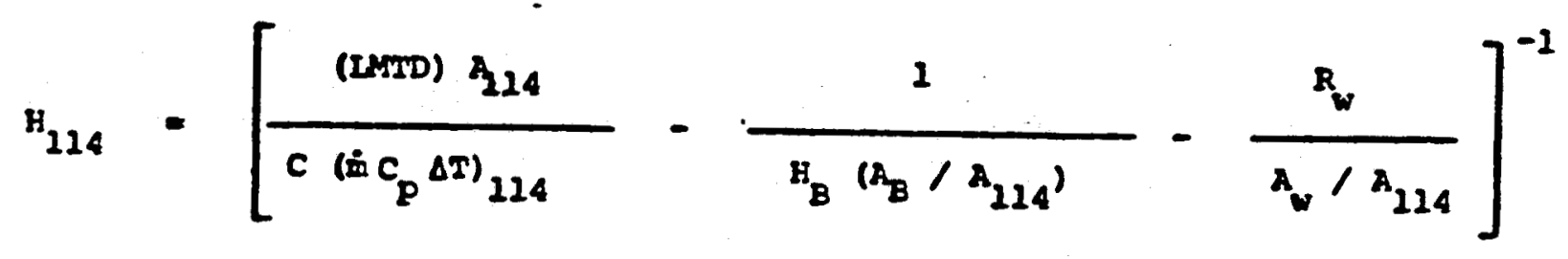

- For water on the organic side of the loop, $k$ is determined by:

$$
\mathrm{x}_{\mathrm{H}_{2} \mathrm{O}}=\quad(\alpha)\left(\mathrm{H}_{\mathrm{H}_{2} \mathrm{O}}{ }^{1.5}\right)\left(\dot{m}_{\mathrm{H}_{2} \mathrm{O}}^{-1.2}\right)\left(\mathrm{H}_{\mathrm{H}_{2} \mathrm{O}} 0.70\right)\left(\mathrm{C}_{\mathrm{B}_{\mathrm{H}_{2} \mathrm{O}}}\right)^{-0.5}
$$

where thermodynamic and transport properties are determined at the mean fluid temperature,

$$
T_{\text {in }} \quad 2 / 2\left(T_{\text {in }}+T_{\text {out }}\right)
$$

and where $\alpha=3.69 \times 10^{-4}$ ( $\alpha$ is determined by system geometry constants)

For $\mathrm{R}-114$ in organic side of $100 \mathrm{p}, \mathrm{k}$ is determined by:

$$
x_{214}=(a)\left(k_{214}^{2.5}\right)\left(\dot{m}_{214}^{-2.2}\right)\left(H_{214} 0.70\right)\left(c_{p_{214}}^{-0.5}\right)
$$

where $\alpha=1.69 \times 10^{-4}$.

THERMAL CONDUCTIVITY CALCULATION USING WILSON PLOT

The Wilson plot is a graphical interpretation of the overall heat transfer coefficient determining equation:

$$
\frac{1}{U}=\frac{1}{H_{0}}+R_{w}+\frac{1}{H_{1}}
$$

There are several tacit assumptions involved in using this technigue which must be understood in order to accurately interpret test data. When these assumptions are recognized, however, the technique is a useful check on other means of data reduction. The assumptions involved in determining $\mathrm{H}_{i}$ from a data set are:
a) Constant heat flux, $Q / A$
b). Constant mass flow, $\dot{m}$ (or constant velocity, $v_{i}$ )
c). As wide a variation in mass flow, $\dot{m}_{0}$ (or $v_{0}$ ), as possible with the experimental apparatus.
d). Known tube-wall materials so that $\mathrm{R}_{\mathrm{w}}$ can be determined
e). Heat transfer coefficient, $H_{0}$, is a function of $\left(v_{0}\right) 0.8$.

The wilson plot technique derives from the fact that the ideal way to measure the tube-side heat transfer coefficient, $H_{i}$, in a shell-and-tube heat exchanger would be to set the shell-side heat transfer coefficient, $\mathrm{H}_{0}$, infinitely high. In this limit, the overall heat transfer coefficient would be simply

$$
\frac{1}{v}=\frac{1}{B_{i}}+R_{w} .
$$


In order to approach this limit, the Wilson plot technique suggests repeating overall heat transfer measurements at a constant overall heat flux and a constant tube-side velocity, while varying the shell-side velocity over a wide range. Inherent in this technique is the assumption that the individual heat transfer coefficients are primarily a function of Reynolds number, (Re) 0.8 , or velocity, v0.8; an assumption which is made in most

- empirical heat transfer coefficient correlations. For each constant heat flux data set, $\left(1 / v_{0} 0.8\right)$ is plotted on the abscissa vs. $(1 / 0)$ on the ordinate. The resulting plot is a straight line with a positive $y-$ intercept, which by inspection is the value of $(1 / \mathrm{U})$ for infinite $v 0.8$ (or infinite heat transfer coefficient, $\left.\mathrm{H}_{0}\right)$. Therefore, the $\mathrm{y}$ - intercept equals $\left(1 / H_{i}+R_{W}\right)$. Since $R_{w}$ is known, $H_{i}$ has been determined.

An advantage of the Wilson plot is that it provides an estimation of the degree of scatter in the test data and determines $\mathrm{H}_{i}$ as the "best-fit" of all data taken. A disadvantage of the technique is that a large data set is required for accurate data interpretation. This fact makes the technique more useful as a check rather than as a primary means of data reduction. 
NOMENCLATURE

$A_{B} \quad$ Brine-side heat transfer area in annular heat exchanger $\left(\mathrm{ft}^{2}\right)$

A114 R-114 - side heat transfer area in annular heat exchanger ( $\mathrm{ft}^{2}$ )

$A_{w} \quad$ Tube-wall heat transfer area of inner tube in annular heat exchanger $\left(\mathrm{ft}^{2}\right)$

C Conversion factor $(\mathrm{min} / \mathrm{hr})$

$C_{p} \quad$ Specific heat at constant pressure (Btu/lb $\left.-O_{F}\right)$

H Heat transfer coefficient (Btu/hr $-\mathrm{ft}^{2}-\mathrm{O}_{\mathrm{F}}$ )

$\mathrm{k}$ Thermal conductivity (Btu/hr $-\mathrm{ft}-\mathrm{O}_{\mathrm{F}}$ )

LMID Heat exchanger $\log$-mean temperature difference $\left(0_{F}\right)$

$\dot{\mathrm{m}} \quad$ Mass flow rate $\left(1 \mathrm{~b}_{\mathrm{m}} / \mathrm{min}\right)$

Q Heat duty (Btu/hr)

$R_{e} \quad$ Reynolds number (dimensionless)

$R_{\mathrm{w}}$ Tube-wall heat transfer resistance of inner tube in annular heat exchanger $\left(\left(\mathrm{Btu} / \mathrm{hr}-\mathrm{ft}^{2}-0_{\mathrm{F}}\right)\right)^{-1}$

$T$ Temperature $({ } \mathrm{F})$

$\triangle T$ Temperature difference $\left({ }^{0} \mathrm{~F}\right)$

$\mathrm{U} \quad$ Overall heat transfer coefficient (Btu/hr $-\mathrm{ft}^{2}-0_{\mathrm{F}}$ )

$v$ Fluid velocity ( $\mathrm{ft} / \mathrm{sec}$ )

$\alpha \quad$ Conversion factor $\left(\mathrm{ft}^{2.7}(\mathrm{hr} / \mathrm{min}) \mathrm{l.2}\right.$ )

$\mu \quad$ Velocity $\left(1 b_{m} / \mathrm{Hr}-\mathrm{ft}\right)$

Subscripts:

B Brine or brine side of test loop

114 Organic or organic side of test loop

$\mathrm{H}_{2} \mathrm{O}$ Water

i Quantity referenced to the inside of the $\mathrm{HX}$ tube

in Annular heat exchanger inlet

m Mean

- Quantity referenced to the outside of the HX tube

out Annular heat exchanger outlet 
The ten-pound loop apparatus was constructed and placed in initial operation. However, contract funds were curtailed before good data were obtained. The apparatus has been transferred with DOE permission to the Mechanical Engineering Dept. of Brown University, Providence, R.I.. They have set it up in their laboratory and intend to use it to obtain data on R-114 and other working fluids of interest. 


\subsubsection{Tube Bundle Geanetry}

In the pump system, there is only one heat exchanger section, a tube bundle unit located just above the downwell turbine - pump unit. Since the ratio of $R-114$ flow rate to brine flow rate is $<1$ and the average temperature difference between $\mathrm{R}-114$ and brine is large, the heat exchanger design is non-critical and easy. However for the gravity-head system, the ratio of $\mathrm{R}-114$ flow-rate to brine flow-rate is $>1$, the temperature difference is small and the heat transfer rate per unit of length must be tailored to a desired function. Therefore, the tube bundle design is critical and difficult. Since the area for $R-114$ flow must be $>$ the area for brine flow, the tubes must be tightly packed and there must be small clearance with the well casing. Also the space for brine flow must be evenly distributed between the tubes to ensure uniform brine flow velocity and heat transfer. Computer programs were written to generate tube bundle designs under constraints, such as tube diameter, ratio of R-114 to brine flow area, maximum and minimum gap dimensions between tubes, inscribed and circumscribed circle diameters, R-114 flow area, etc. These programs would generate tube bundle layouts and derived parameters, such as number of tubes, brine flow area, etc. typical computer-generated tube layout is shown in Figure \#34. Note that it is not possible to achieve uniform spacing for brine flow. This is not a problem for the pump system, but would be for the gravity-head system. An alternative design approach for the tube bundles for the gravity-head heat exchanger is to spiral the tubes through $1 / 2$ turn over their length, with adjacent layers spiraled in opposite sense. This configuration would be expected to result in turbulence and thorough mixing of the brine flow. Heat exchanger manufacturers were consulted concerning the feasibility and cost of fabricating such a configuration. They agreed that it could be done and that it was a more practical and less expensive approach than trying to add baffles in such close-packed bundles. However, no such design was fabricated prior to termination of funding. 


\subsubsection{Tube Sheet Seals}

One of the major concerns of the downhole equipment design was to minimize the possibility of leaks because much of the equipment would be inaccessible for repairs. A tubesheet leak, for example, might require pulling the entire downhole string in order to gain access to the defective

- part. Since tubesheets are notorious for becoming the "weak link" in the integrity of tubular heat exchangers, particular attention was paid to their design in the Gravity Head downwell system.

A double tubesheet was designed to accept double-rolled, welded tubes and, as a backup, to accept and contain an injected sealing compound between the two sheets. Test sections of the design were fabricated and experiments were run using various rolling, welding, and backup sealant combinations. The experiments, which are described in Appendix $\mathbf{H}$, "Double Tubesheet Leak Test Report" from Mustang Engineering Company, resulted in a successful design which was utilized in the fabrication of the downwell heat exchanger which was to be used with the Stand Alone Organic Turbine Pump Unit (TPU). The same design approach was planned to be used in the gravity head system also. 


\subsection{ENTHALPY RECOVERY UNIT}

The "enthalpy recovery unit" or ERU is not essential for the operation of -a binary-type geothemal plant. However, from a thermodynamic viewpoint,

- the inclusion of an ERU produces certain advantages, the main one being an improvement in the cycle efficiency. The design of the downhole heat exchanger is predicted on the "enthalpy recovery" to be provided by the ERU.

3

The ERU is shown in Fig. 35. The basic purpose of the ERU is to capture same of the energy (heat) remaining in the $R-114$ exhaust gas leaving the turbine. Since this gas is still relatively hot (approx. 106 $0_{\mathrm{F}}$ ), it can be used to preheat the R-114 liquid prior to its being piped to the main downhole heat exchanger. The temperature of the R-114 liquid as it leaves the BAC units is about $850^{\circ}$. In many applications a unit such as the ERU is called an exhaust-gas heat recuperator.

The design calls for a direct-contact type unit in which the exhaust gas is allowed to bubble up through a falling liquid stream. Excellent heat transfer can be expected as long as the tray remains free of contaminants that might clog the holes through which the fluids must pass.

The barometric leg is supplementary to the ERU. By allowing for an elevation difference between the BAC outlet and the liguid level in the ERU, this component can restore nearly all the pressure that was lost in the coils of the BAC due to friction.

The use of the ERU reduces the heating duty of the geothermal brine. Assuming a constant brine flow rate, this means that the exit temperature of the brine as it emerges from the downhole heat exchanger will be somewhat higher than if the ERU were not used. This may have certain chemical advantages with regard to scale formation.

Mechanically, the ERU is a straightforward system similar apparatus is commonly found in chemical process plants. With proper maintenance it should perform reliably. 

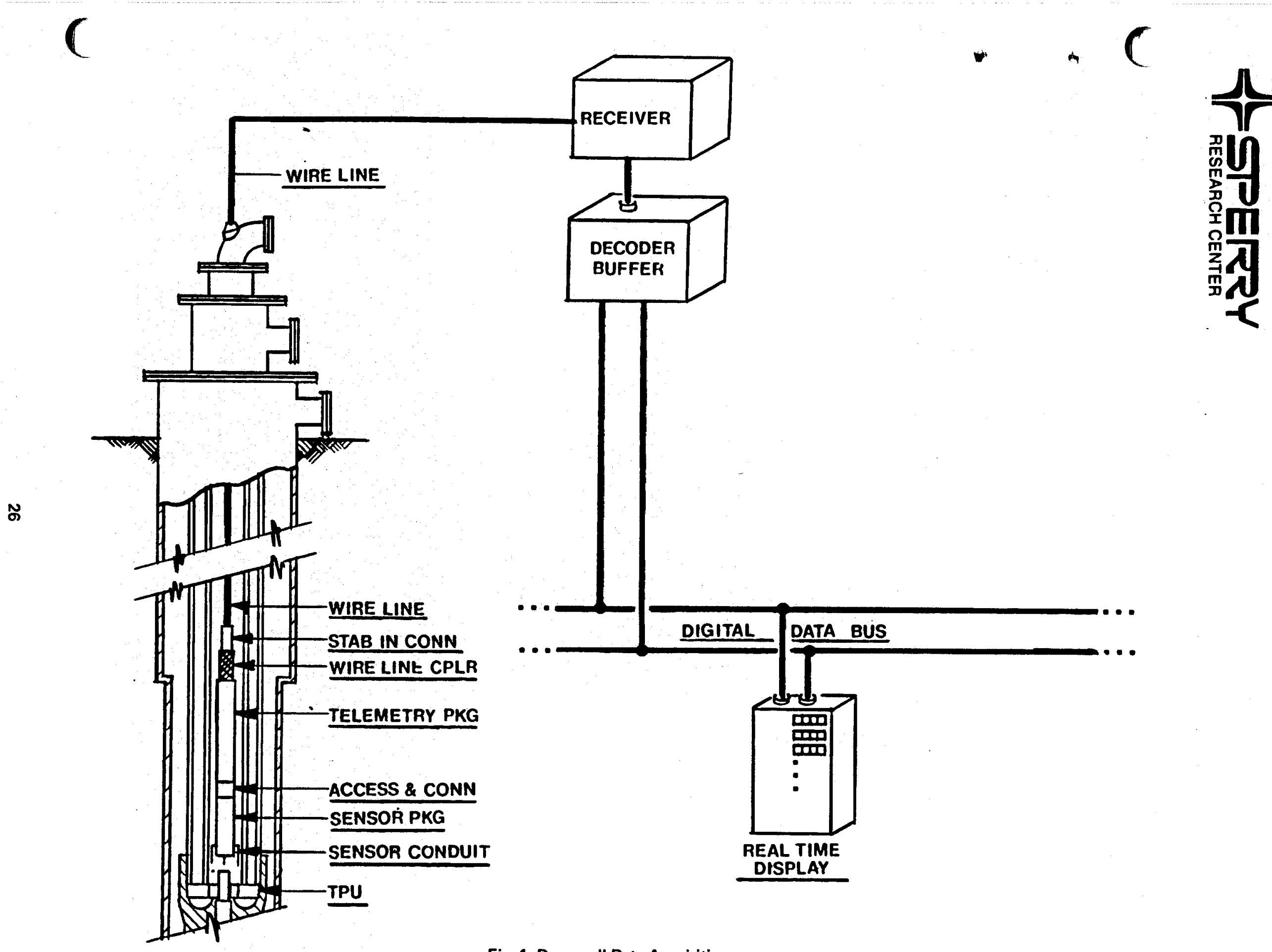

Fig. 1 Downwell Data Acquisition 


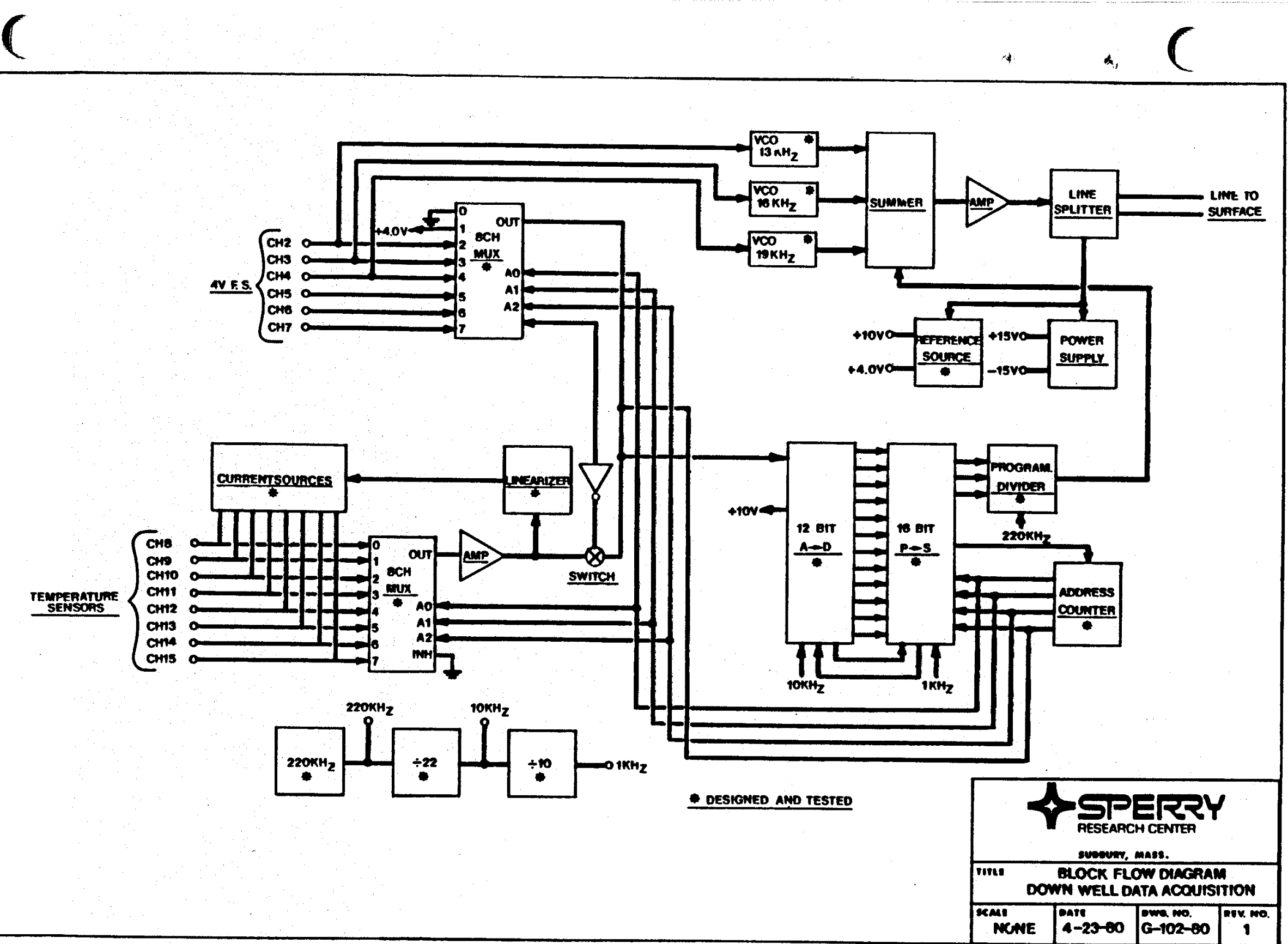

FIG. 2 Block Flow Diagram Down Well Data Acquisition. 


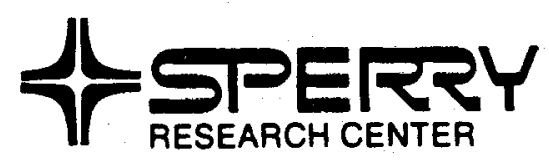

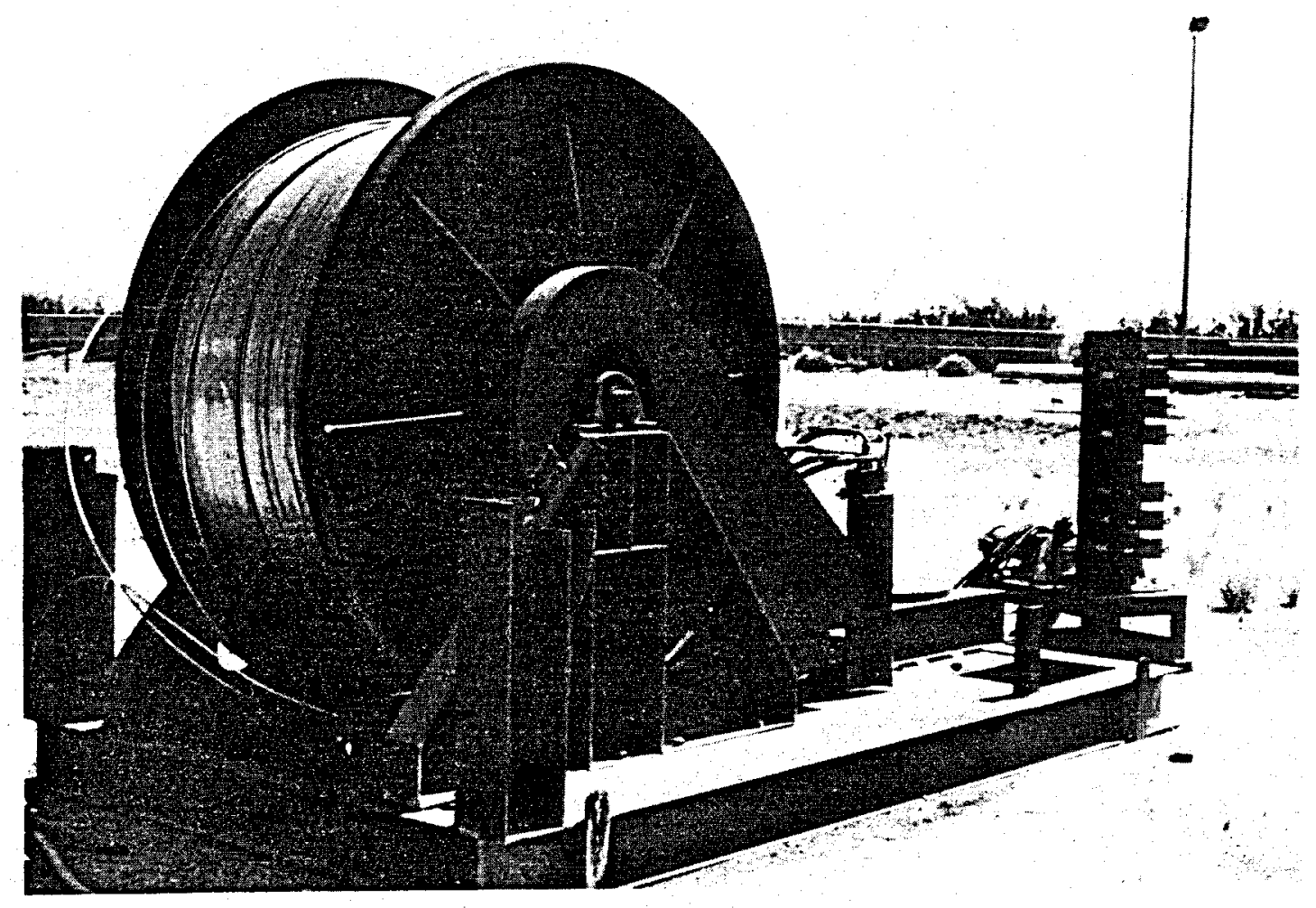

Fig. 3 Hoisting Drum for Lube/Signal Line 




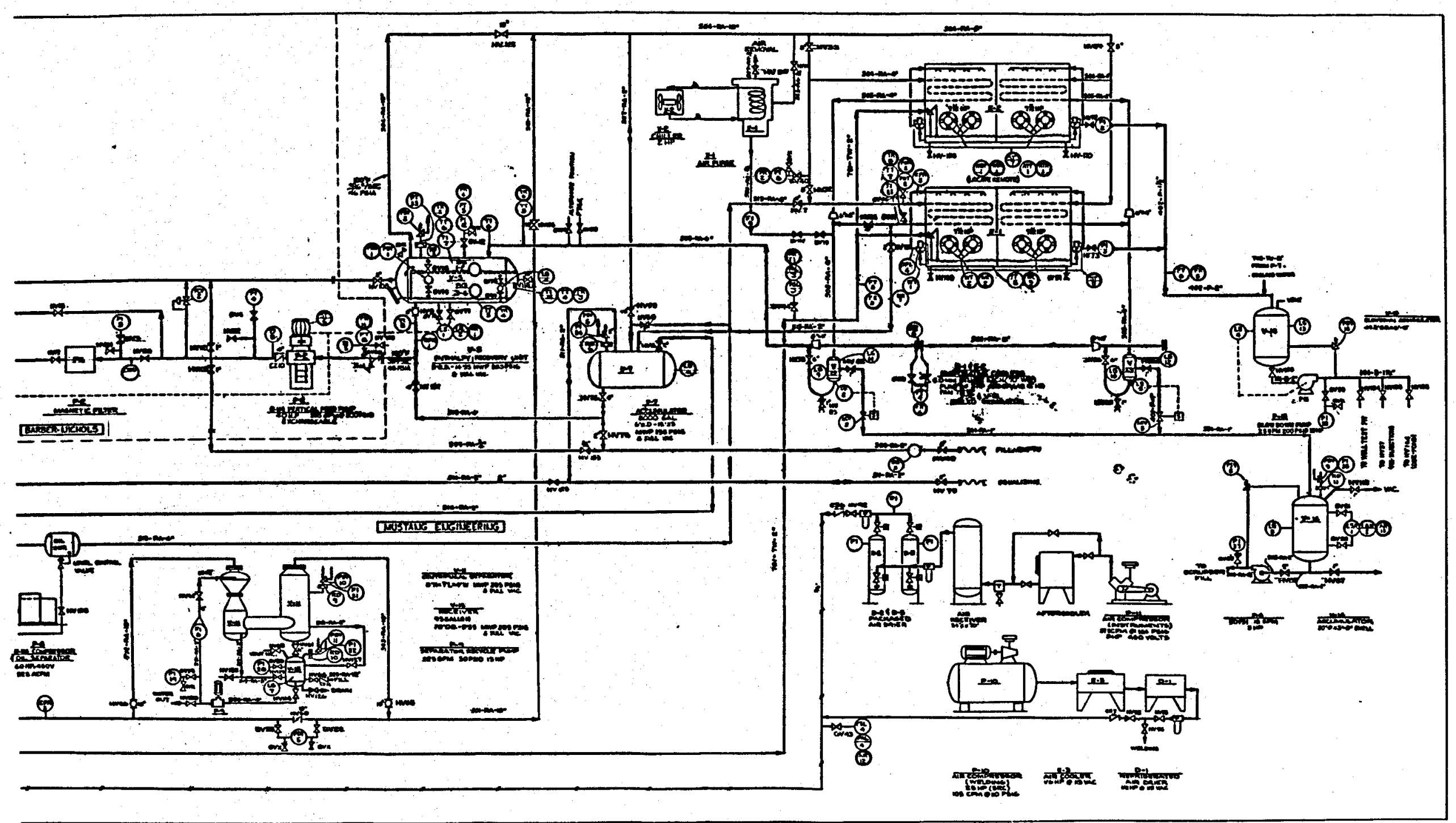




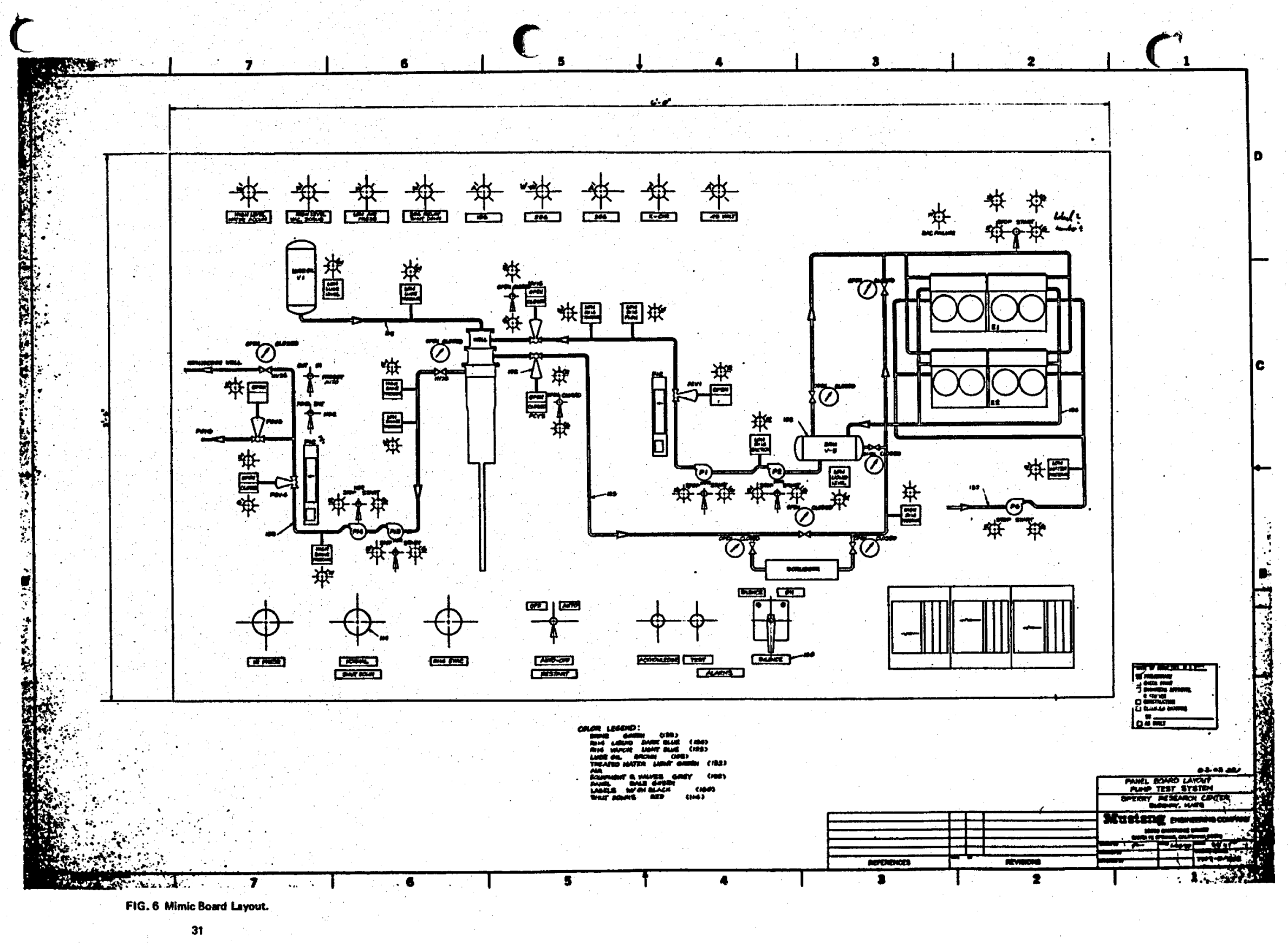




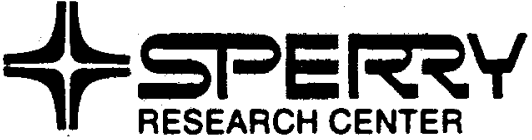

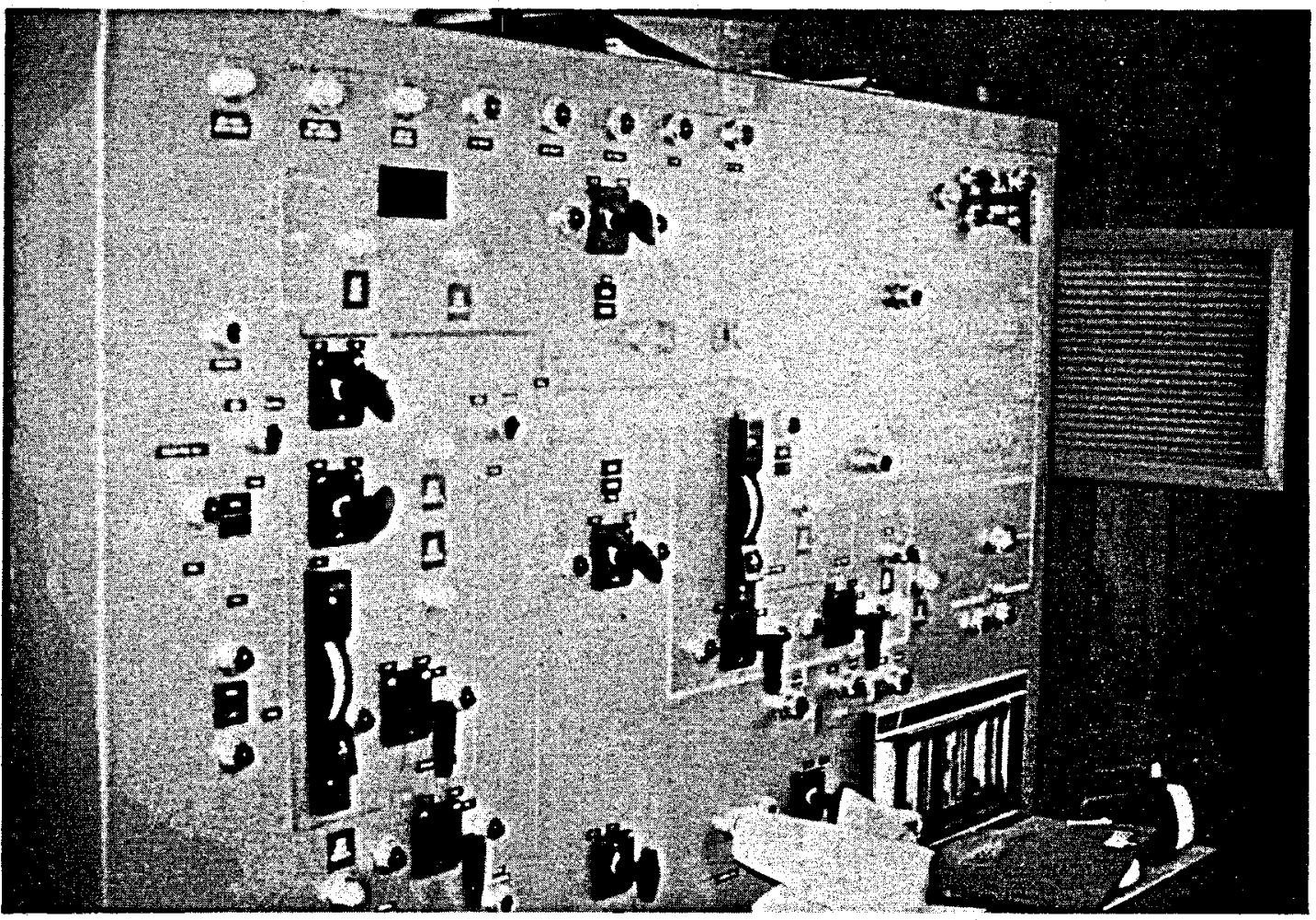

Fig. 7 Pump System Control Panel 


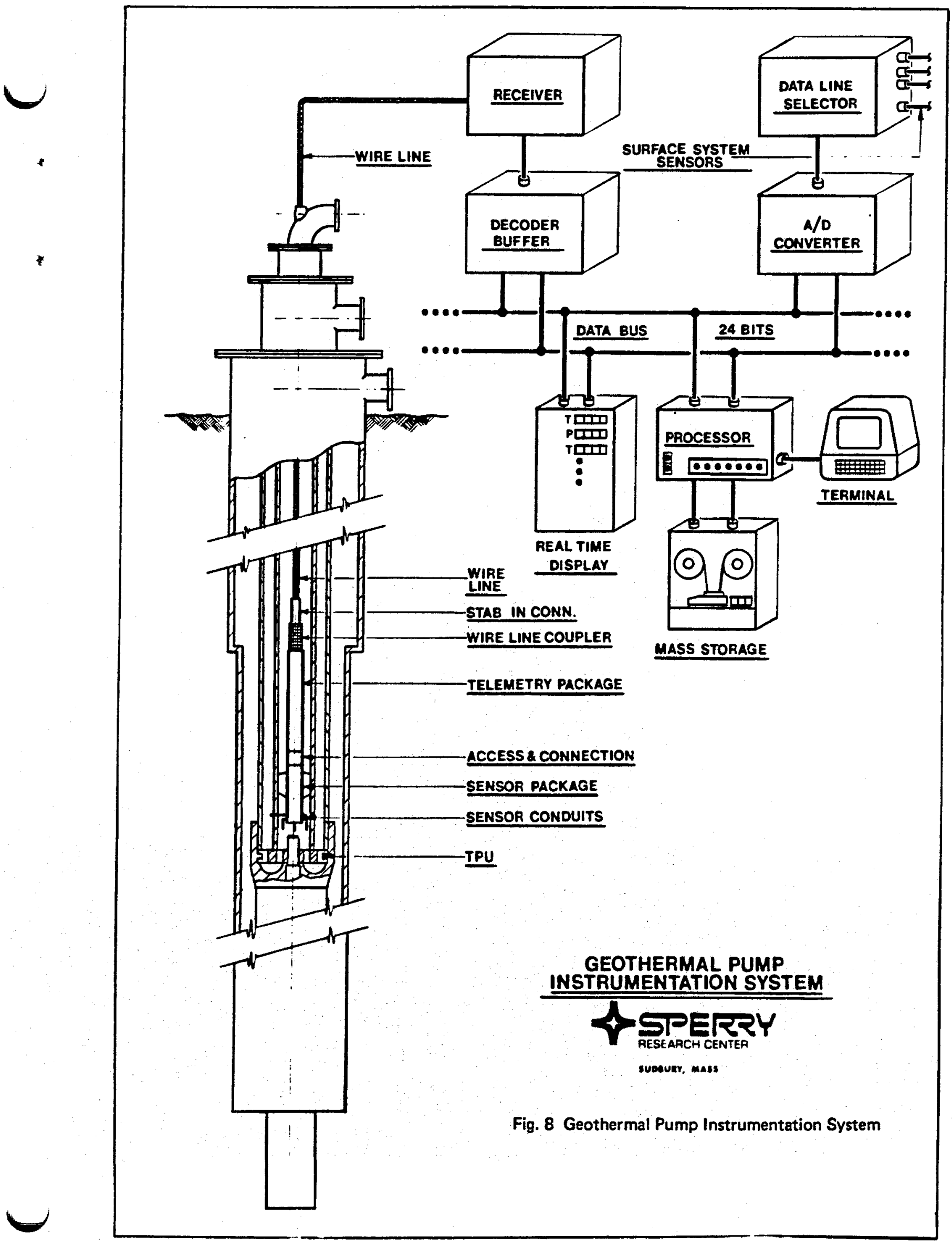




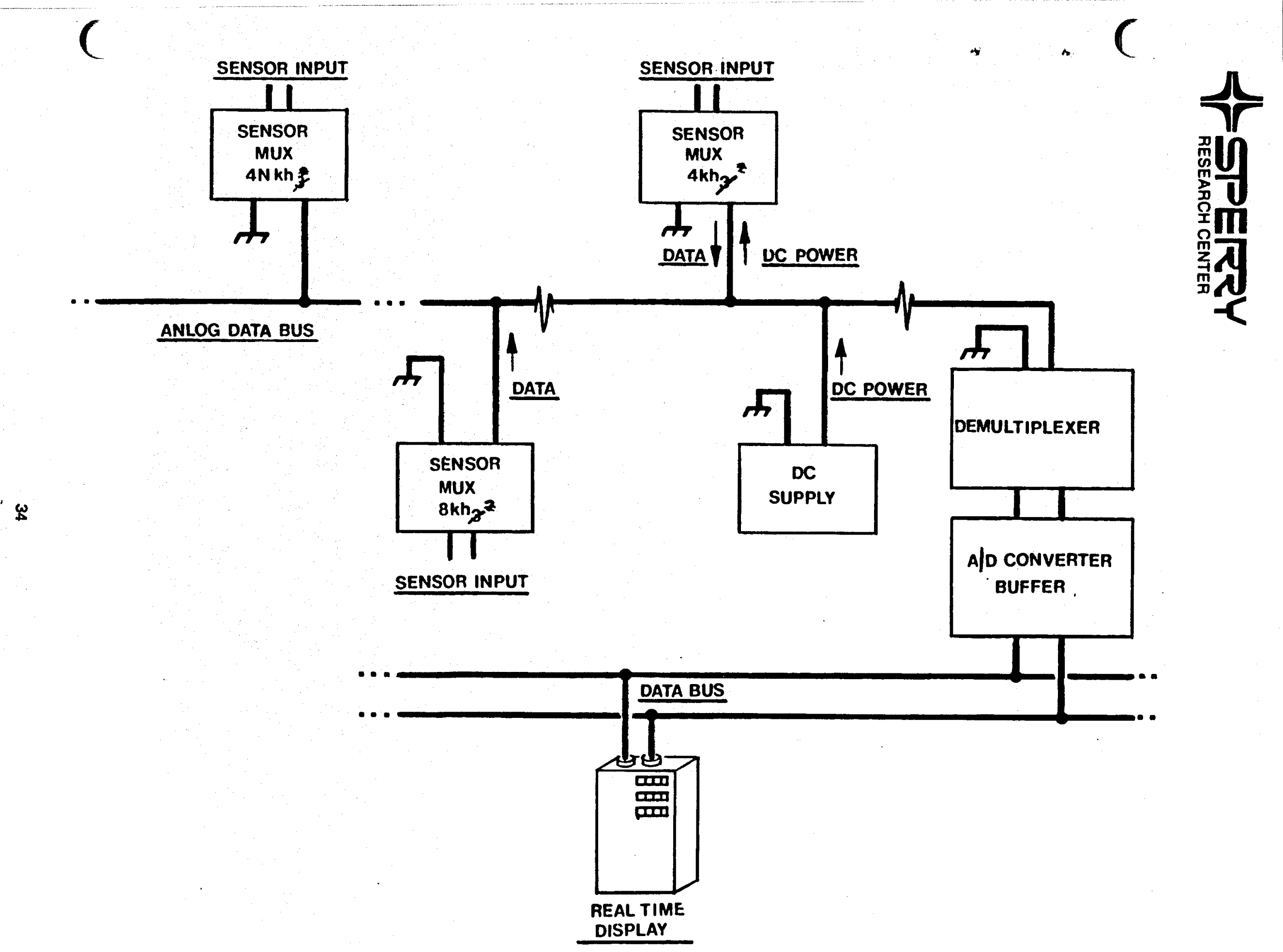

Fig. 9 Surface Data Acquisition 
e

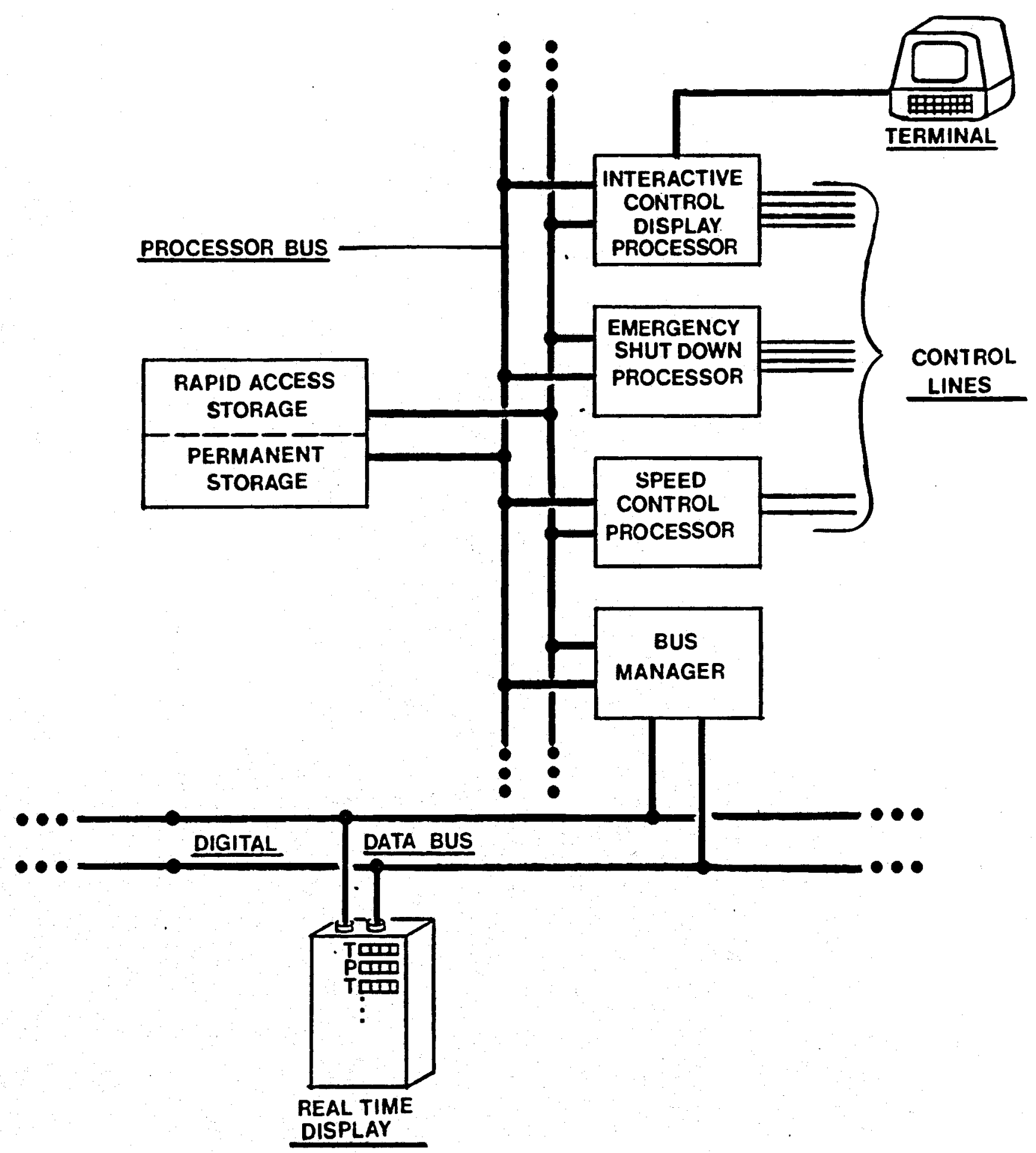

Fig. 10 Data Storage and Control 


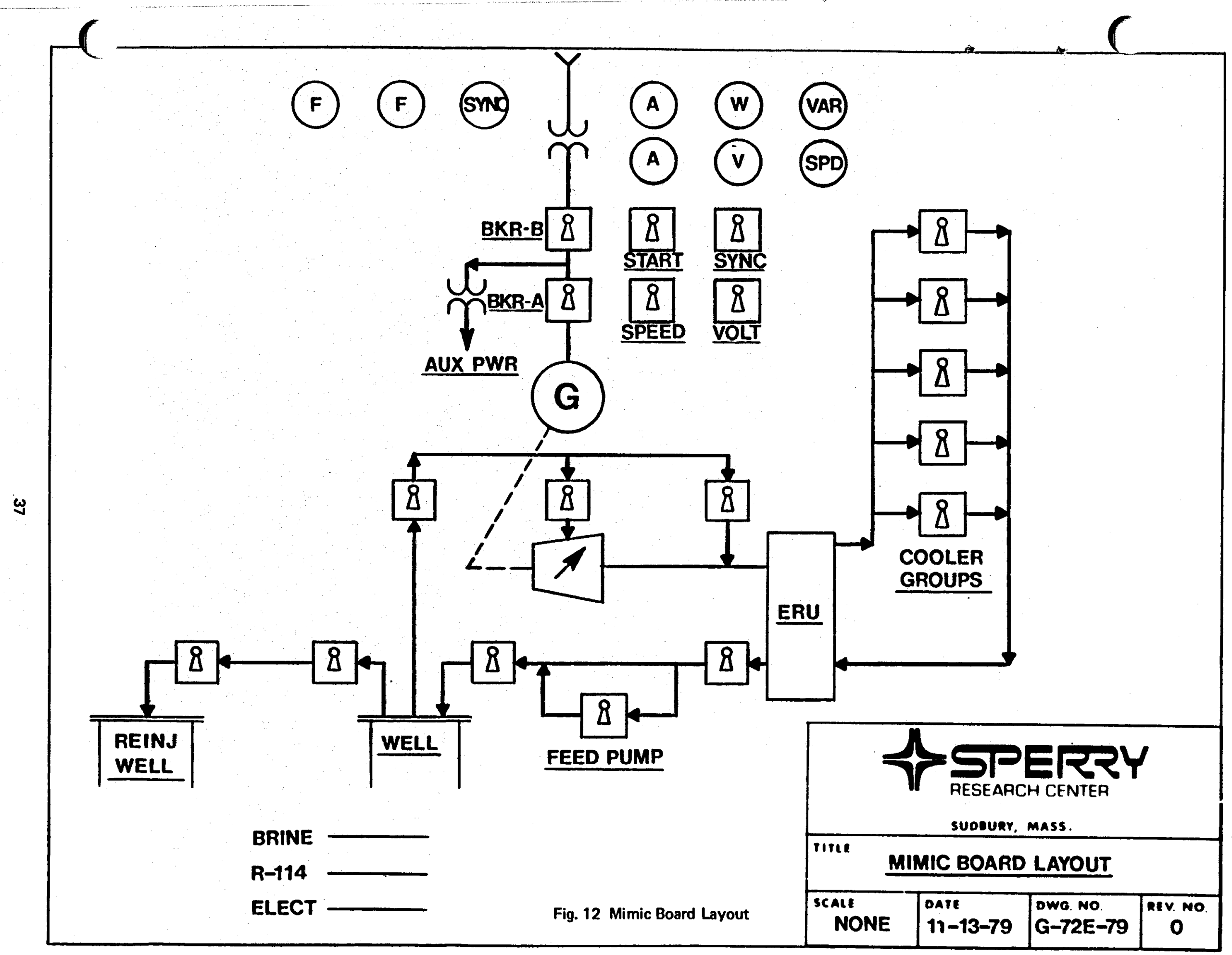




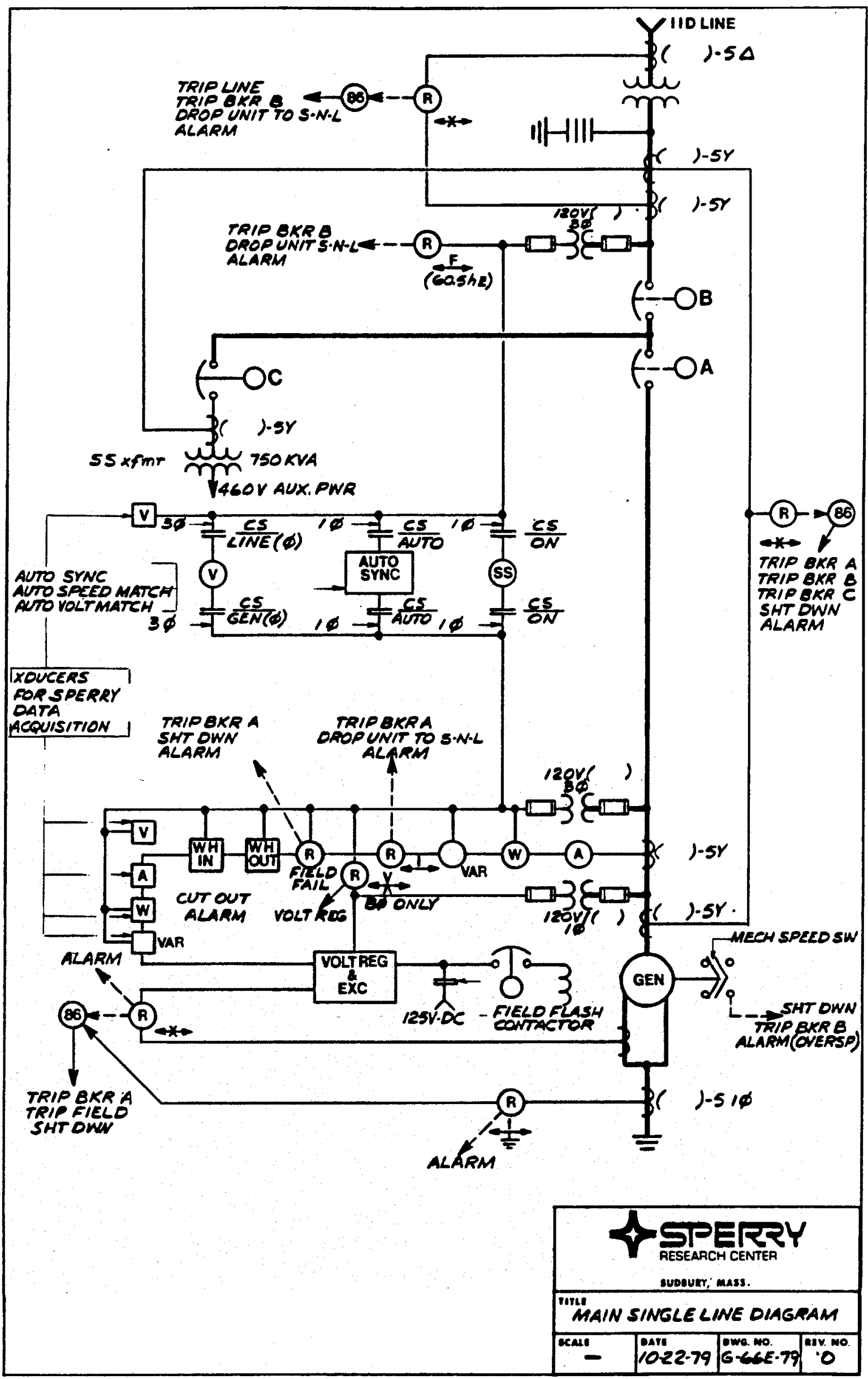

FIG. 13 Main Single Line Diagram. 


\section{tr}

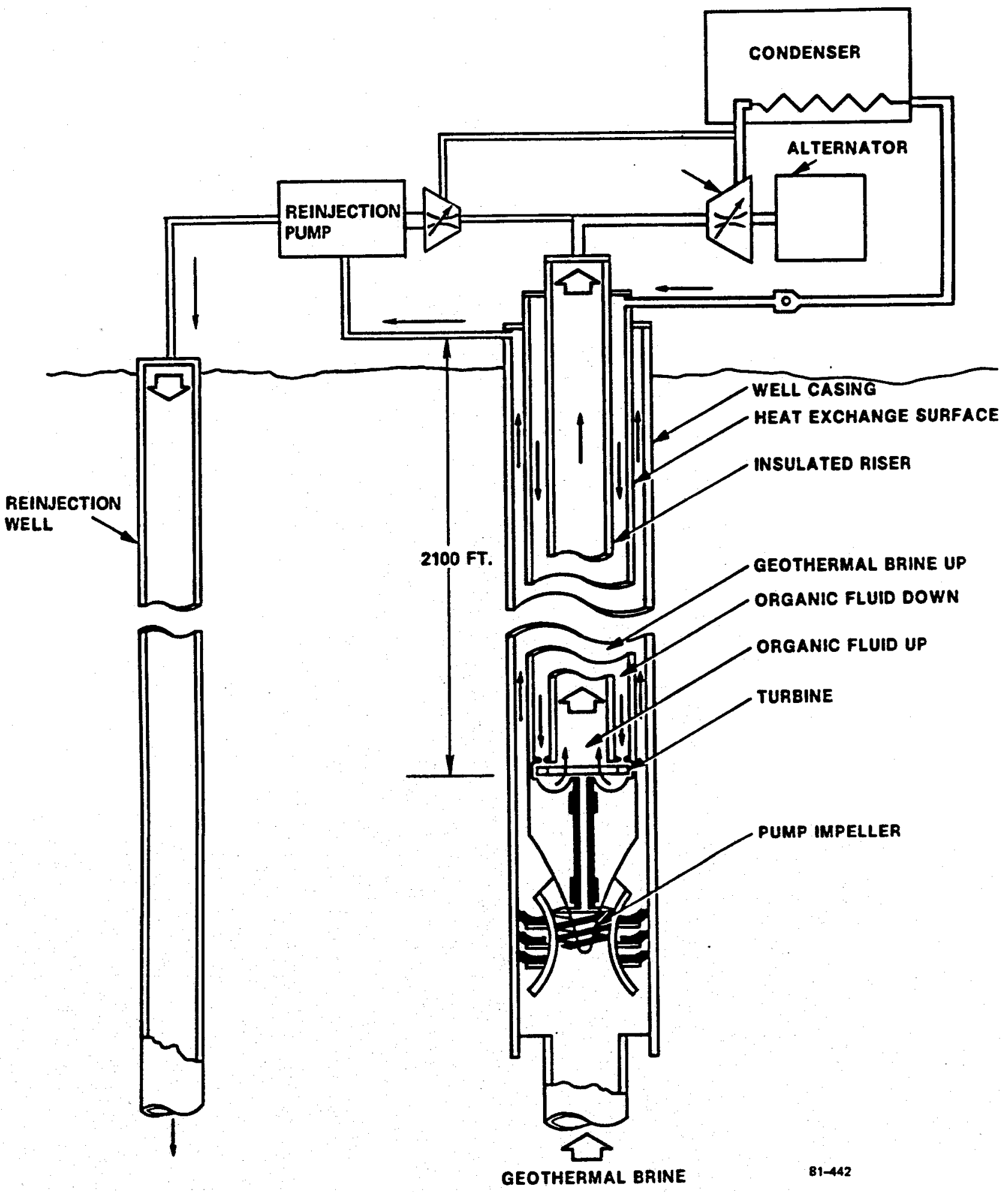

FIG. 14 Gravity Head System Schematic. 


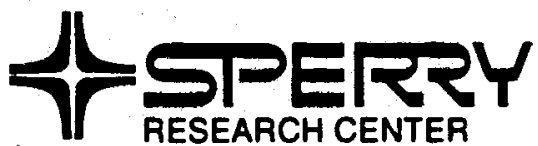

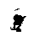

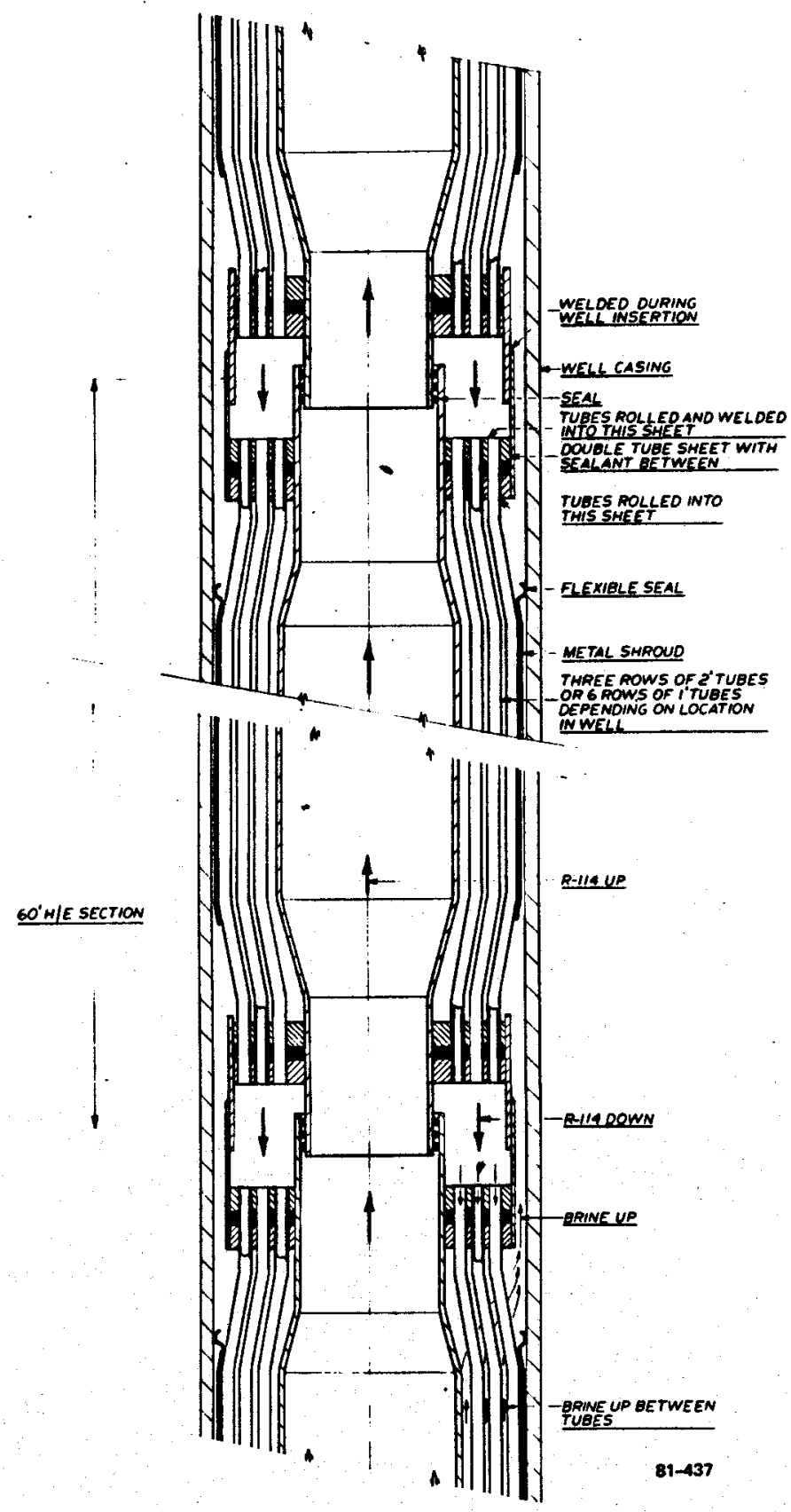

Fig. 15 Typical Tubular Heat Exchanger Section 


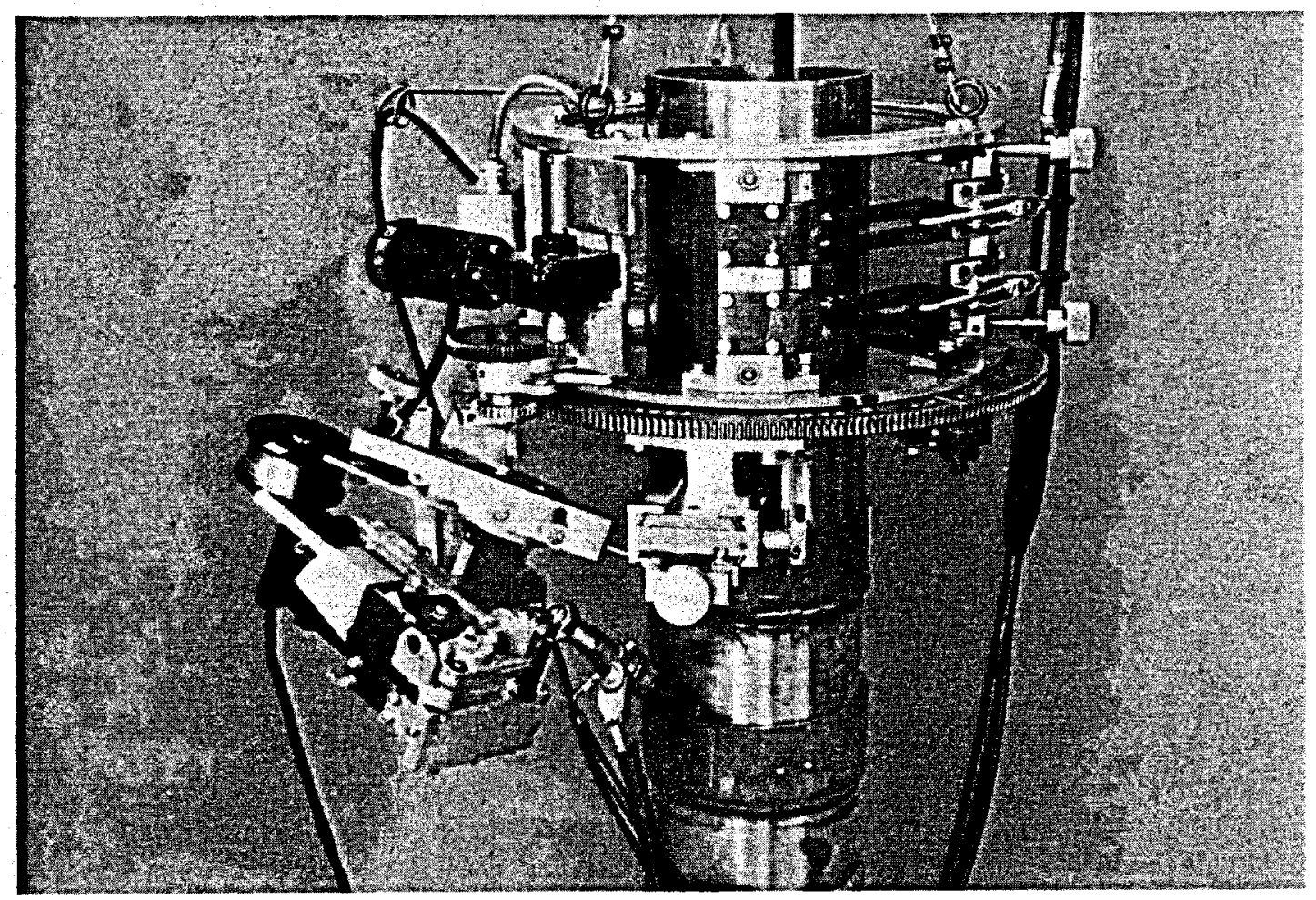

Fig. 16 Automated Welding Lathe 


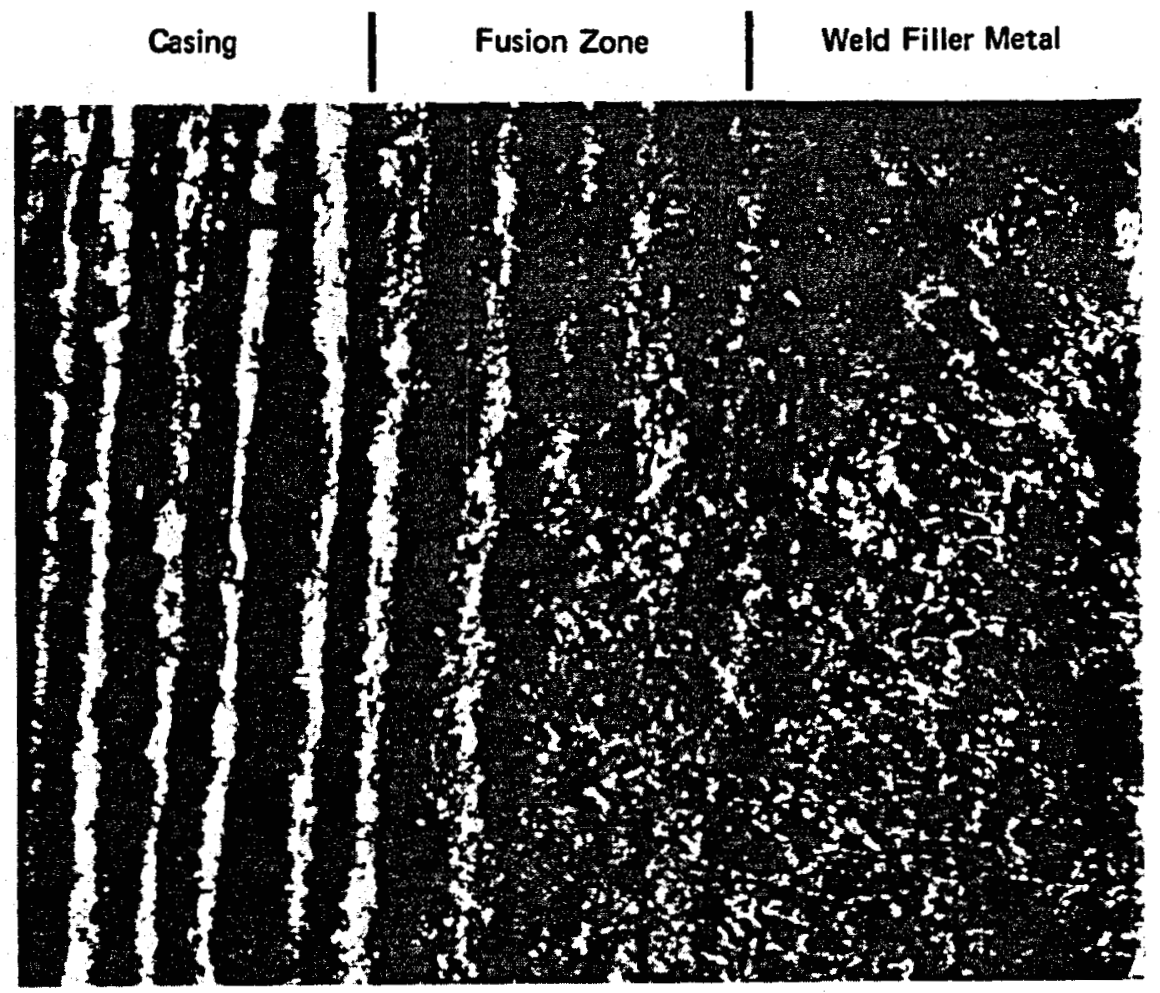

$75 x$

Figure 17: Photomicrograph of welded section of casing.

The weld is sound, free of porosity, and relatively free of slag. The vertical black streaks readily visible in the fusion zone are inclusions (probably silicate) normally present in the pipe. They are elongated during forming of the pipe.

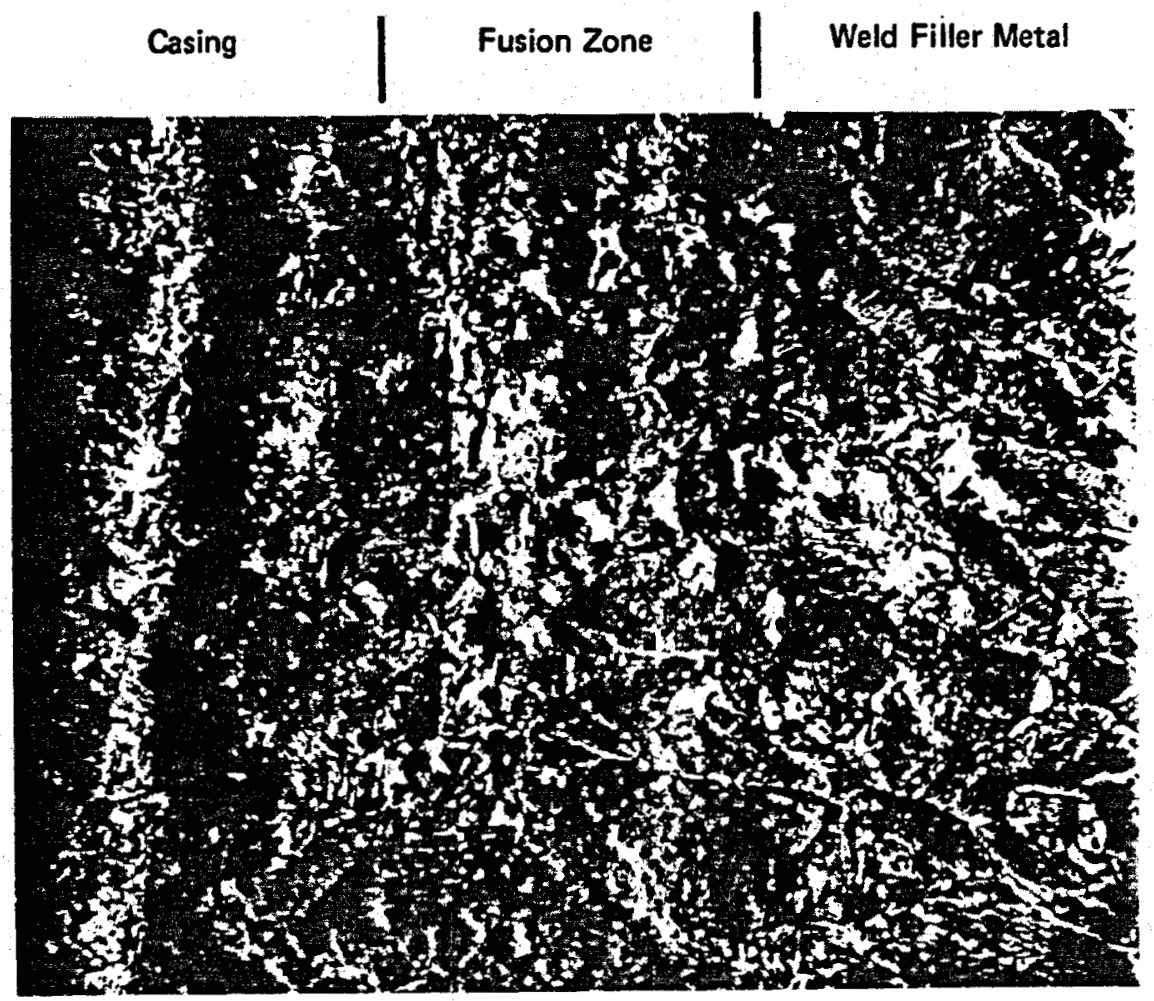

$150 X$

Figure 18. A higher magnification photo of the region shown in Figure 17. Inclusions present in the casing are more visible but the weld is of a high quality. 


\section{th}

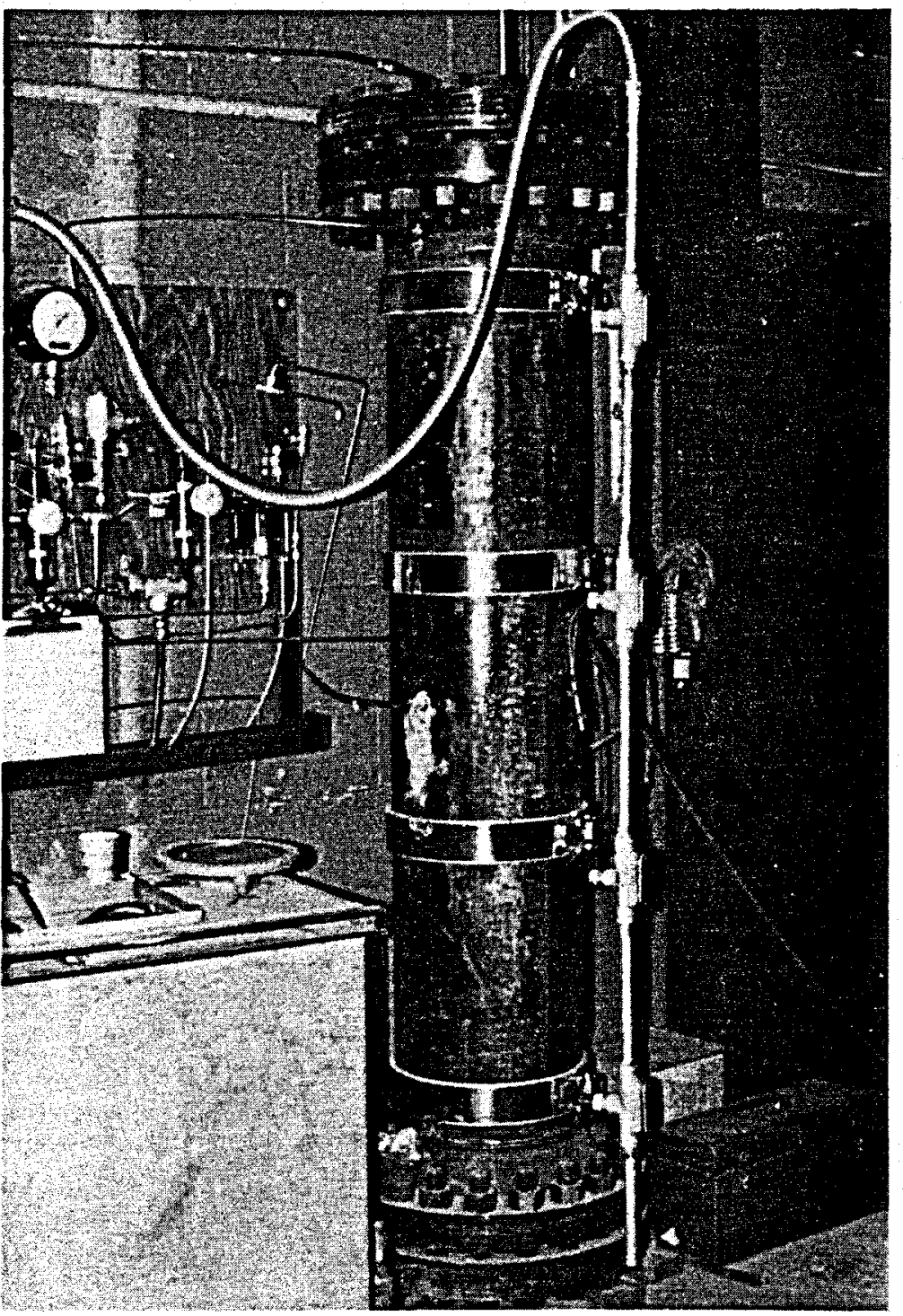

Fig. 19 Packer Cup Test Facility 


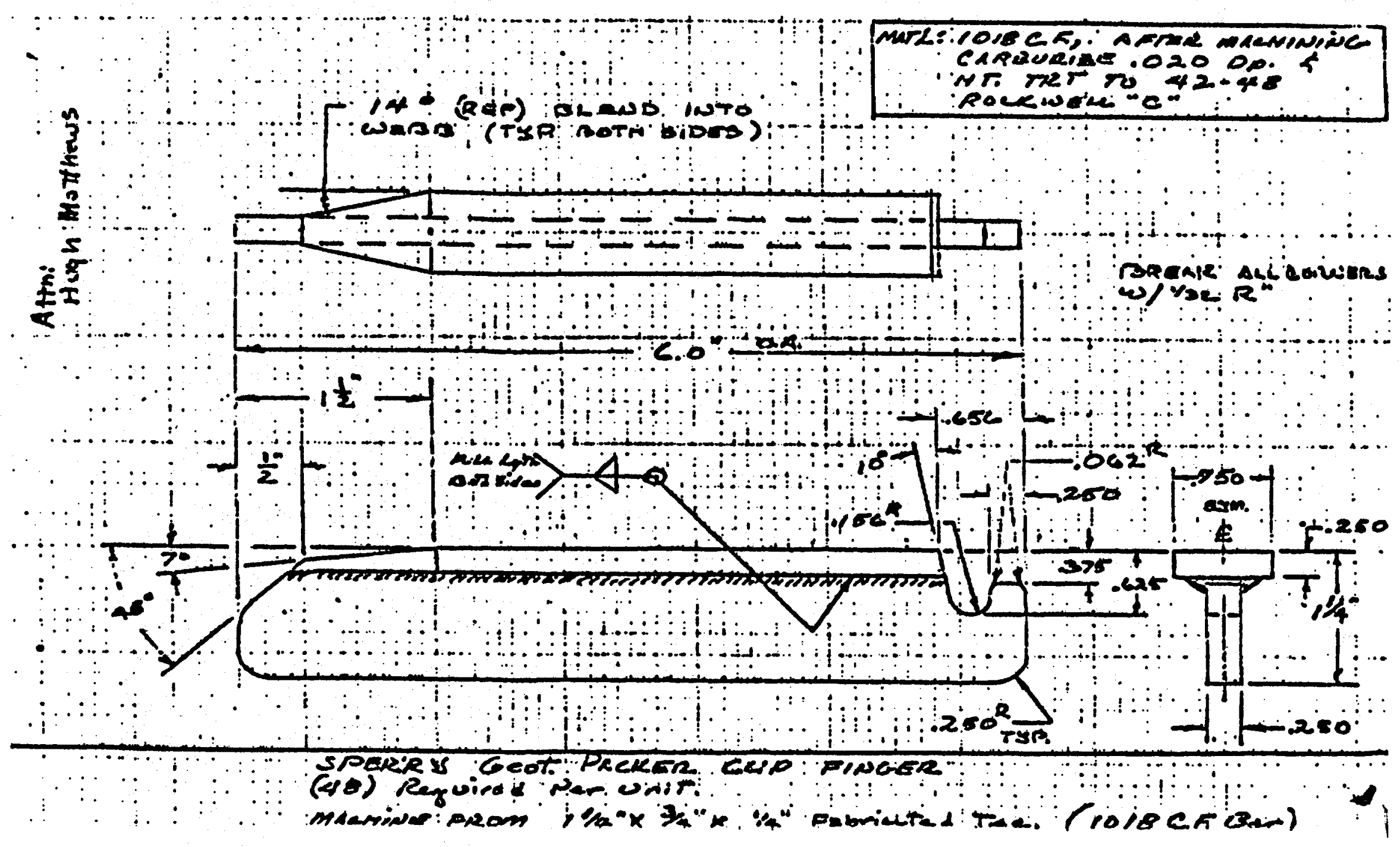

FIG. 21 T-Bar Fingers for Packer Cup. 


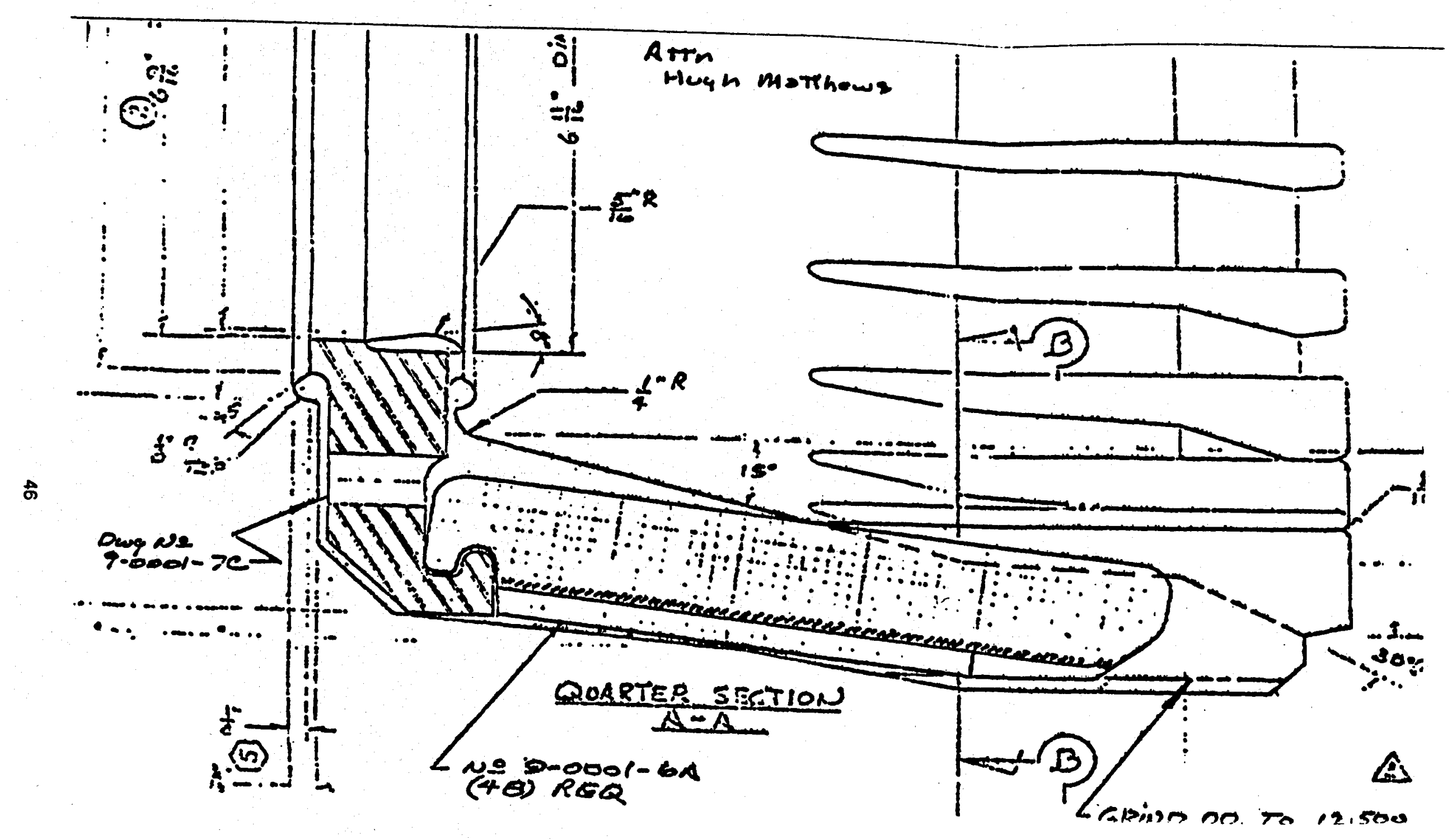

FIG. 22 Modified Cup Design Cross-Section. 
$y$
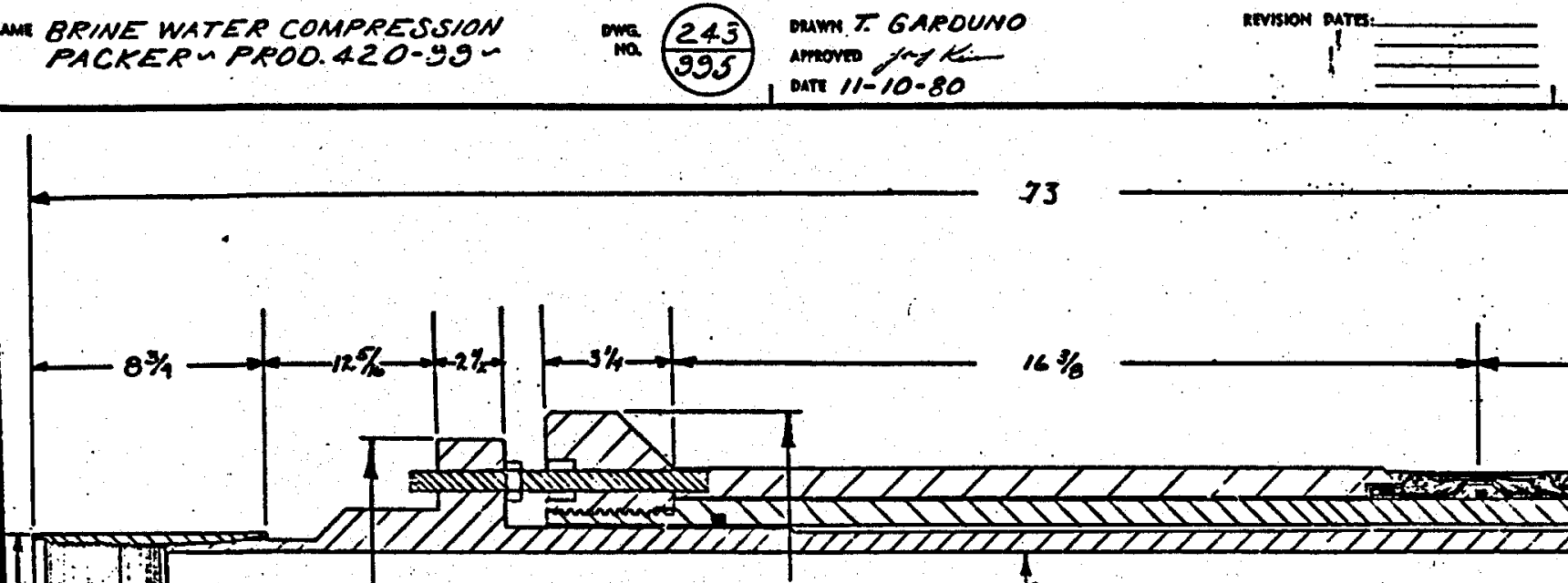

$16 \%$

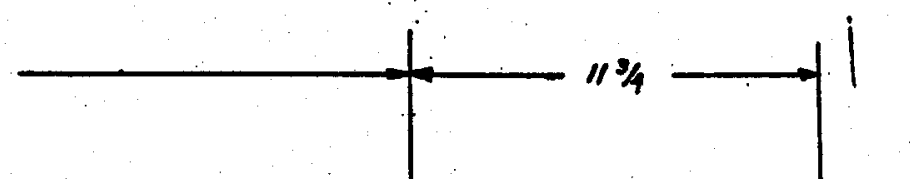

$6 \frac{5}{8} 880 \angle$ LNG CASING THPEAD BOTHENOSN7
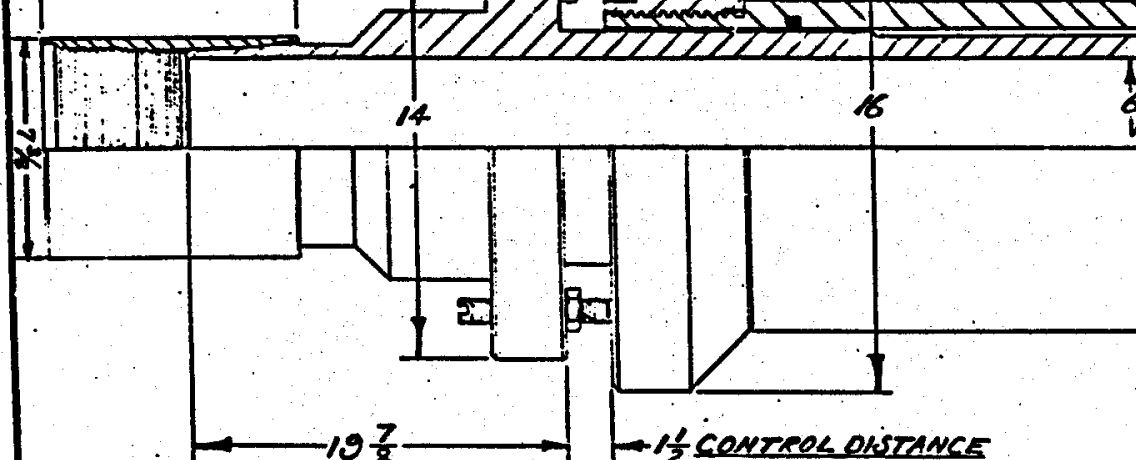

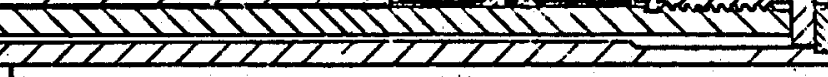

if

$66 \frac{5}{8}$

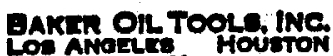

NEW YomK

ILLUETRATIVE DRAMnNos

T

TOOLS AND METHODS

Fig. 23 Fixed Baker Pucker 


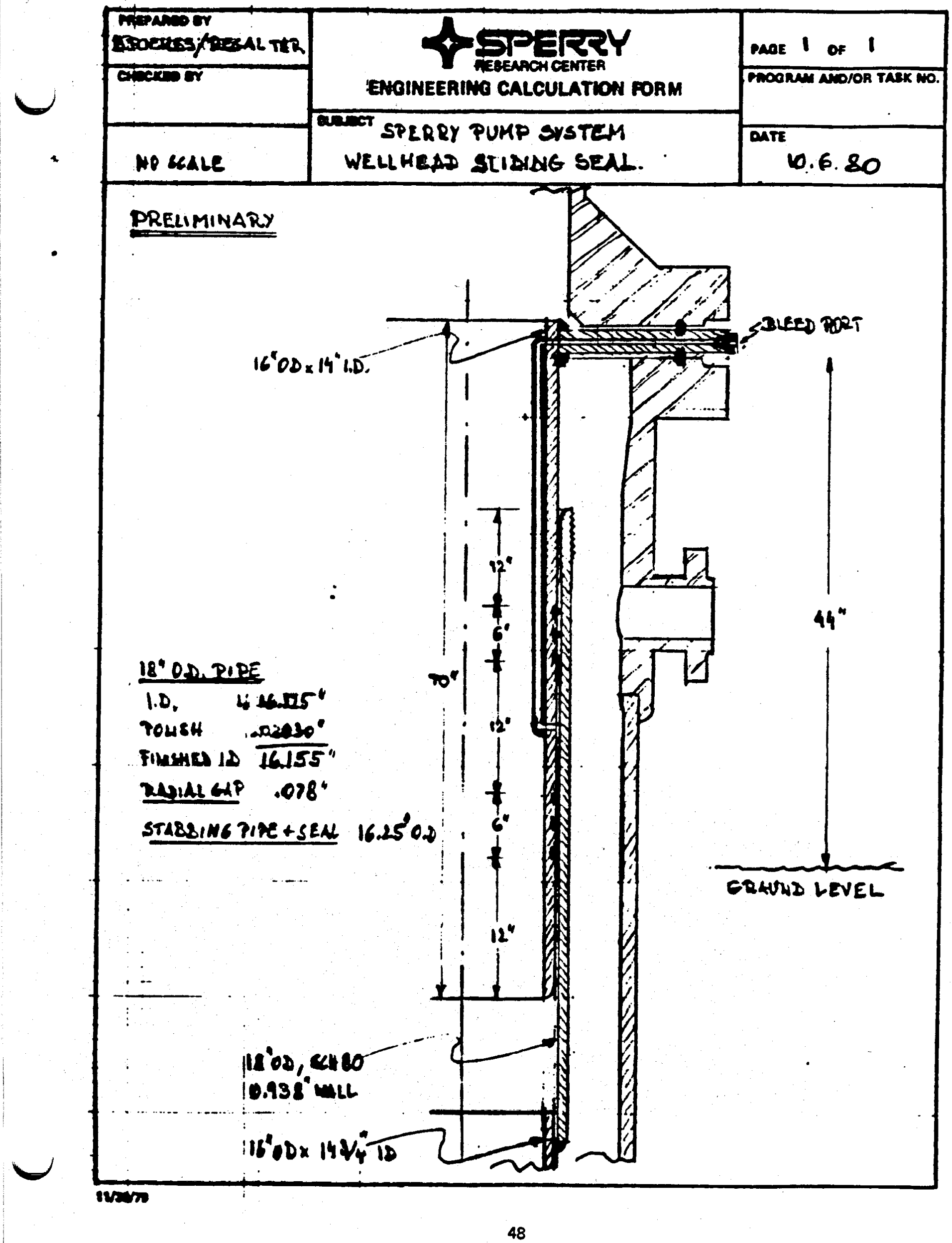



(

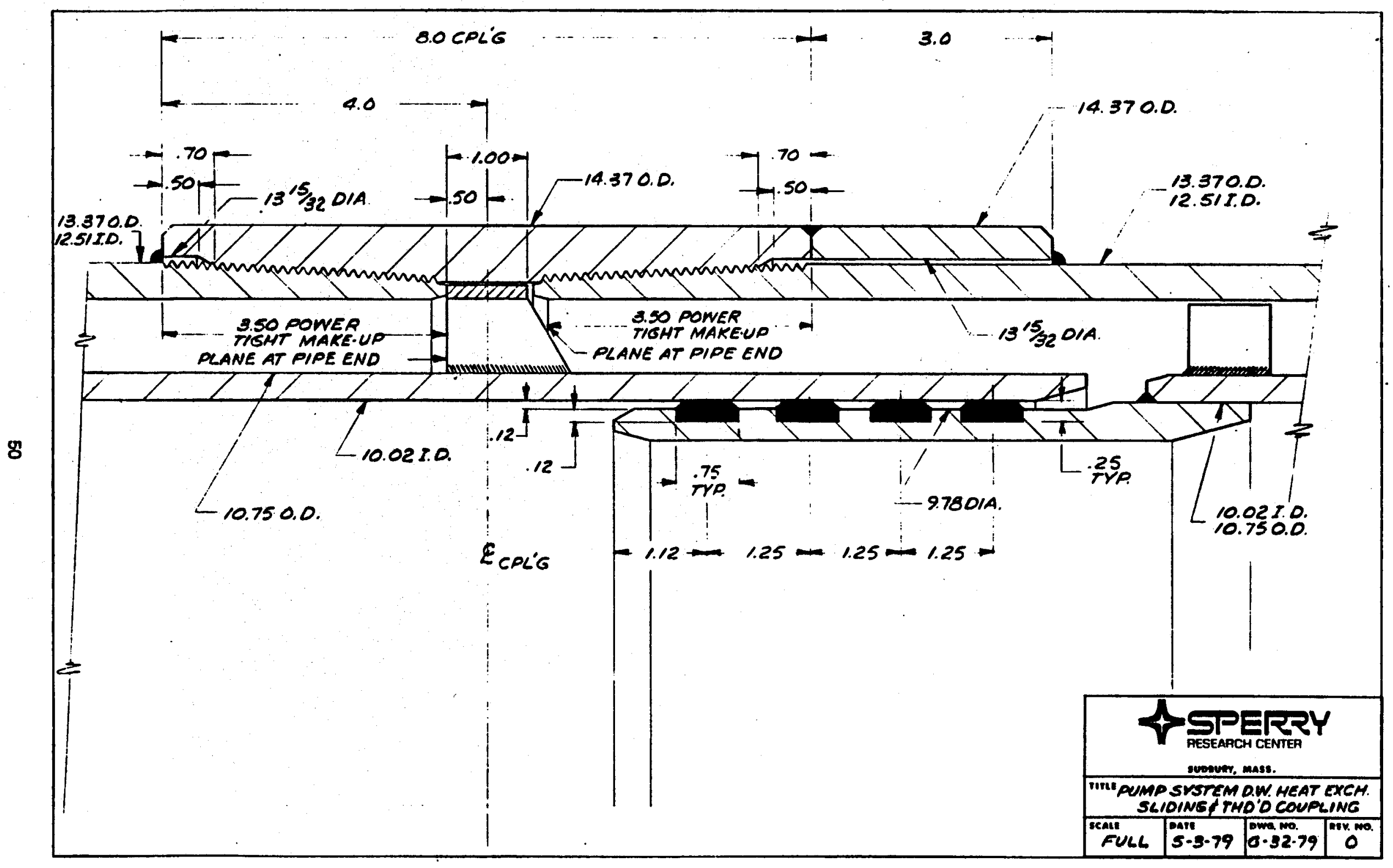

Fig. 26 Downwell Heat Exchanger Coupling 


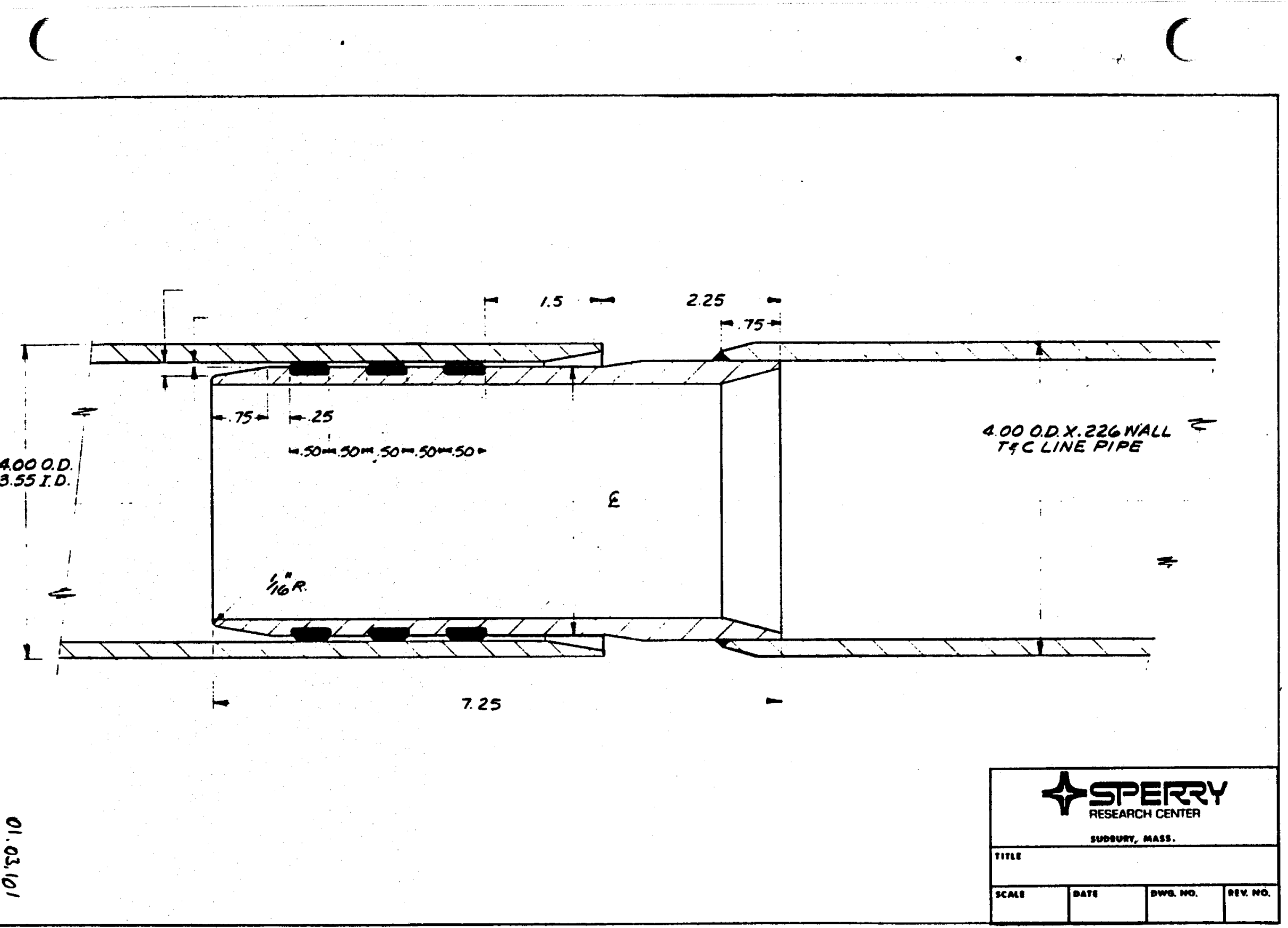

FIG. 27 R-114 Downcomer Seal. 


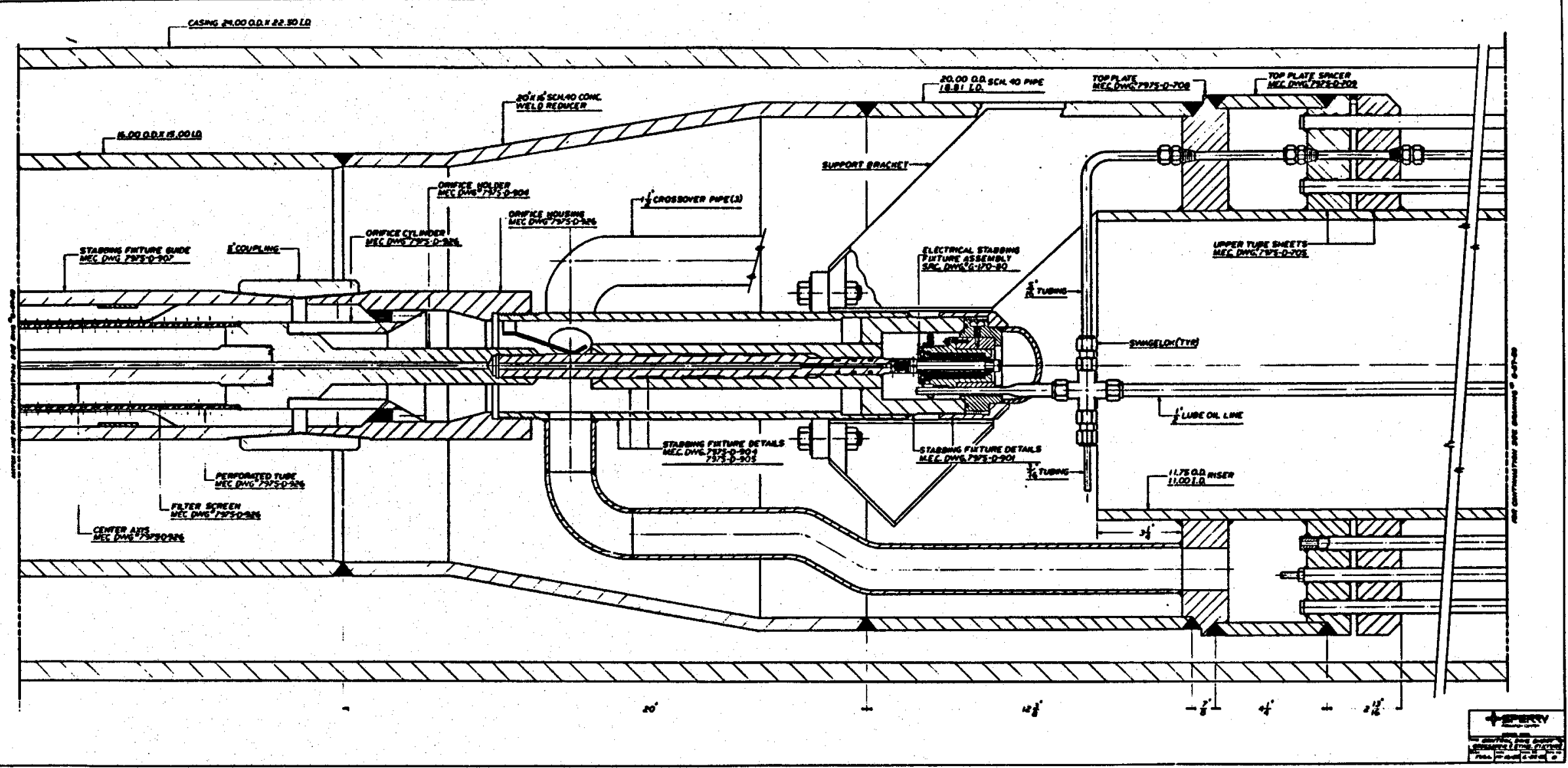

FIG. 28 Lube Oil/Electrical Stabbing Fixture. 


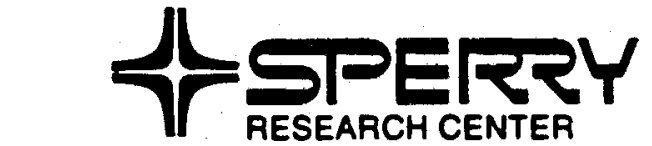

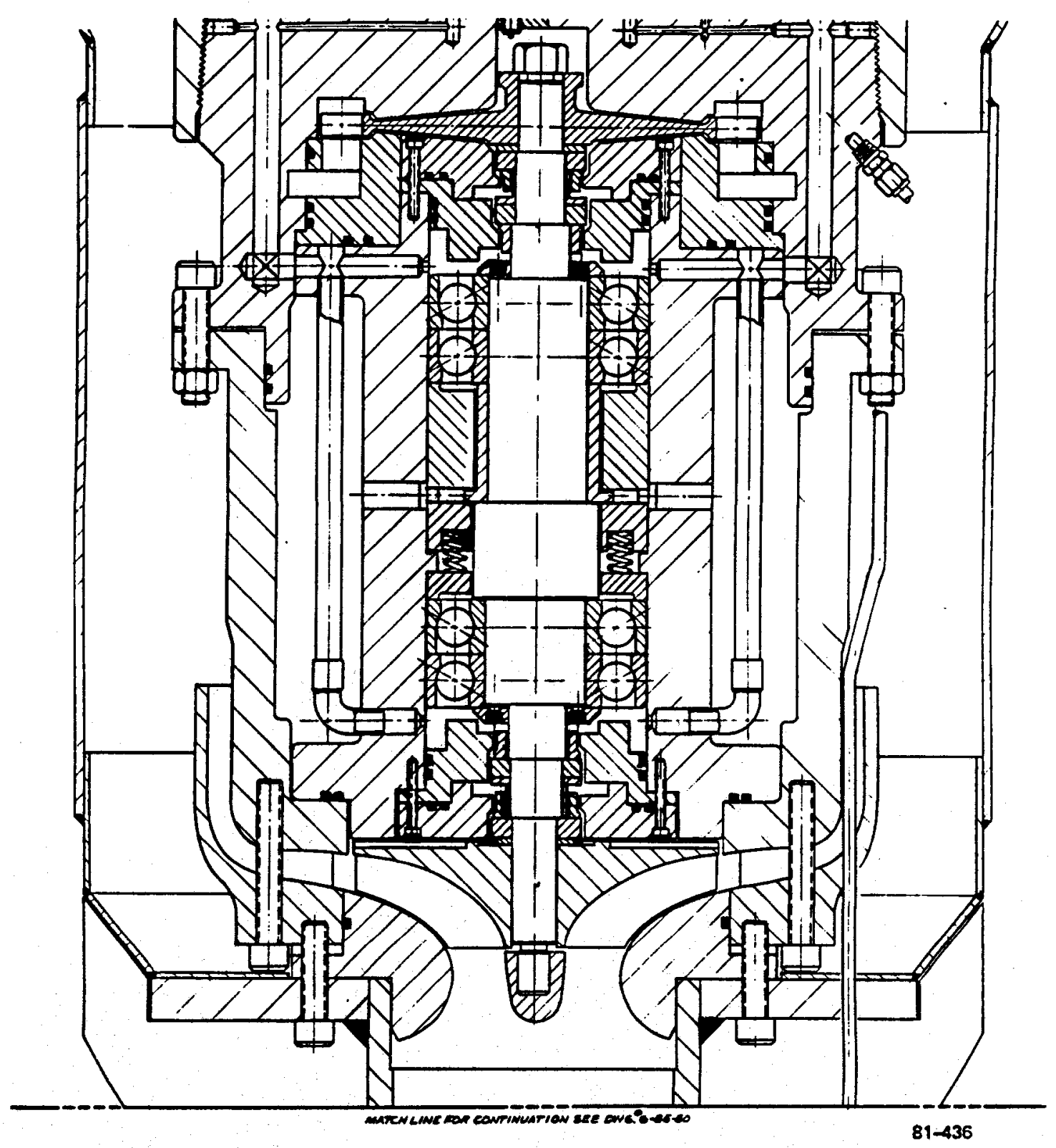

FIG. 29 Pump System TPU Layout. 


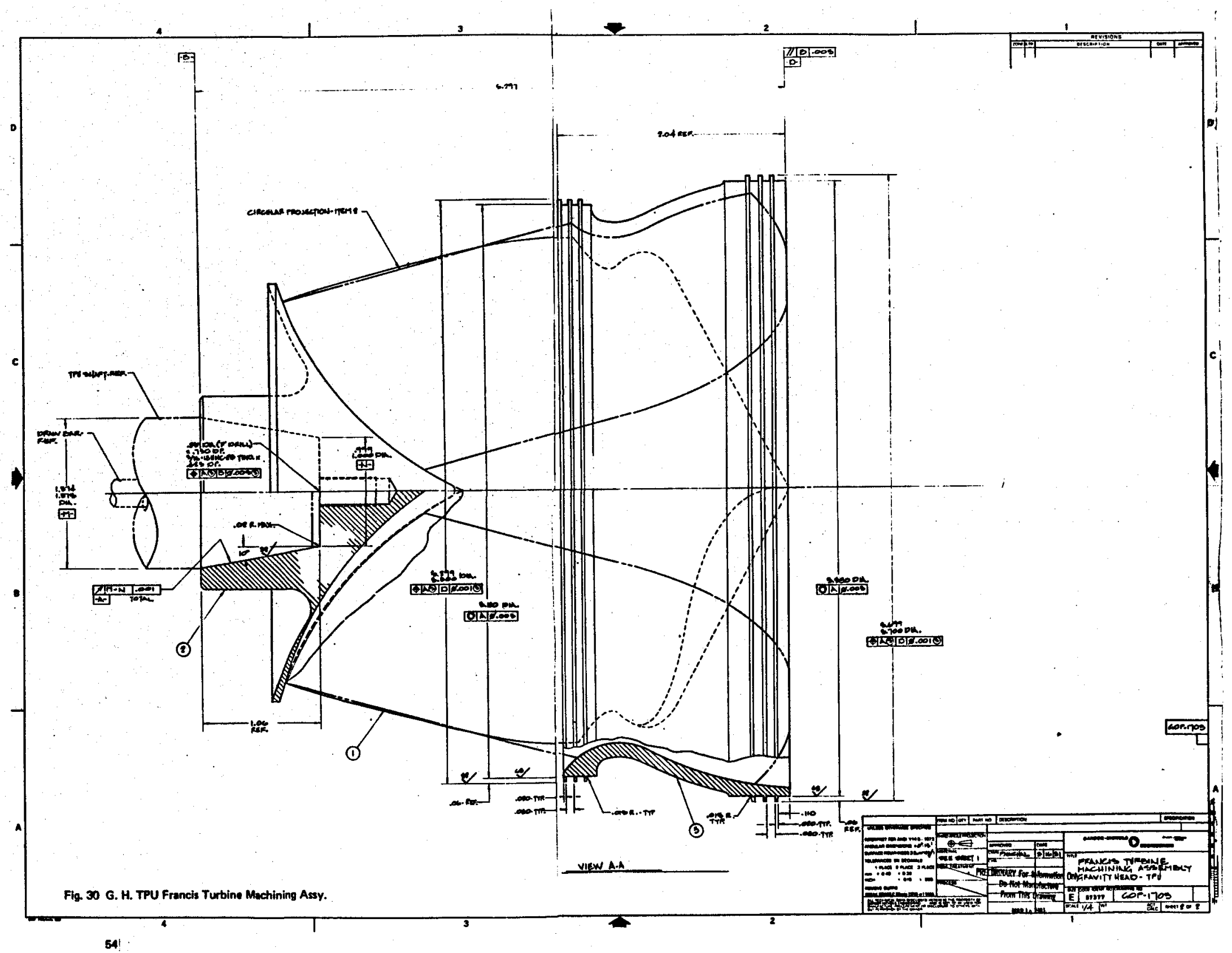




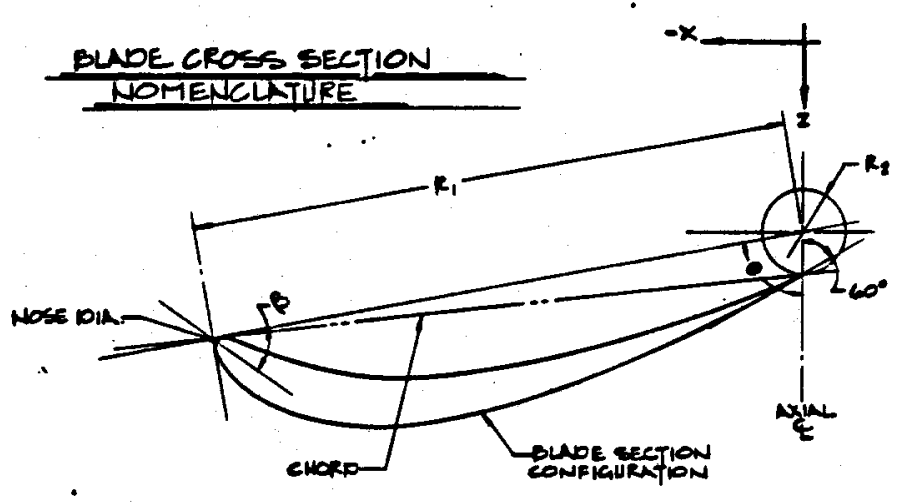

\begin{tabular}{|c|c|c|c|c|c|c|}
\hline Taxis & $x \Delta \times 10$ & $R_{1}$ & $\beta$ & $R_{2}$ & $\bullet$ & NOSE DI \\
\hline-0.91 & -1.78 & $1.72+.14$ & $-\infty 0^{\circ}$ & $0+.14$ & $94.6^{\circ}$ & .015 \\
\hline-1.87 & -1.02 & $102+.00$ & $-79.7^{\circ}$ & $0+.06$ & $98^{\circ}$ & 1 \\
\hline-1.66 & -1.90 & 1.90 & $-79.5^{\circ}$ & .04 & $298^{\circ}$ & \\
\hline-1.86 & -1.90 & 1.78 & $-77.9^{*}$ & .12 & $878^{\circ}$ & 1 \\
\hline-8.17 & $-2 \alpha$ & 8.06 & $-76.1^{\circ}$ & .80 & $85^{\circ}$ &. $\mathrm{Fib}^{\circ}$ \\
\hline 240 & -2.14 & 8.4 & $-7 a 5^{\circ}$ & .85 & $82.60^{\circ}$ & .062 \\
\hline 781 & 2.85 & 229 & $-\infty .7^{\circ}$ & .87 & $\infty$ & .040 \\
\hline .201 & -2.58 & 9.20 & $-\cos 9^{\circ}$ & As & $76.4^{\circ}$ & 1 \\
\hline$-8 x$ & -8.87 & 251 & $-97.1^{\circ}$ & .01 & $76^{\circ}$ & \\
\hline .840 & -8.09 & 89 & $-46^{\circ}$ & .60 & $78^{\circ}$ & \\
\hline-2.4 & -841 & 8.42 & $-46^{\circ}$ & .86 & $70^{\circ}$ & \\
\hline-8.70 & -8.04 & 246 & $-44^{\circ}$ & .61 & $67^{\circ}$ & \\
\hline-9.90 & -2.81 & 8.08 & $-45^{\circ}$ &.$\omega$ & $64^{\circ}$ & .050 \\
\hline
\end{tabular}

WTE: BEE BUDE TABULTTON POR SECTON CONFKURATIONAS.

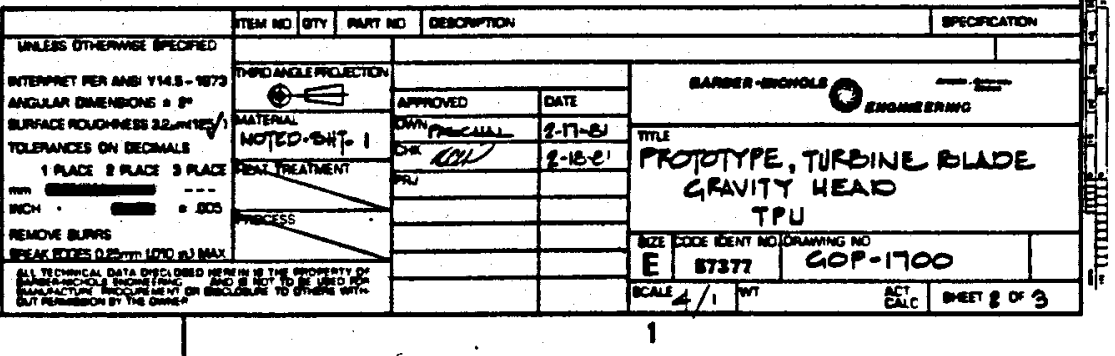




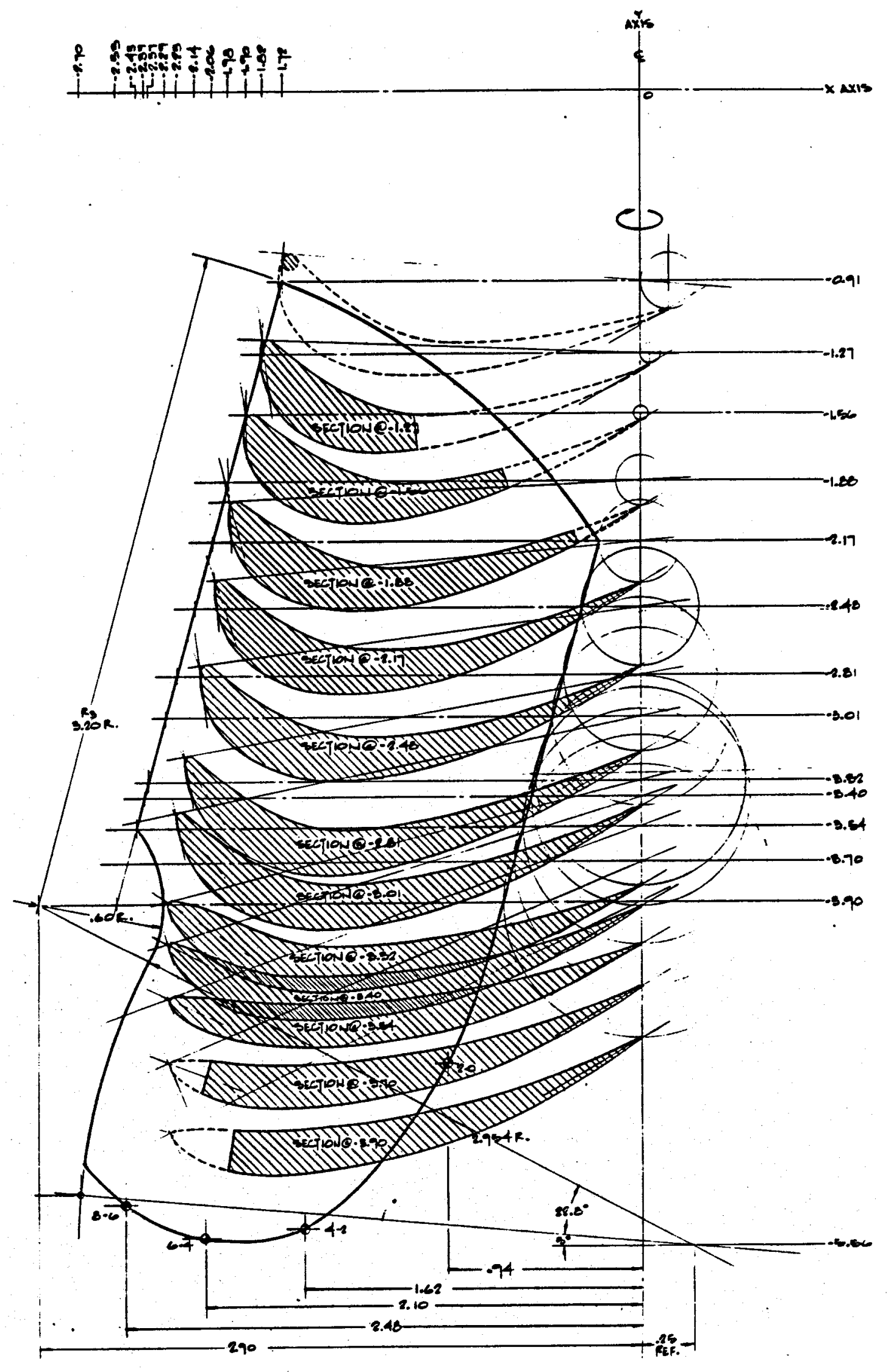

NOTE: PROFILE DEFINED IN THK

VIEW IS a CIRCULAR PROSLCTION 


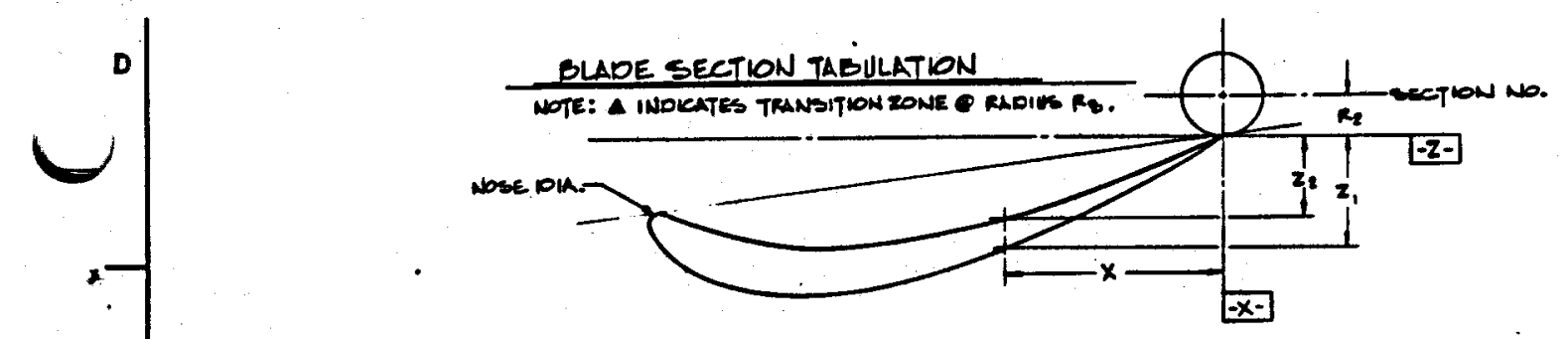

\begin{tabular}{|c|c|c|c|c|c|c|c|c|c|c|c|c|c|c|c|c|c|c|c|c|c|c|c|}
\hline \multirow{2}{*}{\multicolumn{3}{|c|}{\begin{tabular}{|c|c|}
\multicolumn{2}{|c|}{ secTlon-asi } \\
$x \mid z_{1}$ & $z_{2}$ \\
\end{tabular}}} & \multicolumn{3}{|c|}{ seg } & \multicolumn{3}{|c|}{ 3xatod-1.626 } & \multicolumn{3}{|c|}{ tefor-1.46 } & \multicolumn{3}{|c|}{ ACION-4.n } & \multicolumn{3}{|c|}{ ScETON-eAs } & \multicolumn{2}{|c|}{ SKCTEN-281 } & & \multicolumn{3}{|c|}{ gacton-s. } \\
\hline & & & $x$ & $\left|z_{1}\right|$ & $\mid z e$ & $x$ & $\mathbf{z}$, & $z$, & $x$ & $z_{1}$ & $z_{4}$ & $x$ & $z_{1}$ & 2, & $x$ & $\left|\mathbf{z}_{1}\right|$ & $z_{2}$ & $x \mid$ & 2,2 & $t_{1}$ & $\times$ & & \\
\hline & & & 이 & 400. & ses & 24 & & 26 & .2 & .106 & - & 0 & 1.010 & $1-\infty$ & 0 & Fon & & 01 & eone & $\infty$ & 0. & 에 & \\
\hline & & & & 5 & (456) & $.7^{2}$ & & 20 & & (i). & . $1 \mathrm{~s}$ & .1 & م & DK & .1 & H. & .04 & .1 & 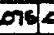 & $\bar{a}$ & 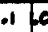 & & \\
\hline & & & 3 & 20.4 & 2209 & $\$$ & Exost & 234 & A) & 200 & Ant & .8 & .120 & Fo & .8 & -10i: & & & 1386 & कान. & .2 & 105. & \\
\hline & & & 1.5 & A33i. & $=6$ & .9 & A10 & 2726 & .5 & .ns. & .78 & .8 & 100 & . 1. & .6 &.$m$ & & &.$n 5.1$ & 18:- & & & \\
\hline & & & 1,4 & $A B L$ & 645 & 1.0 & tasc. & nng & .6 & INE. & .200 & .4 & 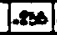 & $=0$ & 4 & .MA & & & 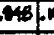 & $\theta$ & & 776 & \\
\hline & & & 16 & .nots & .006 & 1.1 & 466 & $\infty$ & .7 & sect & .783 & .8 & .004 & $n$ & .6 & mol & $\operatorname{nn}$ & & 996. & 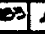 & & $\infty .19$ & \\
\hline & & & 100 & न & 085 & 1.2 & 475 & तथ & $\infty$ & 1.50 & $\infty$ & .6 & 180 & . $5 \times 6$ & .6 & mat & 2028 & & 20 & 210. & & & \\
\hline & & & 1.7 & matr. & 0,016 & 18 & 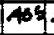 & .729 & .9 & 425. & .260) & -7 & .57\% & .24 & .7 & 00 & .258 & .7 & & 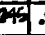 & & 고. 28 & \\
\hline & & & B. & 216 & & पा & A659. & .2206 & 10 & $A=0$. & .200 & $-\infty$ & tan & 我的 & 0 & $\mid$ & .200 & $\because 1$ & 20.2 & $\bar{x}$ & & 1005 & \\
\hline & & & 1.77 & $-t$ & ind & 1.5 & A7B: & $n$ & 1.1 & ATS: & .235 & 9 & AfEO & D2835 & 9 & 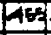 & 300 & .9 & 1656 & $\overline{0}$ & & 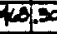 & \\
\hline & & & 1.8 & $-11 \beta_{1}$ & & 1.6 & 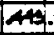 & WA & L2 & Ast. & 285 & 10 & Aาद & .006 & 10 & 103 & $\infty 7$ & $10:$ & 40 & 8001 & & $\operatorname{sog}=2$ & \\
\hline & & & inen & - .0os. & & 1.7 & 1009 & 100 & 1.8 & naf. & .036 & 1.1 & $\operatorname{tin} 6$ & 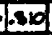 & 6.1 & $-\infty$ & 28 & 1.1. & 6301. & 3891 & & 29 & \\
\hline & & & Ls] & $-\infty$ & & 1.8 & 316 &.$\infty$ & 1,4 & ind. & & LE & 1510 & 9.012 & 102 & $\sqrt{1235}$ & 534 & 1.4 & 50013 & 501 & & $\mathrm{sens}$ & \\
\hline & & & & & & 1.04 & .853 & $=$ & 1.4 & 1060 & .225 & 15 & 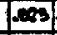 & 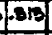 & 16s & 1540 & $\infty$ & 1.87 & .0735 & $\begin{array}{lll}513.1 & \end{array}$ & & 575.57 & \\
\hline & & & & & & 187 & -1 & Dent & 1.0 & And & $\sqrt{778}$ & $1 \mathrm{AA}$ & $+\infty$ & 1.500 & 14 & & $\infty$ & 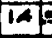 & $\operatorname{sen} 1=$ & $\overline{57} 1$ & IAा & 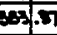 & \\
\hline & & & & & & 1.9 & .100 & -1 & 1.7 & Asso, & 180 & 1.5 & 1.525 & 1,258 & 16. & $1 \mathrm{sac}$ & 580 & 1.65 & 5795 & 501 & & 43.5 & \\
\hline & & & & & & 1.91 & 10 & -1 & 1.8 & $.05-6$ &.$\infty$ & 1.6 & $1 . \$ 16$ & 2215 & 16 & exes & $=0$ & (15). & $\cos 2$ & 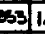 & & 20.3 & \\
\hline & & & & & & & & & Laר &. $\mathrm{nag}$ & $\infty$ & 8.7 & 1405 & $n_{n}$ & 1.7 & & .945 & 1.7. & 57013 & $38 / 1$ & & 679. & \\
\hline & & & & & & & & & 1.76 & -6 & $-\cos$ & 18 & 450 & 3.165 & 1.8 & $\mid+\infty$ & .6 & 1.81 & $\cos .7$ & 271 & & 000.6 & \\
\hline & & & & & & & $\cdot$ & & 1.76 & .1000 & -1 & 1.9 & 1.202 & 2.04 & 19 & & -10 & 1.97 & ABs. .2 & 101 & & & \\
\hline & & & & & & & & & 1,98 & .04 & -1 & 126 & 6.800 & $9-1$ & 80 & $|m|$ & Fos & 200 & $.425+4$ & 1012 & & 453.10 & \\
\hline & & & & & & & & & & & & 20 &. .28 & -1 & 200 & 2725 & $=$ & 2.16 & .2510 & $501 \%$ & & 500.11 & \\
\hline & & & & & & & & & & & & 20 & $2-1$ & $-\infty=0$ & 200 & $1-1$ & .000 & $2 . \pi$ & -1.0 & 915 & & $\mathrm{ma}_{3}-$ & $E$ \\
\hline & & & & & & & & & & & & 204 & 4.468 & $1-1$ & 21 & 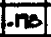 & - & & $.016-$ & -18 & & $195-$ & \\
\hline & & & & & & & & & & & & 200 & $\$ 000$ & - & 2.11 & & $=$ & & .042 & -12 & & & \\
\hline & & & & & & & & & & & & & & & & & & & & & & & \\
\hline & & & & 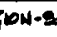 & & & $1+$ & a. & Sect & 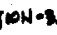 & & & efont & & & & & & & & & & \\
\hline$x$ & 101 & 2, & $x$ & $z_{1}$ & 2. & $x$ & $x_{1}$ & $\pi$, & $x$ & $z, 2$ & & $x$ & $x_{1}$ & 2, & & & & & & & & & \\
\hline 0 & $\cos$ & $\infty$ & 0 & $\infty$ & $\infty$ & 0 & 1004 & $\infty$ & 0 & eods & $\infty$ & 0 & 1004 & for & & & & & & & & & \\
\hline 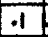 & and & oses & .1 &.$\infty 00$ & ores & .1 & as & - & .1 & Dorste & $\infty=0$ & .1 & tors & 94 & & & & & & & & & \\
\hline .8 & $1 \mathrm{AB}$ & 00 & .2 & 1iss & $\infty$ & .2 & 1no & ag & .2 & $-103 k$ & & 4 & $t, 43$ & Ind & & & & & & & & & \\
\hline 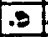 & .175. & 105 & $B$ & ns. & 120 & .3 & Ins & -75 & .8 & not & & 5 & 1.200 & 0.1011 & & & & & & & & & \\
\hline$A$ & 2226. & .191 & $\sqrt{A}$ & 2432 & & 14 & .228 & .116 & A & 1816.1 & 130 & $A$ & Tas & म"लn & & & & & & & & & \\
\hline s. & ens & sis & .5 & -200.1 & 105 & .6 & $\sqrt{\pi 0}$ & 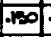 & .81 & - -2911. & & 8 & 510 & $\sqrt{2}$ & & & & & & & & & \\
\hline 6 & sis: & 100 & 6 & sos. & .215 & .6 & .010 & $\operatorname{lng}$ & .6 & $=06.6$ & & .6 & $\omega$ & 201 & & & & & & & & & \\
\hline 1 & tost & 200 & .1 & 2000.6 & 40 & .7 & 245 & . 175 & .7 & Eeo: & & 7 & ais & . $2 \pi$ & & & & & & & & & \\
\hline 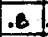 & 280 & & 8 & $A B$. & 20 & .81 & & $-\infty$ & 6 & 445 & & 8 & 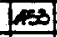 & 200 & & & & & & & & & \\
\hline 9 & $|100|$ & 58 & .9 & 43 & & $a$ & 1.40 & .200 & 9 & ASOL & & 9 & 10 & & & & & & & & & & \\
\hline No & 1433 & .200 & 10 & 1476. & 75 & 10 & 15055 & 1.45 & 10 & $A T B$ & 2780 & 10 & 1503 & & & & & & & & & & \\
\hline 1.1 & 14s. & $\omega$ & 1.11 & lood: & & 1.1 & 1.55O & .203 & 1.1 & Land: & 128 & 1.1 & 1550 & & & & & & & & & & \\
\hline 2 & 478 & .230 & 1.21 & $\ln 18:$ & .18 & 1.2 & 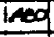 & .206 & 1.2 & wof & $\infty$ & 1.8 & 578 & & & & & & & & & & \\
\hline .8 & AAs!. & .200 & 131 & 10301 & & 1.91 & 1493 & .273 & 100 & $\cos 1$. & 20 & 15 & tons & $1 . n 5$ & & & & & & & & & \\
\hline 4 & Hos.t. & & IA! & 160801. & & 1.4 & 1.000 & .200 & \begin{tabular}{|l|}
.4 \\
\end{tabular} & 4536 & wats & 4 & $\mid 163$ & & & & & & & & & & \\
\hline 65 & Lșisi.2. & & 1.8 & 10131. & 201 & 1.5 & 1500 & & \begin{tabular}{|l|}
1.5 \\
\end{tabular} & 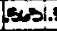 & & 165 & & & & & & & & & & & \\
\hline .6 & 500.2 & & 16 & Esta. & & 1.6 & 50 & & 1.6 & 5716 & 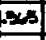 & 16 & $1+\infty 37$ & & & & & & & & & & \\
\hline .7 & $\operatorname{los}_{2}$ & & 1.71 & . &.$\infty$ & & 1503 & & 1.7 & 1,775 & 28 & 1.7 & $1+150$ & $d a$ & & & & & & & & & \\
\hline 8 & tanol. & & $18 !$ & 1.5861. & 120 & 1.81 & 1A95: & & & & & & & 3,135 & & & & & & & & & \\
\hline 11 & $143_{i}$ & & L & 1.5512 & 273 & & 1.00 & & 169 & $\operatorname{los} 1$. & & 1.9 & Loso & & & & & & & & & & \\
\hline 20 & Insi. & & 20 & 1478. & 200 & 2.01 & 140 & & 20 & 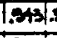 & $\sqrt{030}$ & 20 & 21620 & & & & & & & & & & \\
\hline 2.1 & 5054 & & 2.1 & & .223 & 2.1 & 14001 & & 2.1 & Bsods. & & 8.1 & t5es & 54 & & & & & & & & & \\
\hline 2.2 & .2300 & & 2.2 & 1.385 .1 & & 2.2 & 1.553 & 1.00 & 2.8 & IASOA. & 100 & & 1.525 & 50 & & & & & & & & & \\
\hline 2.25 & -1 & 1008 & 285 & -1. & 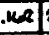 & 2.5 & 1.08 & .57 & 8.25 & -1. & 1.520 & & BA9197 & & & & & & & & & & \\
\hline 2.20 & $i .4 s$ & -1 & 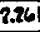 & 1.245. & & 2.27 & 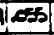 & $1-1$ & [6.0] & $1.405^{\circ}$ & & & & & & & & & & & & & \\
\hline & & & 2.28 & & & & & & & 110 & & & 1415 & & & & & & & & & & \\
\hline
\end{tabular}

NOTE: SEE BUDE NOMENCLATURE POR EUGINEERING OATA. 


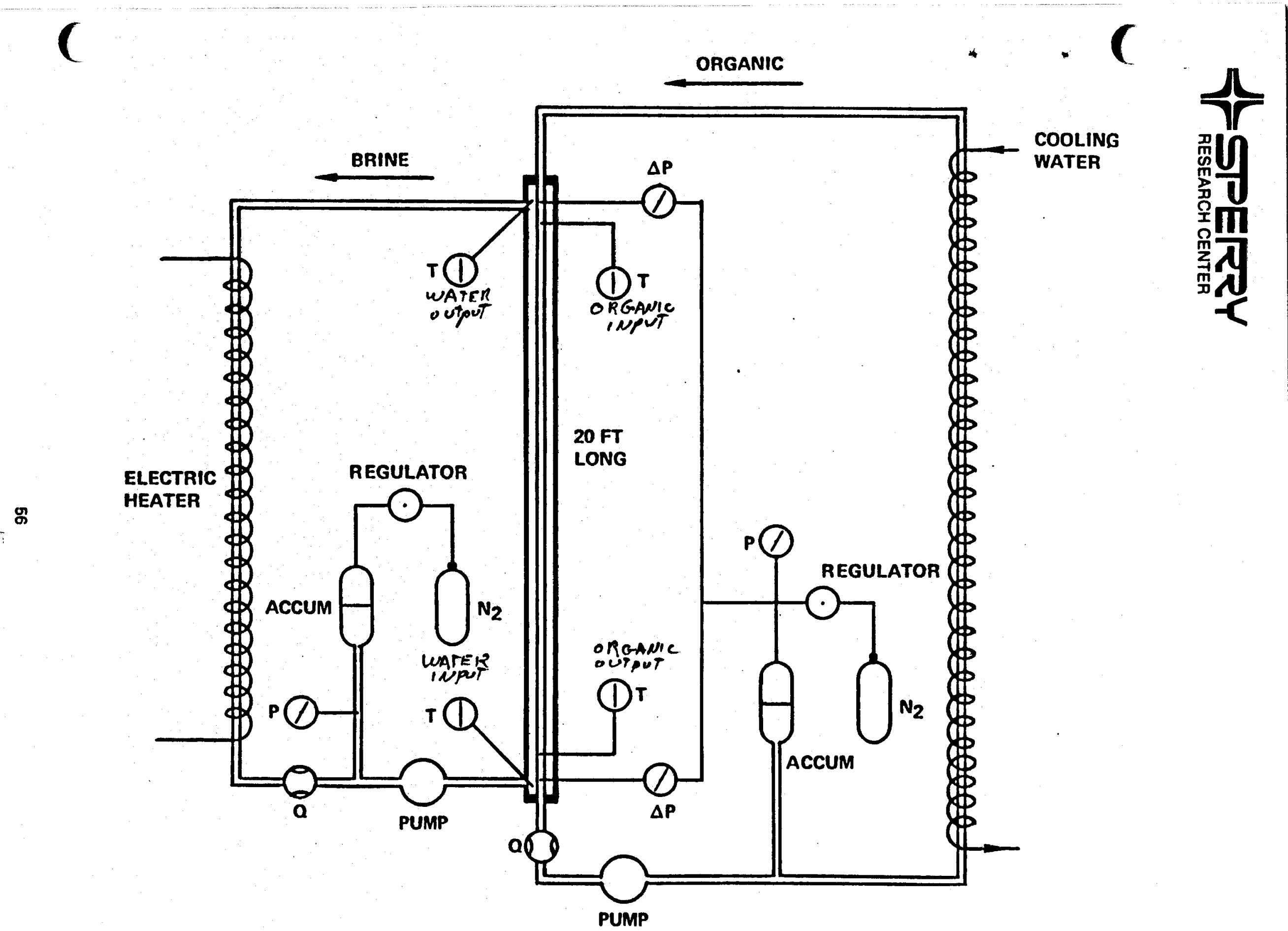

Figure 32 Fluid Test Apparatus 


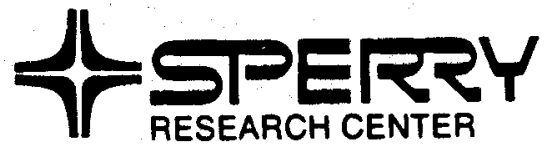
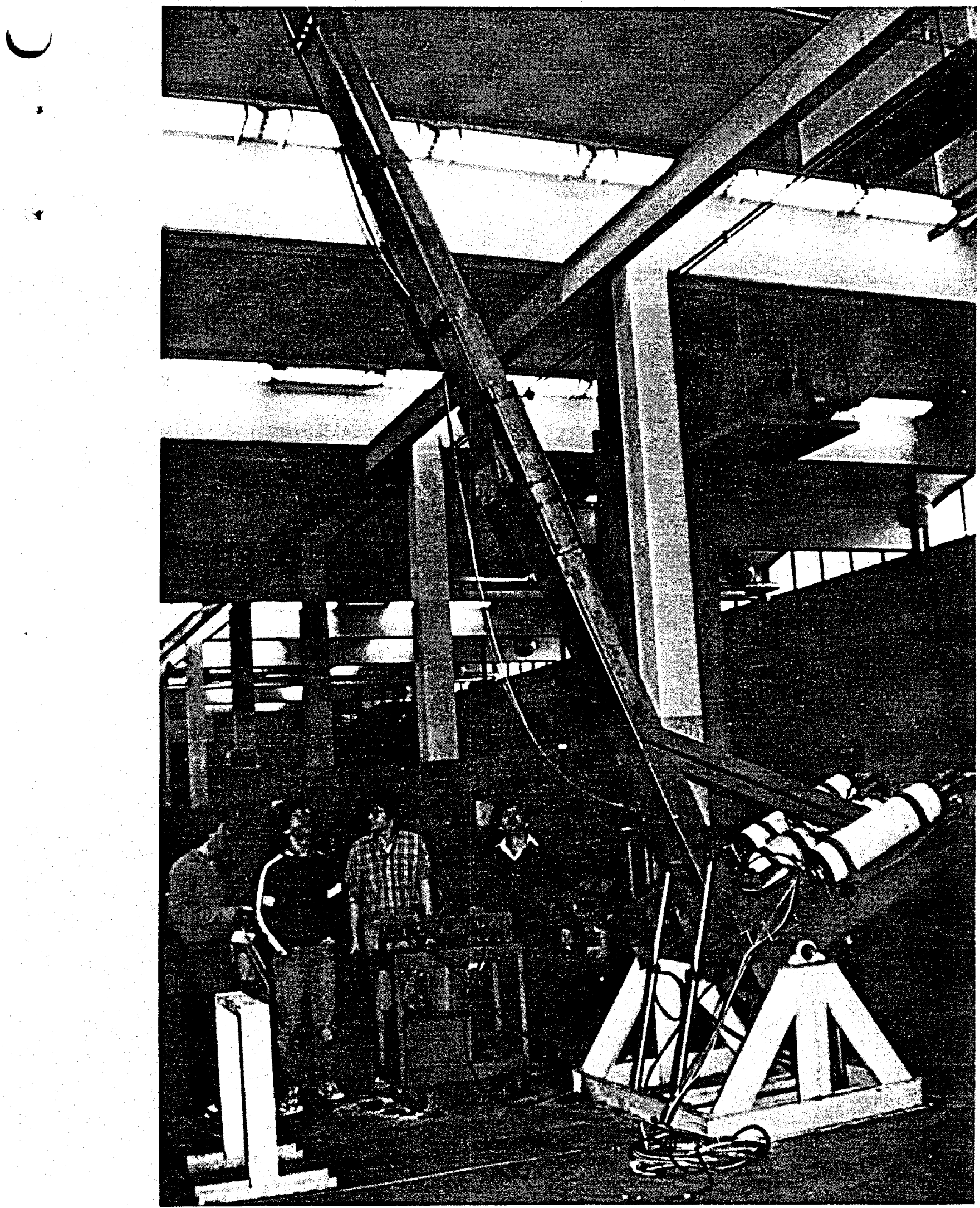

Figure 33. Ten Pound Loop 


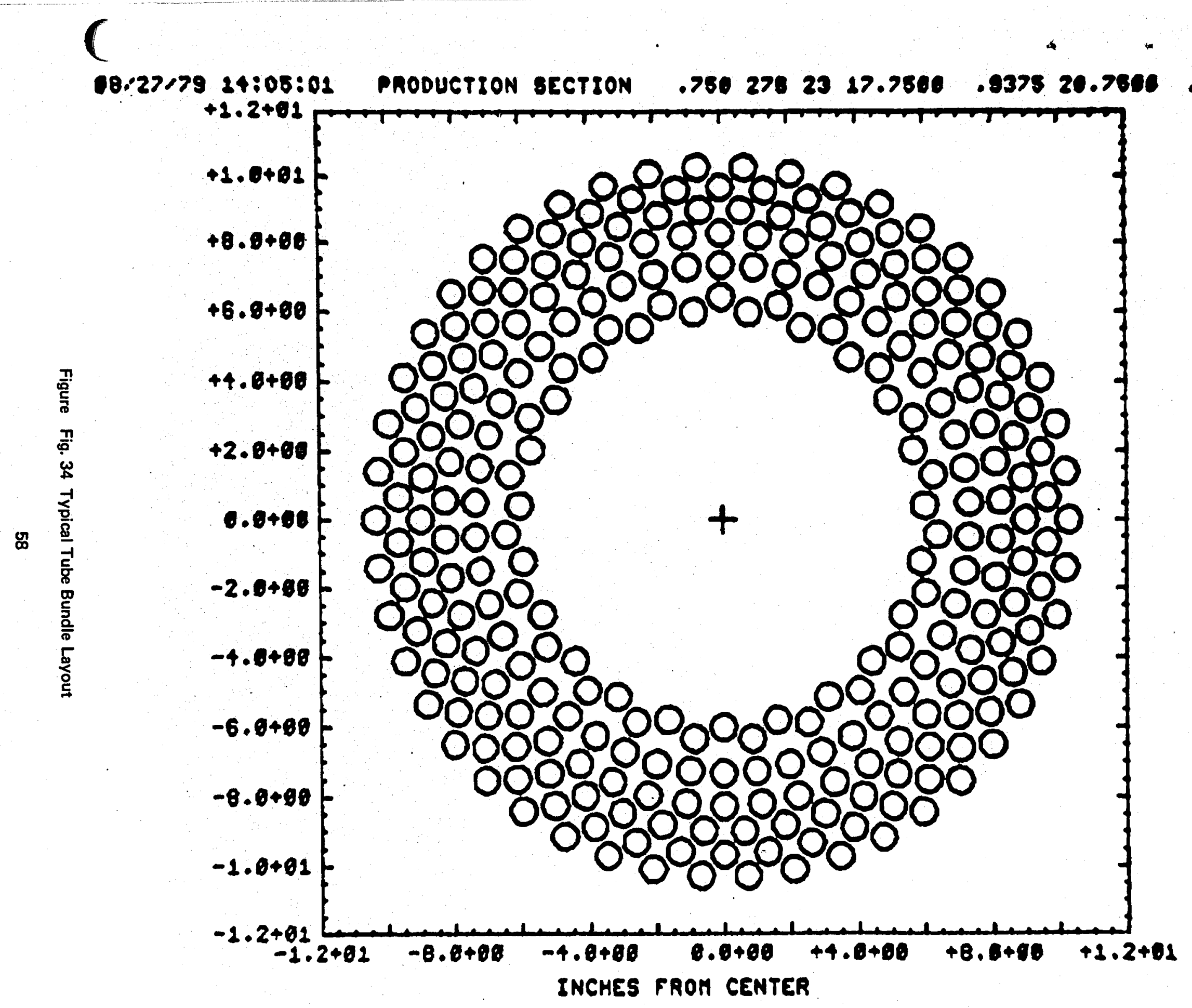




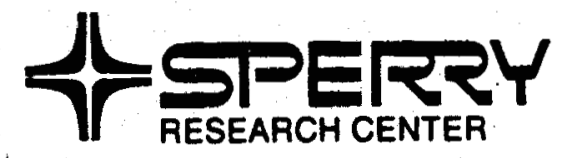

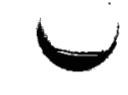

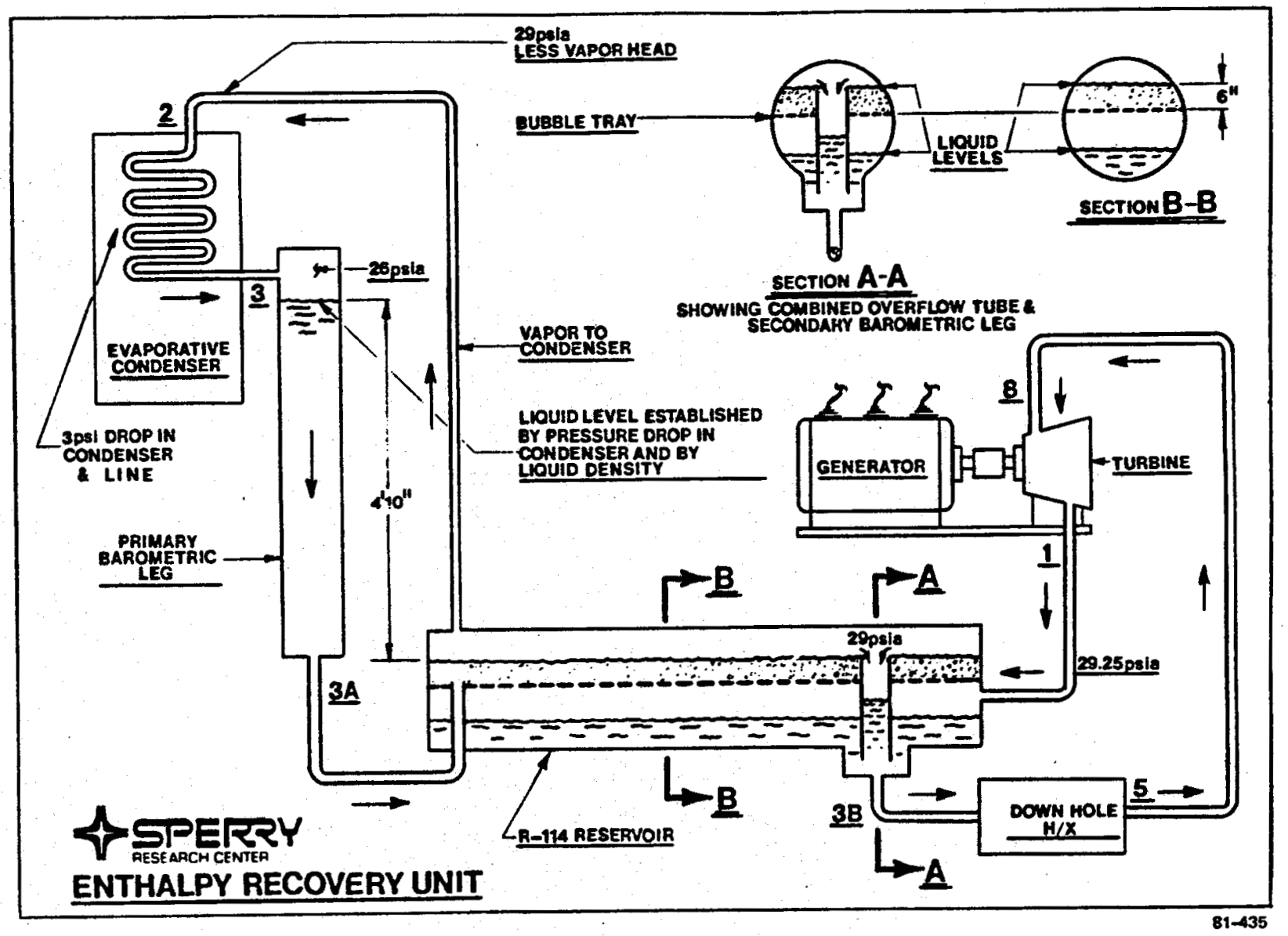

FIG. 35 Emthalpy Recovery Unit. 
APPENDIX A

\section{OPERATING INSTRUCTIONS \\ FOR \\ SCIENTIFIC INSTRUMENTATION \\ SYSTEM}




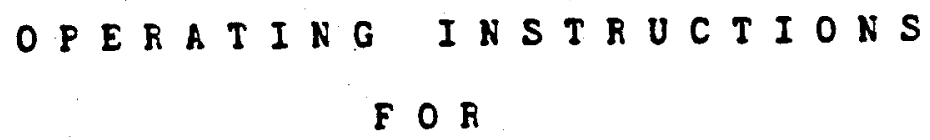

$M A Y 29,198 \quad 81$

D. Peterson

P. Schottler 
This manual contains operating instructions for the scientific instrumentation system for the geothermal pump plant. The scientific instrumentation system is a time-division multiplexed data acquisition and control system which consists of four main parts: 1. A Univac v77/600 minicomputer with $128 \mathrm{~K}$ words of 16 bit mexory, a $10 \mathrm{M}$ byte disk, and one magnetic tape drive, 2. A Cutler-Hamer multiplex system consisting of two mux stations (one in the control box and one near the ERU) and a commications station (in the instrumentation van), 3. Various discrete and analog sensors as specified on the pump plant P\&ID, and 4. The downwell instrument package. The computer and Cutler-Hammer communications station are located in the Sperry Instrumentation Van, and the scientific instrumentation system is run from the computer terminals located in the van.

This manual is organized into seven sections. The content of the various sections is as follows:

Section 1: Contains instructions for starting-up the scientific instrumentation system.

Section 2: Contains instruetions for running the scientific instrumentation system from the computer consoles. The various options available to an operator are 1llustrated as well as the prompting available at the consoles from the computer software.

Section 3: Contains instructions for shutting-down the instrumentation system.

Section 4: The various signals that are recorded by the scientific instrumentation system from the surface plant are related to the corresponding transwitters, control box signals, and local field indicators as shown on the pump plant P\&ID.

Section 5: The Cutler-Hammer mux system can be used to display data from the surface-plant sensors independently of the computer-driven system. Section 5 contains instructions for displaying data on the CutlerHammer monitor panel (located in the Sperry van). 
Section 6: The computer software makes use of three disk files which contain reference information on the signals and sensors which tie into the scientific instrumentation system. These three files are (1) Cutler-hammer file (CHFILE), which contains information on all of the signals which tie into the scientific instrumentation system via the Cutler-Hammer mux, (11) Downwell file (DWFILE), which contains information on the signals from the downwell instrument package, and (iii) Engineering file (ENGFIL), which specifies the ranges and units of the analog (4-20 ma.) signals in CHFILE and all of the signals in DWFILE. Listings of these three files are included in Section 6 for reference purposes.

Section 7: Contains an octal-decimal integer conversion table. 
The purpose of this document is to summarize the start up procedure to enable the computer to take data. There are 3 sub-procedures: power, computer operating system, and the data collection programs.

\section{A) Internal Van Power}

1) Turn on the power switches on the back right hand wall of the van.

Red - Computer power

Orange - Peripheral power (tape, Cutter-Hammer, terminals, (There is an additional circuit breaker in the blue rack behind the Cutter-Hammer monitor panel. All the peripherals are on 1 t. It is normally on. If the Cutler-Hammer monitor panel (blue rack) shows "MEMORY PARITY ADDRESS 7777", switch peripherial power off and then on again. System normal (green) LED should be lit on the monitor panel.)

2) Computer

Turn the four position key located on the computer panel to ON.

* WARNING DO NOT RUN THE COMPUTER WITH OUT AIR CONDITIONING

3) Disk

Turn disk power to ON. Position thumb wheel switch to 1 . Press the RUN/STOP button. The computer system will be ready when the READY 1 ight on the disk is ON (3-5 min.).

4) Tape

Press the top RED power switch on the mag tape unit.

5) Terminals \& Printers

Most terminals and printers have power swltches on the back, sowe on the front, turn them all on.

6) Cutier-Hammer Mux stations

Mux-1: Turn on the red circult breaker on mux-1 inside the control box. ( nomally on)

Max-2: Turn on the $A C$ power and the fan.

B) Computer Operating System - VORTEX

1) First vortex must be loaded from the disk into the computer memory (booting). This is done using the buttons on the computer's front panel. 
PANEL MODEL

D $x \quad x x x \quad x x x \quad x x x \quad x x x \times 1 x$

$x \quad C \times L$

$x x x \quad x \times x \times \operatorname{Prxx} x \times x x R$ Sx

C - Clear register select

D - Display clear

L - Load

P - P-register

R - Reset

$r$ - Register select

S - Step/run

1 - Boot device address

$x$ - Not used

* VORTEX will not boot if the disk is not READY *

VORTEX BOOT

- Press R (Reset)

- Press P (P-register)

- Press D (Display clear)

- Press r (register select)

- Press C (Clear register select)

- Press D (Display clear)

- Press 1 (boot device address)

- Press R (Reset)

- Press S (Step/run)

- Press L (Load)

Boot summary : R P D C C I R S L

- VORTEX will now boot. There will be some disk activity and some messages on the OPCOM terminal.

The booting procedure is completed on the OPCOM terminal.

- to erase an incorrect line type I (back slash) then retype

Enter date: MNDD/YY ex. 04/28/81 (return)

Enter time: HEMM ex. 1304 (return)

Type "I (control I ... while pressing down the CTRL key type I).

Enter /OPEN, LO, CRT4,244 (return)

This completes the booting of VORTEX. We'll now $10 \mathrm{~g}$ on to terminal CRTI and start the data collection programs.

C) Data Collection Programs

We'll take you through a sample start up and exercise one of the program's control options. In the example user responses will be followed with " (return) ", and comments will be 
bracketed by . LOg on to CRT1.

(return)

USERID:

GEO (return)

PASSWORD:

- User ids are secret and DONOT print on the terminal

(return)

- If typos are made hit return until asked for USERID:*

- log on completed.

- Assign data collection program files type:

AS, 1 , CHFILE, DT (return)

AS, 2 , DWFILE, DT (return)

AS, 3, ONELIN, DT (return)

AS, 4 , ENGFIL, DT (return)

- Hount a tape for the acqusition program

- Place a tape with a write ring on the lower drive.

- Thread the tape using the picture in the upper left

- of the mag tape unit.

- Press the LOAD button twice to bring the tape to

- load point. The tape should stop at load point in a

- few moments. If the load point was missed press REWIND.

- Press ON LINE.

* TNSLCT can be run even if the mag tape is broken. You could th 1: use the programs for display only. To do this on OPCOM type an ** /ASSIGN, 18, DUM (return)

- Run the collection program INSLCT. (sample start up)

R, TNSLCT,LI (return)

SELECT JOB TYPE:

O - STOP

1 - SURFACE AND DOWN WELL WITH DATA COLLECTION

2 - DOWN WELL ONLY WITH DATA COLLECTION

3 - SURFACE ONLY NITH DATA COLLECTION

4 - CALIBRATION

3 (return) default type $=1$.

SELECT GLOBAL TASK PARTITION ASSIGNMENT OPTION:

1 - PROCEED WITH DEFAULT TASK PARTITIONS

2 - EXAMINE/MODIFY TASK PARTITIONS

(return) default $=1$

- TNSCLT is now active and collecting data

BELP (return) Type HELP to view and select program options.

Select change code:

O - Stop

1 - Change TCHACQ sample rate

2 - Change Cutler-Hammer outputs

3 - Change delays between formatted outputs on devices 

4 - Change Cutler-Hawmer read status word flag
5 - Write END OF FILE on out put tape
6 - Indicate new tape loaded
7 - Change delay for unsolicited inputs
8 - Change DWACQ sample rate
9 - Print Cutler-Hamwer error counters
10 - Suspend/resume tape writing
11 - Compose a line of sensor names for single line printout
12 - Force output of the single line print
13 - Retrieve pre-stored single line printout sensor names
14 - Flip flop outputs between octal and engineering units 


\section{DAIA ACQUISITION PROGRAMS ( TNSLCT)}

The data acquisition programs are written to collect surface and down well data from the geothermal test site. A good deal of human engineering went into the design, to make a friendly, informative system. We can monitor, collect and display any of the surface and down well sensors. There is also a control "output" capability built in. We can change any of the analog and discrete out puts on the Cutler-Hammer system. Presently the control is manual, future designs will include automated control.

The program is "gorilla" proor. By that I wean users should not be afraid to type on the keyboard. Incorrect entries are ignored and the user is requested to retry with informative prompts. Program control options may always be veiwed by typing HELP.

We'll take you through a sample start up and exercise each of the program's control options. In the example user responses will be followed with " (return) ", and coments will be bracketed by . Start the computer as described in the start up procedure, Section 1 . Then 108 on to CRT1:

(return)

USERID:

GEO (return)

PASSWORD:

(return)

- log on coopleted

- Assign data collection program files,type: *

AS, 1 , CHFILE, DT (return)

AS, 2, DWFILE, DT (return)

AS, 3, ONELIN, DT (return)

AS, 4, ENGFIL, DT (return)

- Mount a tape for the acqusition program

- Place a tape with a wite ring on the lower orive.

- Thread the tape using the plcture in the upper left

- of the mag tape unit.

- Press the LOAD button twice to bring the tape to

- load point. The tape should stop at load point in a

- few moments. If the load point was missed press REWIND.

- Press ON LINE.

- Run the collection program TNSLCT. (sample start up)

R, INSLCT,LI (return)

SELECT JOB TYPE:

O - STOP 
1 - SURFACE AND DOWN WELL WITE DATA COLLECTION

2 - DOWN WELL ONLY WITH DATA COLLECTION

3 - SURFACE ONLY WITH DATA COLLECTION

4 - CALIBRATION

3 (return) default type $=1$.

SELECT GLOBAL TASK PARTITION ASSIGNMENT OPTION:

1 - PROCEED WITH DEFAULT TASK PARTITIONS

2 - EXAMINE/MODIFY TASK PARTITIONS

(return) default $=1$.

- TNSCLT is now active and collecting data

HELP (return) Type HELP to view and select program options. -

Select change code:

o - Stop

1 - Change TCHACQ sample rate

2 - Change Cutler-fiammer outputs

3 - Change delays between formatted outputs on devices

4 - Change Cutler-Hammer read status word flas

5 - Write END OF FILE on output tape

6 - Indicate new tape loaded

7 - Change delay for unsolicited inputs

8 - Change DWACQ sample rate

9 - Print Cutler-Hammer error counters

10 - Suspend/resume tape writing

11 - Compose a line of sensor names for single line printout

12 - Force output of the single ilne print

13 - Retrieve pre-stored single line printout sensor names

14 - Flip flop outputs between octal and engineering units

Option 0: Stop

Halts the data collection program (TNSLCT).

To restart TNSLCT, go back to $R$, TNSLCT, $L$.

Option 1: Change TCHACQ sample rate.

Modify or examine the computer's sampling rate of the Cutler-Hamer sensors. The rate $1 \mathrm{~s}$ entered in minutes and 5 milli-sec ticks.

EXAMPLE:

1 (return) Change rate to 5 min 0 (MINUTES) 2000 (5 MSEC INTERVALS) = CURRENT TCHACQ SAMPLE RATE

$0=$ MINUTES ACCEPT - TYPE RETURN MODIFY TYPE - DIGITS

- Cutler-Hammer data is being sample every 0 min 2000 (5msec intervals) $/ 200$ (intervals/sec) $=10 \mathrm{sec}$

5 (return) change minute portion of sample rate to 5 minutes $2000=5$ MSEC INTERVALS ACCEPT-TYPE RETURN MODIFY TYPE DIGITS

O (return) cannge 5 msec portion of sample rate to 0 -

Option 3: Change delays between formatted outputs on devices

Each of our 3 outputs; surface, down-well, or one-liners can have its own print rate to the terminal screen or the printer.

Option 3 will rirst ask for the device to change the print 
rate for, then the print type for that device, followed by the print rate in secs.

EXAMPLE: Print one IIners every $10 \mathrm{sec}$ on the CRT screen

3 (return) Choose option 3 .

SELECT OUTPUT DEVICE RATE EXAMINE/MODIFY OPTION:

O - USE ESTABLISHED DELAYS BETWEEN PRINTOUTS

1 - EXAMINE/MODIFY SCREEN TIMING

2 - EXAMINE/MODIFY PRINTER TIMING

1 (return) - Modify screen printout rate

SELECT OUTPUT FORMAT ON THIS DEVICE:

1 - SURFACE DATA SET

2 - DOWN WELL DATA SET

3 - SINGLE LINE OF SELECTED VARIABLES

3 (return) Choose single line printouts

60 = SEC. BETWEEN OUTPUTS ACCEPT - TYPE RETURN MODIFY - TYPE DIGITS

10 (return) Choose $10 \mathrm{sec}$.

SELECT OUTPUT DEVICE RATE EXAMINE/MODIFY OPTION:

0 - USE ESTABLISHED DELAYS BETWEEN PRINTOUTS

1 - EXAMINE/MODIFY SCREEN TIMING

2 - EXAMINE/MODIFY PRINTER TIMING

O (return) - Quit option 3, we'll use the $10 \mathrm{sec}$ we established -

Option 4: Change Cutler-Hammer read status word flag

Enable or disable the reading of the Cutler-hammer status word If there is a problem acknowldging faults from the monitor panel then reading the status word flas should be disabled. EXAMPLE: - Disable reading the status word flas -

4 (return) Choose option 4 .

RSWFLG 1 Enter new value (1->TRUE, O->FALSE):

$O$ (return) BSWFLG = false 1.e. do not read the status word -

Option 5: Write END OF FILE on output tape

The current tape will be closed and rewound allowing a new tape to be mounted.

EXAMPLE:

5 (return) Choose option 5: the tape will rewind -

Option 6: Indicate new tape loaded

When the program detects a new tape should be mounted because

the last one was full, or the operator did option 5 , or

the last tape had a write error, it will inform the operator

that 1ts walting. Option 6 will indicate that a new tape is

loaded and ready for writing on.

EXAMPLE:

6 (return) Choose option 6 .

Operator requested tape rewind.

TAPE LOG CH data frow 05/05/81

to $05 / 05 / 81 \quad 18: 30: 00$

TAPE LOG no DH data on tape

PRESS RETURN WHEN READY

- Label the tape with the TAPE LOG data, then press return (return) 
Option 7: Change delay for unsolicited inputs

You might modify the time the program gives you to type in an option. Because the program first waits for you to enter an option and then prints out vaiting information, decreasing the wait time could speed up print out. EXAMPLE:

7 (return) Choose option 7 cahnge time to $10 \mathrm{sec}$. CURRENT DELAY'IS: 15 SEC ... NEW DELAY ? 10 (return) Enter $10 \mathrm{sec}$.

Option 8: Change TDWACQ sample rate. Modify or examine the computer's sampling rate of the down well sensors. The rate is entered in minutes and 5 milli-sec ticks.

Option 9: Print Cutler-Hammer error counters Print all the accumulated comunication errors between the Cutler-Hammer and the computer, include total scan count.

Option 10: Suspend/resume tape writing

Tape writing can be enabled or disabled with this switch.

You might want to display data only, or walt before saving data.

Option 11: Compose a line of sensor names for single line printout This option incorporates a one line editor to create or change sensor names for single line print out. The editor works thus:

/string1/string2/ means search the line for "stringl" and replece it with "string2".

ex. The sensor names are:

TIME(CH) AR13 PAL6 RPMR1

$16 / 6$ STR5/ to add STR5 arter PAL6

TIME(CH) AR13 PAL6 STR5 RPMR 1

In order to insert sensor names use //new names/.

This causes "new names" to be added to the left of the current Iine. Old names shifted off to the right are lost.

In our above example to add PDR2 and WR1 type:

I/PDR2 WR 1 / would yield

PRD2 WR1 TIME(CH) AR13 PAL6 STR5 RPMRI

You may choose any combination of sensor names including TIME(CH) and TIME(DW) for Cutler-Hammer and down well sample times.

$/ / /$ terminates option 11.

Option 12: Force output of the single line print You might have had the sensor names scroll off the top of the screen. Option 12 will reprint them.

Option 13: Retrieve pre-stored single line printout sensor names File ONELIN, DT contains some frequently used single line sensor names. This option w1ll allow you to retrieve them instead of needing option 11 to make new ones each tIme.

Option 14: Flip-flop outputs between octal and engineering units; switching to engineering units. 
AR1: R114 LEVEL ALARM LOW IN ERU DI

AR2: TPU LUBE OIL PRESSURE ALARM LOW , DI

AR3: WELLHEAD BRINE PRESSURE ALARM HIGH , DI

AR4: BRINE PUMP P13 SUCTION PRESS ALARM LOW, DI

AR6: BRINE PUMP P14 DSCHRGE PRESS ALARM HIGH, DI

AR7: TPU LUBE OIL LEVEL ALARM LOW , DI

AR8: R114 TO WELL FLOW ALARM LOW , DI

AR9: R114 TO WELL PRESSURE ALARM LOW , DI

AR 11: MAKE-UP WATER SUPPLY PRESS ALARM LOW, DI

AR 12: INSTRUMENT AIR PRESSURE ALARM LOW , DI

AR 13: BAROMETRIC LEG WATER LEVEL ALARM HIGH, DI

PAL6: RII4 AUX PUMP PI SUCTION PRESS ALRM LOW, DI

PAR1: R114 FROM WELL PRESSURE ALARM HIGH , DI

AR 186:MASTER SHUTDOWN RELAY 186 ALARM , DI

AR286:MASTER SHUTDOWN RELAY 286 ALARM , DI

AR386:MASTER SHUTDOWN RELAY 386 ALARM , DI

ST 1R: BRINE PRESS CNTRL VLVE PCV4 OPEN , DI

ST 1G: BRINE PRESS CNTRL VLVE PCV4 CLOSED , DI

ST2R: BRINE PUMP P14 ON , DI

ST3R: BRINE PUMP P13 ON , DI

ST4R: R114 TO WELL FLOW CNTRL VALVE ECVI OPEN, DI

ST11R:BRINE PRESS CONTROL VALVE PCV3 OPEN, DI

ST5R: R114 AUX PUMP P1 ON , DI

ST6R: R114 FEED PUMP P2 ON , DI

ST7R: BAC E2 ON , DI

ST8R: BAC EI ON , DI

ST9R: R114 OUT PRESS CNTRL VALVE PCV5 OPEN, DI

ST9G: R114 OUT PRESS CNTRL VALVE PCV5 CLOSED, DI

ST 1OR:R114 TO WELL HAND VALVE HV16 OPEN ODI

ST 1OG:R114 TO WELL HAND VALVE HV16 CLOSED, , DI

FIC 1: R114 TO WELL FLOW CNTRLER FIC1 SETPOINT, AO

PIC 1: BRINE BACK PRESS CNTRLER PIC1 SETPOINT, AO

PR6: R114 TO WELL PRESSURE, AI

TR 10: R114 TO WELL TEMPERATURE, AI

FR2: R114 TO WELL FLOW , AI

TR7: R114 FROM WELL TEMPERATURE , AI

PR3: R114 FROM WELL PRESSURE, , AI

PR5: BRINE WELLHEAD PRESSURE, AI

FR 1: BRINE WELLHEAD FLOW , AI

TR5: BRINE WELLHEAD TEMPERATURE , AI

RPMR 1:TPU RPM , AI

LR 1: TPU LUBE OIL SUPPLY LEVEL, AI

TR2: R114 GAS TEMP ABOVE ERU BUBBLE TRAY , AI

TR3: R114 GAS TEMP BELOW ERU BUBBLE TRAY , AI

TR4: R114 LIQUID TEMP BELOW ERU BUBBLE TRAY , AI

TR6: R114 LIQUID TEMP ABOVE ERU BUBBLE TRAY, AI

PDR 1: R114 DIFF GAS PRESS ACROSS ERU BUB TRAY, AI 
PR4: R114 GAS PRESS ABOVE ERU BUBBLE TRAY, AI

PR 11: R114 FEED PUMP P2 SUCTION PRESSURE , AI

PR9: TPU LUBE OIL SUPPLY PRESSURE, AI

PR2: RII4 GAS PRESS AT BAC EI INLET , AI

TR8: R114 LIQUID TEMP AT BAC E1 OUTLET , AI

PDR2: R114 DIFE PRESS ACROSS BAC E1 , AI

FR4: RII4 LIQUID RETURN FLOW BAC'S TO ERU, AI

WR 1: BAC E1 SPRAY PUMP POWER CONSUMPTION AI

HR2: BAC EI COOLING FANS POWER CONSUMPTION, AI

FR3: MAKE-UP WATER FLOW TO BAC'S, AI

TR9: COOLING WATER RESERVOIR TEMP BAC E1, AI

FR8: BLEED WATER FLOW FROM BAC'S , AI

PR 10: BRINE PRESSURE AT PCV 4 DISCHARGE , AI

WBR 1: WET BULB TEMPERATURE , AI

ATR 1: AIR TEMPERATURE , AI

VR1: 120 VAC FROM 480 VAC BUS , AI

CR1: CORR RATE AT BRINE VALUE PCV4 DSCHRG, AI

CR2: CORR RATE AT BRINE INLET TO P13\&P14, AI

CR3: CORR RATE AT WELLHEAD BRINE DISCHARGE, AI

CR4: CORR RATE AT BAC-EI COOLING SPRAY , AI

TR 15: MUX 2 STATION TEMPERATURE , AI

Down well:

Name Function

-.-

CAL 1: ZERO CALIBRATION

CAL2: FULL SCALE CALIBRATION

PIP: PUMP INLET PRESSURE

POP: PUMP OUTLET PRESSURE

TIP: TURBINE INLET PRESSURE

TOP: TURBINE OUTLET PRESSURE

LUEP: LUBRICATION OIL PRESSURE

POT: PUMP OUTLET TEMPERATURE

TIT: TURBINE INLET TEMPERATURE

TOT: TURBINE OUTLET TEMPERATURE

MANT: TRANSDUCER MANIFOLD TEMPERATURE

CANT: INSTRUMENT CANNISTER TEMPERATURE

HXBI: HX BRINE INLET TEMPERATURE

HXBO: HX BRINE OUTLET TEMPERATURE

HXOI: HX ORGANIC INLET TEMPERATURE

HXOO: HX ORGANIC OUTLET TEMPERATURE

RPM1: TPU RPM

RPM2: TPU RPM 
SECTION 3

DATA ACQUSITION SEUT-DOWN

The purpose of this document is to summarize the shut down procedure to halt the data collection programs and shut the computer off There are 3 sub-procedures; halting the data collection programs, halting the cooputer operating system, and power down.

A) Data Acqusition Programs

If TNSLCT is running type 0 (return) on CRT1.

Wait until TNSLCT has completed and the tape is rewound.

Dismount, label, and save the data tape.

Dismount tape by:

- press ON LINE (light should be off)

- press REWIND (LOAD light will come on)

- Press REWIND

Type CP HALT (return) "optional*

Type LOG (return) coptional*

* The data collection programs are now halted *

B) Computer Operating System - VORTEX

The computer operating system is halted at the computer's Iront panel.

1) At the computer front panel press RESET.

PANEL MODEL

$x \quad x \quad x \times x \quad x \times x \quad x \times x \quad x \times x \quad x \times x$

$x \quad x \times x$

$x \times x \times x \times x \times x \times x \times x \times x R \times x$

R- Reset

$x$ - not used

- The computer operating system VORTEX is halted *

C) Power down

1) Computer

Turn the 4 position key to HOLD.

(Memory initialization on the V77 computer is complex, therefore; the computer should NEVER have its power turned completely OFF.)

2) Disk

Turn the thumb wheel switch to 0 .

Press the RUN/STOP button. 
Turn the thumb wheel switch to 1.

Wa1t for the SAFE 11ght to come on then turn power off.

3) Tape

Dismount tape by: (1f still mounted)

- press ON LINE (1ight should be off)

- press REWIND (LOAD light wll cowe on)

- Press REWIND

Press RED power switch.

4) Terminals \& Printers

Most terminals and printers have power switches on the back, some on the front, turn them all off.

5) Cutler-Hammer Mux Stations

If the instrumentation system is going to be off

for an extended period of time, then power down wax 1 and Mux 2.

Mux 1: Turn the red circuit breaker off (inside the control box).

Mux 2: Turn off the AC power and the fan.

6) Internal Van Power

The van power switches are on the back right hand wall.

Red - Computer power ... NEVER turn off the computer power unless you plan to re-initialize memory.

Orange - Shut down all peripheral power. 
SECTION 4

CORRESPONDENCE AMONG PEID INSTRUMENTATION SIGNAL MAMES

$\begin{array}{ccccc}\text { VAN } & \text { CONTROL } & \text { FIELD } & \text { XMTR } & \text { SIGNAL } \\ \text { NAME } & \text { NAME } & \text { NAME } & \text { NAME } & \\ - & - & -\end{array}$

1

\begin{tabular}{|c|c|c|c|c|}
\hline AR 1 & : LAL2 & : & : LS1 & : R114 LEVEL ALARM LOW IN ERU \\
\hline AR2 & : PAL1 & : & : PSL6 & : TPU LUBE OIL PRESSURE ALARM LOW \\
\hline AR3 & : PAH 1 & : & : PSH 1 & : WELLHEAD BRINE PRESSURE ALARM HIGH \\
\hline AR4 & : PAL2 & : & : PSL8 & $\begin{array}{l}\text { : BRINE PUMP P13 SUCTION PRESS } \\
\text { ALARM LOW }\end{array}$ \\
\hline AR6 & : PAH2 & : & : PSH4 & $\begin{array}{l}\text { : BRINE PUMP P14 DSCHRG PRESS } \\
\text { ALARM HIGH }\end{array}$ \\
\hline AR7 & : LAL1 & : & : LSL1 & : TPU LUBE OIL LEVEL ALARM LOW \\
\hline ARB & : EAL 1 & : & : FSL1 & : R114 TO WELL FLOW ALARM LOW \\
\hline ARg & : PAL5 & : & : PSL7 & : R114 TO WELL PRESSURE ALARM LOW \\
\hline AR11 & : PAL3 & : & : PSL3 & $\begin{array}{l}\text { : MAKE-UP WATER SUPPLY PRESS } \\
\text { ALARM LOW }\end{array}$ \\
\hline AR 12 & : PAL4 & : & : PSL4 & : INSTRUMENT AIR PRESSURE ALARM LOW \\
\hline AR13 & : LAH2 & : & & $\begin{array}{l}\text { : BAROMETRIC LEG WATER LEVEL } \\
\text { ALARM HIGH }\end{array}$ \\
\hline PAL6 & : PAL6 & : & : PSL2 & $\begin{array}{l}\text { : R114 AUX PUMP PI SUCTION PRESS } \\
\text { ALARM LOW }\end{array}$ \\
\hline PAR 1 & : PAH3 & : & : PSH6 & : R114 FROM WELL PRESS ALARM HIGH \\
\hline AR 186 & : & : & : & : MASTER SHUTDOWN RELAY 186 ALARM \\
\hline AR286 & : & : & : & : MASTER SHUTDOWN RELAY 286 ALARM \\
\hline AR386 & : & $:$ & : & : MASTER SHUTDOWN RELAY 386 ALARM \\
\hline ST IR & : & : & $:$ & : BRINE PRESS CNTRL VLVE PCV 4 OPEN \\
\hline STIG & : & : & : & : BRINE PRESS CNTRL VLVE PCV 4 CLOSED \\
\hline ST2R & : & : & : & : BRINE PUMP P14 ON \\
\hline ST3R & : & : & : & : BRINE PUMP P13 ON \\
\hline STHR & : & : & : & $\begin{array}{l}\text { R114 TO WELL FLOW CNTRL VLVE } \\
\text { FCVI OPEN }\end{array}$ \\
\hline ST11R & : & : & : & : BRINE PRESS CNTRL VLVE PCV3 OPEN \\
\hline ST5R & $:$ & : & : & : R114 AUX PUMP PI ON \\
\hline ST6R & : & : & : & : RI14 FEED PUMP P2 ON \\
\hline ST7R & : & : & : & : BAC E2 ON \\
\hline STBR & : & : & : & : BAC EI ON \\
\hline ST9R & : & : & $:$ & $\begin{array}{l}\text { : R114 OUT PRESS CNTRL VLVE } \\
\text { PCV } 5 \text { OPEN }\end{array}$ \\
\hline ST9G & : & : & : & $\begin{array}{l}\text { : R } 114 \text { OUT PRESS CNTRL VLVE } \\
\text { PCV5 CLOSED }\end{array}$ \\
\hline ST1OR & : & : & : & $\begin{array}{l}\text { : R114 TO WELL HAND VALVE } \\
\text { HV } 16 \text { OPEN }\end{array}$ \\
\hline & : & : & : & $\begin{array}{l}\text { : R114 TO WELL BAND VALVE } \\
\text { HV } 16 \text { CLOSED }\end{array}$ \\
\hline
\end{tabular}




$\begin{array}{cll}\text { FIC1 : FIC1 } & : & \text { : FIC1 : R114 TO WELL FLOW CONTROLLER } \\ \text { PIC1 : PIC1 } & : & \text { : PIC1 : BRINE BACK PRESSURE CONTROLLER } \\ & & \text { PIC S SETPOINT }\end{array}$

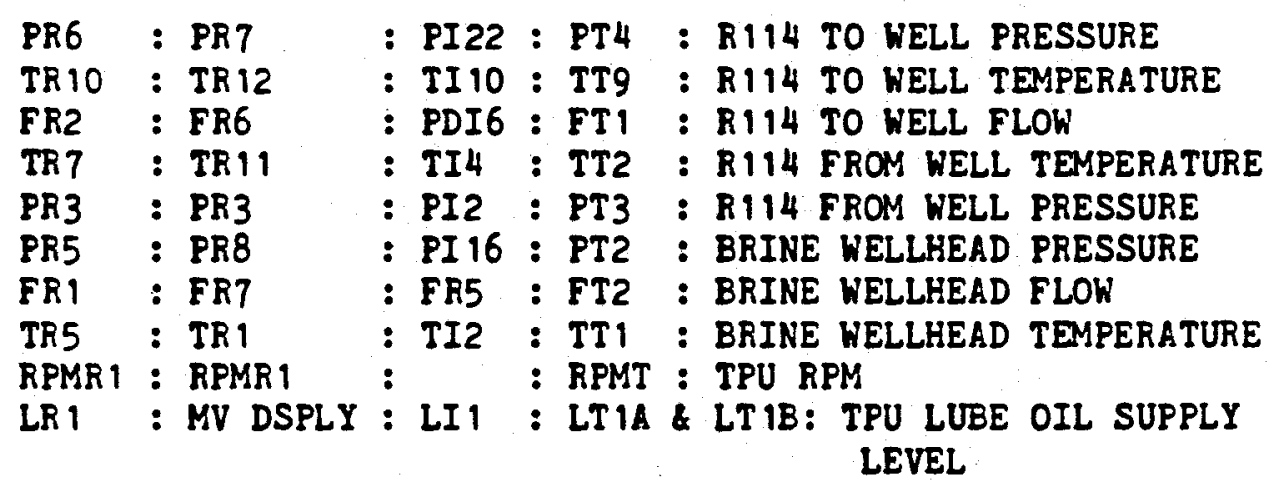

\begin{tabular}{|c|c|c|c|c|}
\hline TR2 & : & : TI7 & : TT6 & $\begin{array}{l}\text { : R114 GAS TEMP ABOVE ERU } \\
\text { BUBBLE TRAY }\end{array}$ \\
\hline TR3 & : & : TI5 & : TT4 & $\begin{array}{l}\text { : R114 GAS TEMP BELOW ERU } \\
\text { BUBBLE TRAY }\end{array}$ \\
\hline TR4 & : & : TIB & : TT3 & $\begin{array}{l}\text { : R114 LIQUID TEMP BELOW ERU } \\
\text { BUBBLE TRAY }\end{array}$ \\
\hline TR6 & : & : TI6 & : TT5 & $\begin{array}{l}\text { : R114 LIQUID TEMP ABOVE ERU } \\
\text { BUBBLE TRAY }\end{array}$ \\
\hline PDR 1 & : & : & : PDT1 & $\begin{array}{l}\text { : R114 DIFFERENTIAL GAS PRESS } \\
\text { ACROSS ERU BUBBLE TRAY }\end{array}$ \\
\hline PR4 & : & : PI12 & : PT5 & $\begin{array}{l}\text { : R114 GAS PRESS ABOVE ERU } \\
\text { BUBBLE TRAY }\end{array}$ \\
\hline $\begin{array}{l}\text { PR } 11 \\
\text { PR9 }\end{array}$ & $:$ & $\begin{array}{l}: \text { PI5 } \\
: \text { PIB }\end{array}$ & $\begin{array}{l}\text { PT8 } \\
: \text { PT } 1\end{array}$ & $\begin{array}{l}\text { : } 114 \text { FEED PUMP P2 SUCTION PRESS } \\
\text { :TPU LUBE OIL SUPPLY PRESSURE }\end{array}$ \\
\hline PR2 & $:$ & $:$ & : PT6 & : R114 GAS PRESS AT BAC E1 INLET \\
\hline TRB & $:$ & : TI11 & : TT7 & : R114 LIQUID TEMP AT BAC EI OUTLET \\
\hline PDR2 & $:$ & : & : PDT2 & $\begin{array}{l}\text { : R114 DIFFERENTIAL PRESS ACROSS } \\
\text { BAC E1 }\end{array}$ \\
\hline ER4 & : & $:$ & : FT4 & $\begin{array}{l}\text { : R114 LIQUID RETURN FLOW BAC'S } \\
\text { TO ERU }\end{array}$ \\
\hline WR 1 & $:$ & : & : HTI & $\begin{array}{l}\text { : BAC EI COOLING WATER SPRAY PUMP } \\
\text { POWER CONSUMPTION }\end{array}$ \\
\hline WR2 & : & : & : WT2 & $\begin{array}{l}\text { : BAC EI COOLING FANS POWER } \\
\text { CONSUMPTION }\end{array}$ \\
\hline FR3 & : & : & : FT5 & : MAKE-UP WATER FLOW TO BAC'S \\
\hline TR9 & $:$ & : & : TT8 & $\begin{array}{l}\text { : COOLING WATER RESERVOIR TENP } \\
\text { BAC EI }\end{array}$ \\
\hline FRE & : & : & $: F$ & : BLEED WATER FLOW FROM BAC'S \\
\hline PR 10 & : & $:$ & : PT7 & : BRINE PRESSURE AT PCV4 DSCHRGE \\
\hline WBR1 & : & : & : WBTI & : WET BULB TEMPERATURE \\
\hline
\end{tabular}




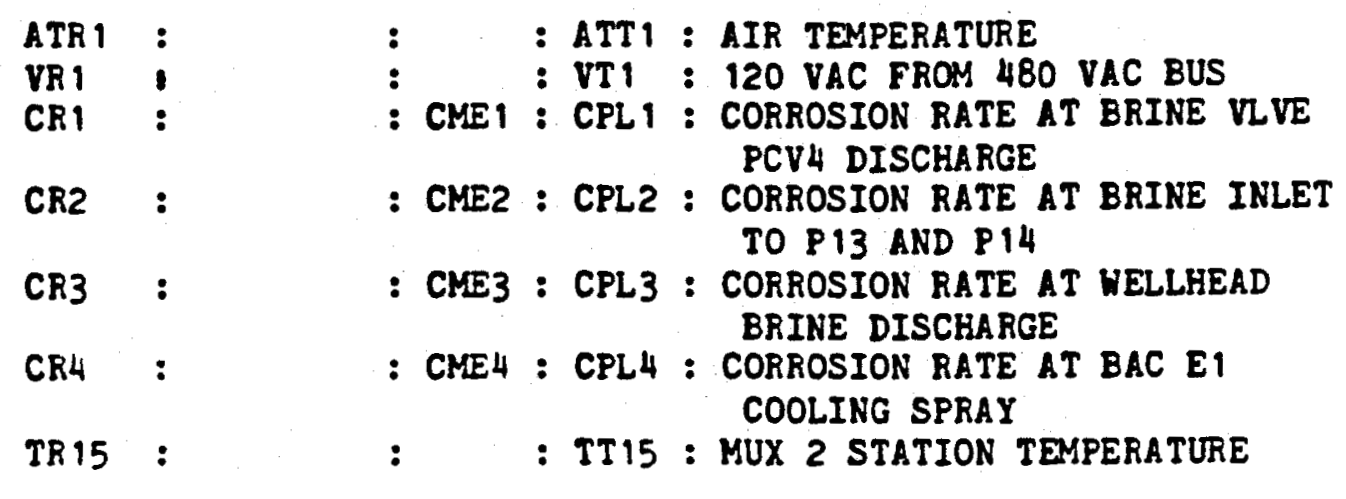




\section{SECTION 5}

INSTRUCTIONS FOR DISPLAYING DISCRETES ON CUTLER-HAMMER MONITOR PANEL

0. EXECUTE STEPS A1(PERIPHERAL POKER ONLY) AND A6 OF SECTION 1.

1. HIT FUNCTION KEY(BLACK 1 KEY) REPEATEDLY UNTIL DISPLAY APPEARS IN THE LEFT HALF OF THE MESSAGE WINDOW.

2. HIT FORM KEY (BLACK 2 REY) REPEATEDLY UNTIL DISCRETE APPEARS IN THE RIGHT HALF OF THE MESSSAGE WINDOW.

3. HIT ADDRESS KEY (BLACK 3 KEY) ONCE.

4. ENTER MODULE ADDRESS USING WHITE KEYS. ADDRESS WILL APPEAR IN ADDRESS WINDOW. HIT ADDRESS KEY AGAIN. DATA WILL APPEAR IN DATA WINDOW.

5. TO DISPLAY A DISCRETE AT A DIFFERENT MODULE ADDRESS, REPEAT STEP 4.

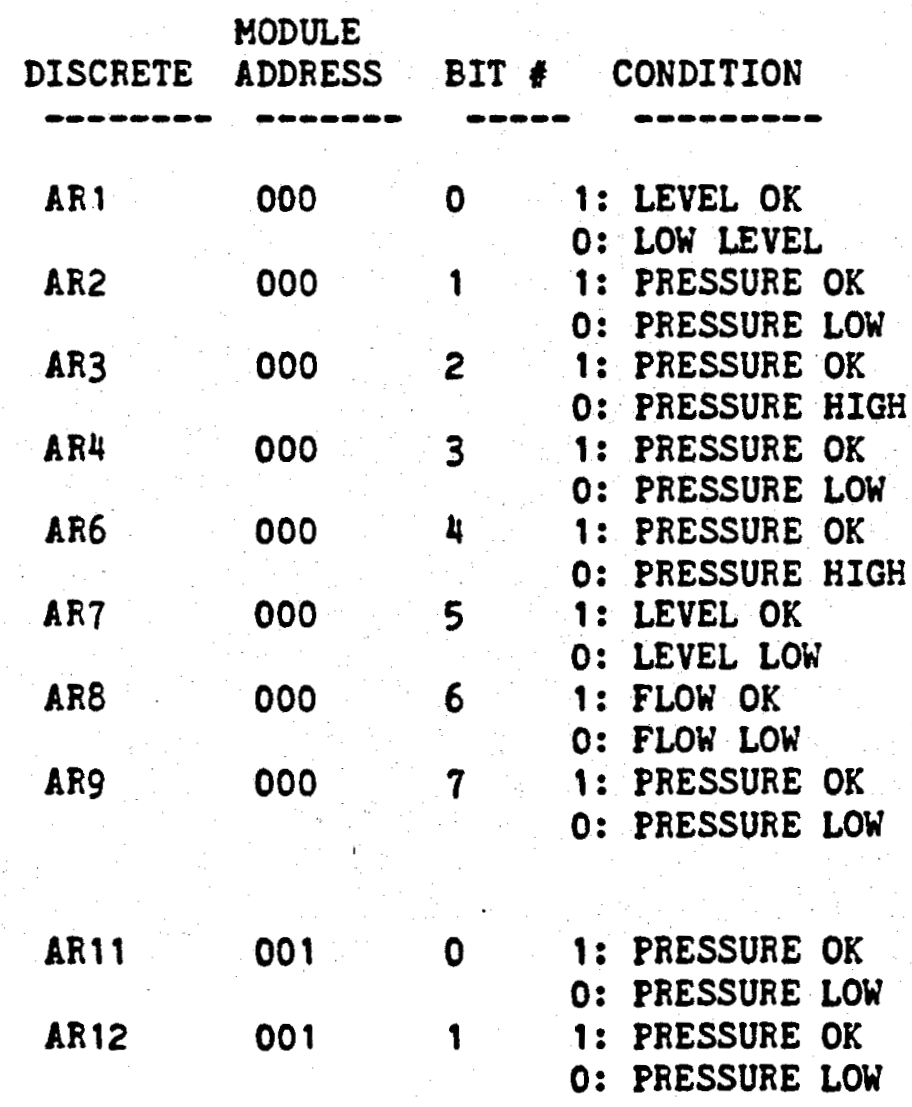




\begin{tabular}{|c|c|c|c|}
\hline AR 13 & 001 & 2 & $\begin{array}{l}\text { 1: LEVEL OK } \\
\text { O: LEVEL HIGH }\end{array}$ \\
\hline PAL6 & 001 & 3 & $\begin{array}{l}\text { 1: PRESSURE OK } \\
0: \text { PRESSURE LOW }\end{array}$ \\
\hline PARI & 001 & 4 & $\begin{array}{l}\text { 1: PRESSURE OK } \\
\text { 0: PRESSURE HIGH }\end{array}$ \\
\hline AR 186 & 002 & 0 & $\begin{array}{l}0: \text { NORMAL } \\
\text { 1: SHUTDOWN }\end{array}$ \\
\hline AR2B6 & 002 & 1 & $\begin{array}{l}0: \text { NORMAL } \\
\text { 1: SHUTDOWN }\end{array}$ \\
\hline AR386 & 002 & 2 & $\begin{array}{l}\text { O: NORMAL } \\
\text { 1: SHUTDOWN }\end{array}$ \\
\hline STIR & 002 & 4 & $\begin{array}{l}\text { 1: PCV4 NOT FULLY CLOSED } \\
\text { O: PCV4 FULLY CLOSED }\end{array}$ \\
\hline STIG & 002 & 5 & $\begin{array}{l}\text { 1: PCV4 NOT FULLY OPEN } \\
\text { 0: PCV4 FULLY OPEN }\end{array}$ \\
\hline ST2R & 002 & 6 & $\begin{array}{l}\text { 1: P14 ON } \\
0: \text { P14 OFF }\end{array}$ \\
\hline ST3R & 003 & 0 & $\begin{array}{l}\text { 1: } P 13 \text { ON } \\
0: P 13 \text { OFF }\end{array}$ \\
\hline ST4R & 003 & 2 & $\begin{array}{l}\text { 1: FCV I NOT FULLY CLOSED } \\
0: \text { FCV I FULLY CLOSED }\end{array}$ \\
\hline STI1R & 003 & 3 & $\begin{array}{l}\text { 1: PCV3 NOT FULLY CLOSED } \\
\text { 0: PCV3 FULLY CLOSED }\end{array}$ \\
\hline ST5R & 003 & 4 & $\begin{array}{l}\text { 1: P1 ON } \\
0: \text { P1 OFF }\end{array}$ \\
\hline ST6R & 003 & 6 & $\begin{array}{l}1: P 2 \text { ON } \\
0: P 2 \text { OFF }\end{array}$ \\
\hline STTR & 004 & 0 & $\begin{array}{l}\text { 1: E2 ON } \\
0: E 2 \text { OFF }\end{array}$ \\
\hline STER & 004 & 2 & $\begin{array}{l}\text { 1: E1 ON } \\
\text { 0: E1 OFF }\end{array}$ \\
\hline STgR & 004. & 4 & $\begin{array}{l}\text { 1: PCV5 NOT FULLY CLOSED } \\
0: \text { PCV5 FULLY CLOSED }\end{array}$ \\
\hline ST9G & 004 & 5 & $\begin{array}{l}\text { 1: PCV5 NOT FULLY OPEN } \\
0: \text { PCV5 FULLY OPEN }\end{array}$ \\
\hline STIOR & 004 & 6 & $\begin{array}{l}\text { 1: HV } 16 \text { NOT FULLY CLOSED } \\
\text { O: HV } 16 \text { FULLY CLOSED }\end{array}$ \\
\hline STIOG & 004 & 7 & $\begin{array}{l}\text { 1: HV16 NOT FULLY OPEN } \\
0: \text { HV16 FULLY OPEN }\end{array}$ \\
\hline
\end{tabular}




\section{INSTRUCTIONS FOR DISPLAYING ANALOGS ON CUTLER-HAMMER MONITOR PANEL}

0. EXECUTE STEPS A1(PERIPHERAL POWER ONLY) AND A6 OF SECTION 1.

1. HIT FUNCTION KEY (BLACK $1 \mathrm{KEY)} \mathrm{REPEATEDLY} \mathrm{UNTIL} \mathrm{DISPLAY}$ APPEARS IN THE LEFT HALF OF TKE MESSAGE WINDOW.

2. HIT FORM KEY (BLACK 2 KEY) REPEATEDLY UNTIL ANALOG APPEARS IN THE RIGHT HALF OF THE MESSAGE WINDOH.

3. HIT ADDRESS KEY (BLACK 3 KEY) ONCE.

4. ENTER CHANNEL ADDRESS USING WHITE REYS. ADDRESS WILL APPEAR IN ADDRESS WINDOW. HIT ADDRESS KEY AGAIN. DATA WILL APPEAR IN DATA WINDOW.

5. TO DISPLAY AN ANALOG AT A DIFFERENT CHANNEL ADDRESS, REPEAT STEP 4.

6. AN ANALOG VALUE WILL APPEAR AS A THREE-DIGIT NUMBER IN THE RANGE $0 .-100$. WHICH REPRESENTS A PERCENTAGE OF THE RANGE COVERED BY THE CORRESPONDING SIGNAL. SUPPOSE THAT THE SIGNAL VALUE VARIES FROM VLOW TO VHIGH AS THE SIGNAL CURRENT VARIES FROM 4 TO $20 \mathrm{MA}$. IF THE ANALOG DISPLAY SHOWS A VALUE $R$, THEN THE CORRESPONDING SIGNAL HAS A VALUE

$$
V=(R / 100)(V H I G H-V L O W)+\text { VLOW }
$$

7. TO DISPLAY AN ANALOG AS AN OCTAL NUMBER:

7.1. PERFORM STEP I ABOVE.

7.2. HIT FORM KEY (BLACK 2 KEY) REPEATEDLY UNTIL BUFFER APPEARS IN THE RIGHT HALF OF THE MESSAGE WINDOW.

7.3 HIT ADDRESS KEY (BLACK 3 KEY) ONCE.

7.4 ENTER BUFFER ADDRESS USING WHITE KEYS. ADDRESS WILL APPEAR IN ADDRESS WINDOW. HIT ADDRESS KEY AGAIN. DATA WILL APPEAR IN DATA WINDOW.

7.5. TO DISPLAY AN ANALOG AT A DIFFERENT BUFFER ADDRESS, REPEAT STEP 7.4.

7.6. AN ANALOG VALUE WILL APPEAR AS A SIX-DIGIT OCTAL NUMBER, 0102030405 06. THE CORRESPONDING 12-BIT BINARY NUMBER, BO-B11, IS OBTAINED AS FOLLOWS: 


$$
\begin{aligned}
& \text { 01: }- \text { - } \mathrm{BO} \quad(\mathrm{BO}=\mathrm{BSD}) \\
& \text { 03: } \mathrm{B} 1 \mathrm{~B} 2 \mathrm{~B} 3 \\
& \text { 04: } \mathrm{B} 4 \mathrm{~B} 5 \mathrm{~B} 6 \\
& \text { 05: } \mathrm{B} 10 \mathrm{~B} 11-(\mathrm{B} 11=\text { LSD }) \\
& \text { 06: }- \text { - }
\end{aligned}
$$




\begin{tabular}{|c|c|c|c|}
\hline ANALOG & $\begin{array}{l}\text { CHANNEL } \\
\text { ADDRESS }\end{array}$ & $\begin{array}{l}\text { BUFFER } \\
\text { ADDRESS }\end{array}$ & $\begin{array}{l}\text { SIGNAL RANGE } \\
\text { (VLOW TO VHIGH) }\end{array}$ \\
\hline MUX 1 & & & \\
\hline $\begin{array}{l}\text { FICI } \\
\text { PICI }\end{array}$ & $\begin{array}{l}0130 \\
0131\end{array}$ & $\begin{array}{l}4000 \\
4001\end{array}$ & \\
\hline $\begin{array}{l}\text { PRE } \\
\text { TR10 } \\
\text { FR2 } \\
\text { TR7 } \\
\text { PR3 } \\
\text { PR5 } \\
\text { FR1 } \\
\text { TR5 } \\
\text { RPMR1 } \\
\text { LR1 } \\
\text { TST } 1\end{array}$ & $\begin{array}{l}0060 \\
0061 \\
0062 \\
0063 \\
0070 \\
0071 \\
0072 \\
0073 \\
0100 \\
0101 \\
0102\end{array}$ & $\begin{array}{l}4004 \\
4005 \\
4006 \\
4007 \\
4010 \\
4011 \\
4012 \\
4013 \\
4014 \\
4015 \\
4016\end{array}$ & $\begin{array}{l}0-500 \text { PSIA } \\
50-150 \text { DEGF } \\
0-600 \text { "H2O } \\
0-400 \text { DEGF } \\
0-300 \text { PSIA } \\
0-500 \text { PSIA } \\
0-86 \text { SQ RT "H2O } \\
0-400 \text { DEGF } \\
0-15000 \text { RPM } \\
0-750 \text { LBS }\end{array}$ \\
\hline
\end{tabular}

MUX 2

- -

\begin{tabular}{|c|c|c|c|}
\hline $\begin{array}{l}\text { TR2 } \\
\text { TR3 } \\
\text { TR4 } \\
\text { TR6 } \\
\text { PDR1 } \\
\text { PR4 } \\
\text { PR11 } \\
\text { PR9 } \\
\text { PR2 } \\
\text { TR8 } \\
\text { PDR2 } \\
\text { FR4 } \\
\text { WR1 } \\
\text { UR2 } \\
\text { FR3 } \\
\text { TR9 } \\
\text { FR8 } \\
\text { PR10 } \\
\text { WBR1 } \\
\text { ATR1 } \\
\text { VR1 } \\
\text { CR1 } \\
\text { CR2 } \\
\text { CR3 } \\
\text { CR4 }\end{array}$ & $\begin{array}{l}0200 \\
0201 \\
0202 \\
0203 \\
0210 \\
0211 \\
0212 \\
0213 \\
0220 \\
0221 \\
0222 \\
0223 \\
0230 \\
0231 \\
0232 \\
0233 \\
0240 \\
0241 \\
0242 \\
0243 \\
0250 \\
0251 \\
0252 \\
0253 \\
0260\end{array}$ & $\begin{array}{l}4020 \\
4021 \\
4022 \\
4023 \\
4024 \\
4025 \\
4026 \\
4027 \\
4030 \\
4031 \\
4032 \\
4033 \\
4034 \\
4035 \\
4036 \\
4037 \\
4040 \\
4041 \\
4042 \\
4043 \\
4044 \\
4045 \\
4046 \\
4047 \\
4050\end{array}$ & $\begin{array}{l}50-150 \text { DEGF } \\
50-150 \text { DEGF } \\
50-150 \text { DEGF } \\
50-150 \text { DEGF } \\
0-30 \text { "H2O } \\
0-100 \text { PSIA } \\
0-200 \text { PSIA } \\
0-200 \text { PSIA } \\
0-50 \text { PSIA } \\
50-150 \text { DEGF } \\
0-100 \text { "H2O } \\
0-15 \text { "H2O } \\
0-3.75 \text { KW } \\
0-7.5 \text { KW } \\
9-100 \text { GPM } \\
50-150 \text { DEGF } \\
9-100 \text { GPM } \\
0-700 \text { PSIA } \\
0-100 \text { DEGF } \\
0-150 \text { DEGF } \\
108-130 \text { VAC } \\
0-100 \text { Mn/Y } \\
0-100 \mathrm{Mm} / Y \\
0-100 \mathrm{M}^{\prime \prime} / Y \\
0-100 \mathrm{Mm} / \mathrm{Y}\end{array}$ \\
\hline
\end{tabular}


TR 15 $0261 \quad 4051 \quad-25-+75$ DEGC

TST2 $0262 \quad 4052$

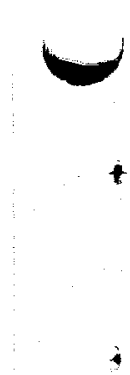

5-6 
AR1: R114 LEVEL ALARM LOW IN ERU

AR2: TPU LUBE OIL PRESSURE ALARM LOW

AR3: WELLHEAD BRINE PRESSURE ALARM HIGH

AR4: ERINE PUMP P13 SUCTION PRESS ALARM LOW

AR6: BRINE PUMP P 14 DSCHRGE PRESS ALARM HIGH,

AR7: TPU LUBE OIL LEVEL ALARM LOW

AR8: R114 TO WELL FLOW ALARM LOW

AR9: R114 TO WELL PRESSURE ALARM LOW

AR 11: MAKE-UP WATER SUPPLY PRESS ALARM LOW

AR 12: INSTRUMENT AIR PRESSURE ALARM LOW

AR 13: BAROMETRIC LEG WATER LEVEL ALARM HIGH

PAL6: R114 AUX PUMP P1 SUCTION PRESS ALRM LOW,

PAR1: R114 FROM WELL PRESSURE ALARM HIGH

AR 186:MASTER SHUTDOWN RELAY 186 ALARM

AR286:MASTER SHUTDOWN RELAY 286 ALARM

AR386: MASTER SHUTDOWN RELAY 386 ALARM

ST IR: BRINE PRESS CNTRL VLVE PCV4 OPEN

ST 1G: BRINE PRESS CNTRL VLVE PCV4 CLOSED

ST2R: BRINE PUMP P14 ON

ST3R: BRINE PUMP P13 ON

ST4R: R114 TO WELL FLOW CNTRL VALVE FCVI OPEN, ST 1IR:BRINE PRESS CONTROL VALVE PCV3 OPEN

ST5R: R114 AUX PUMP PI ON

ST6R: R114 FEED PUMP P2 ON

ST7R: BAC E2 ON

ST8R: BAC EI ON

ST9R: R114 OUT PRESS CNTRL VALVE PCV5 OPEN?

ST9G: R114 OUT PRESS CNTRL VALVE PCVS CLOSED,

ST 1OR:R114 TO WELL HAND VALVE HV16 OPEN

ST 1OG:R114 TO WELL HAND VALVE HVI6 CLOSED

FIC1: R114 TO WELL FLOW CNTRLER FIC1 SETPOINT,

PIC 1: BRINE BACK PRESS CNTRLER PIC1 SETPOINT

PR6: R114 TO WELL PRESSURE

TR 10: R114 TO WELL TEMPERATURE

FR2: R114 TO NELL FLOW

TR7: R114 FROM WELL TEMPERATURE

PR3: R114 FROM WELL PRESSURE

PR5: BRINE HELLHEAD PRESSURE

FR 1: BRINE WELLHEAD FLOW

TR5: BRINE WELLHEAD TEMPERATURE

RPMR 1: TPU RPM

LR 1: TPU LUBE OIL SUPPLY LEVEL

TST 1: TEST 1

TR2: R114 GAS TEMP ABOVE ERU BUBBLE TRAY

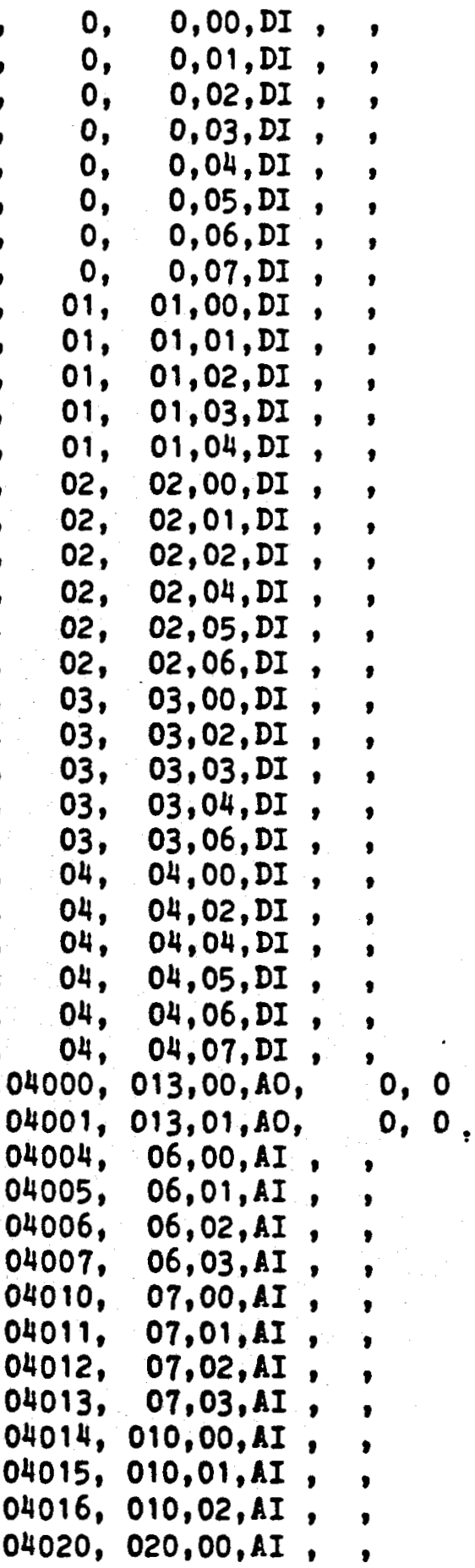


TR3: R114 GAS TEMP BELOW ERU BUBBLE TRAY ,04021, 020,01,AI, , TR4: R114 LIQUID TEMP BELOW ERU BUBBLE TRAY ,04022, 020,02, AI; ; TR6: R114 LIQUID TEMP ABOVE ERU BUBBLE TRAY ,04023, 020,03,AI , PDR 1: R114 DIFF GAS PRESS ACROSS ERU BUB TRAY, 04024, 021,00,AI, , PR4: R114 GAS PRESS ABOVE ERU BUBBLE TRAY ,04025, 021,01,AI, , PR11: R114 FEED PUMP P2 SUCTION PRESSURE ,04026, 021,02,AI , PR9: TPU LUBE OIL SUPPLY PRESSURE

PR2: R114 GAS PRESS AT BAC E1 INLET

TRB: R114 LIQUID TESP AT BAC EI OUTLET

PDR2: R114 DIFF PRESS ACROSS BAC E1

FR4: R114 LIOUID RETURN FLOW BAC'S TO ERU

WR 1: BAC EI SPEAY PUMP POWER CONSUMPTION

WR2: EAC EI COOLING FANS POWER CONSUMPTION

FR3: MAKE-UP WATER FLOW TO BAC'S

TR9: COOLING WATER RESERVOIR TEMP BAC E1

FR8: BLEED WATER FLOW FROM BAC'S

PR 10: BRINE PRESSURE AT PCV4 DISCHARGE

WBR 1: WET BULB TEMPERATURE

ATR 1: AIR TEMPERATURE

VR 1: 120 VAC FROM 480 VAC BUS

CR 1: CORR RATE AT BRINE VALVE PCV 4 DSCHRG

CR2: CORR RATE AT BRINE INLET TO P13\&P 14

CR3: CORR RATE AT WELLHEAD BRINE DISCHARGE

CR4: CORR RATE AT BAC-E I COOLING SPRAY

TR 15: MUX 2 STATION TEMPERATURE

TST2: TEST 2

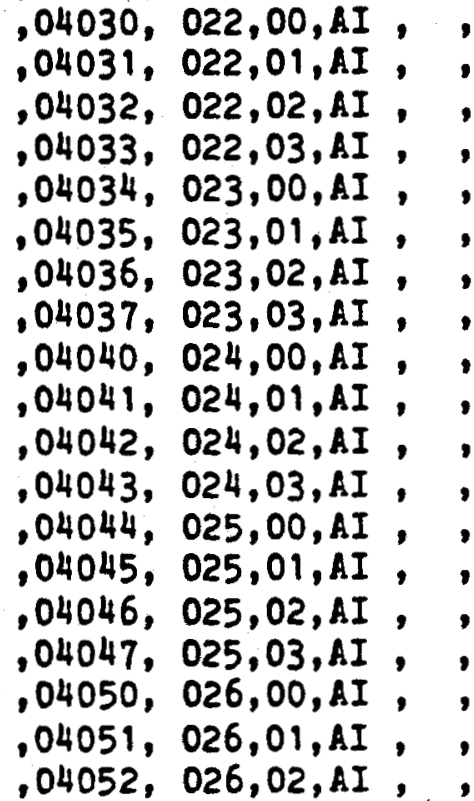


CAL1: ZERO CALIBRATION

CAL2: FULL SCALE CALIBRATION

PIP: PUMP INLET PRESSURE

POP: PUMP OUTLET PRESSURE

TIP: TURBINE INLET PRESSURE

TOP: TUREINE OUTLET PRESSURE

LUBP: LUBRICATION OIL PRESSURE

POT: PUMP OUTLET TEMPERATURE

TIT: TURBINE INLET TEMPERATURE

TOT: TURBINE OUTLET TEMPERATURE

MANT: TRANSDUCER MANIFOLD TEMPERATURE

CANT: INSTRUMENT CANNISTER TEMPERATURE

HXBI: HX BRINE INLET TEMPERATURE

HXBO: HX BRINE OUTLET TEMPERATURE

HXOI: HX ORGANIC INLET TDMPERATURE

HXOO: HX ORGANIC OUTLET TEMPERATURE

RPM 1: TPU RPM

RPM2: TPU RPM

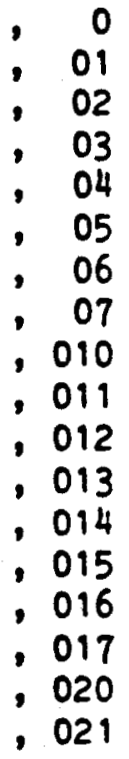


FIC1: R114 TO WELL FLOW CNTRLER FIC1 SETPOINT, ,10,0,4095,0.,4095.,0. PIC1: BRINE BACK PRESS CNTRLER PICI SETPOINT

PR6: R114 TO NELL PRESSURE

TR 10: R114 TO WELL TEMPERATURE

FR2: R114 TO WELL FLOW

TR7: R114 FROM WELL TEMPERATURE

PR3: R114 FROM WELL PRESSURE

PR5: BRINE WELLHEAD PRESSURE

FR 1: BRINE WELLHEAD FLOW

TR5: BRINE WELLHEAD TEMPERATURE

RPMR 1 : TPU RPM

LR 1: TPU LUBE OIL SUPPLY LEVEL

TR2: R114 GAS TEMP ABOVE ERU BUBBLE TRAY

TR3: R114 GAS TEMP BELOW ERU BUBBLE TRAY

TR4: R114 LIQUID TEMP BELOW ERU BUBBLE TRAY

TR6: R114 LIQUID TEMP ABOVE ERU BUBBLE TRAY

PR4: R114 GAS PRESS ABOVE ERU BUBBLE TRAY

PR 11: R114 FEED PUMP P2 SUCTION PRESSURE

PR9: TPU LUBE OIL SUPPLY PRESSURE

PR2: R114 GAS PRESS AT BAC E1 INLET

TR8: R114 LIQUID TEMP AT BAC E1 OUTLET

PDR2: R114 DIFF PRESS ACROSS BAC E1

FR4: R114 LIQUID RETURN FLOW BAC'S TO ERU

WR 1: BAC EI SPRAY PUMP POWER CONSUMPTION

WR2: BAC EI COOLING FANS POWER CONSUMPTION

FR3: MAKEUP WATER FLOW TO BAC'S

TR9: COOLING WATER RESERVOIR TEMP BAC EI

FR8: BLEED WATER FLOW FROM BAC'S

PR 10: BRINE PRESSURE AT PCV4 DISCHARGE

WBR 1: WET BULB TEMPERATURE

ATR 1: AIR TEMPERATURE

VR 1: 120 VAC FROM 480 VAC BUS

CR1: CORR RATE AT BRINE VALVE PCV4 DSCHRG

CR2: CORR RATE AT BRINE INLET TO P13\&P 14

CR3: CORR RATE AT VELLHEAD BRINE DISCHARGE

CR4: CORR RATE AT BAC-E I COOLING SPRAY

TR 15: MUX 2 STATION TEMPERATURE

CAL1: ZERO CALIBRATION

CAL2: FULL SCALE CALIBRATION

PIP: PUMP INLET PRESSURE

POP: PUMP OUTLET PRESSURE

TIP: TURBINE INLET PRESSURE

TOP: TURBINE OUTLET PRESSURE

LUBP: LUBRICATION OIL PRESSURE

POT: PUMP OUTLET TEMPERATURE

TIT: TURBINE INLET TEMPERATURE

TOT: TURBINE OUTLET TEMPERATURE

MANT: TRANSDUCER MANIFOLD TEMPERATURE ,DEGF, AI, 0,4095,50, 150.,1.5

$, A 0,0,4095,0 ., 4095 ., 0$. ,PSIA, AI, 0, 4095,0.,500.,5. ,DEGF, AI, 0, 4095,50., 150., 1.5 ,"HZ2O,AI, 0, 4095, 0.,600.,6.0 , DEGF, AI, 0, 4095, 0., 400. , 4. ,PSIA, AI, 0, 4095,0., 300., 3 . ,PSIA, AI, 0,4095, 0. ,500., 5 . ,H2O* .5, AI, 0,4095,0.,86.,.86 ,DEGF, AI, 0,4095,0., 400., 4 . , RPM , AI, 0,4095,0.,15000., 150. , LES , AI, 0,4095,0., 750, 7.5 , DEGF, AI, 0,4095,50., 150., 1.5 ,DEGF, AI, 0,4095,50., 150., 1.5 , DEGF, AI, 0, 4095, 50., 150., 1.5 , PSIA, AI, 0,4095,0., 100., 1 . , PSIA, AI, 0, 4095, 0. ,200., 2 . ,PSIA, AI, 0, 4095, 0.,200.,2. ,PSIA, AI, 0,4095,0., 50., .5 , DEGF, AI, 0,4095,50., 150., 1.5 , "H2O, AI, 0, 4095, 0. , 100 . , 1 . ,"H2O, AI, 0, 4095, 0., 15., . 15 , KW , AI, 0,4095,0.,3.75,.0375 , KW , AI, 0,4095,0.,7.5,.075 ,GPM ,AI, 0,4095,9.,100., 1. , DEGF, AI, 0,4095,50., 150., 1.5 ,DEGF, AI, 0, 4095,0., 100., 1. ,DEGF, AI, 0, 4095, 0., 150., 1.5 ,VOLT, AI, 0, 4095, 108. , 130. , 1.3 , $M^{\prime \prime} / Y, A I, 0,4095,0 ., 100 ., 1$. , M'IY,AI, 0,4095,0., 100., 1 . , $M^{m} / Y, A I, 0,4095,0 ., 100 ., 1$. ,M" / , AI, 0, 4095,0., 100., 1. . , DECC, AI, 0, 4095,-25., 75.,.5 ,CNTS, , , $0 ., 0 ., 1$. , CNTS, , , 3968., 3968. , 1. ,PSIA, , ,.,0.,750., 1. ,PSIA, , , 0., 1500., 1 . ,PSIA, , , ,0.,750., 1. ,PSIA, ,.,0.,400.,.1 ,PSIA, , ,0., 1500.,1. , DEGC, $, 1,0,, 200 ., 1$ , DEGC, , , , 0.,200.,.1 , DEGC, ,,, $0 ., 200 ., 1$ ,DEGC, , , $0 ., 200 ., 1$ ,GPM ,AI, 0,4095,9.,100., 1 . ,PSIA, AI, 0, 4095, 0. , 700 . , 7 . 
CANT: INSTRUMENT CANNISTER TEMPERATURE

HXBI: HX BRINE INLET TEMPERATURE

HXBO: HX BRINE OUTLET TEMPERATURE

HXOI: HX ORGANIC INLET TEMPERATURE

HXOO: HX ORGANIC OUTLET TEMPERATURE

RPM 1: TPU RPM/10

RPM2: TPU RPM/ 10
,DEGC, , , $0 ., 200 ., 1$

, DEGC, , , , 0.,200.,.1

,DEGC, , , , 0.,200.,. 1

,DEGC, , , , 0.,200.,.1

,DEGC, , , , 0.,200.,.1

$, R P M / 10, \ldots, 0 ., 1500 ., 1$.

,RPM/10, , , , 0., 1500., 1 . 


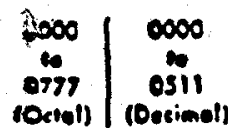

Otral Desimal $10000 \cdot 1086$ $20000 \cdot 8182$ $30000 \cdot 12288$ $10000 \cdot 16384$ $50000 \cdot 20480$ 60000.24576 $70000 \cdot 28672$

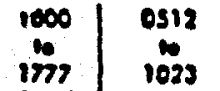

(Oxtol) (Becimel)

\section{- 1234519}

000000000001000200030004000500060007 001000080009001000110012001300140015 0020 0016 0017 0018 00190020002100220023 $\begin{array}{llllllllll}0030 & 0024 & 0025 & 0026 & 0027 & 0028 & 0028 & 0030 & 0031\end{array}$ $00400032 \quad 003300340035003600390038 \quad 0039$ 0050,0010 0041 00120043 0044 0045. D046 0047 0050 0048 0048 coso 0051 0052 Dos3 0034 005s 0070 0056 c057 0058 00590060008100620063

0100 0068 0085 0068 00690068006900700071 011000720073007400730076007700780079 0120 0080 0081 0082 0083 0084 0085 0086 0087 0130 0088 0089 0090 0091 0092 0083 0091 0095 0140,00980097009800990100010101020105 0150 010 0105010501070108010901100111 $0160 \quad 01120113$ 0116 0113 0116 0117 0116 0119

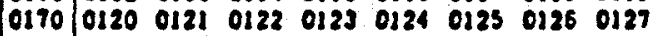

$0200 \quad 0128 \quad 01280130 \quad 01310132 \quad 013301340135$ $0210 \quad 013601370138$ 0139 0140 0141 0142 0143 0220,0144014501460147014801490150 0151 $0230,0152 \quad 01530154015501560157$ 0138 0159 $\begin{array}{lllllllll}0240 & 0760 & 0161 & 0162 & 0163 & 0164 & 0165 & 0166 & 0167\end{array}$ 0250,016801690170 0171 0172 0173 0174 0175 0280 0176 0177017801700180018101820183 0270 0181 0183018601870188038901900181

$0900 ; 01920193$ o181 0193 0198 010701980189 $0910.0200 \quad 0201020202030204020302060207$ 0320.02080209021002110212021302140213 $\begin{array}{lllllllllll}0330,0218 & 0217 & 0211 & 0218 & 0220 & 0221 & 0222 & 0223\end{array}$ 0340 : 02240225022602270228022902300231 $\begin{array}{llllllllllll}0350 & 0232 & 0233 & 0234 & 0235 & 0236 & 0237 & 0238 & 0239\end{array}$ $\begin{array}{lllllllllll}0360 & 0240 & 0241 & 0242 & 0243 & 0244 & 0245 & 0248 & 0247\end{array}$ $\begin{array}{ll:llllllll}0370 & 0248 & 0249 & 0250 & 0251 & 0252 & 0253 & 0254 & 0253\end{array}$

\section{\begin{tabular}{llllllll}
\hline 0 & 1 & 2 & 3 & 4 & 5 & 6 & 9
\end{tabular}}

1000 0512 0513 0514 0515 0516 0517 05180519 $1010 \quad 0520 \quad 0521 \quad 0522 \quad 0523 \quad 0524 \quad 0523 \quad 0525 \quad 0527$ 1020 O528 0520 0530 0533 O532 0533 0534 0533 1030 0536 0537 0538 0539 0540 0541 n512 0543 j040.0544 0545 0546 0547 0548 0549 0550 0551

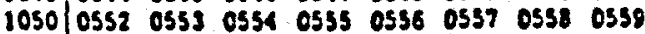
1050 0560 us61 0562 0589 0564 0585 0586 0567 1070 0568 0569 0570 0571 0572 0573 0574 0575

1100 0576 0597 0578 0579 0510 0581 0582 0583 1110 0584 0585 0586 0517 0588 0589 0590 0591 $1120 \quad 0592 \quad 0593$ 0594 C595 0595 0597 0598 0599 1130 0600 0601 0602 0603 0604 0605 0606 0607 $\begin{array}{llllllllll}1140 & 0608 & 0609 & 0810 & 0811 & 0612 & 0813 & 0814 & 0615\end{array}$ IIso $0616 \quad 0517$ 0618 $0618 \quad 0620 \quad 0521 \quad 0622 \quad 0623$ $\begin{array}{lllllllll}1160 & 0524 & 0625 & 0626 & 0627 & 0628 & 0629 & 0630 & 0631\end{array}$ $\begin{array}{lllllllll}1110 & 0632 & 0633 & 0631 & 0635 & 0638 & 0637 & 0631 & 0639\end{array}$

$1200 \quad 0640 \quad 0641 \quad 064208430844$ 0645 06460647 1230.0648 0649 0650 0851 0652 0653 0654 0655 1220 065 0657 0658 $06590660 \quad 06610662$ 0663 $\begin{array}{lllllllllll}1230 & 0664 & 0685 & 0666 & 0667 & 0668 & 0669 & 0570 & 0671\end{array}$ $\begin{array}{llllllllllll}1240 & 0672 & 0673 & 0574 & 0675 & 0676 & 0677 & 0678 & 0679\end{array}$ $1250 \quad 0680 \quad 0681 \quad 0582 \quad 0683 \quad 0684068308860687$ 1260 0688 $08890890 \quad 0691069206930694 \quad 0695$ 12700696069706980698070007010702.0703 I300 0704 o70s 07080707070807090710 07II 1310 07120711071407150716071907180710 1320 0720 $07210722 \quad 07230724 \quad 072507260737$ $1330 \quad 0728072007300731 \quad 0732 \quad 073307340735$ $\begin{array}{llllllllll}1340 & 0736 & 0737 & 0738 & 0739 & 0740 & 0741 & 0742 & 0743\end{array}$ j350 07440745074607470748074907500751 lis60 0752 0753 0754 075s 0756 0757 0758 0758

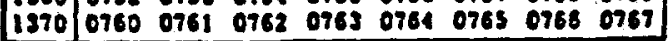

\begin{tabular}{llllllll}
\hline & 1 & 2 & 3 & 1 & 5 & 6 & 1
\end{tabular}

$0400 \quad 02360237023802590260026102620263$ $\begin{array}{lllllllllll}0410 & 0264 & 0263 & 0268 & 0267 & 0268 & 0269 & 0270 & 0271\end{array}$ $\begin{array}{lllllllll}0430 & 0272 & 0273 & 0274 & 0275 & 0276 & 0279 & 0274 & 0278\end{array}$ $\begin{array}{lllllllllll}0430 & 0280 & 0281 & 0282 & 0283 & 0284 & 0285 & 0288 & 0287\end{array}$ $\begin{array}{lllllllllll}0440 & 0218 & 0289 & 0290 & 0291 & 0292 & 0293 & 0294 & 0293\end{array}$ $\begin{array}{llllllllll}0450 & 0298 & 0297 & 0298 & 0299 & 0300 & 0301 & 0302 & 0303\end{array}$ 0460 0304 0305 030603070308030903100311 6470 03120313031403150316031703110319

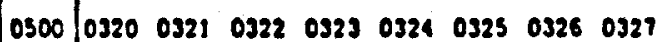
$\begin{array}{llllllllllllllll}0510 & 0328 & 0329 & 0330 & 0331 & 0332 & 0333 & 0334 & 0325\end{array}$ $\begin{array}{lllllllllll}0520 & 0336 & 0337 & 0338 & 0339 & 0340 & 0341 & 0342 & 0343\end{array}$ $\begin{array}{llllllllll}0330 & 0344 & 0345 & 0346 & 0347 & 0348 & 0349 & 0350 & 0331\end{array}$ $\begin{array}{llllllllll}0 & 0340 & 0352 & 0353 & 0354 & 0353 & 0336 & 0359 & 0338 & 0359\end{array}$ $\begin{array}{lllllllll}0550 & 0360 & 0361 & 0362 & 0363 & 0364 & 0365 & 0366 & 0367\end{array}$ $\begin{array}{lllllllllllll}0560 & 0368 & 0369 & 0370 & 0371 & 0372 & 0373 & 0374 & 0373\end{array}$

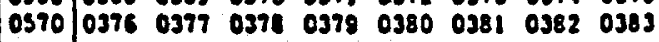

$\begin{array}{lllllllll}0500 & 0384 & 0385 & 0386 & 0387 & 0388 & 0389 & 0390 & 0391\end{array}$ $\begin{array}{llllllllll}0610 & 0392 & 0393 & 0394 & 0395 & 0396 & 0397 & 0398 & 0359\end{array}$ 0820 0400 0401040204030404040504060407 $0630.0408 \quad 0409 \quad 0410 \quad 0411 \quad 0412$ O413 0414 0415 $\begin{array}{llllllllll}0640 & 0416 & 0417 & 0418 & 0419 & 0420 & 0421 & 0422 & 0423\end{array}$ $\begin{array}{llllllllll}0650 & 0424 & 0425 & 0426 & 0427 & 0428 & 0429 & 0430 & 0431\end{array}$ 0660|0432 $04330434 \quad 0435 \quad 0435 \quad 0437 \quad 0438 \quad 0439$ 0670 j440 044104420443 O444 044504460447

0700 0448 0419 0450 0451 0452 04530454 a4ss $\begin{array}{lllllllll}0710 & 0436 & 0457 & 0438 & 0458 & 0460 & 0461 & 0462 & 0463\end{array}$ 0720 :0454 0485 0468 0457 0468 $04690470 \quad 0471$ $\begin{array}{llllllllll}0730 & 0472 & 0473 & 0474 & 0473 & 0476 & 0477 & 0478 & 0479\end{array}$ 0740 0480 O481 0482 0483 0484 O485 0486 0487 $\begin{array}{lllllllll}0730 & 0488 & 0489 & 0490 & 0491 & 0492 & 0493 & 0494 & 0495\end{array}$ 0760 O498 04970498 0495 $0500 \quad 0501 \quad 0502 \quad 0503$ 0770 0504 0505 0506 0507 0508 0509 0510 0511

\section{$\begin{array}{llllllll}0 & 1 & 2 & 3 & 4 & 5 & 6 & 7\end{array}$}

140007680769077007710772077307740775 1410 o775 0779 0778 0779 0780 0781 0762 0719 1420 0786 0785 07860787 o788 078907900781 143007920793079407950796079707980789 14400850080108020803 0804 0805 08060807 1450 0808 0809 0810 $0811 \quad 081208130816$ 0815 $\begin{array}{llllllllll}1460 & 0816 & 0817 & 0818 & 0819 & 0820 & 0831 & 0822 & 0823\end{array}$ 1470 0821 $0825082608270824 \quad 08290830 \quad 0831$

isoo $0832 \quad 08330834$ 0835 0836083708380838 is10 $0840 \quad 084108420843 \quad 0844084508460847$ 1520 $08480849 \quad 0830 \quad 0851 \quad 0852 \quad 0853$ 0854 0855 1530/0856 0857 0858 0859 0850 0851 0852 0883 is40 08540865086808570858086908700871 $\begin{array}{lllllll}1550 & 0872 & 08730874 & 0875 & 0876 & 0877 & 08780870\end{array}$ 15EO OBEO 088108820883 0884 0883 0886 0887 1570|0888 0889 0890 0891 0892 0193 0896 0895

$1600 \quad 08950897089808990900 \quad 080105020903$ 2610 0904 0903 0906 0907 0908 090909100911 $1620 \quad 0912091309140915$ 0916 0917 0918 0919

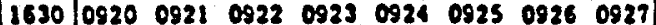
$\begin{array}{lllllllll}1640 & 0928 & 0929 & 09330 & 0931 & 0932 & 0935 & 0934 & 0935\end{array}$ i6so $09360937093809390940 \quad 0941 \quad 0942 \quad 0943$ 1650 0944 094509460947094109490950 0951 1870 0952 0953 0951 0953 0956095709580939 $1700 \quad 0980 \quad 0961098209830961098309860957$ 1971009680969097009710972 0973 0971 0975 1720 0978 0977097809790980008109820983 173009840983098609870988098909800981 174009820993099409950986099709980098 \begin{tabular}{l|lllllllll}
1750 & 1000 & 1001 & 1002 & 1003 & 1004 & 1005 & 1008 & 1007
\end{tabular} 1760 1001 1008101010121012 l015 1014 1015 1770 $101810191018 \quad 1018$ 10:: $1021 \quad 10221023$ 


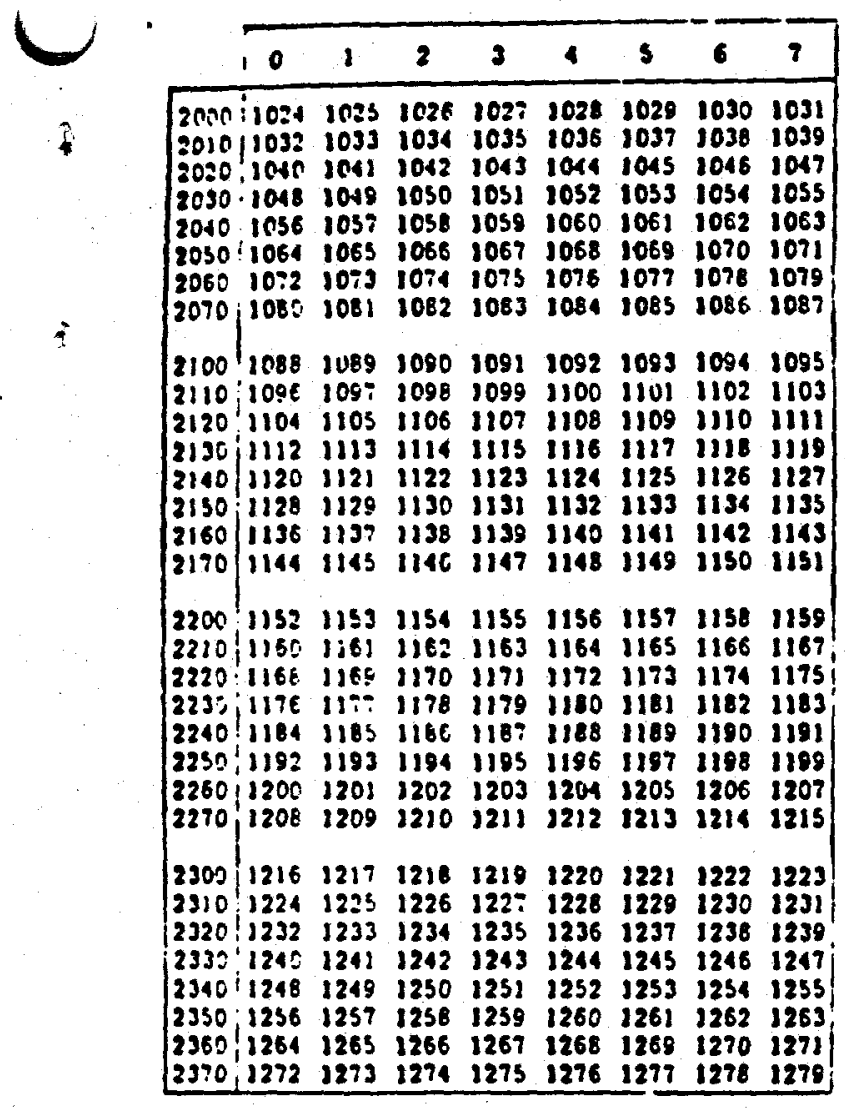

\begin{tabular}{|llllllll}
\hline 0 & 1 & 2 & 3 & 4 & 5 & 6 & 7 \\
\hline
\end{tabular}

$3000 \quad 1536 \quad 1537 \quad 1538 \quad 1539 \quad 1540 \quad 1541 \quad 1542 \quad 1543$ 3010 is44 154515461547 is48 1549 1550 1551 3020.13521553 1554 1555 1556 1357 15581539 $\begin{array}{lllllllllllll}3030 & 1560 & 1561 & 1562 & 1563 & 1564 & 1565 & 1566 & 1567\end{array}$ 3040 156e 1569 1570 1571 1572 1573 1574 1575 $3050: 1576 \quad 1577 \quad 1578 \quad 1570 \quad 1580 \quad 1581 \quad 15821583$ 3060 /1584 1585 $1586 \quad 1587 \quad 15881589 \quad 1590 \quad 1391$ 3070 1592 1593 is94 1593 is96 1597 is98 1599

$\begin{array}{llllllll}3100 \quad 1600 & 1602 & 1602 & 1603 & 1604 & 1605 & 1606 & 1607\end{array}$ \begin{tabular}{ll|llllllllll}
3110 & 1608 & 1609 & 1610 & 1611 & 1612 & 1613 & 1614 & 1615
\end{tabular} $\begin{array}{llllllllll}3120 & 1616 & 1617 & 1618 & 1618 & 1620 & 1621 & 1622 & 1623\end{array}$ $\begin{array}{llllllllll}3130 \mid 1624 & 1625 & 1626 & 1627 & 1628 & 1629 & 1630 & 1631\end{array}$ $\begin{array}{lllllllllll}3140 & 1632 & 1633 & 1634 & 1635 & 1636 & 1637 & 1638 & 1639\end{array}$ $\begin{array}{llllllllllll}3150 & 1640 & 1641 & 1642 & 1643 & 1644 & 1645 & 1646 & 1647\end{array}$ $\begin{array}{llllllllllll}3160 & 1648 & 1649 & 1650 & 1651 & 1652 & 1653 & 1624 & 1655\end{array}$ $\begin{array}{llllllllll}3170 & 1656 & 1657 & 1656 & 1659 & 1650 & 1661 & 1662 & 1663\end{array}$ $\begin{array}{lllllllllll}3200 & 1664 & 1663 & 1686 & 1667 & 1668 & 1669 & 1670 & 1671\end{array}$ \begin{tabular}{ll|llllllllllll}
3210 & 1572 & 1673 & 1674 & 1675 & $1676 \quad 1677$ & 1678 & 1678
\end{tabular} $\begin{array}{lllllllllllllll}33220 & 1680 & 1621 & 1682 & 1683 & 1684 & 1683 & 1686 & 1687\end{array}$ $\begin{array}{lllllllll}3230 & 16881689 & 1690 & 1691 & 1692 & 1693 & 1694 & 1695\end{array}$ 32401696 169: $169816991700 \quad 1701 \quad 1702 \quad 1703$ 3250?1704 1705 $17061707 \quad 1708 \quad 1709 \quad 1710 \quad 3711$ 3260 [172 1713 i714 1715 i716 171717181718 $\begin{array}{lllllllll}3270 & 1720 & 1721 & 1722 & 1723 & 1724 & 1725 & 1726 & 1727\end{array}$

$\begin{array}{lllllllll}3300 & 1928 & 1728 & 1730 & 1733 & 1732 & 1733 & 1734 & 1733\end{array}$ $\begin{array}{lllllllllll}3310 & 1736 & 1737 & 2738 & 1739 & 1740 & 1741 & 1742 & 1743\end{array}$ 33201744 1745 1746 i747 i742 1749 1730 1753 3330 1752 1753 1754 1755 i756 1757 i758 i7so $\begin{array}{lllllllll}3340 & 760 & 1761 & 1762 & 1763 & 1764 & 1765 & 1765 & 1764\end{array}$ 3350 $1768 \quad 1789 \quad 1770 \quad 1771 \quad 1772 \quad 1773 \quad 1774 \quad 1775$ 3564 j1776 1777 1778 1778 1780 178 ) $1782 \quad 1783$ [370 1784 i78s $1786 \quad 1787$ i788 $17801790 \quad 3791$

\begin{tabular}{llllllll}
0 & 1 & 2 & 3 & 4 & 5 & 6 & 7 \\
\hline
\end{tabular}

$\begin{array}{llllllll}2400 & 1280 \quad 1281 & 1282 & 1283 \quad 1284 & 1285 & 1286 & 1287\end{array}$ $2410 \quad 1288 \quad 1289 \quad 1290 \quad 1291 \quad 3292 \quad 1293 \quad 1294 \quad 1295$ $\begin{array}{llllllllll}2620 & 1296 & 1297 & 1298 & 1299 & 1300 & 1301 & 1302 & 1303\end{array}$ $2130 \quad 1304 \quad 130513061307 \quad 1308 \quad 13091310 \quad$ [311) $\begin{array}{lllllllll}2410 & 1312 & 1313 & 1314 & 1315 & 1316 & 1317 & 1318 & 1318\end{array}$ $\begin{array}{llllllllll}2430 & 1320 & 1321 & 1322 & 1323 & 1324 & 1325 & 1326 & 1327\end{array}$ $\begin{array}{lllllllllllll}2460 & 1328 & 1329 & 1330 & 1331 & 1332 & 1333 & 1334 & 1335\end{array}$ $\begin{array}{llllllllll}2470 & 1336 & 1337 & 1338 & 1338 & 2340 & 1341 & 1342 & 1343\end{array}$

$\begin{array}{lllllllll}2500 & 1344 & 1345 & 1346 & 1347 & 1348 & 1349 & 1350 & 1951\end{array}$ $\begin{array}{lllllllll}2310 & 1352 & 1353 & 1354 & 1353 & 1356 & 1337 & 1958 & 1359\end{array}$ $\begin{array}{llllllllll}2520 & 1360 & 1361 & 1362 & 1363 & 1364 & 1355 & 1366 & 1367\end{array}$ $\begin{array}{lllllllllll}2530 & 1368 & 1369 & 1370 & 1371 & 1372 & 1373 & 1374 & 1375\end{array}$ $\begin{array}{llllllllllllll}2340 & 1376 & 1377 & 1378 & 1379 & 1380 & 1381 & 1382 & 1383\end{array}$ $\begin{array}{llllllllll}2550 & 1384 & 1385 & 1386 & 1387 & 1388 & 1389 & 1390 & 1391\end{array}$ $\begin{array}{llllllllll}2360 & 1392 & 1393 & 1394 & 1395 & 1396 & 1397 & 1398 & 1399\end{array}$ $2570 \quad 1400 \quad 1401 \quad 1402 \quad 1403 \quad 1404 \quad 14051406 \quad 1407$ $2600 \quad \begin{array}{llllllll}1408 & 1409 & 1410 & 1411 & 1412 & 1413 & 1414 & 1413\end{array}$ $2610 \quad 1416 \quad 1417 \quad 1418 \quad 1419 \quad 1420 \quad 1421 \quad 1422 \quad 1423$ $\begin{array}{lllllllll}2520 & 1424 & 1425 & 1426 & 1427 & 1428 & 1429 & 1430 & 1431\end{array}$ $\begin{array}{llllllllll}2630 & 1432 & 1433 & 1434 & 1435 & 1436 & 1437 & 1438 & 1439\end{array}$ $2640 \quad 1440 \quad 1441 \quad 1442 \quad 1443 \quad 1444 \quad 1443 \quad 1446 \quad 1449$ $\begin{array}{llllllllll}2630 & 1448 & 1449 & 1450 & 1451 & 1452 & 1453 & 1454 & 1453\end{array}$ $\begin{array}{llllllllll}2650 & 1456 & 1457 & 1456 & 1459 & 1450 & 1451 & 1482 & 1463\end{array}$ $2670 \quad 14641465 \quad 3466 \quad 1467 \quad 1468 \quad 1469 \quad 1470 \quad 1671$

$\begin{array}{lllllllll}2700 & 1472 & 1473 & 1474 & 1475 & 1476 & 1477 & 1478 & 1479\end{array}$ $\begin{array}{lllllllllllll}2710 & 1480 & 1481 & 1482 & 1483 & 1484 & 1485 & 2486 & 1487\end{array}$ $2720 \mid \begin{array}{llllllllll}1488 & 1489 & 1490 & 1491 & 1492 & 1493 & 1484 & \text { L485 }\end{array}$ $\begin{array}{lllllllll}2730 & 1496 & 1497 & 1498 & 1499 & 1500 & 1501 & 1502 & 1503\end{array}$ $2740 \quad 1504 \quad 1505 \quad 1506 \quad 1507 \quad 1508 \quad 1509 \quad 1510 \quad 1511$ $2750 \quad 1512 \quad 1513$ 1514 is15 $1516 \quad 1517$ is18 1519 $2760 \quad 1520 \quad 1521 \quad 1522 \quad 1523 \quad 1524 \quad 1525 \quad 1526 \quad 1527$ $\begin{array}{lllllllll}2770 & 1328 & 1529 & 1530 & 1531 & 1532 & 1533 & 1534 & 1535\end{array}$

$$
\begin{array}{llllllll}
0 & 1 & 2 & 3 & 4 & 5 & 6 & 7
\end{array}
$$

\begin{tabular}{|l|llllllll|}
3400 & 1792 & 1793 & 1794 & 1795 & 1790 & 1799 & 1798 & 1799
\end{tabular} $\begin{array}{lllllllllll}3410 & 1800 & 1801 & 1802 & 1803 & 1804 & 1805 & 1806 & 1807\end{array}$ $\begin{array}{lllllllllll}3420 & 1808 & 1809 & 1810 & 1811 & 1812 & 1813 & 1814 & 1815\end{array}$ $\begin{array}{lllllllllll}3430 & 1816 & 1817 & 1818 & 1810 & 1820 & 1621 & 1822 & 1823\end{array}$ $3410 \quad 1824 \quad 182518261827 \quad 1828 \quad 1829 \quad 1830 \quad 1831$ 34501832 1839 1834 i835 1836 iej7 18381839 $\begin{array}{llllllllllll}3460 & 1840 & 1841 & 1842 & 1843 & 1844 & 1845 & 1846 & 1847\end{array}$ $3470 \quad 1848 \quad 1849 \quad 1850 \quad 1851 \quad 1852 \quad 1853 \quad 1854 \quad 1855$

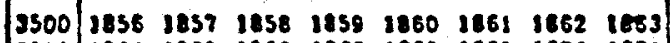
$\begin{array}{lllllllll}3310 & 1864 & 1865 & 1856 & 3867 & 1868 & 1869 & 1870 & 1871\end{array}$ \begin{tabular}{ll|lllllllll}
3320 & 1872 & 1873 & 1874 & 1875 & 1876 & 1877 & 1878 & 1879
\end{tabular} $\begin{array}{llllllllllllll}3530 & 1880 & 1881 & 1882 & 1883 & 1884 & 1885 & 18 B 6 & 1887\end{array}$ $\begin{array}{lllllllllllll}3540 & 1888 & 1889 & 1890 & 1891 & 1892 & 1893 & 1894 & 1895\end{array}$ $\begin{array}{lllllllllll}3350 & 1896 & 1897 & 1898 & 1899 & 1800 & 1901 & 1902 & 1003\end{array}$ $3360 \quad 1804 \quad 190519061907 \quad 1908 \quad 19091910 \quad 1911$ $\begin{array}{lllllll}3570 & 1912 \quad 1013 & 1014 & 1915 & 1916 & 1817 \quad 1818 & 1918\end{array}$

$\begin{array}{lllllllll}3600 & 1920 & 1921 & 1922 & 1923 & 1924 & 1925 & 1926 & 1927\end{array}$ $\begin{array}{llllllllllll}36) & 1998 & 1929 & 1930 & 1931 & 1932 & 1833 & 1934 & 1935\end{array}$ $\begin{array}{llllllllll}3620 & 1936 & 1937 & 1938 & 1039 & 1940 & 1941 & 1942 & 1943\end{array}$ $\begin{array}{lllllllll}3630 & 1044 & 1945 & 1946 \quad 1847 & 1048 & 1949 & 1950 & 1951\end{array}$ $\begin{array}{llllllllll}3640 & 1852 & 1953 & 1954 & 1035 & 1956 & 1957 & 1958 & 1959\end{array}$ $\begin{array}{lllllllll}3630 & 1960 & 1961 & 1962 & 1953 & 1954 & 1953 & 1966 & 1967\end{array}$ $\begin{array}{lllllllllll}3650 & 1968 & 1969 & 1970 & 1871 & 1972 & 1973 & 1974 & 1875\end{array}$ $3670 \quad 1976 \quad 1977 \quad 1978197919801981 \quad 1982 \quad 1983$

$3700 \quad 19841985198519871988198919901992$ $\begin{array}{llllllllllllll}3710 & 1092 & 1993 & 1984 & 1995 & 1996 & 1997 & 1998 & 1999\end{array}$ $3720 \quad 200020012002 \quad 20032004300520062007$ $3730 \quad 20082009201020112012 \quad 201320142015$ $\begin{array}{lllllllll}3740 & 2016 & 2017 & 2018 & 2019 & 2020 & 2021 & 2022 & 2023\end{array}$ 3750 $20242025 \quad 2026 \quad 20272028202920302031$ $\begin{array}{lllllllll}3760 & 2032 & 2033 & 2034 & 2035 & 2036 & 2037 & 2038 & 2039\end{array}$ $\begin{array}{lllllllll}3770 & 2040 & 2041 & 2042 & 2043 & 2044 & 2045 & 2046 & 2047\end{array}$

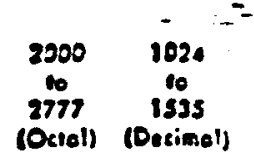

Ortal Derimal $10000 \cdot 1096$ $20000 \cdot 8192$ $30000 \cdot 12288$ $40000 \cdot 16384$ $50000-20435$ $60000 \cdot 21576$

$70050 \cdot 26672$

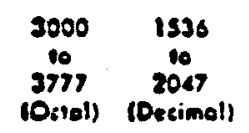


i)

\section{Ocfal-Decimal Integer Conversion Table}

\begin{tabular}{c|c}
1000 & 2028 \\
10 & 10 \\
258 & 258
\end{tabular}

10 croll li Decsimals

Octal Deximal $10000 \cdot 1098$ $20000 \cdot 8182$ $30000 \cdot 12288$ $10003 \cdot 16384$ $50000 \cdot 20480$ $60000 \cdot 24576$ $70000 \cdot 28672$

\begin{tabular}{c|c}
5000 & 2580 \\
10 & 10 \\
5777 & 3081 \\
(Ortol) & (Derimal)
\end{tabular}

$\begin{array}{llllllll}0 & 1 & 2 & 2 & 4 & 5 & 6 & 7\end{array}$

100020482049205020512052205320542053 $4010 \quad 20562057205820592060206120622063$ 1020 20512065206620672068206820702071 $1030 \mid \begin{array}{llllll}2072 & 2073 & 2074 & 2075 & 2076 & 2077 \\ 2078 & 2079\end{array}$ 1040 20802081208220832084208320862087 14050 20882089209020812092209320912095 $4060 \mid 2096209720982099210021012102 \quad 2103$ 407021042105210521072108210921102111

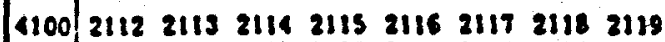
$\begin{array}{lllllllll}4110 & 2120 & 2121 & 2122 & 2123 & 2124 & 2125 & 2126 & 2127\end{array}$ $\begin{array}{llllllll}4120,21: 8 & 2129 & 2130 & 2131 & 2132 & 2133 & 2134 & 2135\end{array}$

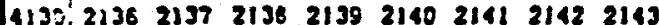
4140 2144 2145 $21462147214821492150 \quad 2151$ 4150 2152 $2153 \quad 2154$ 2155 $2156 \quad 2157 \quad 21582159$

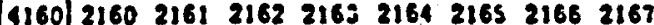

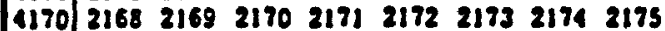

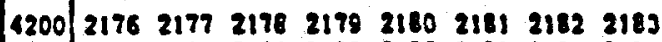
$4210 \quad 218421852186 \quad 21872188218921902191$

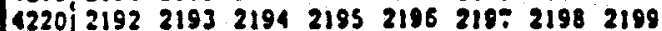
$4230 \quad 220022012202 \quad 2203 \quad 2204 \quad 22052206 \quad 2207$ $\begin{array}{lllllllll}4240 & 2208 & 2209 & 2210 & 2211 & 2212 & 2213 & 2214 & 2215\end{array}$

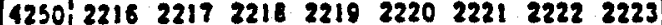
1260 $2224 \quad 2225222622272228 \quad 22292230 \quad 2231$

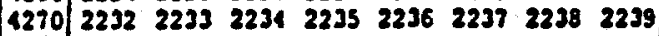

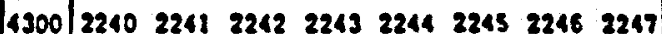
\begin{tabular}{l|llllllll}
4310 & 2240 & 2249 & 2250 & 2251 & 2252 & 2253 & 2254 & 2255
\end{tabular}

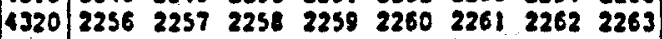
$\begin{array}{lllllllll}4330 & 2264 & 2265 & 2268 & 2267 & 2268 & 2269 & 2270 & 2271\end{array}$ $\begin{array}{lllllllll}4340 & 2272 & 2273 & 2274 & 2275 & 2276 & 2277 & 2278 & 2279\end{array}$ $\begin{array}{llllllllll}4350 ! & 2280 & 2281 & 2282 & 2283 & 2284 & 2285 & 2286 & 2287\end{array}$ 4360'2288 $228922902291 \quad 2292 \quad 22932294 \quad 2295$

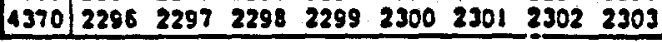

$\begin{array}{llllllll}0 & 1 & 2 & 3 & 4 & 5 & 6 & 7\end{array}$

$\begin{array}{lllllllll}5000 & 2560 & 2561 & 2562 & 2563 & 2564 & 2565 & 2566 & 2567\end{array}$ \begin{tabular}{l|llllllll}
5010 & 2568 & 2369 & 2570 & 2571 & 2572 & 2573 & 2574 & 2575
\end{tabular} $\begin{array}{lllllllll}3020 & 2576 & 2577 & 2578 & 2579 & 2580 & 2381 & 2582 & 2583\end{array}$

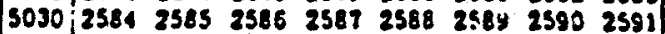

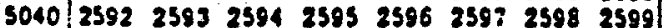
$3050 ! 26002601260226032604260526062507$ $\begin{array}{llllllllll}5060 & 2608 & 2609 & 2610 & 2611 & 2612 & 2613 & 2614 & 2615\end{array}$ $5070 \quad 2616 \quad 2617 \quad 2616 \quad 2619 \quad 2620 \quad 2621 \quad 2622 \quad 2623$

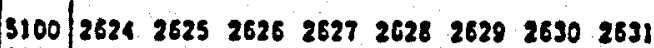
$\begin{array}{lllllllll}5110 & 2632 & 2633 & 2634 & 2635 & 2636 & 2637 & 2638 & 2639\end{array}$ $\begin{array}{llllllllll}5120 & 2640 & 2641 & 2642 & 2643 & 2644 & 2645 & 2646 & 2647\end{array}$ $\begin{array}{llllllllll}5130 & 2648 & 2648 & 2650 & 2651 & 2632 & 2653 & 2654 & 2655\end{array}$ $5140 \quad 26562657265826392660 \quad 2661 \quad 2662 \quad 2663$ \begin{tabular}{l|llllllll}
5150 & 2664 & 2665 & 2665 & 2667 & 2668 & 2669 & 2670 & 2671
\end{tabular} $\begin{array}{llllllllll}\$ 160 & 2672 & 2673 & 2674 & 2675 & 2678 & 2677 & 2678 & 2670\end{array}$

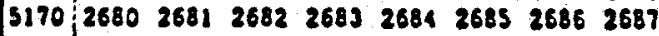

$3200 \quad 26882689269026912692 \quad 269926942695$ $\begin{array}{lllllllll}5210 & 2696 & 2697 & 2698 & 2699 & 2700 & 2701 & 2702 & 2703\end{array}$ $\begin{array}{lllllllll}5220 & 2704 & 2705 & 2706 & 2707 & 2708 & 2709 & 2710 & 2711\end{array}$ $5230 \quad 2712 \quad 271327142715 \quad 2716 \quad 2712 \quad 2718 \quad 2719$ $\begin{array}{lllllllll}5240 & 2720 & 2721 & 2722 & 2723 & 2724 & 2725 & 2726 & 2727\end{array}$ $5230 ! 2738 \quad 2729 \quad 2730 \quad 2731 \quad 2732 \quad 2733 \quad 2734 \quad 2735$ \begin{tabular}{l|llllllll}
5260 & 2736 & 2737 & 2738 & 2739 & 2740 & 2741 & 2742 & 2749
\end{tabular} $5270 \quad 274127452746 \quad 27472748 \quad 27482750 \quad 2751$

\begin{tabular}{l|llllllll}
5300 & 2732 & 2733 & 2754 & 2755 & 2756 & 2757 & 2738 & 2759
\end{tabular} $5310 \quad 2760 \quad 2762 \quad 2762 \quad 2763 \quad 2764 \quad 2765 \quad 2766 \quad 2767$ $5920 \quad 2768 \quad 276027702771 \quad 2772 \quad 27732774$ 2775 $5330 \mid 2778277727782779278027812782 \quad 2783$ $\begin{array}{lllllllll}5340 & 2784 & 2745 & 2786 & 2787 & 2788 & 2789 & 2790 & 2791\end{array}$ S350 $2792 \quad 279327942795 \quad 2796 \quad 2797 \quad 2798 \quad 2799$ 596028002801280228032804280528062807

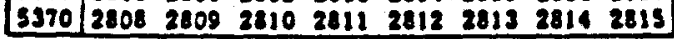

\section{9}

$4400 \quad 23 n 4230529062307 \quad 2308 \quad 230923102311$ $4410 \quad 2312 \quad 2313 \quad 2314 \quad 2315 \quad 2316 \quad 2317 \quad 2314 \quad 3318$ \begin{tabular}{ll|lllllll}
4420 & 2320 & 2321 & 2328 & 2323 & 2324 & 2325 & 2326 & 2327
\end{tabular} $\begin{array}{lllllllllll}440 & 2328 & 2329 & 2330 & 2131 & 2332 & 2333 & 2334 & 2335\end{array}$ $\begin{array}{llllllllll}4440 & 2336 & 2337 & 2338 & 2339 & 2340 & 2341 & 2342 & 2349\end{array}$ 4450|2344 $23452346 \quad 2347 \quad 2348 \quad 2349 \quad 2350 \quad 2351$ $\begin{array}{llllllllll}4460 & 2352 & 2533 & 2354 & 2355 & 2356 & 2357 & 2550 & 2359\end{array}$

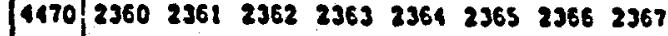

$\begin{array}{lllllllll}4500 & 2368 & 2369 & 2370 & 2371 & 2372 & 2373 & 2374 & 2375\end{array}$ $\begin{array}{lllllllllll}4510 & 2376 & 2377 & 2378 & 2379 & 2380 & 2381 & 2382 & 2383\end{array}$ $\begin{array}{lllllllll}4520 & 2384 & 2385 & 2386 & 2387 & 2388 & 2383 & 2390 & 2391\end{array}$ $\begin{array}{lllllllll}4530 & 2392 & 2393 & 2394 & 2395 & 2396 & 2397 & 2398 & 2399\end{array}$ \begin{tabular}{ll|lllllllll}
1540 & 2400 & 2401 & 2402 & 2403 & 2404 & 2405 & 2406 & 2407
\end{tabular} $4550,2408 \quad 2409 \quad 2410 \quad 2411 \quad 2412 \quad 2413 \quad 2414 \quad 2415$ $\begin{array}{llllllllll}4560 & 2416 & 2417 & 2418 & 2410 & 2420 & 2421 & 2422 & 2423\end{array}$ \begin{tabular}{ll|llllllll}
4570 & 2424 & 2425 & 2436 & 2427 & 2428 & 2429 & 2430 & 2431
\end{tabular}

$\begin{array}{lllllllll}4600 & 2432 & 2433 & 2434 & 2495 & 2436 & 2437 & 2438 & 2439\end{array}$ $4810 \mid 2440 \quad 24412442 \quad 2443 \quad 2444 \quad 2445 \quad 2446 \quad 2447$ $\begin{array}{llllllllll}4620 & 2448 & 2449 & 2450 & 2451 & 2452 & 2453 & 2454 & 2453\end{array}$

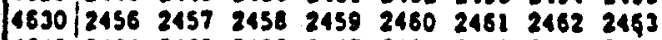
$\begin{array}{lllllllll}4640 & 2464 & 2465 & 2466 & 2467 & 2468 & 2468 & 2470 & 2471\end{array}$ \begin{tabular}{l|lllllllll}
4650 & 2472 & 2473 & 2474 & 2475 & 2476 & 2477 & 2478 & 2479
\end{tabular} $\begin{array}{lllllllllll}4660 & 2480 & 2481 & 2482 & 2483 & 2484 & 2485 & 2486 & 2487\end{array}$ \begin{tabular}{ll|lllllll}
4670 & 2488 & 2489 & 2490 & 2491 & 2492 & 2493 & 2494 & 2495
\end{tabular}

$\begin{array}{lllllllll}4700 & 2496 & 2497 & 2498 & 2499 & 2500 & 2501 & 2502 & 2503\end{array}$ $4710 \quad 25042505 \quad 2506 \quad 25072508 \quad 2509 \quad 2510 \quad 2511$ $\begin{array}{llllllllll}4720 & 2512 & 2513 & 2514 & 2515 & 2516 & 2317 & 2518 & 2519\end{array}$ $\begin{array}{llllllllll}4730 & 2520 & 2521 & 2522 & 2523 & 2524 & 2525 & 2526 & 2527\end{array}$ $\begin{array}{llllllllll}4740 & 2528 & 2529 & 2530 & 2531 & 2532 & 2533 & 2534 & 2535\end{array}$ $\begin{array}{llllllllll}4750 & 2536 & 2537 & 2538 & 2539 & 2540 & 2541 & 2542 & 2543\end{array}$ $\begin{array}{lllllllll}4760 & 2544 & 2545 & 2546 & 2547 & 2348 & 2540 & 2550 & 2531\end{array}$ \begin{tabular}{ll|llllllll}
4770 & 2552 & 2553 & 2554 & 2555 & 2556 & 2557 & 2558 & 2559
\end{tabular}

\begin{tabular}{llllllll}
\hline 0 & 1 & 2 & 3 & 4 & 5 & 6 & 7
\end{tabular}

$5400 \quad 2816 \quad 2817 \quad 2818 \quad 2819 \quad 2820 \quad 28712822 \quad 3829$ \begin{tabular}{ll|lllllllll}
5410 & 2824 & 2825 & 2826 & 2827 & 2828 & 2829 & 2830 & 2831
\end{tabular} \begin{tabular}{l|llllllllll}
5420 & 2832 & 2833 & 2834 & 2835 & 2836 & 2837 & 2838 & 2830
\end{tabular} $\begin{array}{llllllllll}5430 & 2840 & 2841 & 2842 & 2843 & 2844 & 2845 & 2846 & 044\end{array}$ $\begin{array}{llllllllll}5440 & 2848 & 2849 & 2850 & 2851 & 2852 & 2853 & 2854 & 2855\end{array}$ \begin{tabular}{l|lllllllll}
5450 & 2856 & 2839 & 2858 & 2859 & 2860 & 2861 & 2862 & 2863
\end{tabular} \begin{tabular}{l|lllllllll}
5460 & 2864 & 2865 & 2866 & 2867 & 2868 & 2869 & 2870 & 2871
\end{tabular} \$470 $28722873 \quad 2874$ 2875 $2876 \quad 2877 \quad 2878 \quad 2874$

5500 2880 $2881 \quad 2882 \quad 28832884 \quad 2885 \quad 2886 \quad 2887$ $\begin{array}{llllllllllll}5510 & 2888 & 2889 & 2890 & 2891 & 2892 & 2893 & 2894 & 2895\end{array}$ $\begin{array}{llllllllll}5320 & 2896 & 2897 & 2898 & 2899 & 2900 & 2901 & 2902 & 2903\end{array}$ $5530 \quad 20042905 \quad 2906 \quad 29072908 \quad 2909 \quad 2910 \quad 2911$ $5540 \quad 2912 \quad 2913 \quad 29142915 \quad 2016 \quad 2917,2918 \quad 3819$ $\begin{array}{lllllllll}5550 & 2920 & 2921 & 2922 & 2923 & 2924 & 2925 & 2926 & 2927\end{array}$ $\begin{array}{llllllllll}5560 & 2928 & 2929 & 2930 & 2931 & 2932 & 2933 & 2934 & 2935\end{array}$ $\begin{array}{lllllllll}5570 & 2936 & 2937 & 2938 & 2939 & 2940 & 2941 & 2942 & 2943\end{array}$

$\begin{array}{lllllllll}5600 & 2944 & 2945 & 2948 & 2947 & 2948 & 2949 & 2950 & 2951\end{array}$ $3610 \quad 295229532954295529562957.29582958$ $\begin{array}{llllllllll}5620 & 2960 & 2961 & 2962 & 2983 & 2964 & 2955 & 2966 & 2967\end{array}$ $5630 \mid \begin{array}{llllllll}2968 & 2069 & 2970 & 2978 & 2972 & 2973 & 2974 & 2975\end{array}$ $\begin{array}{llllllllll}5640 & 2976 & 2977 & 2978 & 2979 & 2980 & 2981 & 2982 & 2983\end{array}$ $\begin{array}{lllllllllll}5650 & 2984 & 2985 & 2988 & 2987 & 2988 & 2989 & 2990 & 2981\end{array}$ $\begin{array}{llllllllll}5660 & 2992 & 2993 & 2594 & 3995 & 2996 & 2997 & 2998 & 2999\end{array}$ 5670 2000 3001 3002 30033004300530083007

$\$ 700 \quad 30085009501050115012301330145015$ $\begin{array}{lllllllllll}5710 & 3016 & 3017 & 3018 & 3019 & 3020 & 3021 & 3022 & 3023\end{array}$ $\begin{array}{lllllllllll}5720 & 3024 & 3025 & 3026 & 3027 & 3028 & 3029 & 3030 & 3031\end{array}$ $\begin{array}{lllllllllll}5730 & 3032 & 3033 & 3034 & 3035 & 3036 & 3037 & 3038 & 3039\end{array}$ $\begin{array}{lllllllll}5740 & 3040 & 3041 & 3042 & 3043 & 3044 & 3045 & 3048 & 3047\end{array}$ $\begin{array}{lllllllllll}3750 & 3048 & 3049 & 3050 & 3051 & 3052 & 3053 & 3054 & 3055\end{array}$ $\begin{array}{lllllllllll}5760 & 3056 & 3057 & 3058 & 3059 & 3060 & 3051 & 305 \% & 3063\end{array}$ $\begin{array}{llllllllll}5770 & 3064 & 3083 & 3068 & 3067 & 3068 & 3069 & 3070 & 3071\end{array}$ 


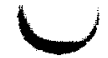

$-$

\begin{tabular}{|c|c|c|c|c|c|c|c|c|}
\hline & 0 & 1 & $z$ & 3 & & & & \\
\hline 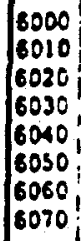 & $\begin{array}{l}3072 \\
3080 \\
3088 \\
3096 \\
3108 \\
3112 \\
3120 \\
3128\end{array}$ & $\begin{array}{l}x \\
x \\
30 \\
x \\
31 \\
31 \\
31 \\
31\end{array}$ & 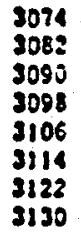 & & & $\begin{array}{l}30 \\
31 \\
31 \\
31 \\
31 \\
31\end{array}$ & & 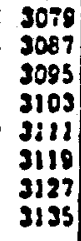 \\
\hline & & $\begin{array}{l}3137 \\
3145 \\
3153 \\
3161 \\
3169 \\
3177 \\
3185 \\
3193\end{array}$ & & $\begin{array}{l}3139 \\
3147 \\
3155 \\
3163 \\
3171 \\
3179 \\
3187 \\
3105\end{array}$ & & & $\begin{array}{l}3138 \\
3166 \\
3174 \\
3182 \\
3180 \\
3198\end{array}$ & $\begin{array}{l}3 \\
3 ! \\
3 ! \\
3 ! \\
3 !\end{array}$ \\
\hline 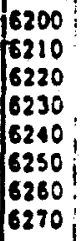 & 32 & $\begin{array}{l}3 \\
3 \\
3\end{array}$ & & $\begin{array}{l}32 \\
32 \\
32 \\
32 \\
32 \\
32 \\
32 \\
32\end{array}$ & $\begin{array}{l}2 \\
0 \\
8 \\
6 \\
1 \\
2 \\
0\end{array}$ & $\begin{array}{l}3 \\
3 \\
3 \\
3 \\
3\end{array}$ & $\begin{array}{l}2 \\
0 \\
8 \\
6 \\
4\end{array}$ & \\
\hline & $\begin{array}{l}32 \\
32 \\
33\end{array}$ & $\begin{array}{l}3273 \\
3281 \\
3289 \\
3297 \\
3305 \\
3313\end{array}$ & $\begin{array}{l}32 \\
32 \\
32 \\
33\end{array}$ & $\begin{array}{l}3 \\
3 \\
3 \\
3\end{array}$ & $\begin{array}{l}6 \\
1 \\
2 \\
0 \\
8\end{array}$ & $\begin{array}{l}3277 \\
3283 \\
3293 \\
3301 \\
3309\end{array}$ & $\begin{array}{l}6 \\
14 \\
0 \\
0\end{array}$ & $\begin{array}{l}331 \\
332\end{array}$ \\
\hline
\end{tabular}

$\begin{array}{llllllll}0 & 1 & 2 & 3 & 4 & 5 & 6 & 7\end{array}$

$7000 \quad 3584 \quad 3585 \quad 3586 \quad 3587 \quad 3588 \quad 35892390 \quad 3592$ 7010 3592 $3593 \quad 3594 \quad 35953598 \quad 359733983599$ 7020 3600 $3601 \quad 3602 \quad 3603 \quad 3694 \quad 3605$ 3606 3607 $\begin{array}{llllllllll}7030 & 3608 & 3609 & 3610 & 3611 & 3612 & 3613 & 3614 & 3615\end{array}$ $\begin{array}{llllllllll}7040 ! & 3616 & 3617 & 3518 & 3610 & 3620 & 3621 & 3622 & 3623\end{array}$ $7050 \quad 362436253626 \quad 3627 \quad 3628 \quad 3629 \quad 3630 \quad 3631$ $\begin{array}{lllllllllll}7060 & 3632 & 3633 & 3634 & 3635 & 3636 & 3637 & 3638 & 3639\end{array}$ 707036403641364236433644364536463647 $7100 \quad 3648 \quad 36493650 \quad 3651 \quad 3652 \quad 3653 \quad 36543655$ $\begin{array}{llllllllll}7310 & 3656 & 3657 & 3658 & 3650 & 3650 & 3661 & 3662 & 3663\end{array}$ $7120 \quad 3664366536663667365836693670 \quad 3671$ $71130 \quad 36723673 \quad 36743673 \quad 3676367936782678$ 7140 3680 3681 3E82 $3683 \quad 3684368536863687$ 7130 3688 $36893690 \quad 3691 \quad 3692 \quad 3693 \quad 36943693$ $\begin{array}{llllllllll}7160 & 3698 & 3697 & 3698 & 3699 & 3700 & 3701 & 3702 & 3703\end{array}$ 717037043705370637073708370937103711

720037123713371437159716371737183710 $\begin{array}{llllllllll}7210 & 3720 & 3721 & 3722 & 3723 & 3724 & 3725 & 3726 & 3727\end{array}$ $7220 \quad 3720 \quad 372937303731 \quad 3732 \quad 3733 \quad 3734$ 3735

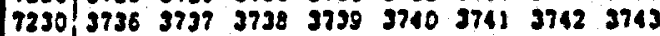

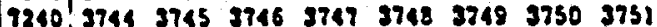
$7250 \mid 3732 \quad 3753 \quad 3754 \quad 3753 \quad 3756 \quad 373737583750$ 7260 3780 $3761 \quad 3762 \quad 3763 \quad 3764 \quad 3765 \quad 3766 \quad 3767$ 7270 ग88 $37693770 \quad 37713772 \quad 377337743775$ ๆ300 37763777377837793780978137823783 7310 3784 $378337863787378837893740 \quad 3701$ 73203792379337943705370637473798 . 3799 $7330 \quad 3800 \quad 3801 \quad 3802 \quad 3803 \quad 3804 \quad 3805 \quad 3806 \quad 3807$ 7340 $380838093810 \quad 3811 \quad 3812 \quad 3813 \quad 3814 \quad 3813$ 7359 3816 $38193818 \quad 3818 \quad 3820 \quad 3821 \quad 3822 \quad 3823$ $\begin{array}{lllllllll}2360 & 3824 & 3825 & 3826 & 3827 & 3828 & 9820 & 3830 & 3891\end{array}$ $\begin{array}{lllllllll}7370 & 3832 & 3833 & 3834 & 3835 & 3836 & 3837 & 3838 & 3839\end{array}$

\section{$\begin{array}{llllllll}0 & 1 & 2 & 3 & 4 & 5 & 6 & 7\end{array}$}

$6400 \quad 3328233283330 \quad 3331333233335334 \quad 3335$ $\begin{array}{llllllllll}6410 & 3336 & 3337 & 3338 & 3339 & 3340 & 3341 & 3342 & 3349\end{array}$ $6420 \quad 3344334533463347334833493350 \quad 3344$ 6430 3332 335333543353335633573358 3359 $6440 \quad 3360 \quad 336133623363 \quad 336433653366 \quad 3367$ 6450 3368 $33693370 \quad 3371 \quad 3372 \quad 3373 \quad 3374 \quad 3375$ 6460 3376 $337733743378338033813382 \quad 3383$ 6440 3984 $33853386 \quad 3387338833893390 \quad 3391$

6500 3392 $3393339433953396 \quad 3397 \quad 33983399$ $6510,3400 \quad 34013402 \quad 34033404340534063407$ $6520 ; 34083409341034113412341334163415$ $6536 \quad 3416 \quad 3417341834193420 \quad 34213422 \quad 3423$ $\begin{array}{lllllllll}6540 & 3424 & 3425 & 3426 & 3427 & 3428 & 3429 & 3430 & 3431\end{array}$ $6550 \quad 34323433 \quad 3434 \quad 3435 \quad 343634373436 \quad 3439$ $6560^{\circ} 3440 \quad 344134423443 \quad 34443443 \quad 3446 \quad 3447$ $6570: 34483419345034513452345334543455$ $\begin{array}{lllllllll}6600 & 3456 & 3457 & 3458 & 3458 & 9460 & 3461 & 3462 & 3463\end{array}$ 6610 3464 $34653466 \quad 3467 \quad 346834893470 \quad 3471$ $6620 \quad 3472 \quad 347334743473 \quad 347634779478 \quad 3479$ 6630 j480 $348134823483 \quad 348434853486 \quad 3487$ 6640 : $348834893490 \quad 3493 \quad 3492 \quad 3493 \quad 3494 \quad 3495$ $6650 \quad 3496349734983485350033013502 \quad 3503$ 6660 3504 3505350635073508350935103511 6670 3512 3513 3514 3515 3516 3517 3518 3510 $6700 \quad 3520 \quad 3521 \quad 3522 \quad 3523 \quad 3324 \quad 35253526 \quad 3527$ $\begin{array}{llllllllll}6710 & 3528 & 3529 & 3530 & 3531 & 3532 & 35.33 & 3534 & 3535\end{array}$ 6730 ! 3536 $3537 \quad 3538 \quad 3539 \quad 3540 \quad 3541 \quad 3542 \quad 3543$ 6730 J544 $3545 \quad 3546 \quad 3547 \quad 3548 \quad 3549 \quad 3550 \quad 3551$ 6740 3552 $3553 \quad 355435553556 \quad 3557 \quad 3538 \quad 3559$ 6750 3560 $3561 \quad 3562 \quad 3563 \quad 3564 \quad 3563 \quad 3566 \quad 3567$ $\begin{array}{lllllllll}6760 & 3568 & 3369 & 3570 & 3571 & 3572 & 3573 & 3574 & 3575\end{array}$ $6770 \mid \begin{array}{llllllll}3576 & 3577 & 3578 & 3579 & 3580 & 3581 & 3582 & 3583\end{array}$

\section{$\begin{array}{llllllll}0 & 1 & 2 & 3 & 4 & 5 & 6\end{array}$}

$7400 \quad 3840 \quad 3841 \quad 38423843 \quad 3844 \quad 38453846 \quad 3847$. \begin{tabular}{ll|lllllll}
7410 & 3848 & 2849 & 3850 & 3851 & 3852 & 3853 & 3854 & 3855
\end{tabular} 7420 3856 $385738583850386038513862 \quad 3863$ 7430 |3854 $3865 \quad 3866 \quad 3867 \quad 3868 \quad 3869 \quad 3870 \quad 3871$ 7440 3872 $3873 \quad 3874 \quad 3875 \quad 3876 \quad 3877 \quad 3876 \quad 3870$ $\begin{array}{llllllllll}7450 & 3880 & 3881 & 3882 & 3883 & 3884 & 3885 & 3886 & 3887\end{array}$ \begin{tabular}{ll|lllllll}
7460 & 3886 & 9888 & 3890 & 3821 & 3892 & 3893 & 3894 & 3895
\end{tabular} $7470 \quad 3896 \quad 389738983899390039013902 \quad 3903$

$1300 \quad 39042905390639073908390039103911$ $7310 \quad 3912 \quad 3913 \quad 391439153916 \quad 391739183910$ $\begin{array}{lllllllll}7520 & 3920 & 3921 & 3922 & 3923 & 9924 & 3925 & 3926 & 3927\end{array}$

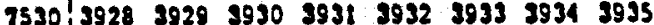

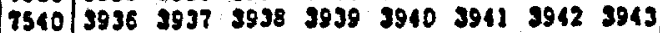
7530 3944 $39453946 \quad 3947 \quad 3948 \quad 3949 \quad 3950 \quad 3951$ $7560 \quad 3952 \quad 3953395639333936393739583959$

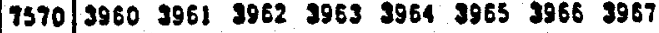
$1600 \quad 39689968997099719972.397399743975$ $\begin{array}{lllllllllll}7610 & 3976 & 3977 & 3978 & 3979 & 3980 & 3981 & 3982 & 3983\end{array}$ $7620 \quad 3984 \quad 2983 \quad 39863987 \quad 3988398939903991$ $7630 \quad 3992 \quad 3993 \quad 399439953936399739983999$ $\begin{array}{lllllllll}7640 & 4000 & 1001 & 4002 & 4003 & 4004 & 4003 & 4006 & 4007\end{array}$ $7630 \quad 1008 \quad 1009 \quad 4010 \quad 4011 \quad 4012 \quad 4013 \quad 4011 \quad 4015$ $\begin{array}{llllllllll}7660 & 4016 & 4017 & 1018 & 4019 & 4020 & 4021 & 1022 & 4023\end{array}$ $\begin{array}{lllllllll}7670 & 1024 & 1023 & 1026 & 4027 & 4028 & 1029 & 1030 & 4031\end{array}$

$\begin{array}{llllllll}7700 & 4032 \quad 4033 \quad 4034 & 4035 & 4036 & 4037 \quad 4038 & 4039\end{array}$

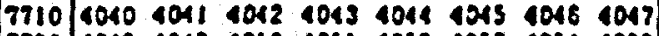
$7720 \quad 1042 \quad 4049 \quad 4050 \quad 4051 \quad 1052 \quad 1053 \quad 4051$ coss $\begin{array}{llllllllllll}7730 & 1056 & 4057 & 1058 & 1058 & 4050 & 1061 & 4062 & 1053\end{array}$ $7740 \quad 1064 \quad 1065 \quad 10654057 \quad 1058106940704071$ $7730 \quad 1072 \quad 4073 \quad 4694$ 4075 $4776 \quad 4077 \quad 4071 \quad 4079$ \begin{tabular}{ll|lllllll}
7760 & 1080 & 4081 & 1082 & 1083 & 4084 & 4083 & 1086 & 1087
\end{tabular} $\begin{array}{lllllllll}7770 & 4088 & 4089 & 4090 & 1081 & 1092 & 4083 & 4094 & 4023\end{array}$ \begin{tabular}{c|c}
6000 & 2072 \\
10 & 10 \\
6777 & 3383 \\
(Octol) & (Detimoll
\end{tabular}

Octal Decimal

$10000 \cdot 1096$

$20000 \cdot 8192$

$30000 \cdot 12288$

$10000 \cdot 16384$

$50000 \cdot 20480$

60003.24576

$70000 \cdot 28672$

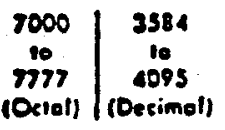


APPENDIX B

REPORT ON TEST FOR $\frac{1}{2} "$ TUBE

(IUBE LINE) 


\section{REPORT ON TEST FOR 1/2" TUBE}

(LUBE LINE)

"PURPOSE":

To determine the strength and endurance of stainless steel tube 1/2"

outside diameter and 0.035 wall thickness through tension and bending.

"APPARATUS":

Flat bar $1 / 2^{\prime \prime} \times 21 / 2^{\prime \prime} \times 4^{\prime}-9^{\prime \prime}$ long bent to $3^{\prime}-0^{\prime \prime}$ radius. Frame to attach bent flat bar. 1/2" sch 80 pipe used as tube sleeve at each end of the tube. 1/2" stainless steel tube; five steel discs each weighting 219.84 lbs, (total 1099.2 lbs.).

\section{DESCRIPTION:}

A piece of 12'-0" long 1/2" stainless steel tube was hung to the top of the bent flat bar by means of steel plate and top sleeve. The bottom sleeve was then welded and a hook type assembly was also welded to the bottom sleeve. The weight of the five steel discs was then hung from the hook attached to the bottom sleeve. In the first phase of the experiment only one bent flat bar was used. Swinging of the hung weight was made unt il the tube made a $15^{\circ}$ angle with the vertical and an elapse time of 12 minutes passed, then the weight was stopped and measures of the tube were made, this was done twice for the first phase of the tube. (See Fig. 1.)

For the second phase of the experiment a second flat bar was added opposite to the first one (Fig. II). The weight was swung so the tube could make the same 150 angle with the vertical. Weight was stopped at five minutes intervals and measures were taken up to an elapsed time of 30 minutes. Three marks were made in the tube: $A, B, C$, (See Fig. III for location). 


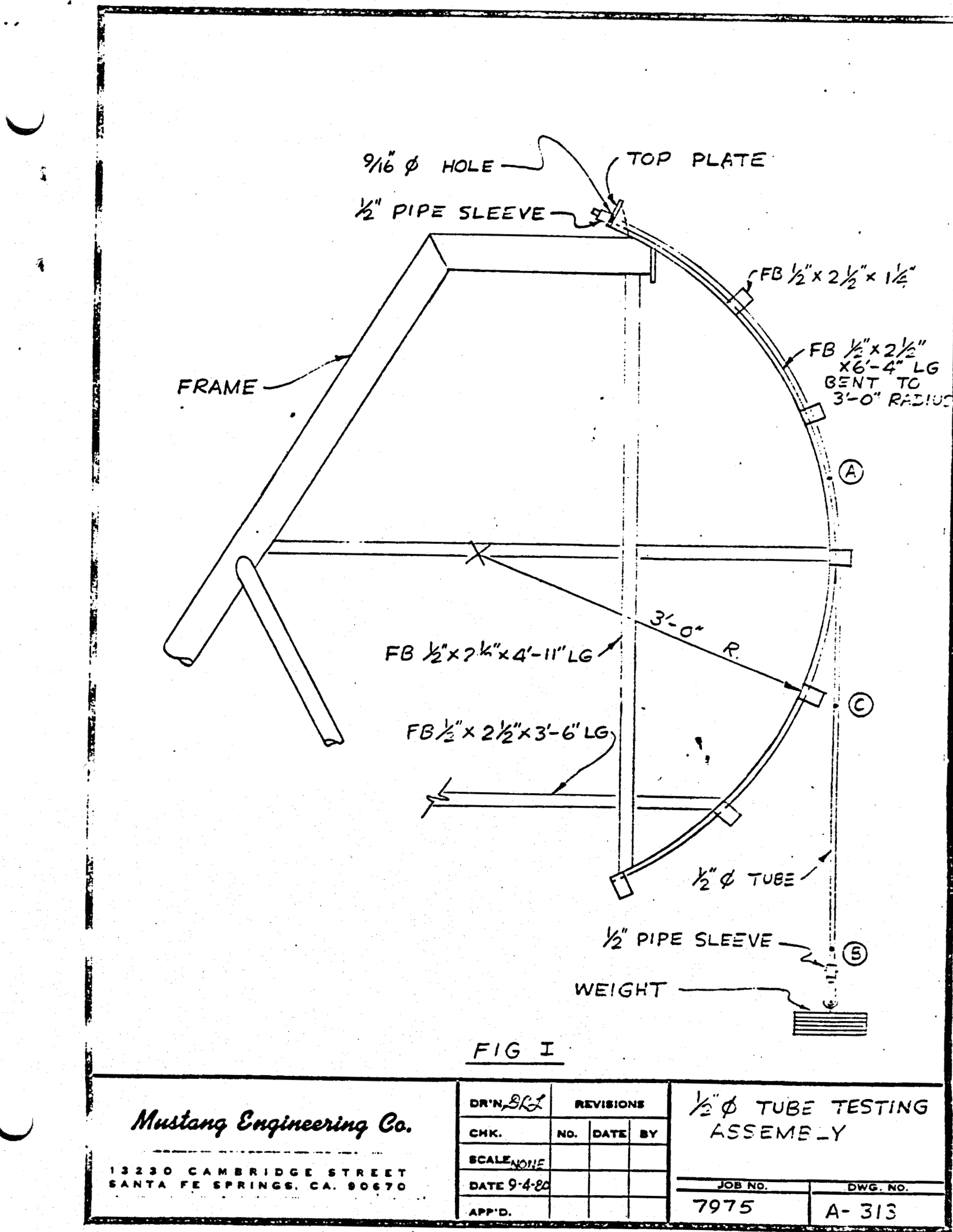


$F B \frac{1}{2} \times 2 \frac{1}{2} \times 2-0^{\prime \prime} L E$ 


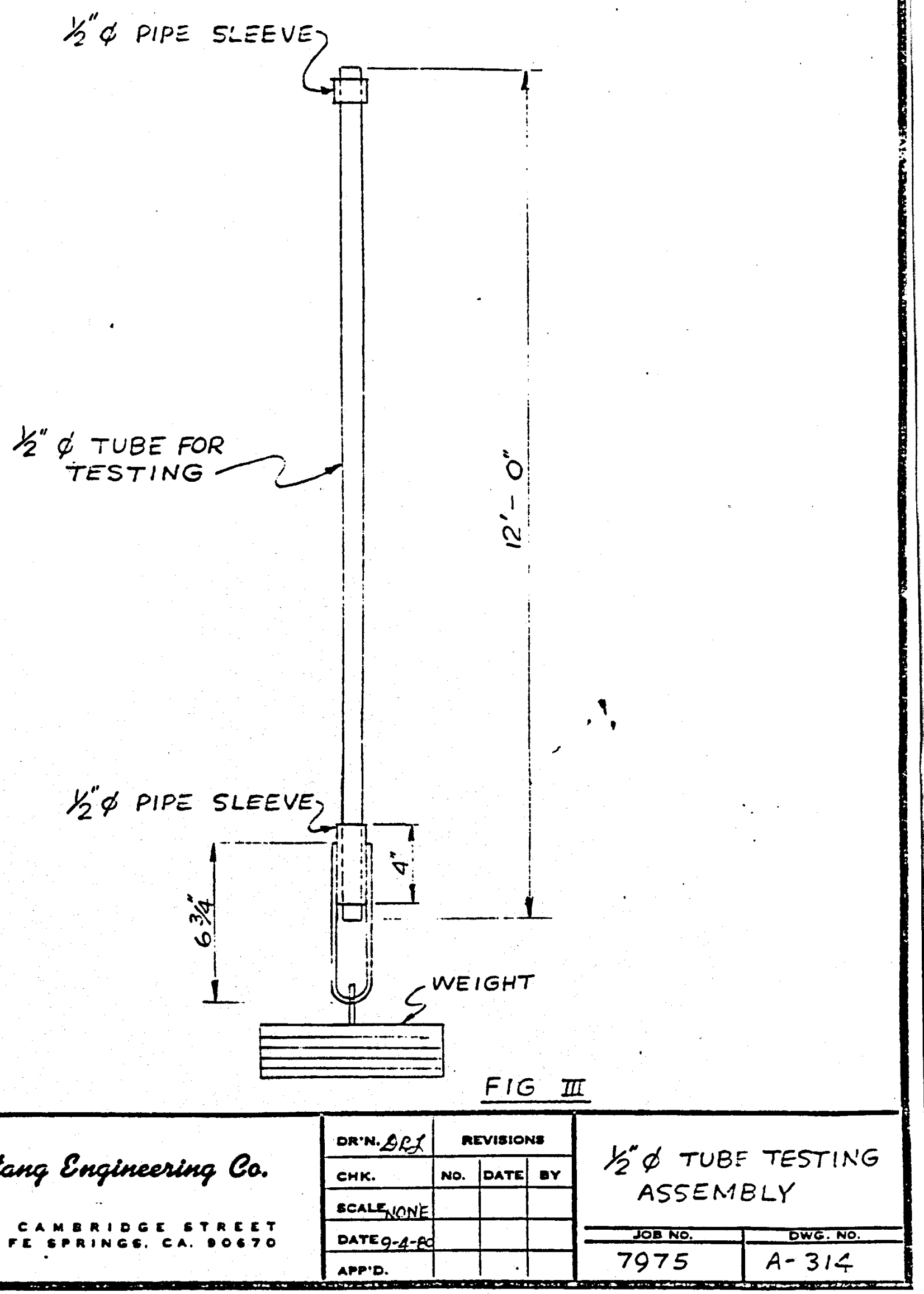


1/2" TUBE TEST

TEST DATA

\begin{tabular}{|c|c|c|c|c|c|c|c|c|}
\hline DATE & $\begin{array}{l}\text { BEGINNING } \\
\text { DIA./IN. }\end{array}$ & $\begin{array}{l}\text { TIME } \\
\text { ELAPSED } \\
\text { IN MIN. }\end{array}$ & $\begin{array}{l}\text { CYCLES } \\
\text { PASSED } \\
\end{array}$ & $\begin{array}{l}\text { TUBE LG. } \\
\text { IN IN. }\end{array}$ & $\begin{array}{l}\text { DIA. A } \\
\text { IN IN. }\end{array}$ & $\begin{array}{l}\text { DIA. B } \\
\text { IN IN. }\end{array}$ & $\begin{array}{l}\text { DIA. C } \\
\text { IN IN. }\end{array}$ & REMARKS \\
\hline $8 / 25 / 80$ & 0.507 & 0 & $\mathbf{0}$ & 43.25 & $0.57 A$ & 0.57 & 0.57 & Only one bent bar (See Fig. 1) \\
\hline $8 / 25 / 80$ & 0.507 & 12 & 325 & 43.50 & $0.501 \mathrm{~A}$ & 0.5015 & 0.5020 & \\
\hline $8 / 25 / 80$ & 0.507 & 10 & 255 & 43.937 & $0.501 A$ & 0.5015 & 0.5020 & Test stopped \\
\hline $8 / 26 / 80$ & 0.507 & 5 & 145 & 44.687 & $0.499 A$ & 0.501 & 0.5015 & \\
\hline $8 / 26 / 80$ & 0.507 & 5 & 145 & 44.875 & $0.496 A$ & 0.501 & 0.5015 & See Fig. II Dble bent bar used \\
\hline $8 / 26 / 80$ & 0.507 & 5 & 145 & 45.0 & $\begin{array}{l}0.425 A^{\circ} \\
0.496 A\end{array}$ & 0.501 & 0.5015 & $\begin{array}{l}\text { Dim A is } 90^{\circ} \text { to other A dia. } \\
\text { measured }\end{array}$ \\
\hline $8 / 26 / 80$ & 0.507 & 5 & 145 & 45.0625 & $\begin{array}{l}0.415 A^{\prime} \\
0.490 A\end{array}$ & 0.501 & 0.5015 & \\
\hline $8 / 26 / 80$ & 0.507 & 5 & 145 & $\begin{array}{r}45.125 \\
1 \\
\end{array}$ & $\begin{array}{l}0.411 A^{\prime} \\
0.501 A^{\prime}\end{array}$ & 0.501 & 0.5015 & $\cdot$ \\
\hline & TOTAL & 52 & 1450 & $1.875^{\circ}$ & 0.096 & 0.006 & 0.005 & \\
\hline
\end{tabular}


SAMPLE CALCULATION

Stress in tube $=\frac{P}{A}+\frac{M}{Z}$

I

But $\frac{P}{A}=\sigma_{T}$ and $\sigma_{T}=\frac{L \times E}{L}=\frac{P}{A}$

+ Test of $B / 25 / 80$ :

$$
=\frac{\left(0.25^{\prime \prime}\right) \times 29 \times 106 \text { lbs. }}{138}=52,536 \mathrm{psi}
$$

For $\frac{M}{\Sigma}$ see conclusions and results 
TABULAR SUMMARY

\begin{tabular}{|c|c|c|c|c|c|c|c|}
\hline DATE & $\begin{array}{l}\text { TIME } \\
\text { ELAPSED } \\
\text { IN MIN. }\end{array}$ & $\begin{array}{l}\text { BEGINNING } \\
\text { LG/INCHES }\end{array}$ & $\begin{array}{l}\text { ENDING LG } \\
\text { IN INCHES }\end{array}$ & $\begin{array}{l}\text { ELONGATION } \\
\text { IN INCHES }\end{array}$ & $\begin{array}{l}\text { MODULUS OF } \\
\text { ELASTICITY }\end{array}$ & $\begin{array}{l}\text { STRESS IN } \\
\text { TUBE /PSI }\end{array}$ & REMARKS \\
\hline $8 / 25 / 80$ & 0 & 138.250 & 138.250 & 0 & $29 \times 10^{6}$ & 21,515 & Using one bent bar only \\
\hline $8 / 25 / 80$ & 12 & 138.250 & 138.500 & 0.250 & $29 \times 10^{6}$ & 52,536 & See conclusions \& results \\
\hline $8 / 25 / 80$ & 10 & 138.500 & 138.937 & 0.437 & $29 \times 10^{6}$ & 91,833 & \\
\hline $8 / 26 / 80$ & 5 & 138.937 & 139.687 & 0.750 & $29 \times 10^{6}$ & 157,609 & Oble bent bar \\
\hline $8 / 26 / 80$ & 5 & 139.687 & 139.875 & 0.188 & $29 \times 10^{6}$ & 39,507 & See conclusions \& results \\
\hline $8 / 26 / 80$ & 5 & 139.875 & 140.000 & 0.125 & $29 \times 10^{6}$ & 26,268 & \\
\hline $8 / 26 / 80$ & 5 & 140.000 & 140.0625 & 0.0625 & $29 \times 10^{6}$ & 13,134 & \\
\hline $8 / 26 / 80$ & 5 & 140.0625 & 140.0625 & 0.0625 & $29 \times 10^{6}$ & - & \\
\hline $8 / 26 / 80$ & 5 & 140.0625 & 140.125 & 0.0625 & $29 \times 10^{6}$ & 13,134 & \\
\hline
\end{tabular}




\section{DONCLUSIONS \& RESULTS}

The test was not conducted under the most strict method. Therefore there is a

- large margin for error.

The stress calculated in the tabular sumnary is the tensile stress of tube after some bending was applied to the tube. But the exact bending stress can not be calculated since the force applied to the weight hung was not a constant force and the angle the tube made with the vertical was not always fifteen degrees. The acceleration of the weight was not a constant one since impulse took a big factor, because the weight was pushed with an uneven force.

If the purpose of the test has been to calculate the bending moment, it would had been a complete failure, even though a more sophisticated mechanism could be used if this were the case.

The purpose of the test was to find the stress and endurance of the $1 / 2^{\prime \prime}$ tube, and these were accomplished with certain accuracy. Since the stress shown in the tabular data shows the effect of bending after it has been applied.

Flattening of the tube occurred in the direction of motion of the weight. Bending in this test was ocurring at the same location in the tube, therefore diminishing the strength of the tube. It can be seen that the endurance limit of the tube was never reached and after 52 minutes and approximately 1450 cycles the tube was still holding and no cracks had occurred in the tube.

In actuality, bending will occur all throughout the length and rotated directions of the tube and not at a specific spot as happened during the test.

The test indicated the tube selection is adequate if the injection and retrieval apparatus subjects the tube to no more sever forces.

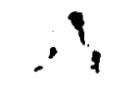




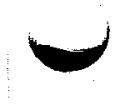

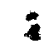

APPENDIX C

REPORT ON PRESSURE/TEMPERATURE TEST OF STABBING FIXTURE SEALS 


\section{REPORT ON \\ PRESSURE/TEMPERATURE TEST OF \\ STABBING FIXTURE SEALS}

The seal teist was dịvided in two parts:

a) Pressurizing with water at amblent temperatures

The first tests showed a failure of the backep rings. This appeared to be due to the insufficlent weight on the stabbing fixture. Pressures over 1400 psi pushed the stabbing fixture up until liquid was escaping which decreased the pressure. This resulted in dropping of the stabbing fixture which sheared the backup rings. After securing the stabbing fixture with a U-bolt test pressures up to 2200 psi were reached, without fallure or detectable leak.

b) Pressurizing with oil at elevated temperatures

For this test the stabbing fixture was filled with light motor oil. By means of a Chromalox bandheater and temperature controller the temperature at the lower part of the stabbing fixture was raised up to $410^{\circ} \mathrm{F}$. During heating up the pressure was kept between 1200 and 1500 psi. Because of heat loss through the test stand this resulted in a seal temperatures of $290-310^{\circ} \mathrm{F}$. When the temperature stabilized, the pressure was ralsed to 1600-1800 DSI and occasionally up to 2000 pSi.

This test was done three times in three consecutive days. At the end of the test a small leak was detected at the $21 / 2^{\prime \prime} 0$-rings. Because of their close proximity to the bandheater the viton 0-rings were damaged. The local temperature must have been well over $410^{\circ} \mathrm{F}$. No visible leak was detected at the $1 / 2^{\text {nt }}$ stabbing fixture seals. 
When the stabbing fixture was taken apart it appeared that the two lower backup seals were damaged. Out of experience from the previous tests our conclusion is that this danage was caused by partially lifting the stabbing fixture at pressures over 1800 psi or shearing the backup rings when Inserting the stabber.

\section{CONCLUSIONS AND RECOMMENDATIONS}

The stabbing fixture seals are capable of holding pressures up to 1800 psi at temperature to at least $310^{\circ} \mathrm{F}$. The usual operating temperature will be around $170^{\circ}$.

It seems advisable to increase the $2^{\prime} 1 / 2^{\prime \prime} \infty, 1^{n}$ ID weight tube to prevent problems as encountered in the test stand. We increased the weight to 550: (4D') which should prevent lifting the weight up to 1900 psi. This will help prevent any seal damage, if any pressure surges occur.

It appears also to be very important that after stretching the backup Iings over the stabber on the o-ring they are forced back to their original dimensions in order to avold shearing the backup rings when inserting the stabber. A final check on this before lowering the $1 / 2^{\prime \prime}$ - tube with the stabbing fixture in the well is recomended. 


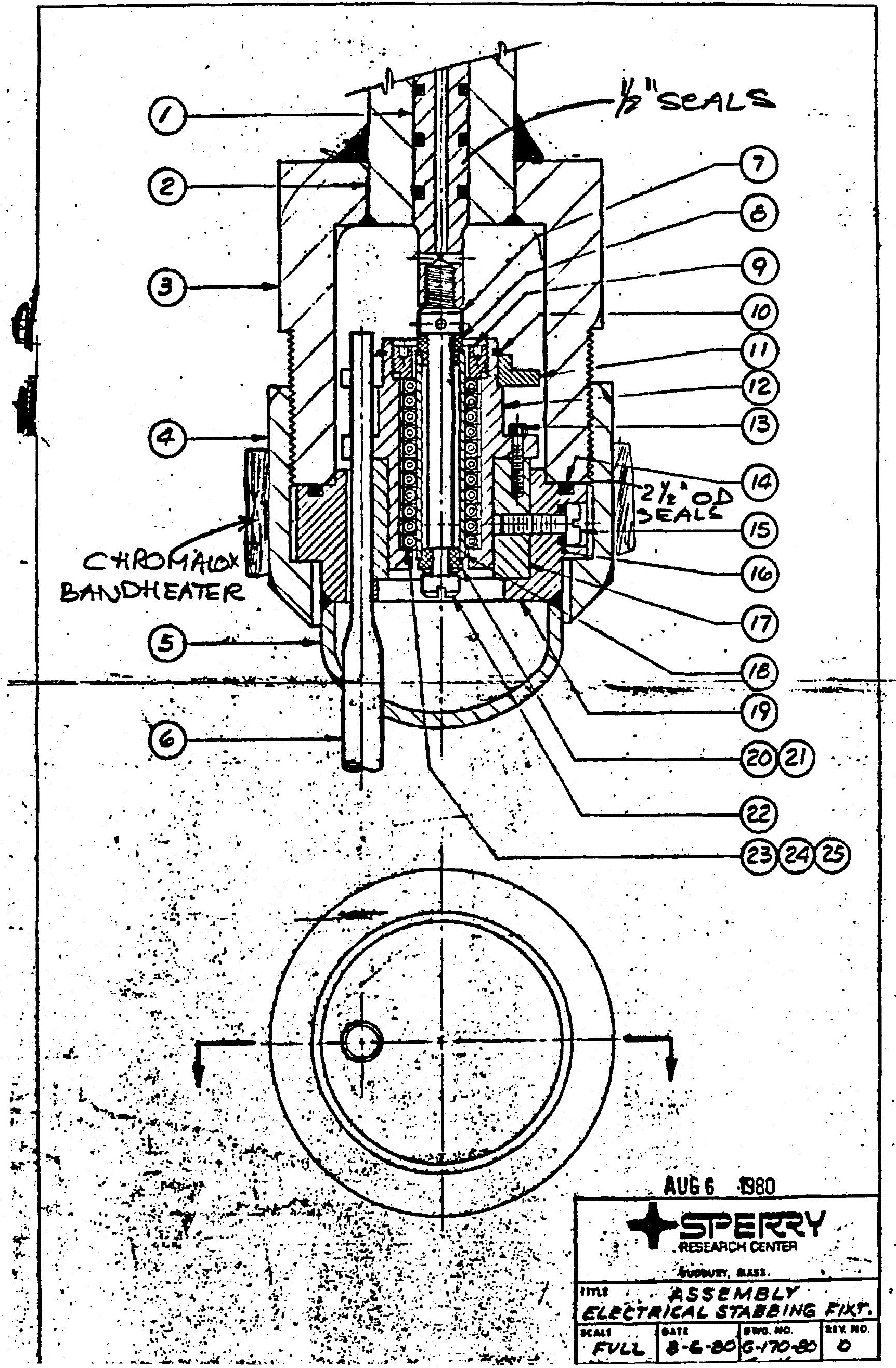


$-$

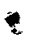

\section{DESIGN AND PREDICTED PERFORMANCE OF SPERRY STAND-ALONE TURBOPUMP UNIT}


$\smile$

DFSIGN AND PREDICTED PERFORMANCE OF SPERRY STAND-ALONE TURBCPUMP UNIT

November, 1979 
TABLE OF CONTENTS

PAGE

1.0 INTRODUCTION 1

2.0 DESIGN CRITERIA 1

3.0 DESIGN AND PERFORMANCE ANALYSIS 1

3.1 PUMP 1

3.2 TURBINE 11

$\begin{array}{lll}4.0 & \text { BEARING SELECTION } & 12\end{array}$

5.0 MECHANICAL DESIGN 18

$\begin{array}{lll}5.1 & \text { LUBRICATION SYSTEM } & 18\end{array}$

5.2 CRITICAL SPEEDS

5.3 SEALS 25

5.3.1 Static Seals $\quad 25$

5.3.2 Dynamic Seals 29

5.4 MATERLALS 29

5.5 STRESS ANALYSIS 29

5.5.1 TPU Loads 29

5.5 .2 Shaft $\quad 29$

5.5.3 Turbine Rotor 33

5.5.4 Pipe String Load on TPU 33

5.5.5 Fasteners $\quad 34$

5.5.6 Main Flange $\quad 35$

REFERENCES 


\section{TABLES}

PAGE

Table I

TPU Design Criteria

Table II Pump Characteristics

Table III

Turbine Characteristics

7

Table IV

Ball Bearing Specifications

Table V Minimum Properties

Table VII TPU Loads

\section{FIGURES}

Figure 1 Pressure Profile in Well 3

Figure 2 Pump Performance 4

Figure $3 \quad$ Pump Head Coefficients Versus Flow 5

$\begin{array}{lll}\text { Figure } 4 & \text { Turbine Performance } & 8\end{array}$

Figure 5 Turbine Efficiency Versus Velocity Ratio 9

Figure $6 \quad$ R-114 Flow Rate vs Turbine Inlet Pressure 10

Figure $7 \quad$ Turbine Power vs Inlet Pressure and Condensing Temperature

Figure $8 \quad$ Performance of Baltimore Air Coil Evaporative Condenser

Figure $9 \quad$ Turbine Performance vs Ambient Wet Bulb Temperature

Figure 10 Turbine Performance vs Ambient Wet Bulb Temperature

Figure 11 Wet Bulb Temps at El Centro, California 


\section{FIGURES (Cont'd.)}

\section{PAGE}

Figure 13 Comparison of Lifetimes for 212 and 310 Ball Bearings

- Figure 14 TPU Oil Viscosity 21

Figure $15 \quad$ Bearing Life Factor vs Temperature 22

Figure 16 Maximum Heat Load to TPU Oil Cooler 26

Figure $17 \quad$ Critical Speed GOP Turbo-Pump-Unit 27

Figure 18 GOP Turbo Pump Unit Third Order Critical Speed $\quad 28$

$\begin{array}{lll}\text { Figure } 19 & \text { TPU Load Diagram } & 31\end{array}$ 


\subsection{INTRODUCTION}

- This document summarizes the Barber-Nichols Engineering design of the turbopump unit (TPU) for the Sperry stand-alone pump system. The subjects discussed include system design criteria, pump and turbine performance analysis, bearing selection, and the major aspects of mechanical design.

\subsection{DESIGN CRITERIA}

The basic TPU design criteria are given in Table $I$. The nominal values of well productivity index (PI) and brine temperature are those estimated for the test well; however, the TPU was designed to pump at least 1000 gpm over as wide a range of well conditions as possible.

The TPU frame size of $141 / 2$ inches is compatible with a standard 16-inch well casing. Although this constraint has been met, it is not firm because future wells will probably be at least 24 inches in diameter.

Figure 1 shows the estimated brine pressure profile in the well for design flow conditions, and for maximum pressure conditions when the pump is momentarily dead-headed at design power. The relationships defining the pressures are also given.

The reference wellhead pressure $P$ who for a hot, non-flowing, unpumped well is assumed to be 130 psig; the desired flowing wellhead pressure Pwh is 175 psig. For a setting depth h of $2180 \mathrm{ft}$, an average brine density $\rho$ of $56.1 \mathrm{lb} / \mathrm{ft}^{3}$, and a friction drop $\Delta \mathrm{P}_{\mathrm{f}}$ of $25 \mathrm{psi}$, the sum of the wellhead pressure and $\Delta P_{1}$ (see equations on Figure 1) determines the pump outlet pressure of 1050 psig for the design flow condition. The pump design pressure rise $\Delta \mathrm{P}_{\mathrm{d}}$ is the sum of the drawdown for $1050 \mathrm{gpm}$ and a PI of 1.89, the additional desired wellhead pressure of $45 \mathrm{psi}$, and $\Delta \mathrm{P}_{\mathrm{f}}$. Thus $P_{d}$ is $625 \mathrm{psi}$, or $1600 \mathrm{ft}$ of head. The pump inlet pressure is consequently 425 psig (the NPSH is 300 psia).

The pump inlet pressure $P_{3}$ for the deadhead condition is the sum of the nonflowing wellhead pressure and the gravity head. The deadhead pressure rise $\Delta \mathrm{P}_{\mathrm{dh}}$ is $27 \%$ higher than the design pressure rise, resulting in 1775 psig at the pump outlet and 925 psig at the wellhead.

The above considerations formed the basis for proceeding with the pump and turbine design.

\section{0 DESIGN AN D PERFORMLANCE ANALYSIS}

3.1 PUMP 
2

TABLE I

PU DESIGN CRITERIA

- Nominal Brine Flow Rate

Brine Temperature

Working Fluid

Maximum Diameter

Setting Depth

Well Productivity Index

Minimum Wellhead Pressure

Nominal Ambient Wet Bulb Temperature

Maximize Overall Efficiency:

- Pump Goal

- Turbine Goal
$1000 \mathrm{gpm}$

$340-350^{\circ} \mathrm{F}$

$R-114$

$141 / 2$ in.

$2180 \mathrm{ft}$.

$1.9 \mathrm{gpm} / \mathrm{psi}$

175 psi

$75^{\circ} \mathrm{F}$

$75 \%$

$70 \%$

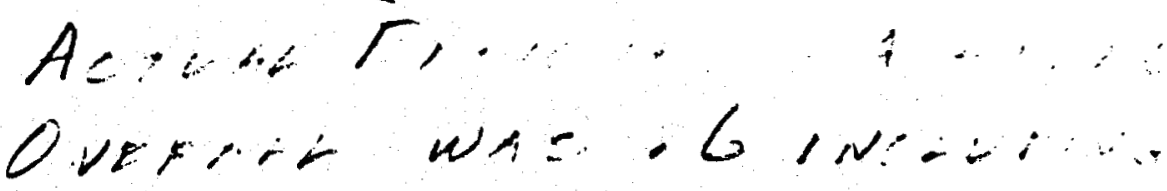
BEANOS LESS, 


\begin{tabular}{|c|c|c|c|c|}
\hline \multirow{2}{*}{$\begin{array}{l}\text { BARBER.NICHOLS } \\
\text { ENGINEERING CO. }\end{array}$} & \multicolumn{2}{|c|}{$\begin{array}{l}\text { PROUECT } \\
\text { GOP }\end{array}$} & \multicolumn{2}{|c|}{$\begin{array}{l}\text { SULUECT } \\
\text { PRESSURE PROFILE }\end{array}$} \\
\hline & $\overline{8 r}$ & $\begin{array}{l}\text { DATE } \\
11-7-79\end{array}$ & IN WELL & \\
\hline
\end{tabular}

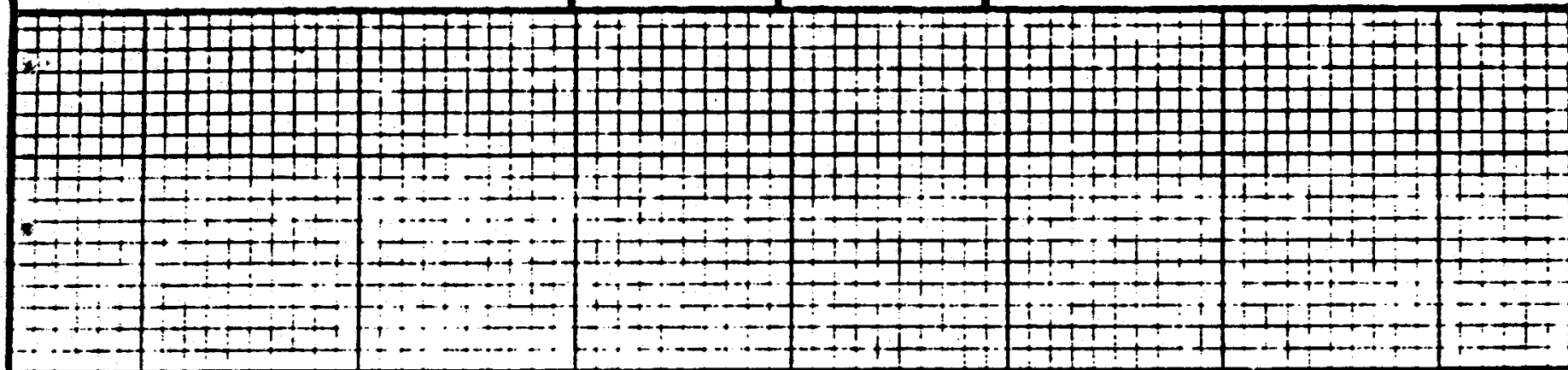

DEADHEAD CONDITION

\begin{tabular}{|c|c|c|c|c|c|c|c|c|c|}
\hline$\because D E$ & AD HEAD:- & EONDITION & & \multicolumn{2}{|c|}{$\because I-D E S$} & \multirow{2}{*}{ GN FLOW } & CONDITId \\
\hline & & $\cdots: \cdots: \therefore$ & & $\therefore 7$ & & & 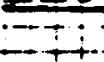 & & \\
\hline & & $1+$ & & $E L C R$ & & 5 & & $\mathrm{Fin}$ & 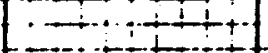 \\
\hline & $925=516$ & 9 & 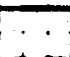 & 5 & 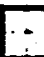 & $-1 T$ & - & $-1=$ & 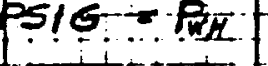 \\
\hline & un & $\because$ & & $\cdots$ & & - & $\cdots$ & - & ... \\
\hline & $\ldots$ & $\therefore$ & & -.+. & & 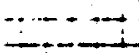 & $i_{1}$ & 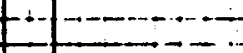 & $-1-1$ \\
\hline & & & & $\ldots \ldots$ & & & $\cdots$ & $\therefore=$ & \\
\hline & $\cdots$ & $:$ & $\therefore$ & $\cdots$ & & $\ldots=$ & $=$ & $\Delta P_{1}=875$ & PSE \\
\hline & & & & & & & & & 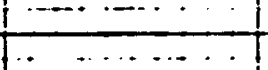 \\
\hline
\end{tabular}

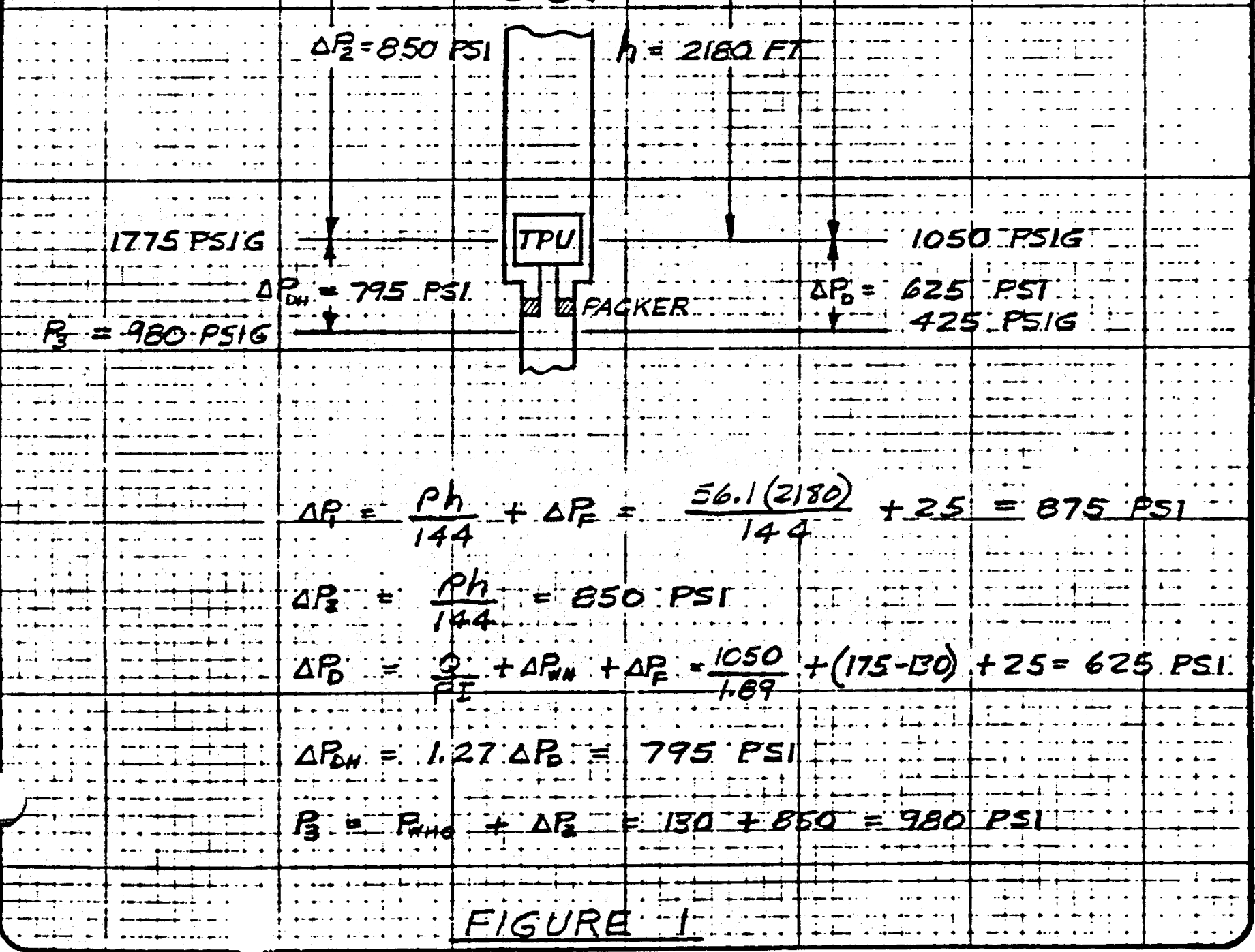




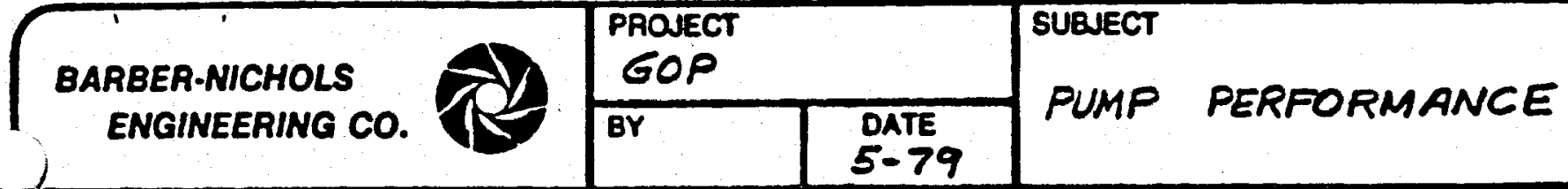

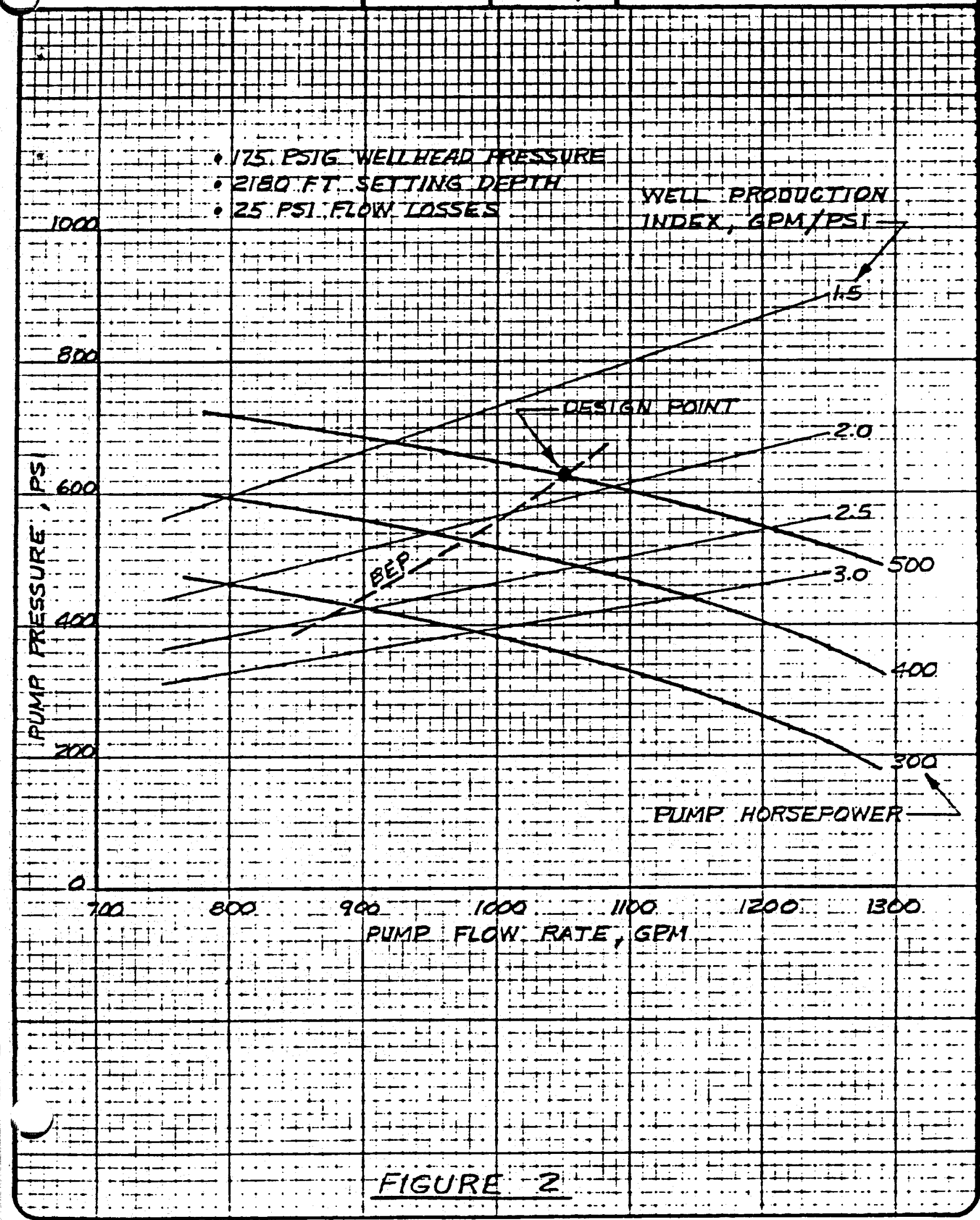




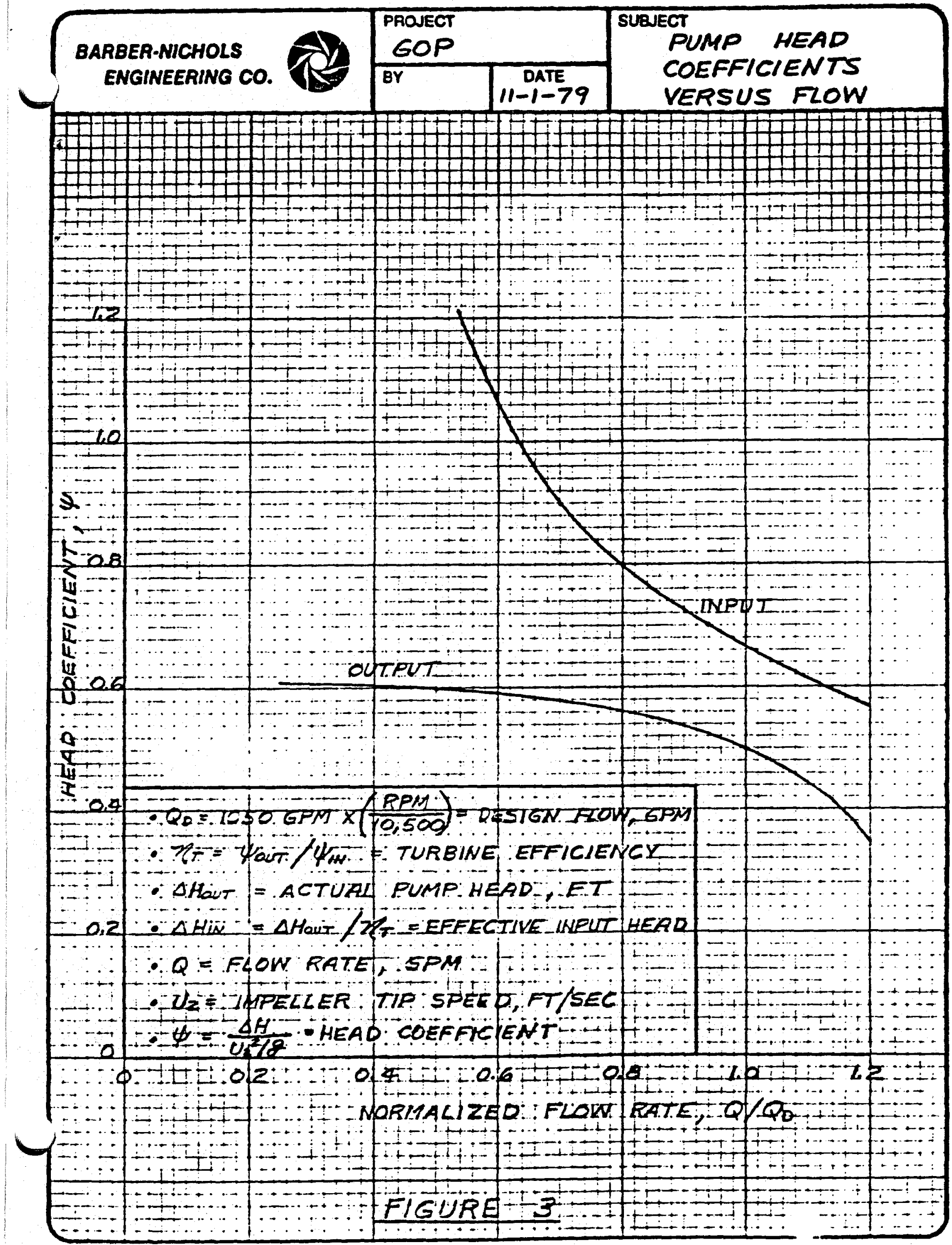


TABLE II

PUMP CHARACTERISTICS

5

Design Specifications

Brine Flow Rate

Well Production Index

Head

Efficiency Goal

Maximum Speed
$1050 \mathrm{gpm}$

$1.89 \mathrm{gpm} / \mathrm{psi}$

$1600 \mathrm{ft}$.

$75 \%$

$12,000 \mathrm{rpm}$

Design Parameters

Type

Impeller Diameter

Hub Diameter

Eye Diameter

Number of Pump Vanes

Type of Pump Vanes

Number of Diffuser Vanes

Number of Thrust - Balance Vanes

Speed

Specific Speed (CFS Units)

Suction Specific Speed (GPM Units)

NPSH

Input Power

Flow Rate

Pressure Rise $\left(330^{\circ} \mathrm{F}\right.$ Brine)

Head Coefficient, $\psi$

Flow Factor, $\emptyset$

Input Pump Power

Thrust Balance Vane Windage Loss

Efficiency
Centrifugal

7. 00 in.

1.25 in.

$3.50 \mathrm{in.}$

6

$25^{\circ}$, Backward Curved

11

11

$10,500 \mathrm{rpm}$

63.5

2334

$767 \mathrm{ft}$.

506 hp

$1050 \mathrm{gpm}$

$625 \mathrm{psi}$

0.502

0.078

$485 \mathrm{hp}$

$21 \mathrm{hp}$

$76 \%$ 
TABLE III

TURBINE CHARACTERISTICS

i

Design Specifications

Working Fluid
Inlet Temperature

Ambient Wet Bulb Temperature

Speed

Efficiency Goal

Cutput Power

$\mathrm{R}-114$

$330^{\circ} \mathrm{F}$

$75^{\circ} \mathrm{F}$

$10,500 \mathrm{rpm}$

$70 \%$

$525 \mathrm{hp}$

Design Parameters

Wheel Mean Diameter

7.884 in.

Blade Height

0.829 in.

Blade Chord

$0.460 \mathrm{in}$.

Number of Blades

86

Blade Tip Radial Clearance

$0.010 \mathrm{in.}$

Specific Speed (CFS Units)

51.3

$\mathrm{Um} / \mathrm{Co}$

Nozzle Type

Nozzle Throat Area

Number of Nozzles

0.454

Rectangular, Straight

1.21 in.

23

Nozzle Height

0.650 in.

Nozzle Exit Angle

Cutput Power

Efficiency (To static exit condition)

Condensing Temperature

Ambient Wet Bulb Temperature

$15^{\circ}$

$525 \mathrm{hp}$

$76^{\circ} \%$

$90^{\circ} \mathrm{F}$

$75^{\circ} \mathrm{F}$

Design Flow Conditions

Exhaust Pressure

Exhaust Temperature

Isentropic Head

Reaction Fraction

Blade Tip Leakage

R-114 Flow Rate

Inlet Pressure
64. ${ }^{2} \mathrm{psia}$

12. $6 \mathrm{BTU} / \mathrm{lb}$

0.15

$1.5 \%$

$38 \mathrm{lb} / \mathrm{sec}$. 570 psia 


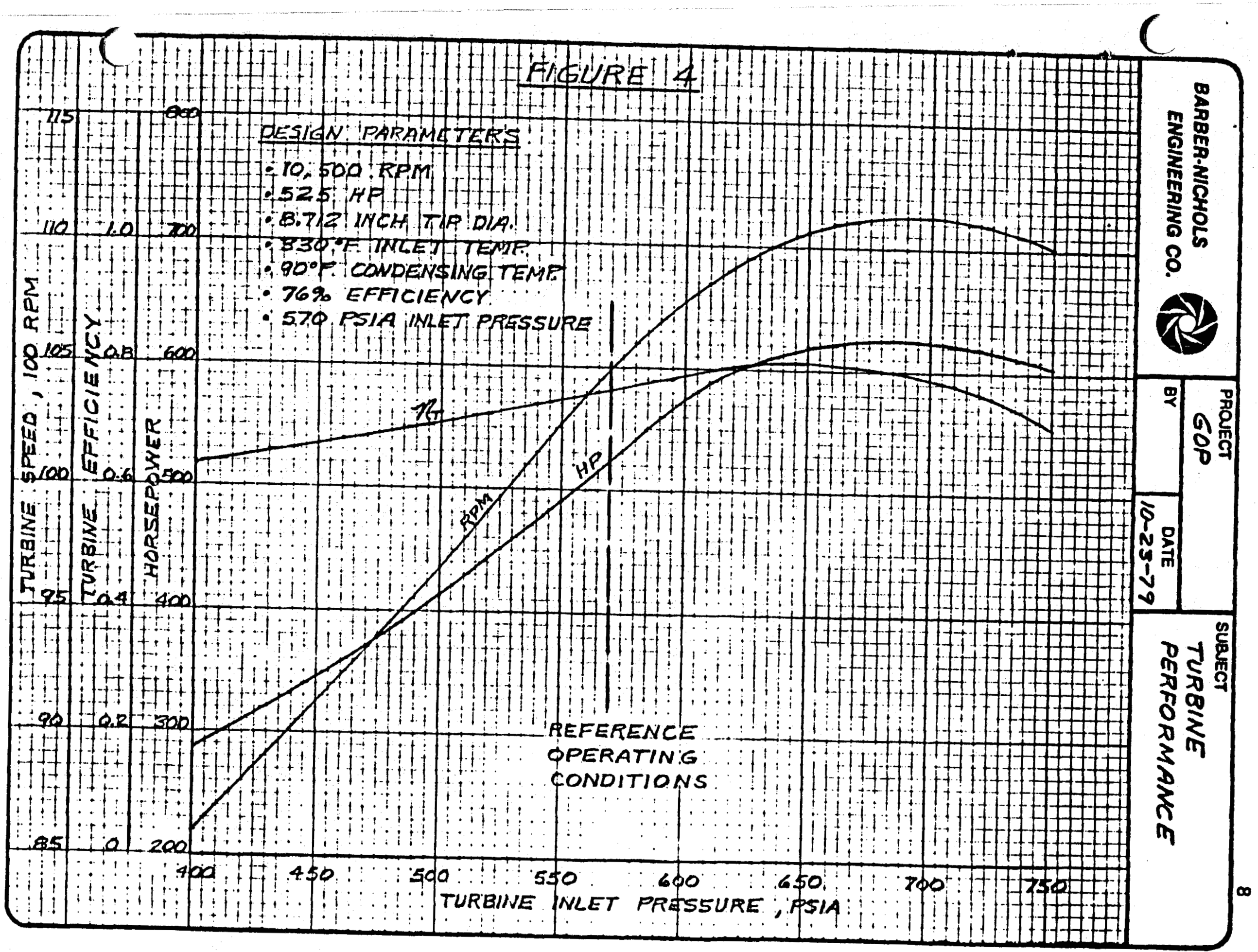




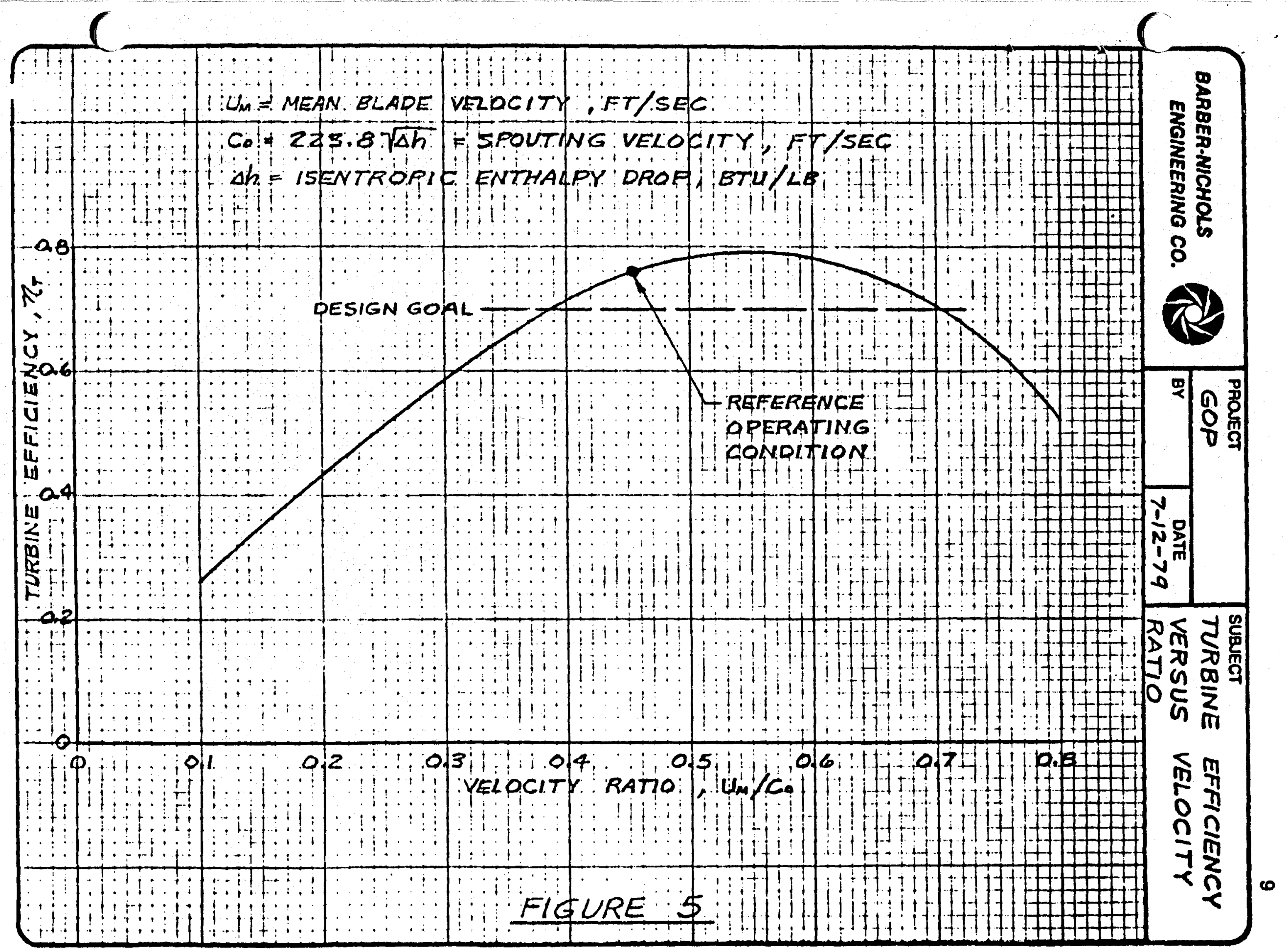




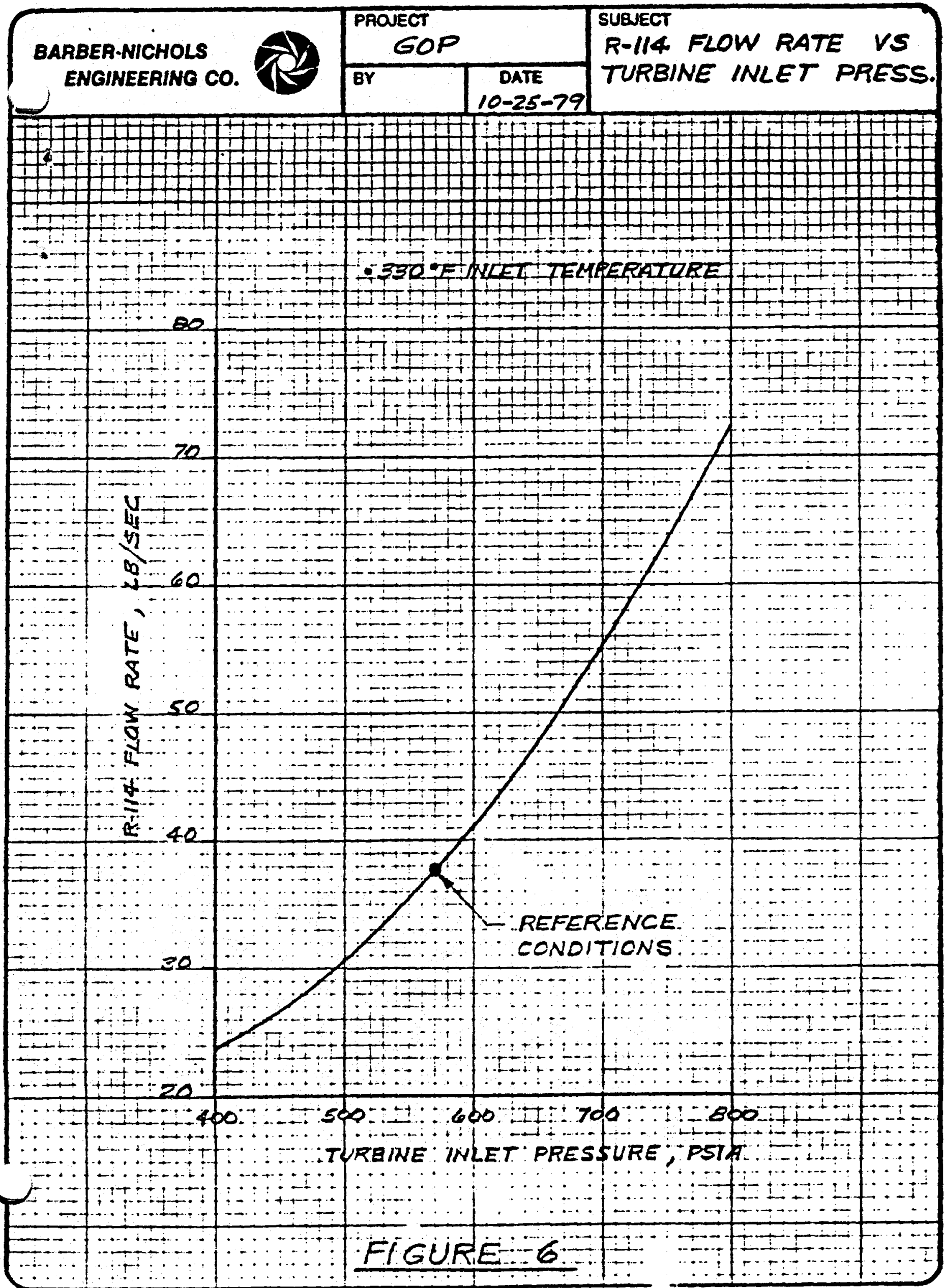


Pump pressure rise versus flow rate is shown for several horsepower levels in Figure 2. Pump pressure rise required to achieve 175 psig wellhead pressure for various $\mathrm{PI}$ values is also indicated. The range of anticipated PI's is from 1.5 to $3 \mathrm{gpm} / \mathrm{psi}$. Required flow rates center about $1000 \mathrm{gpm}$, with some bias toward the high side. The range of pump power considered was limited to $500 \mathrm{hp}$. Therefore, the design point was chosen on the best-efficiency-pump (BEP) curve at the maximum horsepower. This biased the design toward the flow rates and makes allowance for the uncertainty in the well PI.

Figure 3 gives the predicted performance of the pump. These data will be verified by laboratory tests on the pump impeller and the diffuser and flowstraightening vanes.

Table II summarizes the pump characteristics at the design point indicated in Figure 2. The flow factor refers to the ratio of the radial velocity of the brine at the impeller tip to the impeller tip speed.

\subsection{TURBINE}

The turbine was designed to operate efficiently over the pump range of Figure 2. With TPU parasitic losses due to bearings, seals, oil pump, and shaft windage, the design output power of $525 \mathrm{hp}$ was chosen. The design specifications and the resulting design parameters and flow conditions are given in Table III.

The turbine design is determined largely by computer analysis because of the many calculations required to optimize performance. Based on design specifications and generalized correlations of specific speed and specific diameter, various cases are first analyzed with the Reaction Turbine Design Program to optimize efficiency and power as a function of velocity ratio and reaction fraction, other parameters being fixed. Then nozzle, wheel and blade geometries are optimized to determine details of the turbine configuration. The Reaction Turbine Off-Design Program is then used to determine off-design performance curves for a fixed geometry. This general procedure is iterated, using scaling relationships as a guide, until satisfactory performance is obtained over the range of interest.

Auxiliary computer calculations were required to relate turbine exhaust conditions to the condensing pressure and ambient wet bulb temperature on the surface.

Figure 4 shows the predicted performance curves and indicates the reference operating conditions corresponding to an inlet pressure of 570 psia.

Figure 5 show $s$ the variation of turbine efficiency with velocity ratio, which is approximately proportional to pump flow rate. Again the higher efficiencies are biased toward the higher pump flow rates.

Fig. 6 indicates how R-114 now rate varies with turbine inlet pressure. 
Figure 7 showg the relationship of condensing temperature with turbine power and inlet pressure. The condensing temperature is determined by the condenser heat load and the ambient wet bulb temperature. The corresponding condensing pressure and the pressure drop in the exhaust return line determine the turbine exhaust pressure which in tum influences the turbine inlet pressure for a given flow rate and inlet temperature. Since the heat load that the evaporative condensers are capable of rejecting is a function of condensing temperat ure and ambient wet bulb temperature, an analysis was made to determine the relationship of actual test site wet bulb temperatures to turbine performa nce.

Figure 8 shows the predicted performance of a Baltimore Aircoil condenser unit, two of which will be available at the test site. The curves estimated by Barber-Nichols were used for the analysis.

Figure 9 shows the relationship between turbine power, inlet pressure, and wet bulb temperature. The range of practical interest is indicated by the condensing temperatures of $85^{\circ} \mathrm{F}$ and $105^{\circ} \mathrm{F}$. The reference condition of $525 \mathrm{hp}$ and 570 psia (and $90^{\circ} \mathrm{F}$ condensing temperature) requires a wet bulb temperature of less than $50^{\circ} \mathrm{F}$. Thus one condenser unit is not sufficient to meet the design criterion of $75^{\circ} \mathrm{F}$. However, the conditions under wh ich one unit would be sufficient are indicated.

Figure 10 presents the same data for two condenser units as Figure 9 does for one unit. The reference conditions are seen to correspond to the specified wet bulb temperature of $75^{\circ} \mathrm{F}$.

Figure 11 shows statistical data for wet bulb temperautres near the test site. The $75^{\circ} \mathrm{F}$ criterion was chosen because the condensers can handle the design heat load for $79 \%$ of the time during the summer months.

Laboratory tests will be performed on the turbine components to determine actual turbine performance curves. During these tests, measurements on a Baltimore Aircoil condenser will be made to refine the curves on Figurc 8.

\subsection{BEARING SELECTION}

Hydrodynamic shaft bearings are more suitable for this TPU application than anti-friction bearings. However, to reduce development cost and to minimize the risk of unpredictable early failure, ball bearings were chosen since they were found to have adequate life for the field test. The disadvantage of ball bearings at high speed and high loads is limited life due to fatigue and the possibility of inadequate lubrication. Therefore, the analysis of the ball bearings revolved about these two factors.

Angular contact ball bearings require an axial preload to prevent centrifugal forces on the orbiting balls from creating a difference between the inner-race contact : 1,jle and the outer-race contact angle that is large enough to cause 


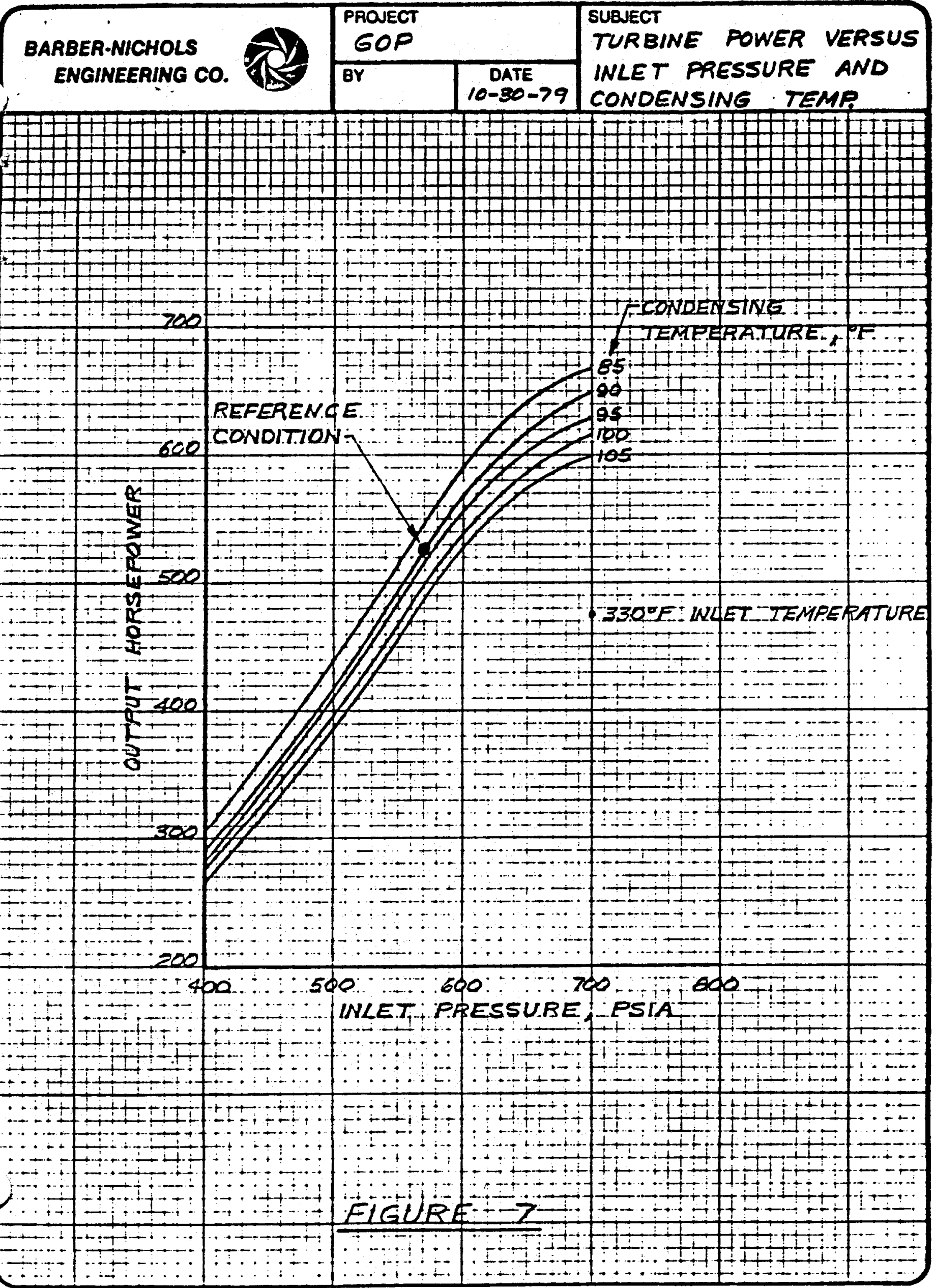




\begin{tabular}{|c|c|c|c|}
\hline \multirow{2}{*}{$\begin{array}{l}\text { RBER-NICHOLS } \\
\text { ENGINEERINO CO. }\end{array}$} & \multicolumn{2}{|c|}{$\begin{array}{r}\text { PAOUECT } \\
\text { GOP }\end{array}$} & \multirow{2}{*}{$\begin{array}{l}\text { SUBECT } \\
\text { PERFORMANCE OF } \\
\text { BALTIMORE AIR COIL } \\
\text { EVAPORATIVE CONDENSEF }\end{array}$} \\
\hline & BY & $\begin{array}{c}\text { DATE } \\
11-1-79\end{array}$ & \\
\hline
\end{tabular}

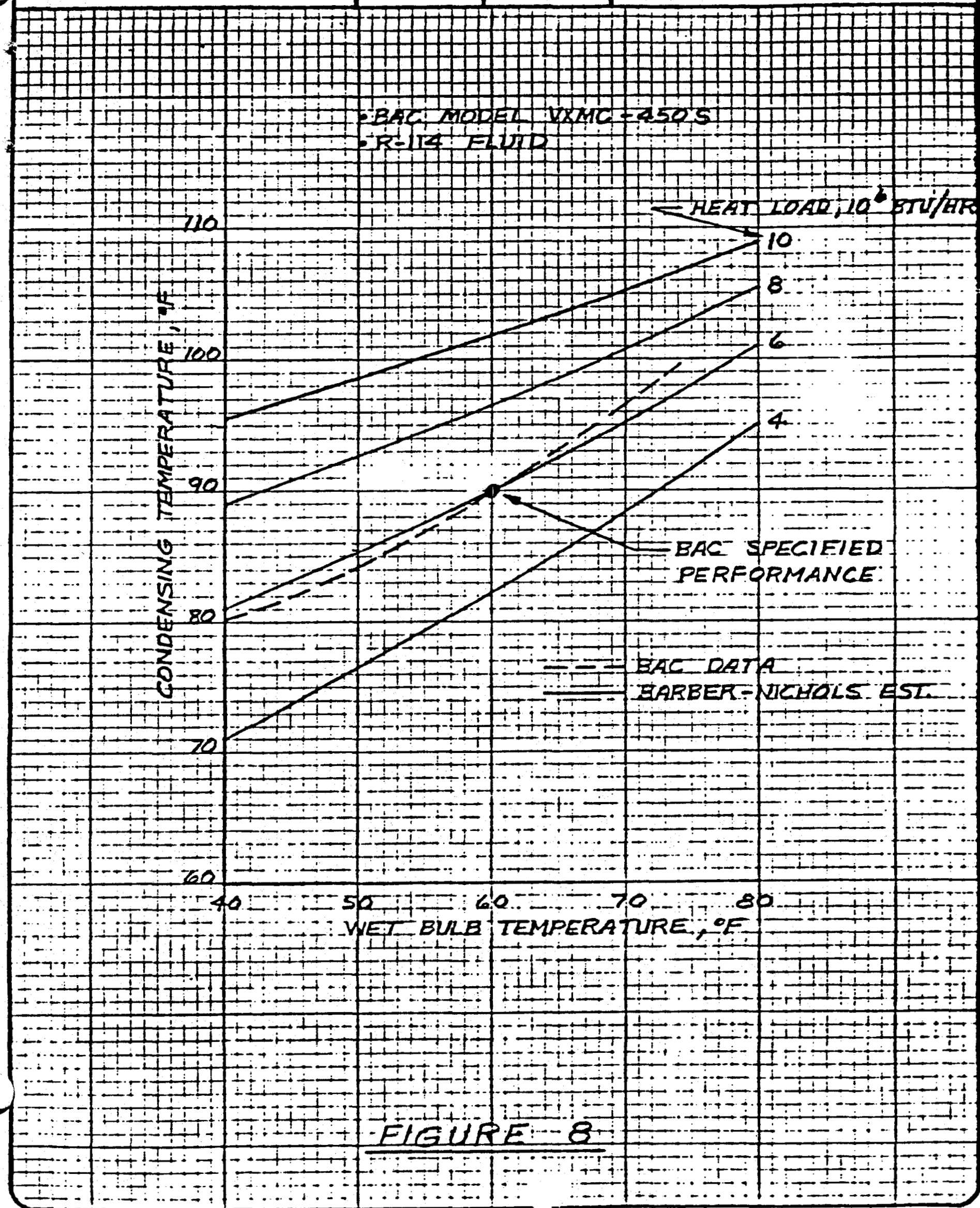




\begin{tabular}{|c|c|c|c|}
\hline \multirow{2}{*}{$\begin{array}{l}\text { BARBER-NICHOLS } \\
\text { ENGINEERING CO. }\end{array}$} & \multicolumn{2}{|l|}{$\begin{array}{r}\text { PAOECT } \\
\text { GOP }\end{array}$} & \multirow{2}{*}{$\begin{array}{l}\text { SUBECT } \\
\text { TURBINE PERFORMANCE } \\
\text { VS AMBIENT WET } \\
\text { BULB TEMPERATURE }\end{array}$} \\
\hline & $\overline{\theta Y}$ & $\begin{array}{l}\text { DATE } \\
10-31-79\end{array}$ & \\
\hline
\end{tabular}

ॠ

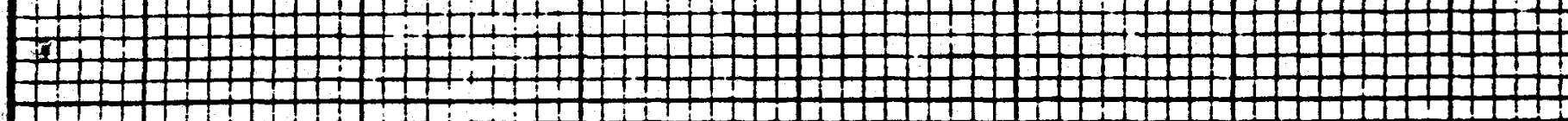
\#

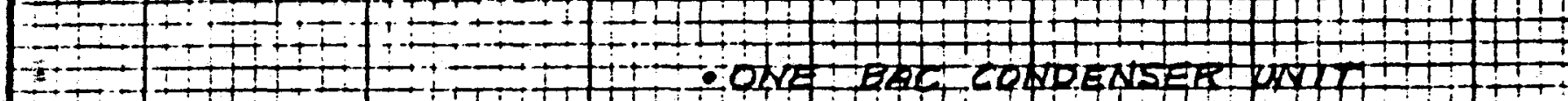

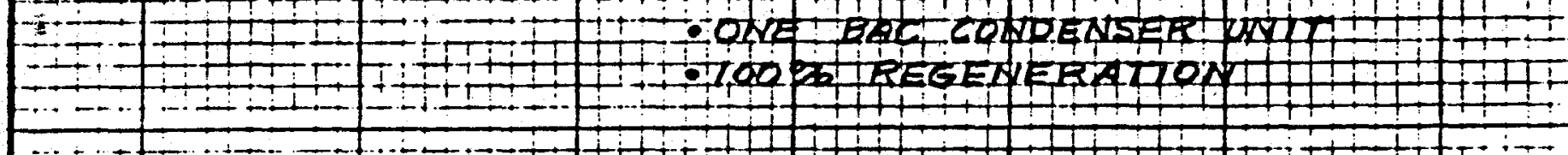

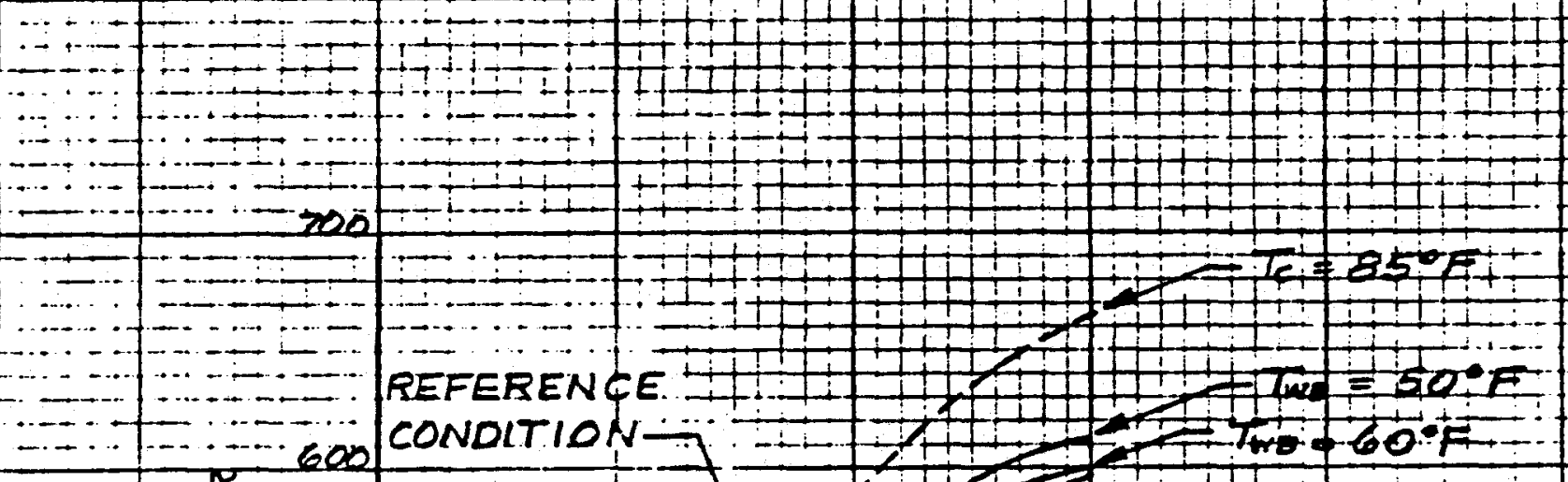

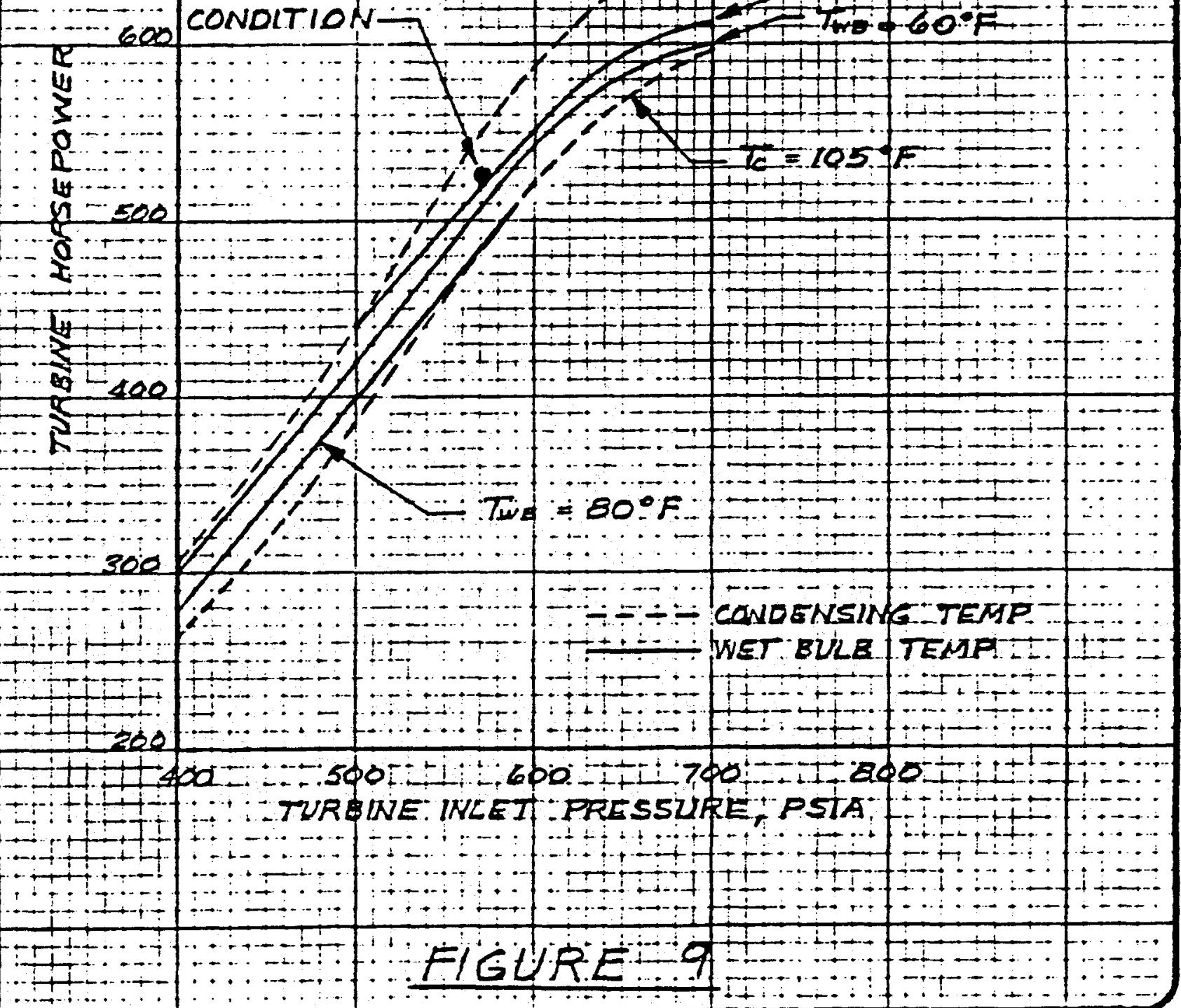




\begin{tabular}{|c|c|c|c|}
\hline \multirow{2}{*}{$\begin{array}{l}\text { BARBER-NICHOLS } \\
\text { ENGINEERING CO. }\end{array}$} & \multicolumn{2}{|c|}{$\begin{array}{l}\text { PAONECT } \\
\text { GOP }\end{array}$} & \multirow{2}{*}{$\begin{array}{l}\text { SUBUECT } \\
\text { TURBINE PERFORMANCE } \\
\text { VS AMBIENT WET } \\
\text { BULB TEMPERATURE }\end{array}$} \\
\hline & BY & $\begin{array}{c}\text { DATE } \\
10-31-79\end{array}$ & \\
\hline
\end{tabular}

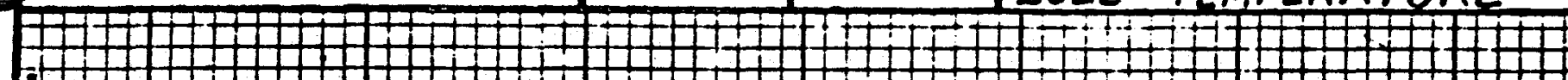

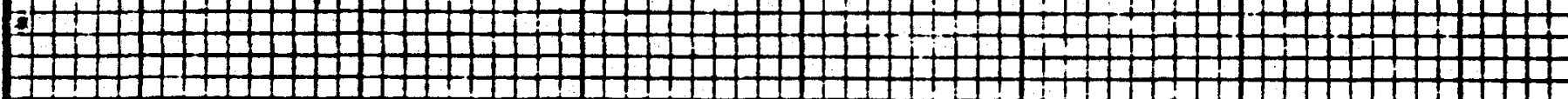

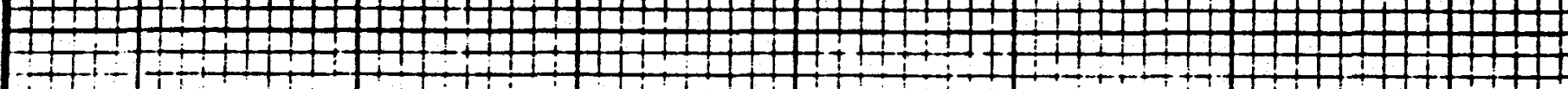

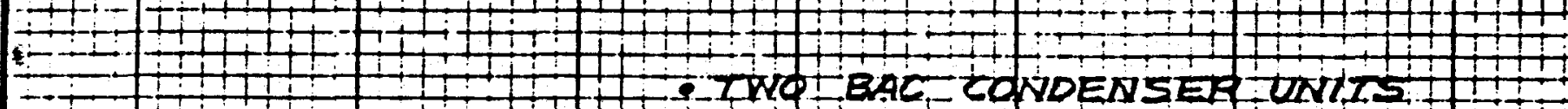

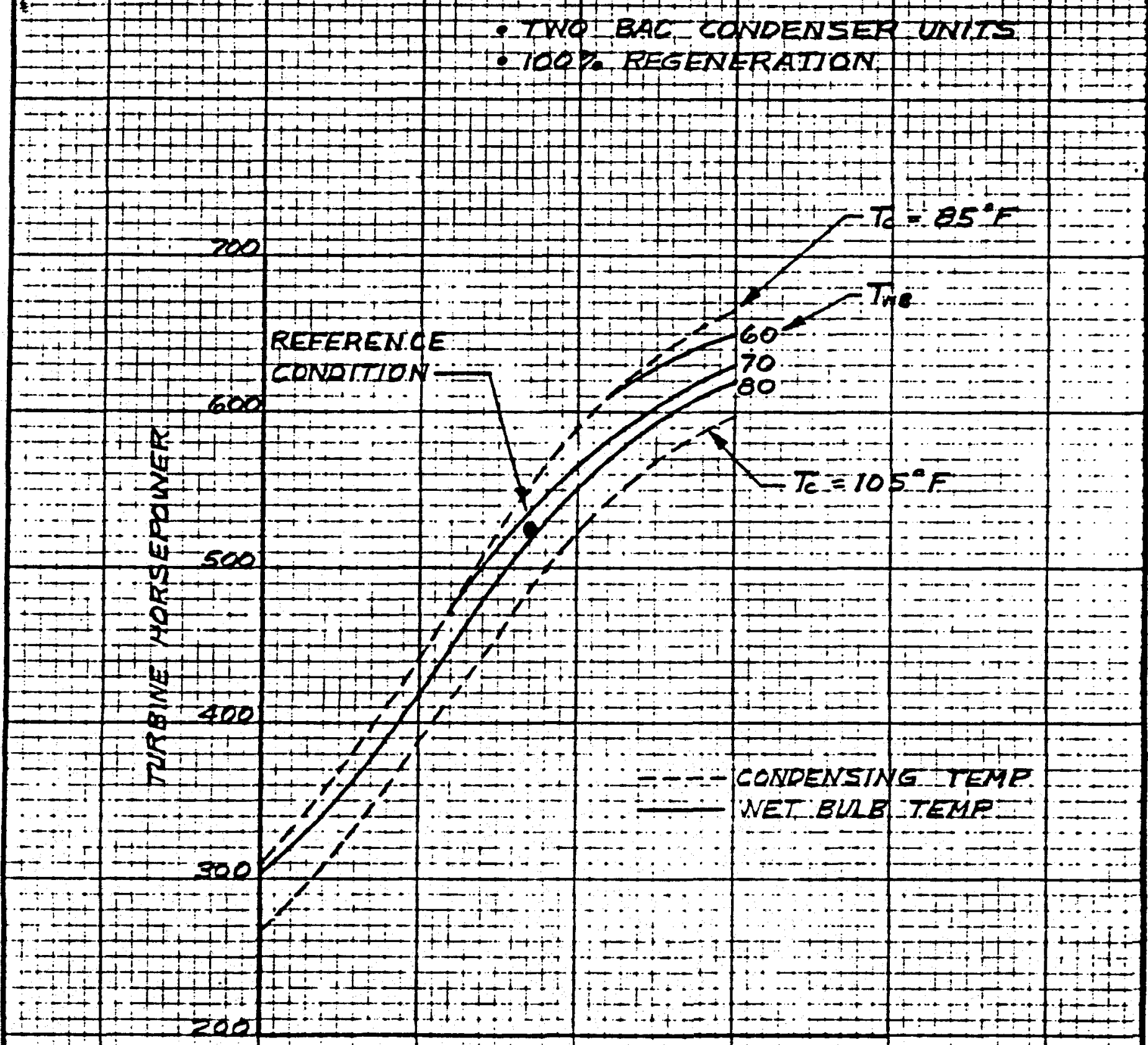

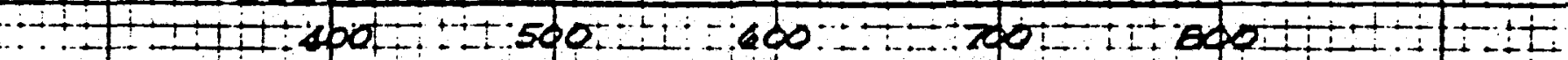

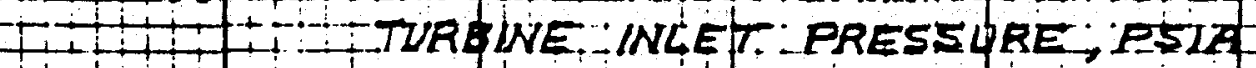

\begin{tabular}{|c|c|c|c|c|c|c|c|c|}
\hline & 4 & $1+0$ & + & 14 & & & -1 & 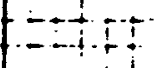 \\
\hline & $1+1$ & $1+4$ & $(++1) f$ & $=11$ & $F$ & \pm & $1+111$ & \\
\hline & $1+4$ & 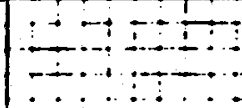 & $F \mid G U$ & 10 & & & $1+1+1$ & \\
\hline
\end{tabular}




\begin{tabular}{|c|c|c|c|}
\hline BAABER-NICHOLS & $\begin{array}{l}\text { PROECT } \\
\text { GOP }\end{array}$ & & $\begin{array}{l}\text { SUBUECT } \\
\text { WET BULB TEMPS AT }\end{array}$ \\
\hline ENGINEERINC & BY & $\begin{array}{l}\text { DATE } \\
11-6-79\end{array}$ & EL CENTRO, CALIF \\
\hline
\end{tabular}

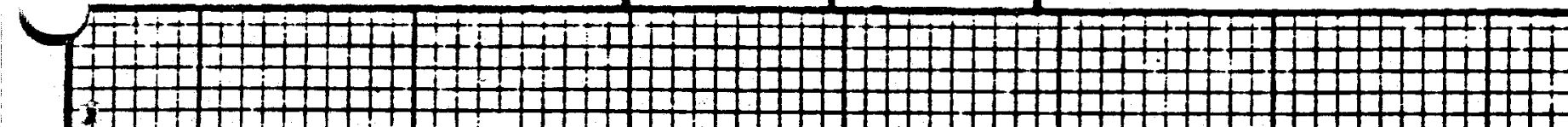
$1+$ I+2

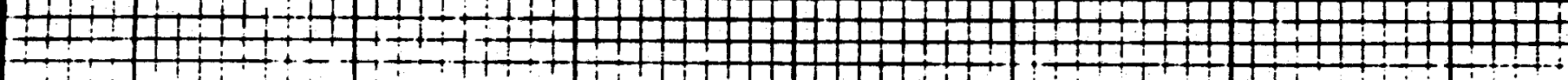
$\frac{1+19}{9}$ $\begin{array}{r}1+1 \\ -1 \\ \hline 85\end{array}$ $=-\frac{4}{2 y-0}$

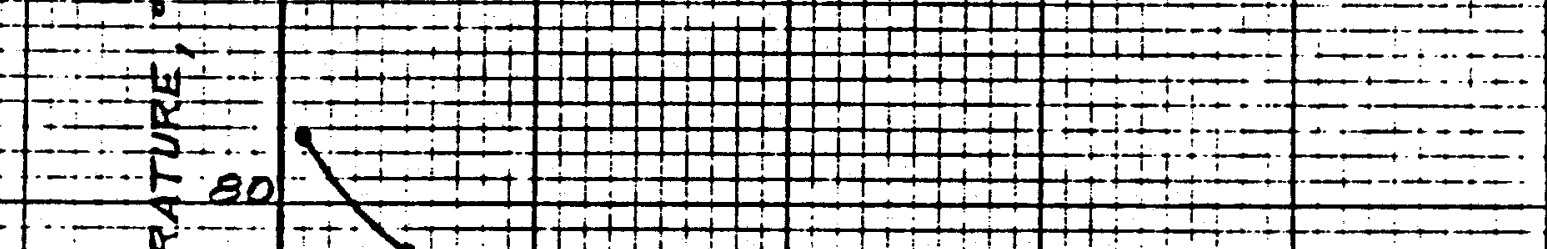

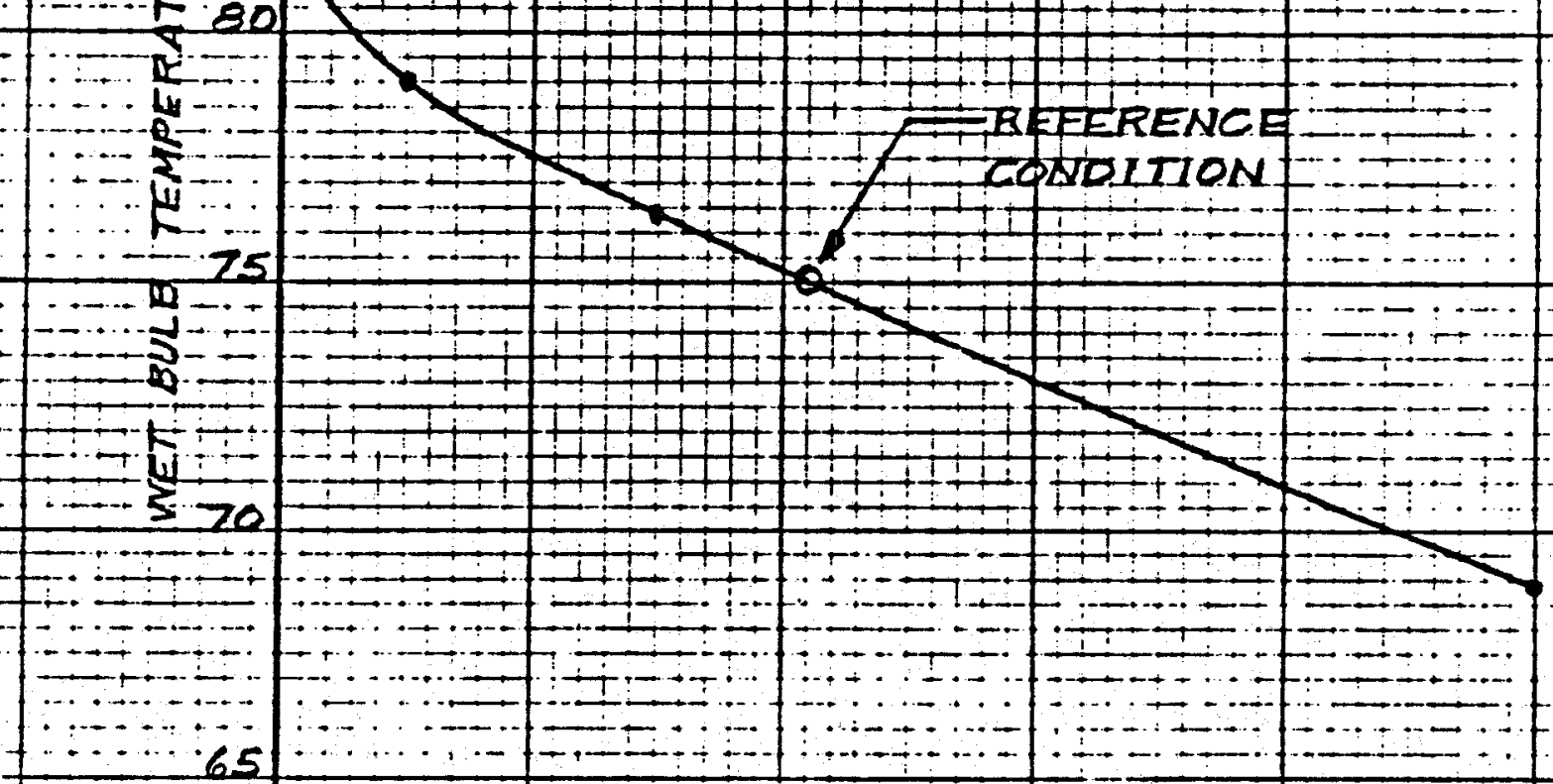
$\frac{1+20}{1+1+\infty}$

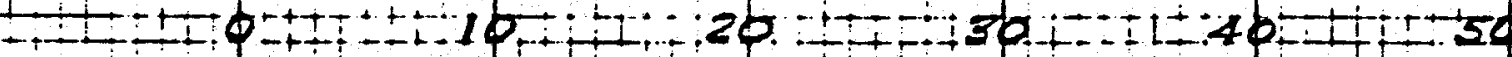

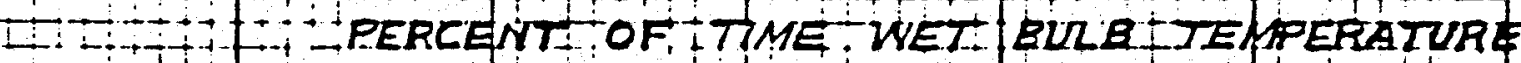
H... I ERCEEDS A GIVEN VALUE

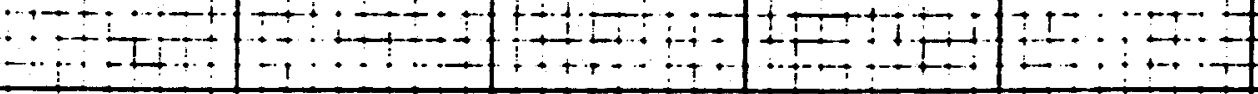
POFURE TH 
excessive skidding of the balls on the outer race. Excessive skidding greatly decreases bearing life. Since any load decreases bearing life, it is desirable to minimize the preload.

Because of the theoretical difficulty of accurately predicting minimum preload for oil immersion, SKF was contracted by Sperry to conduct a detailed computer analysis. The results are shown in Figure 12 for size 212 bearings, with a $30^{\circ}$ contact angle, arranged in a tandem duplex. A minimum load of about $800 \mathrm{lbs}$ is indicated for a speed of $13,750 \mathrm{rpm}$. This is $21 \%$ less than the load predicted by the formula presented in Reference 1. Because of the complicated behaviour of the bearing for loads less than 1000 pounds, laboratory tests will be made to verify the minimum preload for the TPU bearings, and for the actual internally spring-preloaded bearing arrangement.

The selection of the bearing size to be used was based on comparative lifetime calculations. Figure 13 shows a comparison between 212 and 310 sizes. The 310 size gave a predicted life greater than any other standard bearing, and was therefore the one chosen for the TPU.

The life adjustment factor $\alpha 23$ accounts for the quality of materials and lubrication. The value used for Figure 13 was four. This is based on published SKF predictive data, use of consumable electrode vacuum melt (CEVM) M-50 steel, and the viscosity characteristics of Mobil SHC 629 oil.

Figure 14 gives the properties of the lubricant selected for the TPU, and Figure 15 presents the variation of $\alpha_{23}$ with temperature. Oil temperature at the bearings is estimated to be around $300^{\circ} \mathrm{F}$ with the present oil cooler design. Consequently, the $\mathrm{L}_{10}$ life for the TPU bearings at $10,500 \mathrm{rpm}$ is estimated as 44,000 hours, as indicated in Figure 13. The calculations were done as described in Reference 1. The bearing specifications are given in Table IV.

\subsection{MECHANICAL DESIGN}

The TPU design is shown in Drawing GOP-900. The following discusses the main design considerations.

\subsection{LUBRICATION SYSTEM}

The TPU cavity will be filled with the oil described in Figure 14. It will be piped from a supply system on the surface that degasses it before use. The inlet $t$ ube is shown on the top left of the TPU drawing, and the outlet tube is on the lower left. The oil circulates through the TPU, lubricating the bearings and seals, and removing the heat created by parasitic losses. The inlet and outlet tubes connect to the oil cooler, which is an annular heat exchanger that filters the oil and transfers the heat to the turbine exhaust gas. The oil in the TPU cavity is maintained by the surface supply 


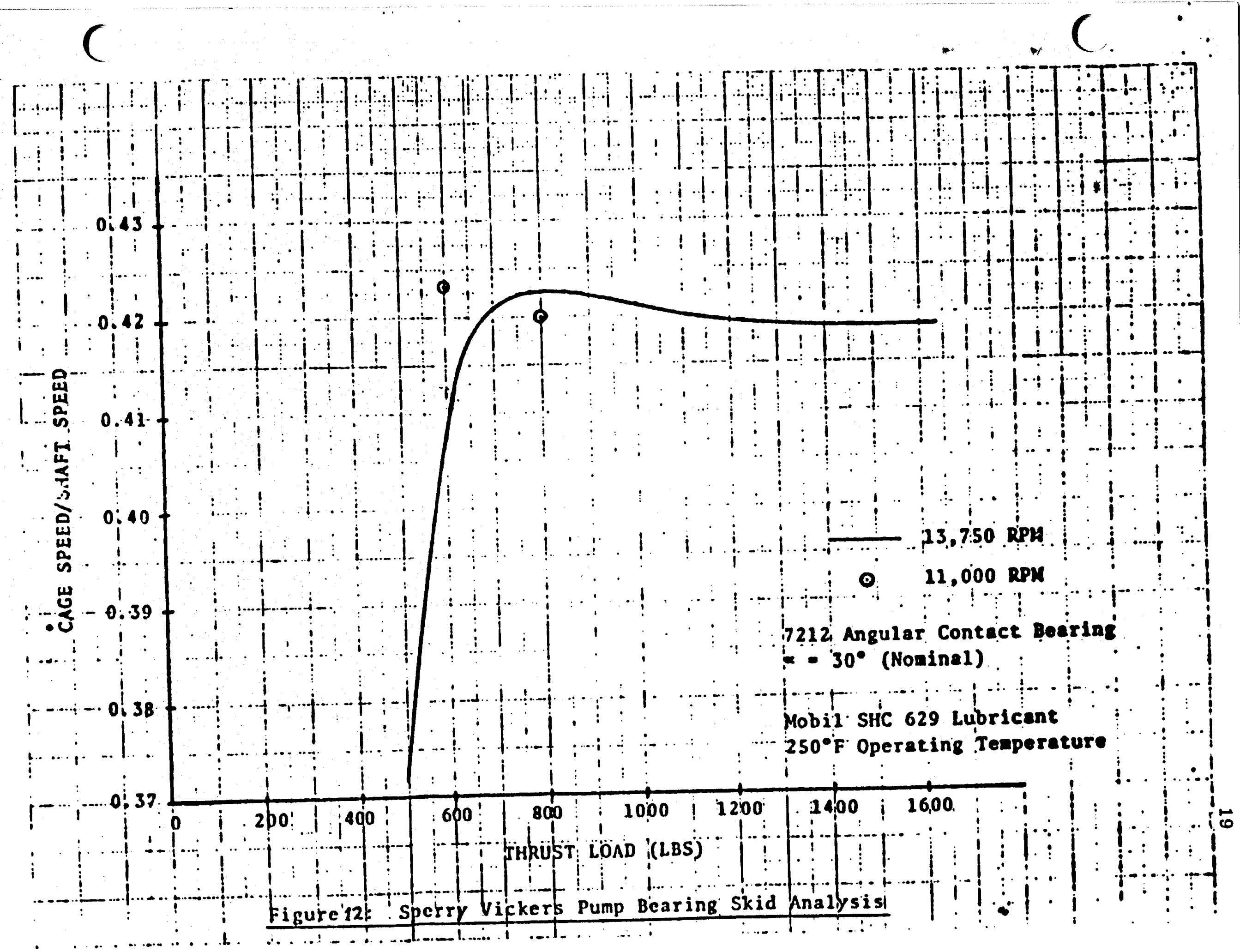




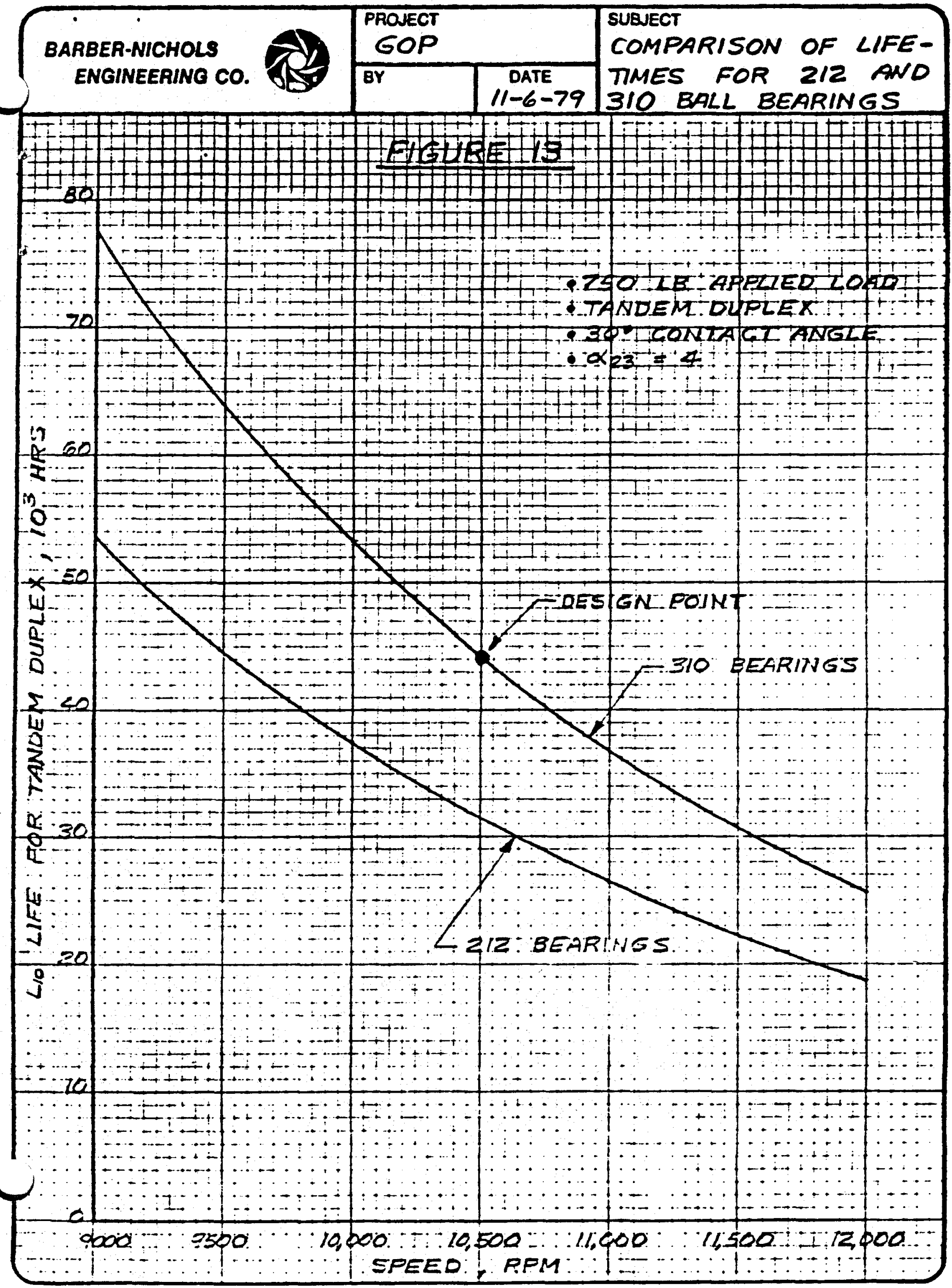




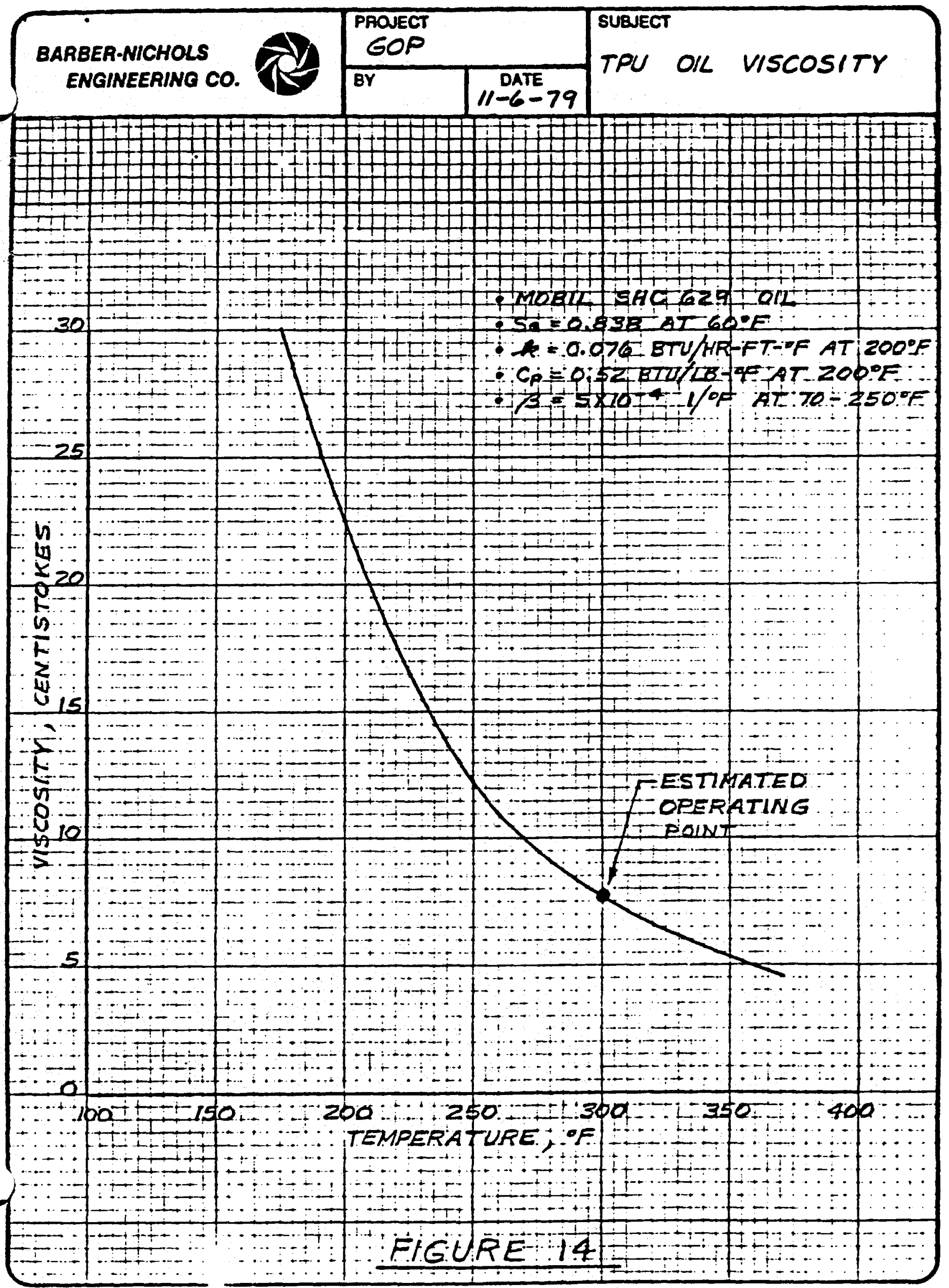




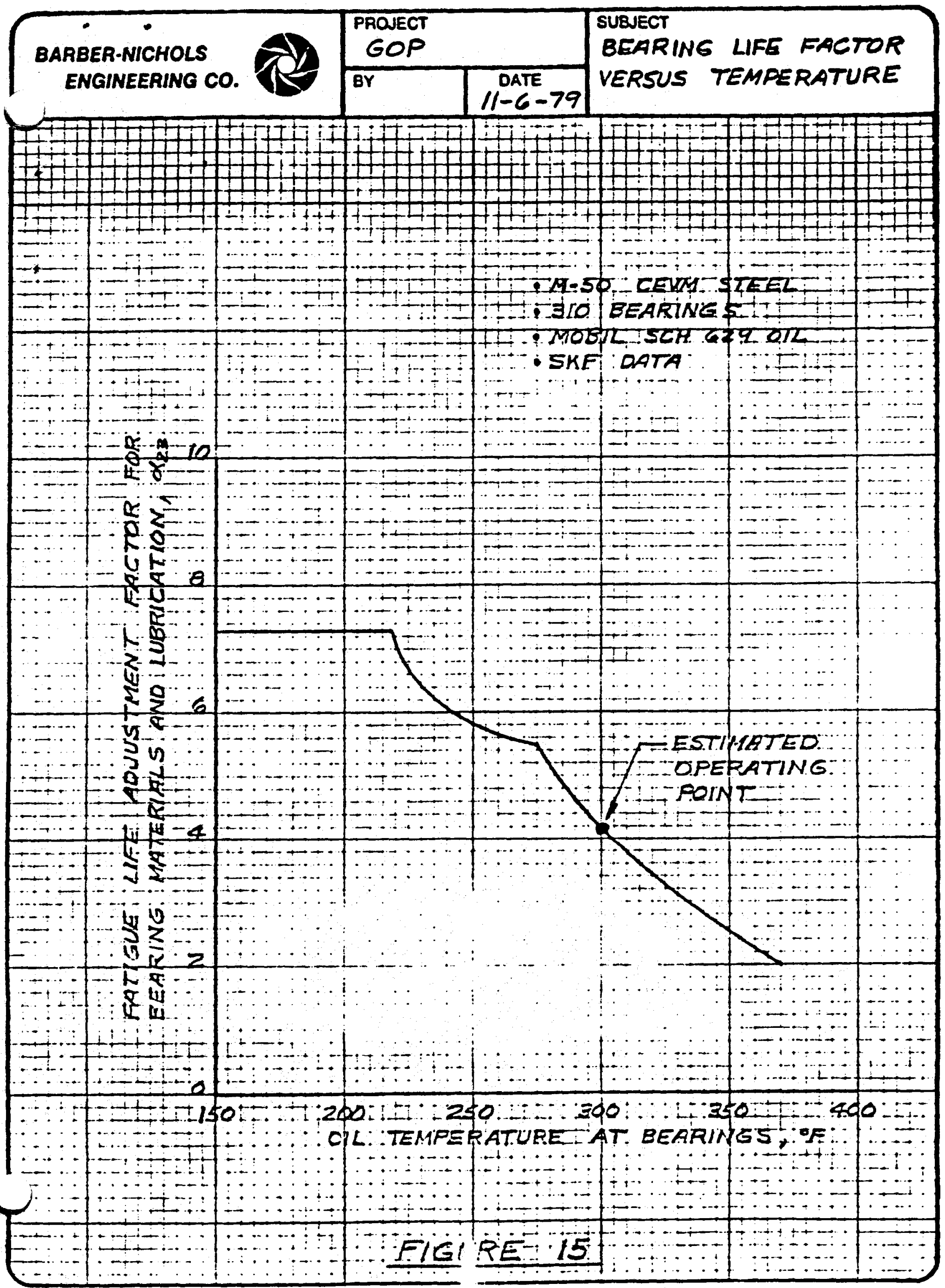


TABLE IV

$\cup$

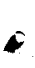

$\$$

Size

Contact Angle

Race Material

Ball Material

Cage Material

Class

Matched Machining
7310

$30^{\circ}$ Nominal

$M-50$ (CEVM)

M-50 (CEVM)

Silicon-Iron Bronze, Silver Plated

5 or Better

Tandem Duplex 


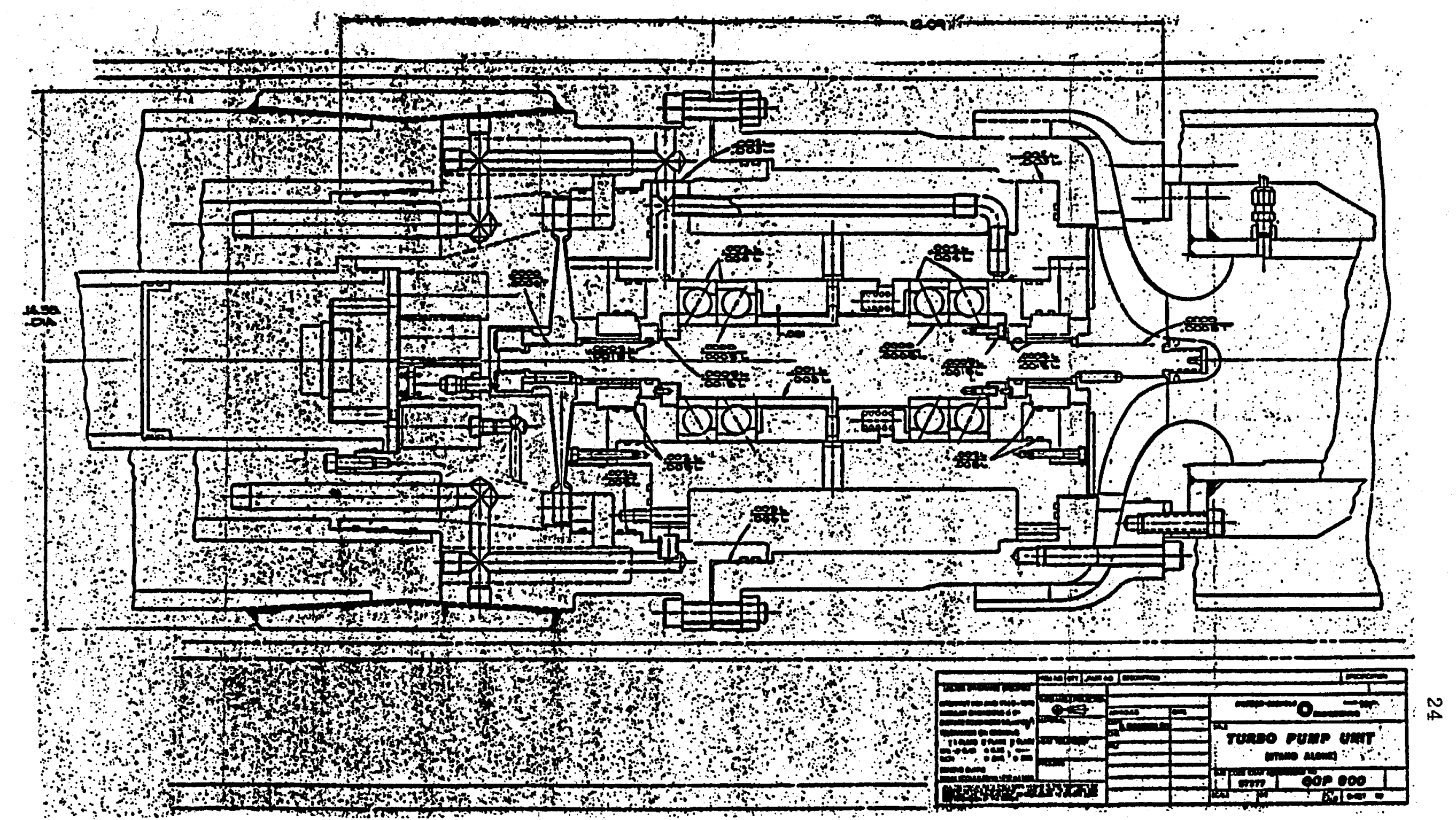


system at a higher pressure than the brine to prevent brine leakage. The oil is circulated by a small impeller attached to the shaft between the two sets of bearings.

The heat load to the oil cooler was determined by estimating the individual parasitic losses associated with the bearings, seals, shaft windage, and oil pump. Heat conducted from the brine through the TPU was also included. The result is shown in Figure 16. The estimated maximum heat load, corresponding to an operating temperature of $300^{\circ} \mathrm{F}$, is $26,000 \mathrm{BTU} / \mathrm{hr}$.

For adequate heat removal in the oil cooler at the worst-case condition $\left(250^{\circ} \mathrm{F}\right.$ exhaust temperature at $75 \%$ of design power and 400 psia turtine inlet pressure), $5 \mathrm{gpm}$ of oil flow is required. The corresponding pressure drop in the cooler and TPU were estimated, resulting in the oil impeller being sized for 30 psi rise.

Shaft windage losses are minimized by having a relatively small $(0.030$ in) clearance between shaft and housing. Oil pump work was also minimized by making the oil now rate and pressure drop as low as practical. Equal oil flow to each pair of bearings is established by balancing the flow resistance with two drilled orifices.

\subsection{CRITICAL SPEEDS}

The critical speeds of the TPU were analyzed using a detailed computer analysis. The geometry is as shown in the TPU drawing. Bearing stiffness was treated as a parameter.

The results of the first two criticals are shown in Figure 17. The two curves are associated with the overhung turbine wheel and pump impeller. The third critical is shown in Figure 18, which is associated with bearing stiffness. The critical speed of the impeller exceeds design speed by more than $50 \%$ a safe margin.

\subsection{SEALS}

\subsubsection{Static Seals}

Double O-ring seals will be used for all interfaces between the oil $\left(300-350^{\circ} \mathrm{F}\right)$, the brine $\left(350^{\circ} \mathrm{F}\right)$, and the R-114 $\left(170-330^{\circ} \mathrm{F}\right)$. A good choice for the oil and water seals and a fair choice for the R-114 seals is Kalrez, made by Dupont. Its disadvantage is a cost of approximately $\$ 2000$ per TPU set. Other candidates are Viton and EPDM for R-114, EPDM for water and Viton for oil. During the laboratory testing, inexpensive Viton and EPDM can be used and replaced as necessary. Sperry will recommend the candidates for final selection, based on the results of compatibility tests. 


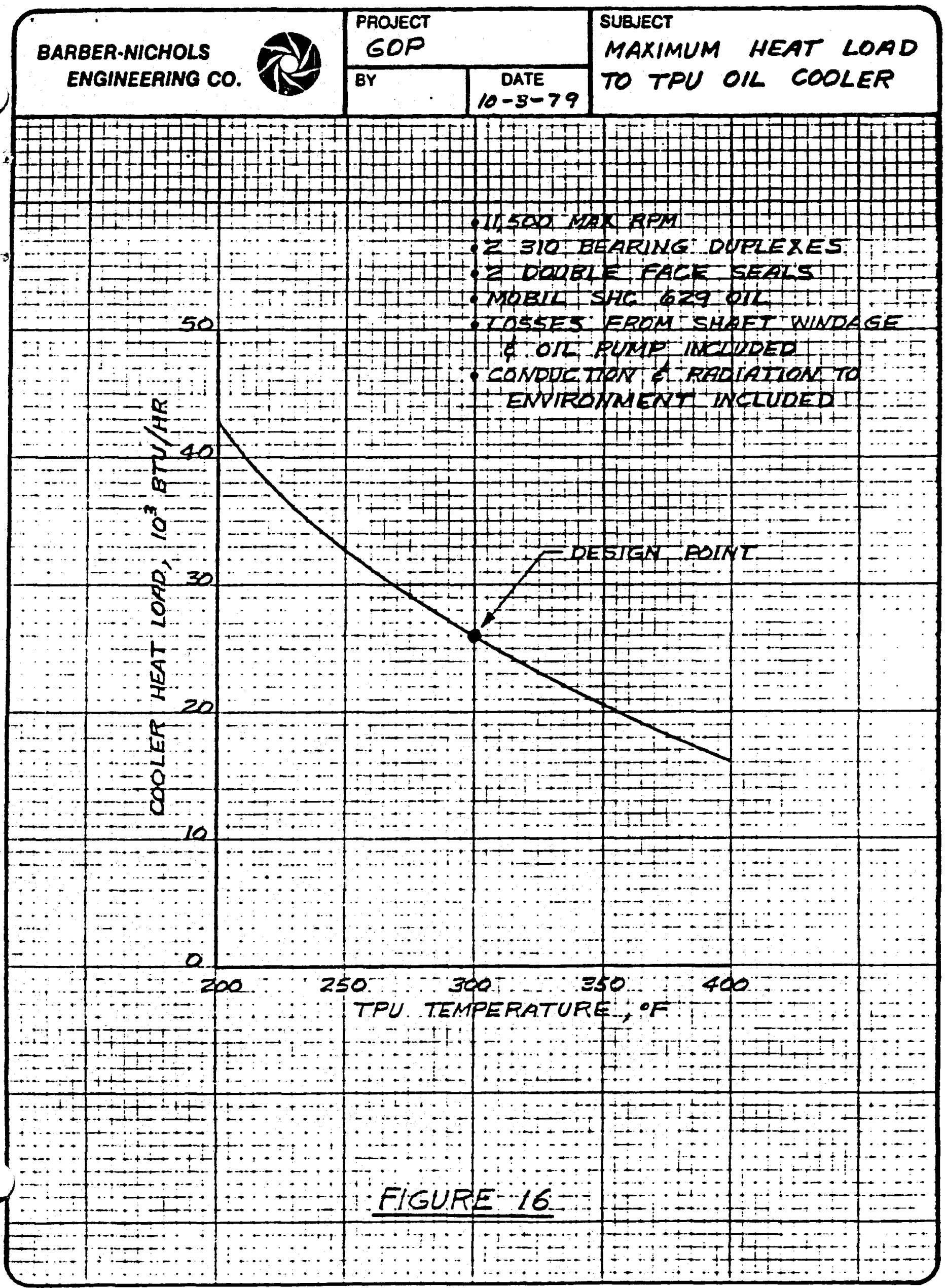




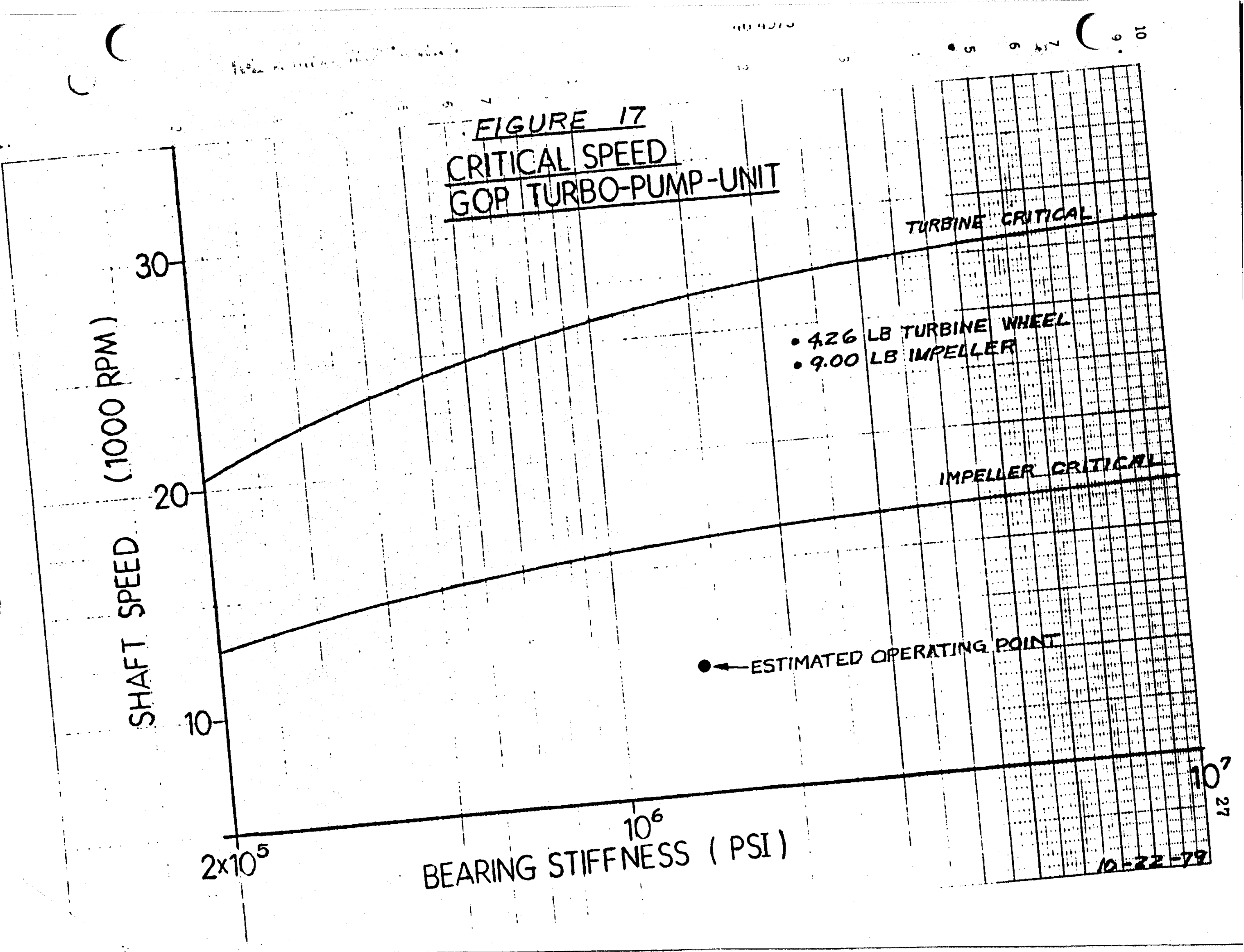




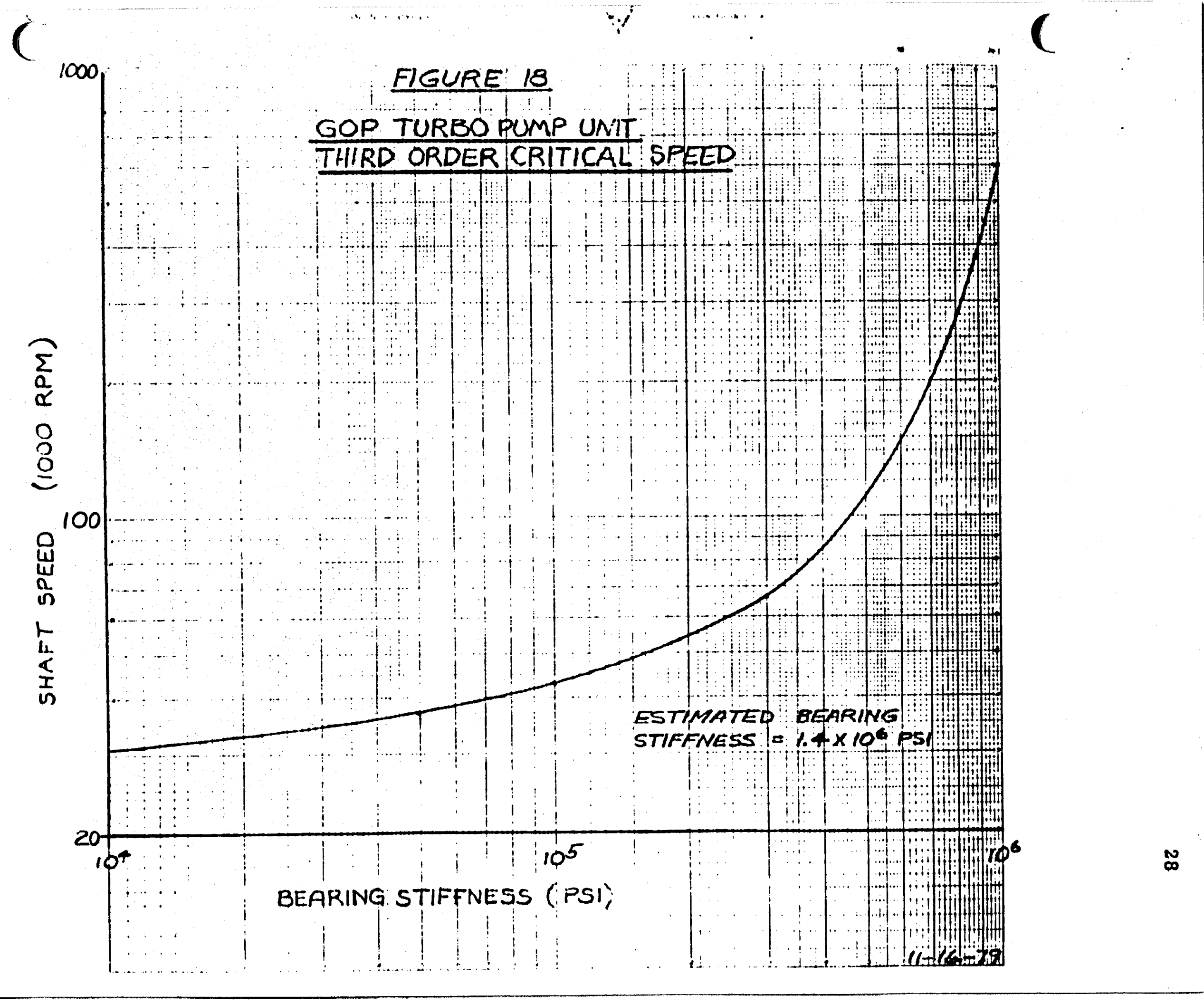




\subsubsection{Dynamic S eals}

The shaft seals will separate the oil and incoming brine at the pump end (approximately 800 psid) and the oil and turbine exhaust at the turbine end (approximately 1160 psid). Tandem seals will be used on both ends. The mating rings and the nose pieces will probably be made of silicon carbide, and the seal carrier made of 15-5 stainless steel. The design and testing of the seals is being performed by Sperry Vickers.

\subsection{MATERIALS}

All of the TPU parts will be made of 15-5 PH stainless steel, including the TPU housing, pump and turbine diffusers, shaft, bearing spacers, bearing housing, pump impeller, turbine wheel, turbine nozzles, and load bolts. Armco 15-5 PH is a high-quality, chromium-based stainless steel which has high strength, excellent corrosion resistance, hardness, notch-toughness, and is easy to heat treat (hold at temperature and air cool). Its high transverse strength is advantageous to turbomachinery applications. It was selected over the more common and very similar 17-4 PH stainless because of superior stress-corrosion cracking. Tables $\mathrm{V}$ and $\mathrm{VI}$ give minimum 15-5 PH properties for various heat treatments. The treatment to be used for the TPU is H1025.

The turbine and pump diffusers, which also form part of the housing, will be sand cast and heat treated before machining. The rest of the parts will be machined from standard stock.

\subsection{STRESS ANALYSIS}

\section{5 .1 TPU Loads}

Figure 19 is a load diagram of the IPU that shows the location of the various loads. Table VII gives the value of each surf ace load and the associats surface area and pressure. The pressures are those for the deadhead condition defined in Figure 1. Also shown are the bolt loads and the maximum thrss loads for the impeller and turbine. These loads were used for the stress analyses discussed below.

\section{5 .2 Shaft}

The maximum torque $r$ occurs at zero speed, and is 2.0 times the torat at design speed:

$$
\begin{aligned}
\tau & =2(63,025) \frac{P}{N}=\frac{126,050(525)}{10,500} \\
& =6303 \text { in }-1 b
\end{aligned}
$$

where $P$ is the turbine horsepower, and $N$ is the speed in $r p m$. 
Tabis

Minimum Properties

Longitudinal Direction - Intermodiat Location

Air Melted (up to a" section) or Consumable Eloctrodo Vacuum Arc Remelted

(up to 12" section)

\begin{tabular}{|c|c|c|c|c|c|c|c|}
\hline & \multicolumn{7}{|c|}{ Coadition } \\
\hline & 1900 & H 925 & H 1025 & H 1075 & $H 1100$ & $\$ 1150$ & H 1150.4 \\
\hline $\begin{array}{l}\text { Ultimate Tensile } \\
\text { Strength - psi }\end{array}$ & 190,000 & 170,000 & 155,000 & 145,000 & 140,000 & 135,000 & 115,000 \\
\hline $\begin{array}{l}0.2 .0 \text { Yield } \\
\text { Strength - psi }\end{array}$ & 170,000 & 155,000 & 145,000 & 125,000 & 115,000 & 105,000 & 75,000 \\
\hline 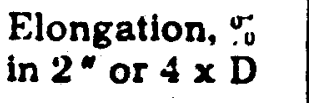 & 10.0 & 10.0 & 12.0 & 13.0 & 14.0 & 16.0 & 18.0 \\
\hline $\begin{array}{l}\text { Reduction of } \\
\text { Area - } \sigma_{0}\end{array}$ & 35.0 & 38.0 & 45.0 & 45.0 & 45.0 & 50.0 & 55.0 \\
\hline $\begin{array}{c}\text { Hardness } \\
\text { Brinell } \\
\text { Rockwell }\end{array}$ & $\left|\begin{array}{l}388 / 448 \\
C \quad 40 / 47\end{array}\right|$ & $\begin{array}{l}375 / 438 \\
\text { C } 38 / 45\end{array}$ & $\begin{array}{l}331 / 401 \\
\text { C } 35 / 42\end{array}$ & $\begin{array}{l}302 / 375 \\
\mathrm{C} 31 / 39\end{array}$ & $\begin{array}{l}311 / 364 \\
\text { C } 32 / 38\end{array}$ & $\left|\begin{array}{l}277 / 352 \\
C 28 / 37\end{array}\right|$ & $\begin{array}{l}255 / 293 \\
\text { C } 24 / 30\end{array}$ \\
\hline $\begin{array}{l}\text { Impact, Charpy } \\
\text { V'-. Notch, ft-lbs }\end{array}$ & - & 5 & 15 & 20 & 25 & 30 & 55 \\
\hline
\end{tabular}

- Minimum impact properties cannot be accepted in this condition.

Table VI

Minimum Properties

Transverse Direction

Consumable Electrode Vacuum Arc Remelted (up to 12" section)

\begin{tabular}{|c|c|c|c|c|c|c|c|}
\hline & \multicolumn{7}{|c|}{ Condition } \\
\hline & H900 & 11925 & H 1025 & H1075 & $M 1100$ & $H 1150$ & H1150.M \\
\hline $\begin{array}{l}\text { Cltimate Tensile } \\
\text { Strength - psi }\end{array}$ & 190,000 & 170,000 & 155,000 & 145,000 & 140,000 & 135,000 & 115,000 \\
\hline $\begin{array}{l}0.2: \text { Y'ield } \\
\text { Strength - psi }\end{array}$ & 170,000 & 155,000 & 145,000 & 125,000 & 115,000 & 105,000 & 75,000 \\
\hline $\begin{array}{l}\text { Flongation, "" } \\
\text { in } 2^{\prime} \text { or } 4 \times 0 \text { " }\end{array}$ & 6.0 & 7.0 & 8.0 & 9.0 & 10.0 & 11.0 & 14.0 \\
\hline $\begin{array}{l}\text { Reduction of } \\
\text { Area }-\%\end{array}$ & 15.0 & 20.0 & 27.0 & 28.0 & 29.0 & 30.0 & 35.0 \\
\hline $\begin{array}{l}\text { Hardness } \\
\text { Brinell } \\
\text { Rockwell }\end{array}$ & $\begin{array}{l}388 / 448 \\
\text { C } 40 / 47\end{array}$ & $\begin{array}{l}375 / 438 \\
\text { C } 38 / 45\end{array}$ & $\begin{array}{l}331 / 401 \\
\text { C } 35 / 42\end{array}$ & $\begin{array}{l}302 / 375 \\
\text { C } 31 / 39\end{array}$ & $\begin{array}{l}311 / 364 \\
C 32 / 38\end{array}$ & $\begin{array}{l}277 / 352 \\
C \quad 28 / 37\end{array}$ & $\begin{array}{l}255 / 293 \\
\text { C } 24 / 30\end{array}$ \\
\hline $\begin{array}{l}\text { Impact, Charpy } \\
\text { V-Notch, ft-lbs } \\
\text { Intermediate } \\
\text { Location }\end{array}$ & & & & & & & \\
\hline
\end{tabular}

- Minimum impact properties cannot be accepted in this condition. 

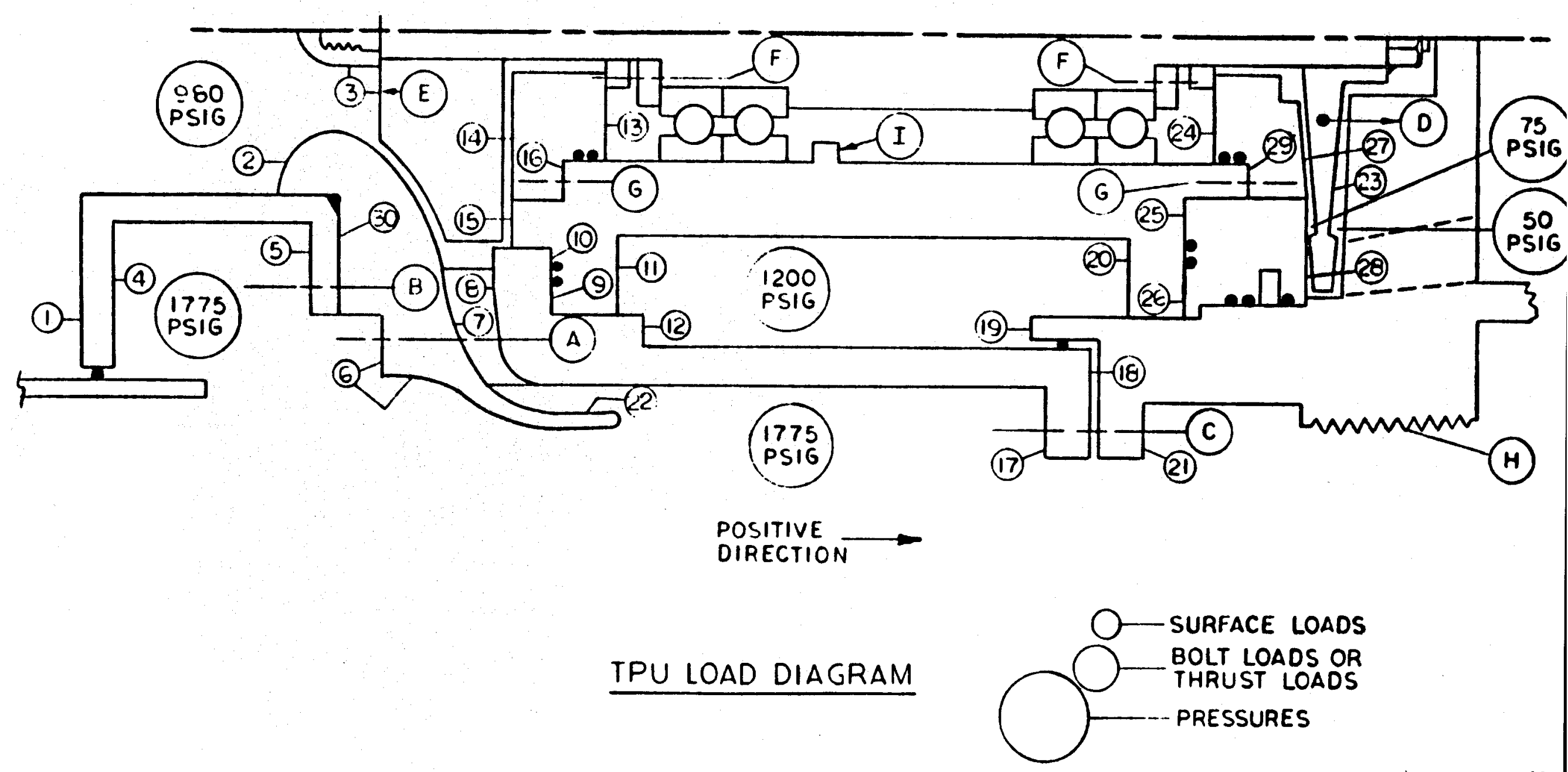

FIGURE IC 


\section{TABLE VII}

TPU LOADS

LOCATION AREA, IN $^{2}$ PRESSURE, PSIG LOAD, IBS

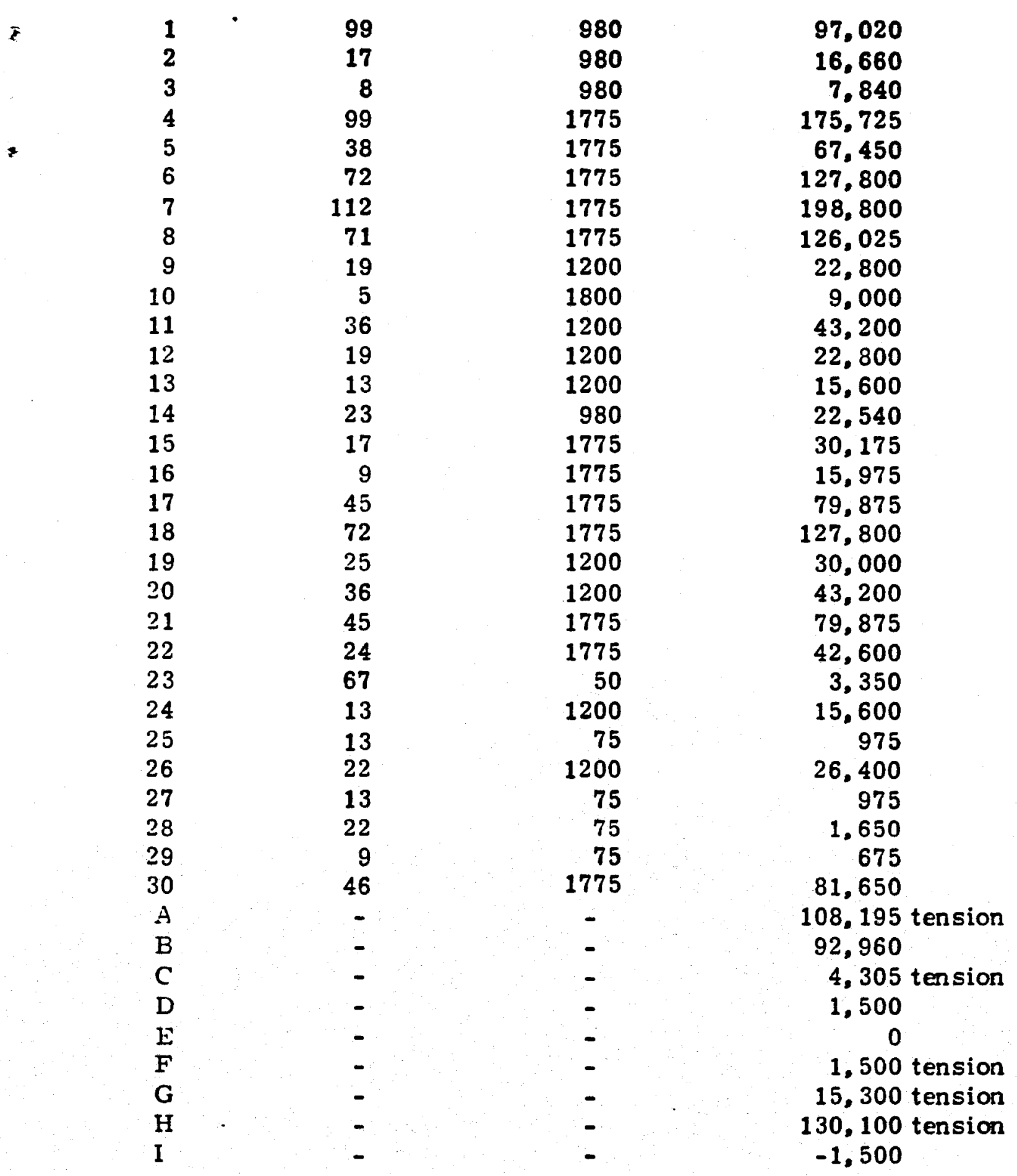


The maximum stress is at the turbine keyway. The shear stress $\sigma_{B}$ is

$$
\sigma_{B}=\frac{16 \mathrm{~K} \tau}{\pi D^{3}}=\frac{16(1.8)(6303)}{\pi(0.875)^{3}}=86.251 \mathrm{psi}
$$

where $K$ is the stress concentration factor at the keyway, and $D$ is the shaft diameter in inches.

The corresponding tensile stress $\sigma_{t}$ is

$$
\sigma_{t}=\frac{4 F_{t}}{\pi D^{2}}=\frac{4(1500)}{\pi(0.875)^{2}}=2,495 \mathrm{psi}
$$

where $F_{t}$ is the turbine thrust.

The maximum combined shear stress is therefore

$$
\sigma_{\mathrm{s}} \max =\sqrt{\frac{1}{4} \sigma_{t}^{2}+\sigma_{s}^{2}}=86,260 \mathrm{psi}
$$

The shaft key shear stress is

$$
\sigma_{s}=\frac{2 T}{D d L}=\frac{2(6303)}{(0.875)(0.25)(0.938)}=61,435 \mathrm{psi}
$$

where $d$ and $L$ are the diameter and length of the cylindrical key. The key and keyway bearing stress $\sigma_{b}$ is

$$
\sigma_{b}=2 \sigma_{s}=122,870 \mathrm{psi}
$$

\subsubsection{Turbine Rotor}

The stress due to rotation and a $13^{\circ} \mathrm{F}$ per inch radial temperature gradient was calculated by computer program for the actual rotor profile. The maximum tangential stress is at the hub keyway, which for a stress concentration factor of 1.3 , is $17,980 \mathrm{psi}$. The maximum radial stress is at the thinnest section, and is due to a combination of rotational forces and bending caused by the pressure differential across the rotor that results in the 1500 pounds of turbine thrust. The maximum radial stress is

$$
\sigma_{\mathrm{r}} \max =\sigma_{\mathrm{r}}+\sigma_{\mathrm{t}}=8608+5878=14,486 \mathrm{psi}
$$

where $\sigma_{r}$ is the radial stress due to rotation, and $\sigma_{t}$ is the tensile stress due to bending.

\subsubsection{Pipe String Load on TPU}

The static load Fs of the pipe string is the weight of a 16 -inch (O.D.) pipe with a $5 / 8$ inch wall, less the weight of the $56.1 \mathrm{lb} / \mathrm{ft}^{3}$ brine displaced by the pipe:

$$
F s=\left(W_{p}-W_{B}\right) L_{p}=(104-78) 2180=56,680 \mathrm{lb}
$$

where $W_{p}$ is the pipe weight in $\mathrm{lb} / \mathrm{ft}, \mathrm{W}_{B}$ is the weight of displaced brine in $\mathrm{lb} / \mathrm{ft}$, and $L_{p}$ is the length of pipe in feet.

The dynamic load $F_{d}$, assuming the TPU bottoms out against the polished-bore receptacle (PBR) while being lowered at one $\mathrm{ft} / \mathrm{sec}$, is

$$
\begin{aligned}
F_{d} & =\sigma A=\rho C V A / g \\
& =0.28(200,000)(12)(30.8) / 386=53,620 \mathrm{lb}
\end{aligned}
$$


where $\sigma$ is the compressive stress in the pipe, A is the area of the pipe wall, $P_{\text {is }}$ the pipe density in $\mathrm{lb} / \mathrm{in}^{3}, \mathrm{C}$ is the speed of sound in the pipe in inches/sec, $v$ is pipe velocity at impact in inches/sec, and $g$ is the acceleration of gravity.

The total load is

$$
F=F_{s}+F_{d}=110,300 \mathrm{lb}
$$

and is transmitted from the threaded coupling, through the TPU, to the contact between the TPU and the PBR.

This load results in a compressive stress of approximately $5000 \mathrm{psi}$ in the main diffuser vanes for the pump. If the PBR has a flared entrance so the pump housing impacts a flat, sloping surface, the local compressive stress in the housing will not exceed 126,600 psi. Even if the PBR has a sharp edge at the impact point, local permanent deformation occurs in the TPU to a depth of only 0.016 inches.

\subsubsection{Fasteners}

The bolt and screw loads are determined by summing the appropriate surface loads shown in Figure 19.

\section{Load A}

Eleven 1/2-20 15-5 PH bolts are used. Load bolts are normally preloaded to $80 \%$ of yield to eliminate cyclic loading, which corresponds in this case to 204,000 pounds. This is $89 \%$ greater than the applied load of 108,195 pounds.

\section{Lcad B}

These bolts are sized to be weaker than the connections at $A, C$ or $\mathrm{H}$ so that, in the event the packer binds when the TPU is pulled from the well and failure occurs, it will occur at $B$.

Nine $1 / 2-2015-5$ PH bolts are used, giving $82 \%$ of the strength of the bolts at $A$. The bolts at $A$ and $B$ will be machined from the same stock, and specimens will be tested to failure to ensure acceptably uniform strength.

An $80 \%$ preload of 166,940 pounds, less the applied load of 92,960 pounds, gives 73,980 pounds required by the packer to reverse the bolt load. A packer load of 130,100 is required to fail the bolts. Initial laboratory tests on the first packer design indicate the packer friction in an unpolished pipe is approximately 10,000 pounds.

\section{$\underline{\text { Load C }}$}

Eighteen $1 / 2-20$ 15-5 PH bolts are used, which are stronger than the flange. 
Therefore the bolts will be preloaded to $80 \%$ of the flange strength. The rlange design strength is 165,000 pounds and its ultimate strength is 282,000 pounds.

\section{Load D}

The turbine thrust is determined by computer analysis, and is due to the pressure differential across the rotor of approximately 25 psi. The thrust is 1500 pounds.

$\underline{\text { Load E }}$

Pump-out vanes on the back of the pump impeller are designed to balance the combined impeller and turbine thrusts so that the net applied load on the shaft bearings is zero at design conditions. Therefore, at design conditions the net pump thrust balances the turbine thrust and is 1500 pounds. However, the maximum stress in the TPU is at zero speed when the pump thrust is zero; this is the value shown in Table VII.

Load $F$

Six 10-24 cap screws are used, resulting in a load of 250 pounds per screw and a safety factor of 7.8 .

\section{Load G}

Ten 10-24 cap screws are used, resulting ina load of 1530 pounds per screw and a safety factor of 1.3 .

$\underline{\operatorname{LOadH}}$

The maximum pipe string load on the TPU threaded coupling was shown in Section 5.5 .4 to be 110,300 pounds compression. The maximum tensile load on the coupling would be the failure load of the load bolts at $B_{;}$i. e., 130,100 pounds. This results in a maximum shear stress on the threads of 2000 psi.

\subsubsection{Mlain Flange}

The Hange was analyzed per the ASME Boiler Code. For a safety factor of 1.6 relative to the yield strength, the flange can safely carry a tensile load of 165,000 pounds, which is $27 \%$ greater than the load required to fail the fuse bolts at $\mathrm{B}$.

\section{REFFRENCES}

(1) Barber-Nichols' Memorandum, "GOP TPU Design", dated May 29, 1979. 
GEOTHERMAL PROGRAMS

WORK \& INFORMATION RELEASE

DATE: December 29, 1980

SRC FIIE NO.03.04.111 SUPERSEDES

DOCUMENT NO. SUPERSEDES

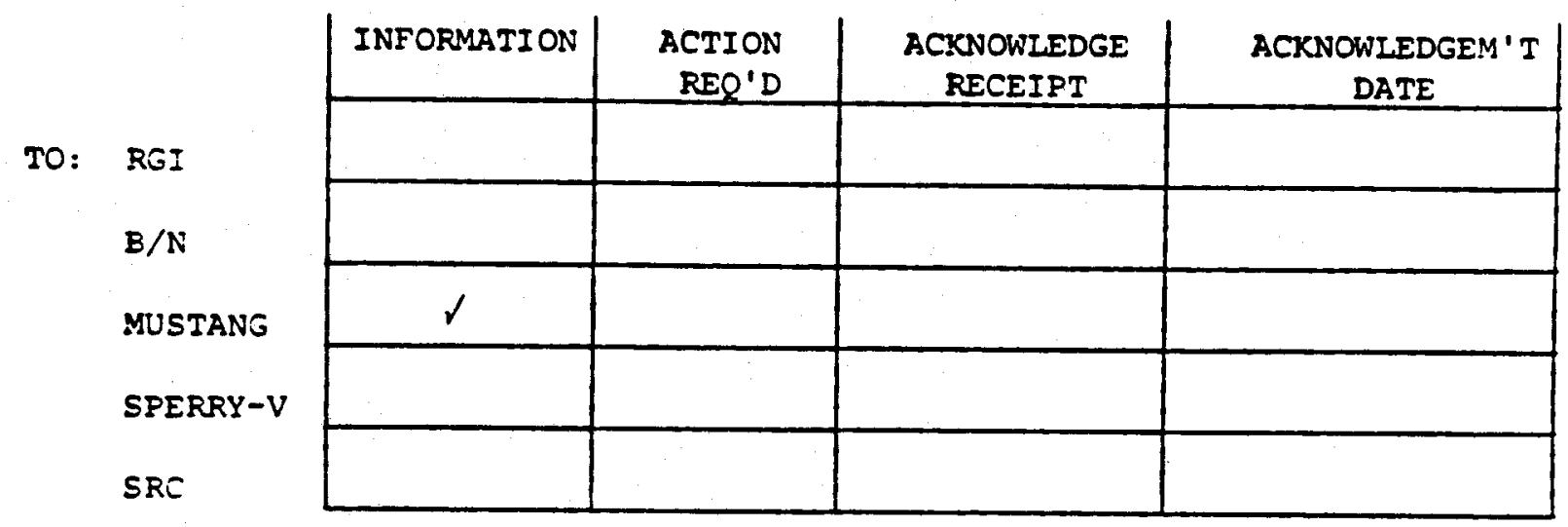

SRC DISTRI'BN: $W$. MCBee (Central File), $/$ H. Matthews, $/$ K. Hules, C. Harvey, R. Mara, $\checkmark$ w. Kent, B. Toekes File, H. Fettig/C. Mchale, D. Gordon, DESCRIPIION: Test site

PUMP SYSTEM PERFORMANCE \& DOWNTELL ORIFICE SIZING

Memo from $B / N$, dated $12 / 16 / 80$

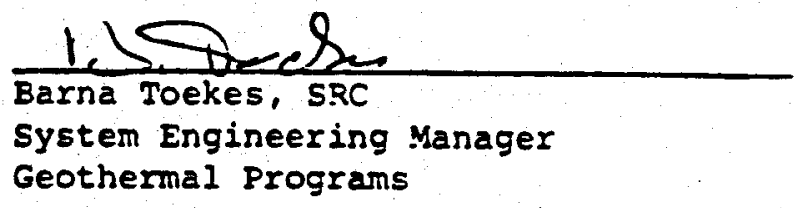

COMYENTS BY ADDRESSEE:

Change in SCOPE, $\cos T$, SCHEDULE OTHER COMMENTS 
December 16, 1980

TO:

Barna Toekes, Sperry Research Center

FROM:

$$
\text { R. W. Langley そWん }
$$

SUBJECT:

1) Pump System Off-Design Performance

2) Downwell Orifices for $R-114$ Feed Line.

cc:

Claude Harvey, SRC

Karst Postma, MEC

Attachment 1 is a summary of an analysis of the off-design performance of the pump system that predicts the brine pressure at the wellhead as a function brine and $R-114$ flow rates and TPU speed.

Attachment 2 gives the sizes of the orifice plates that restrict the $\mathrm{R}-114$ feed to maintain a liquid-filled downcomer. Table 1 gives the orifice plate dimensions for a corresponding range of $R-114$ flow rates and feed pump pressures. The orifices, to be fabricated by Mustang Engineering, were sized to be housed in the same configuration as the body of the Vickers pressure control valve that the orifices will replace. 
SLMMARY

Welltead trine pressure was predicted for the Sperry stand-alone pump system as a function of $R-114$ now rate and brine now rate. The results are presented in Figure 1.

DISCUSSION

Throughout the analysis, a $70^{\circ} \mathrm{F}$ wetbulb temperature and a $119^{\circ} \mathrm{F}$ surface exhaust stream temperature were assumed. Also, assuming an oversized heat exchanger, the turbine inlet temperature To was held constant at $330^{\circ} \mathrm{F}$ for all now conditions. Turbine inlet pressure Po was varied from 250 to 650 psia. Additional assumptions and the analytical procedure, as outlined in Figure 2, are discussed below.

A turbine inlet pressure Po was specified which, assuming a $330^{\circ} \mathrm{F}$ turbine inlet temperature ard using a choked flow model, establisted an R-114 Now rate iR-114. Figure 3 summarizes predicted $R-114$ Iow rate as a function of Po.

Knowing UR-114 and $T w b$, the condensing temperature Tc was determined by using the predicted performance for one Baltimore condenser shown in Figure 4. Assuming saturated condenser Inlet and exit conditions and a $70^{\circ} \mathrm{F} \mathrm{Twb}$, the heat load divided by the latent heat at Ic determines the condenser R-114 now rate. Since two condersers are required, the total $R-114$ now rate is equal to twice the flow rate through one condenser. Thus the relationship between the total $\mathrm{R}-114$ flow rate and the condensing temperature determined from predicted condenser performance establishes the condensing temperature. The condensing presslire is then equal to the saturation pressure at Tc.

Condensing pressure Pc, surface equipment pressure drop $\Delta$ Ps.e., and exhaust column static head $\triangle \mathrm{Pg}$ determines the turbine exhaust pressure. The frictional pressure drop in the exhaust stream was neglected because a preliminary analysis showed it was small relative to the static pressure. The surface equipment pressure drop was assumed to be proportional to the $R-114$ Now rate squared ard inversely proportional to the average density: At a flow rate of $38 \mathrm{lbm} / \mathrm{sec}$ and an average density of $1.377 \mathrm{lbm} / \mathrm{sec}$, $\triangle P$ se was assumed to be 6.8 psid. The static head was determined using ideal gas relations and assuming an isentropic process. The equations used and resulting turbine exhaust pressures are summarized in Figure 5.

Knowing Pe and specifying a turbine speed from a range of 6,000 to $12,000 \mathrm{spm}$, the isentropic head $\Delta \mathrm{h}^{\prime}$ and the velocity ratio $U / C o$ were evaluated. The turbirie efficiency $\eta t$ was then obtained irom BarberNichols turbire performance data of $9 / 23 / 80$ summarized in Figure 6 and the turbire horsepower was calculated. Figure 7 shows the predicted turtire power as functions of speed and inlet pressure. 
The turbine horsepower minus mechanical losses determines pump horsepower. Mechanical losses were assumed to be proportional to the speed squared and were $15 \mathrm{hp}$ at $10,500 \mathrm{rpm}$. Knowing the pump horsepower and speed, the pressure rise through the pump and the brine now rate were obtained using the purnp performance curves shown in Figure 8 and pump similarity laws. These performance curves were developed using - Barber-Nichols pump performance data of 10/3/80, see Figure 9.

Finally, the wellhead pressure Pwh was determined by summing the shut-in wellhead pressure, assumed to be 130 psia, and the pump pressure rise and subtracting the drawdown for a PI of $2.4 \mathrm{gpm} / \mathrm{psi}$ and the friction drop $\triangle \mathrm{P}$ now. It was assumed that the friction drop was proportional to the brine now rate squared and at $1050 \mathrm{gpm}$ its value was 25 psid.

The results of these calculations are summarized in Figure 1. 


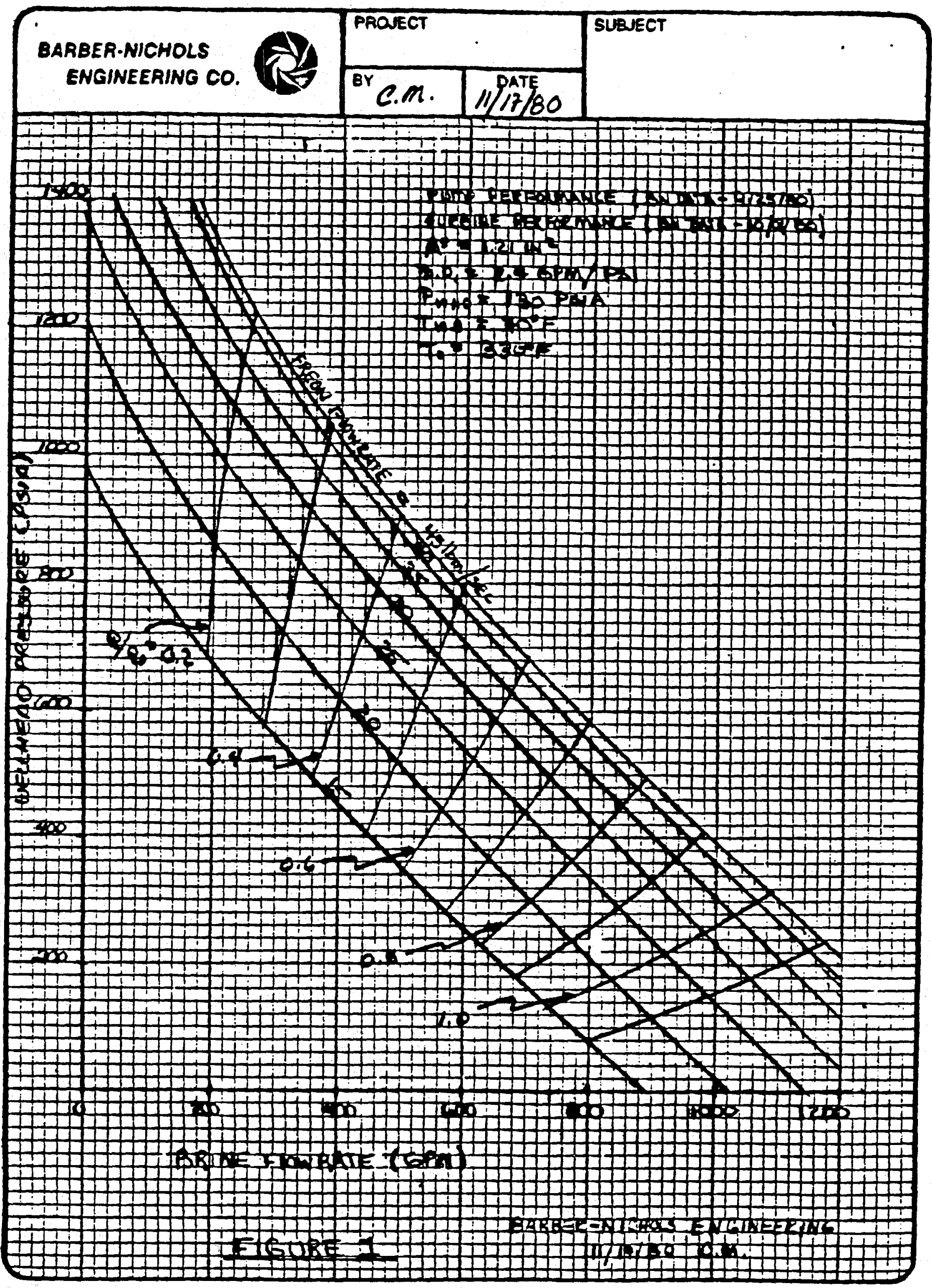




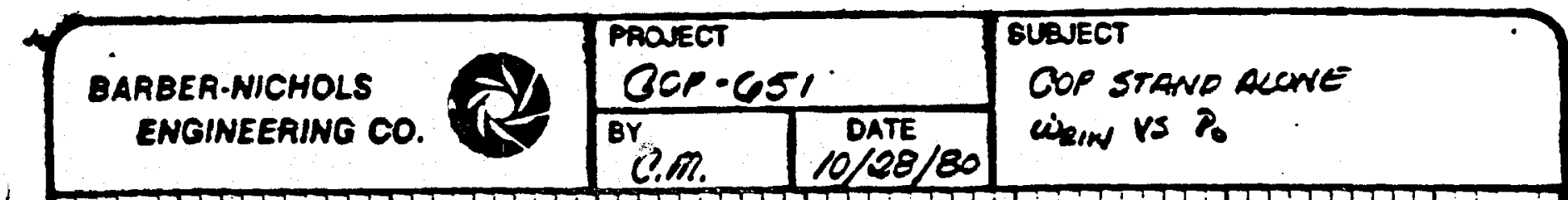

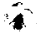

$-$

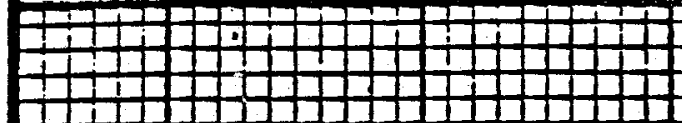
It

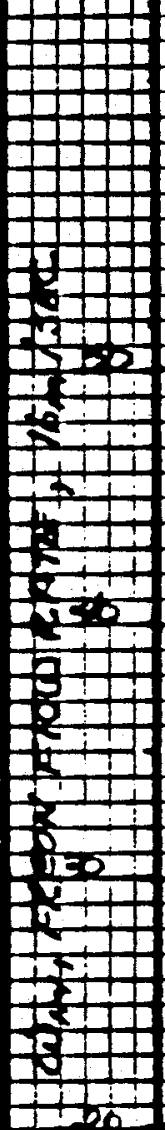

\begin{tabular}{lll}
\hline & & \\
\hline & & \\
\hline & 1 \\
& & 1 \\
\hline & & 1 \\
\hline &
\end{tabular} tattit $1+1710$

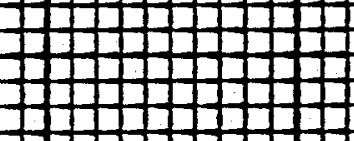

$$
\text { tf }
$$

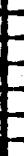

1 thathitat 


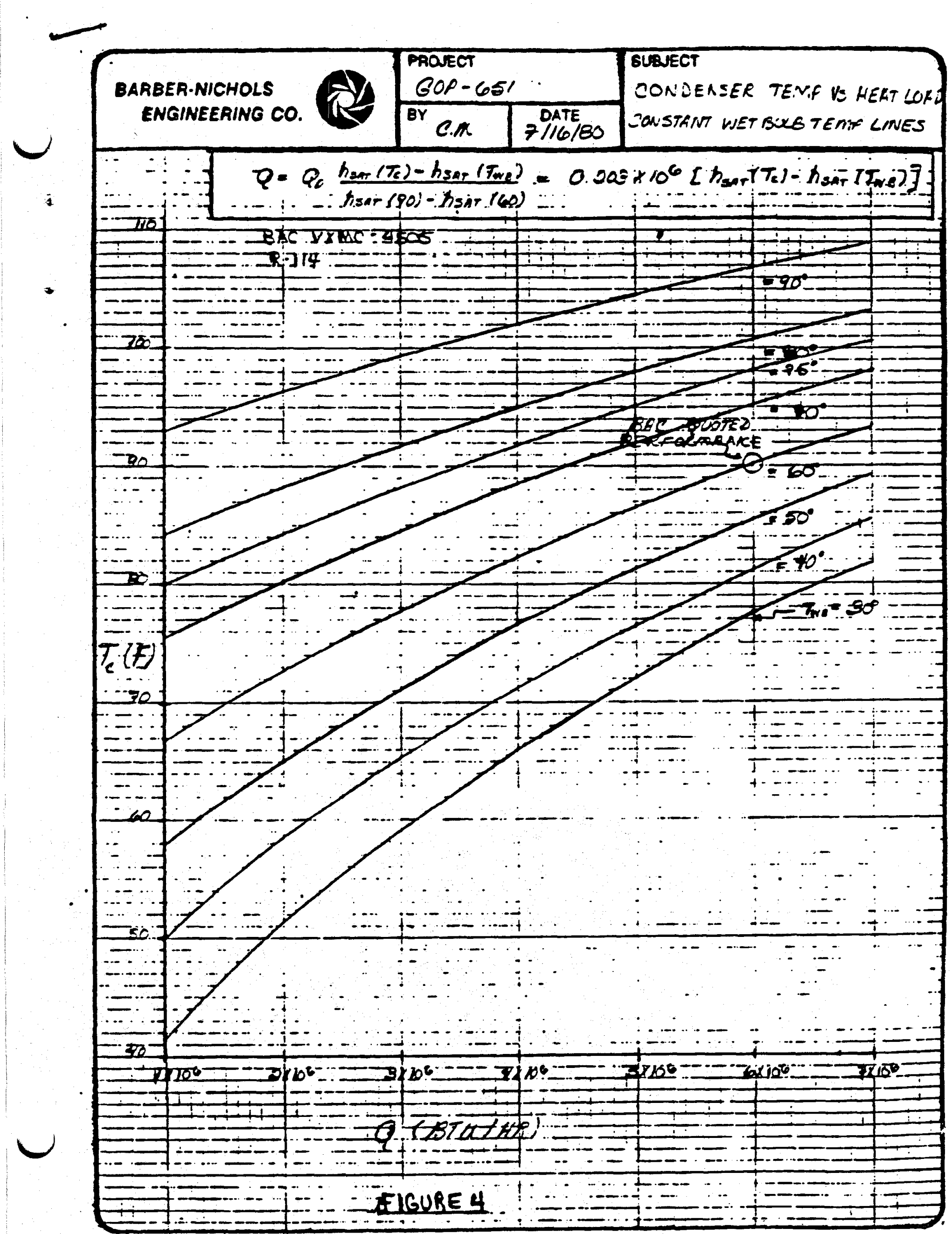




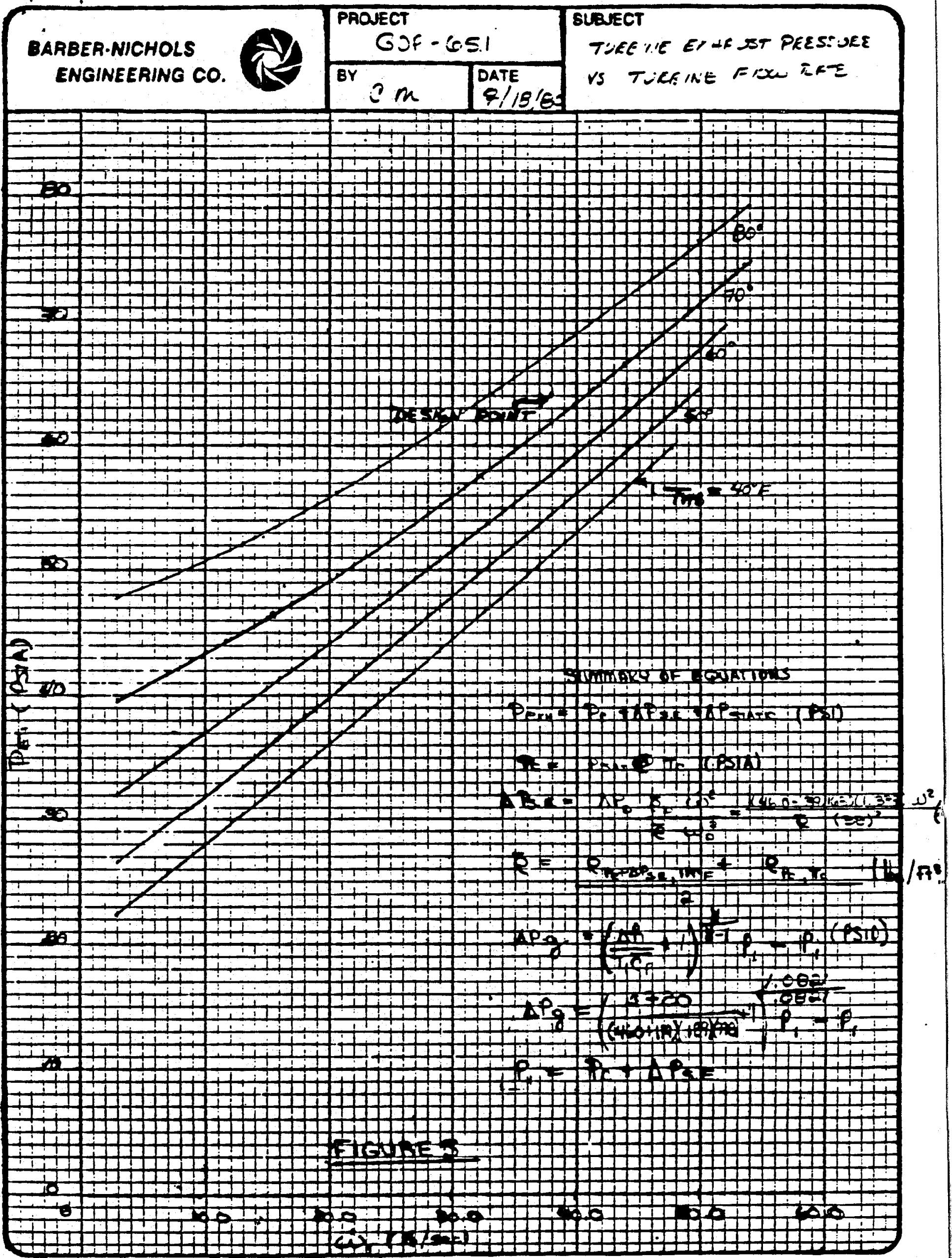




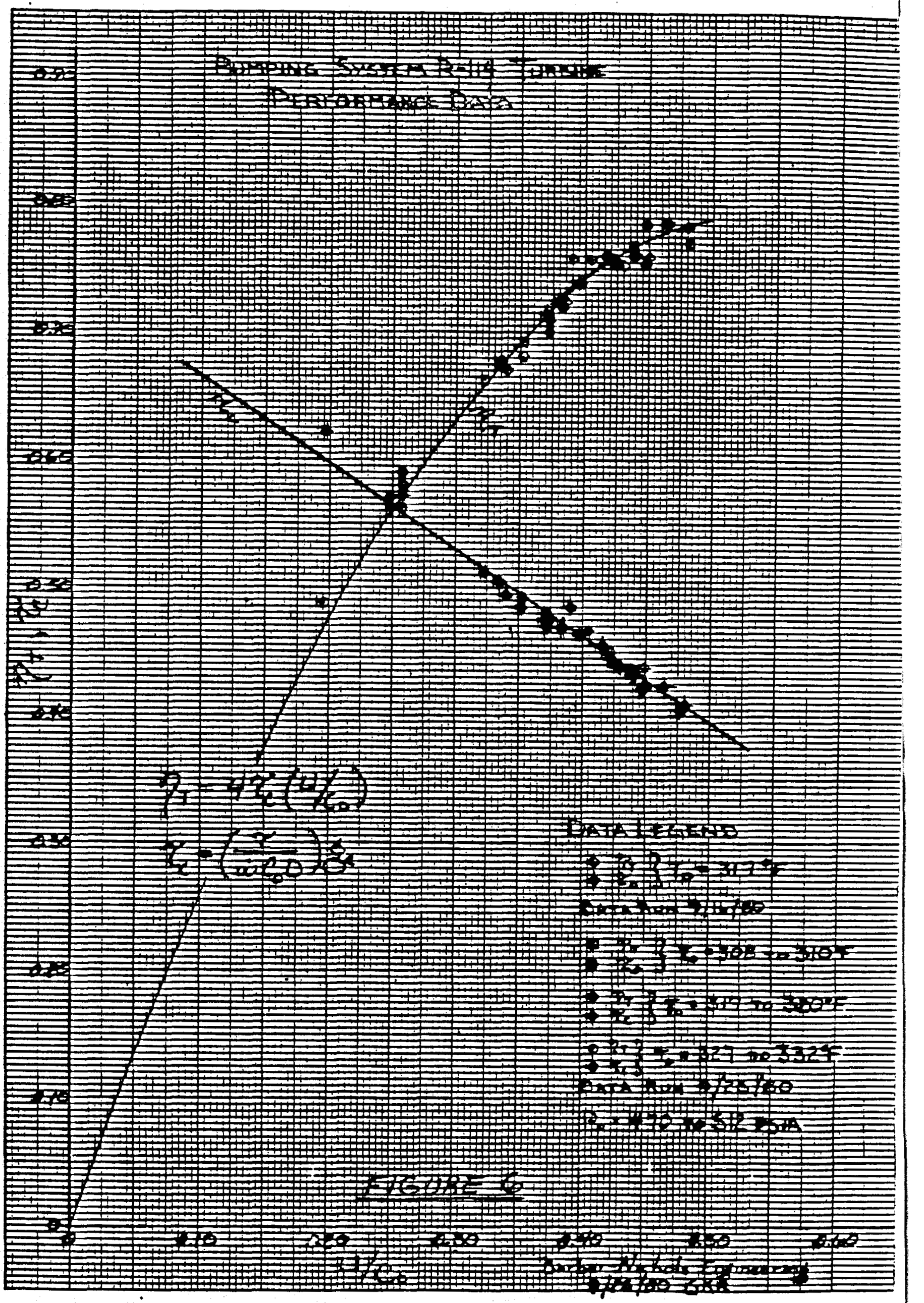




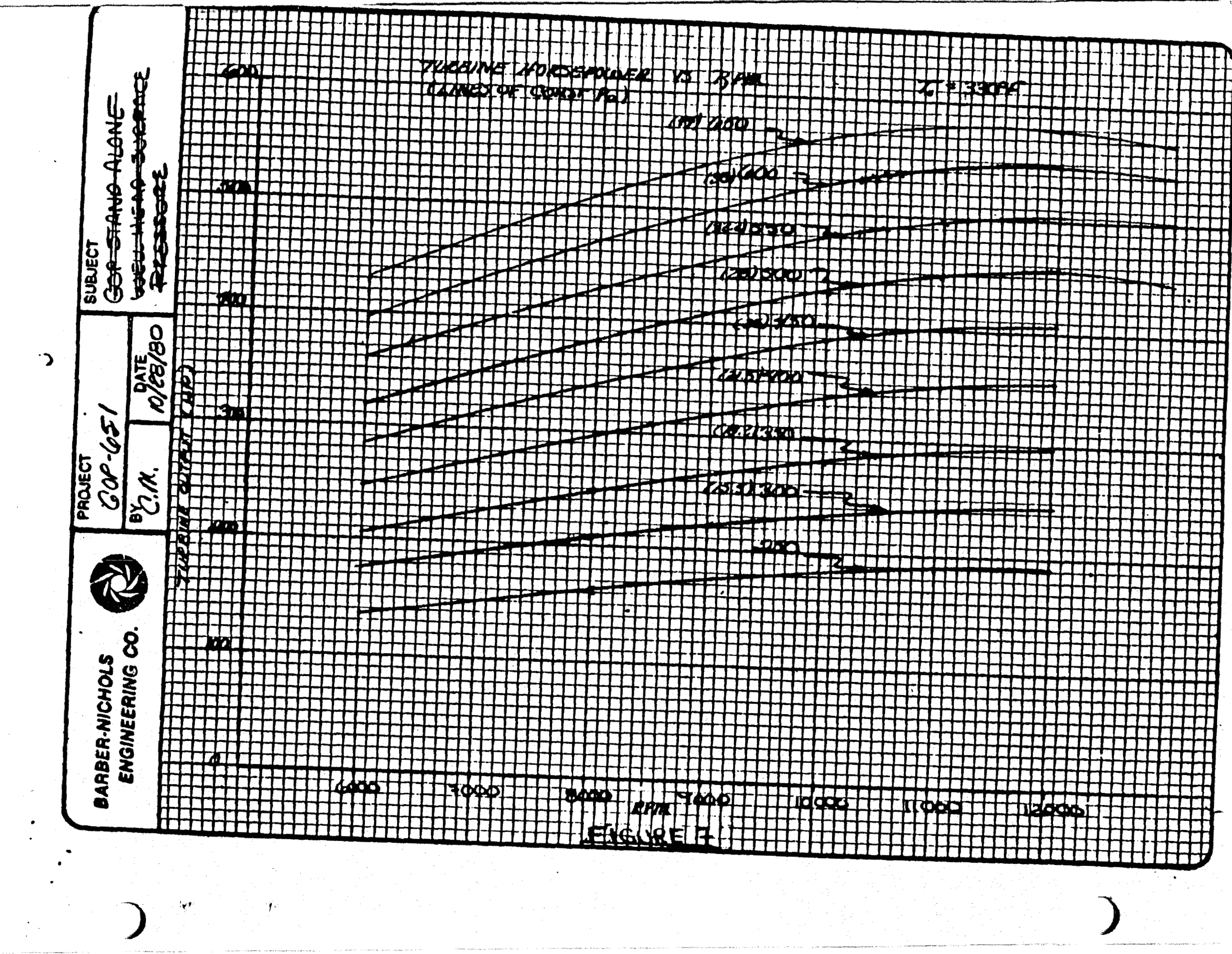




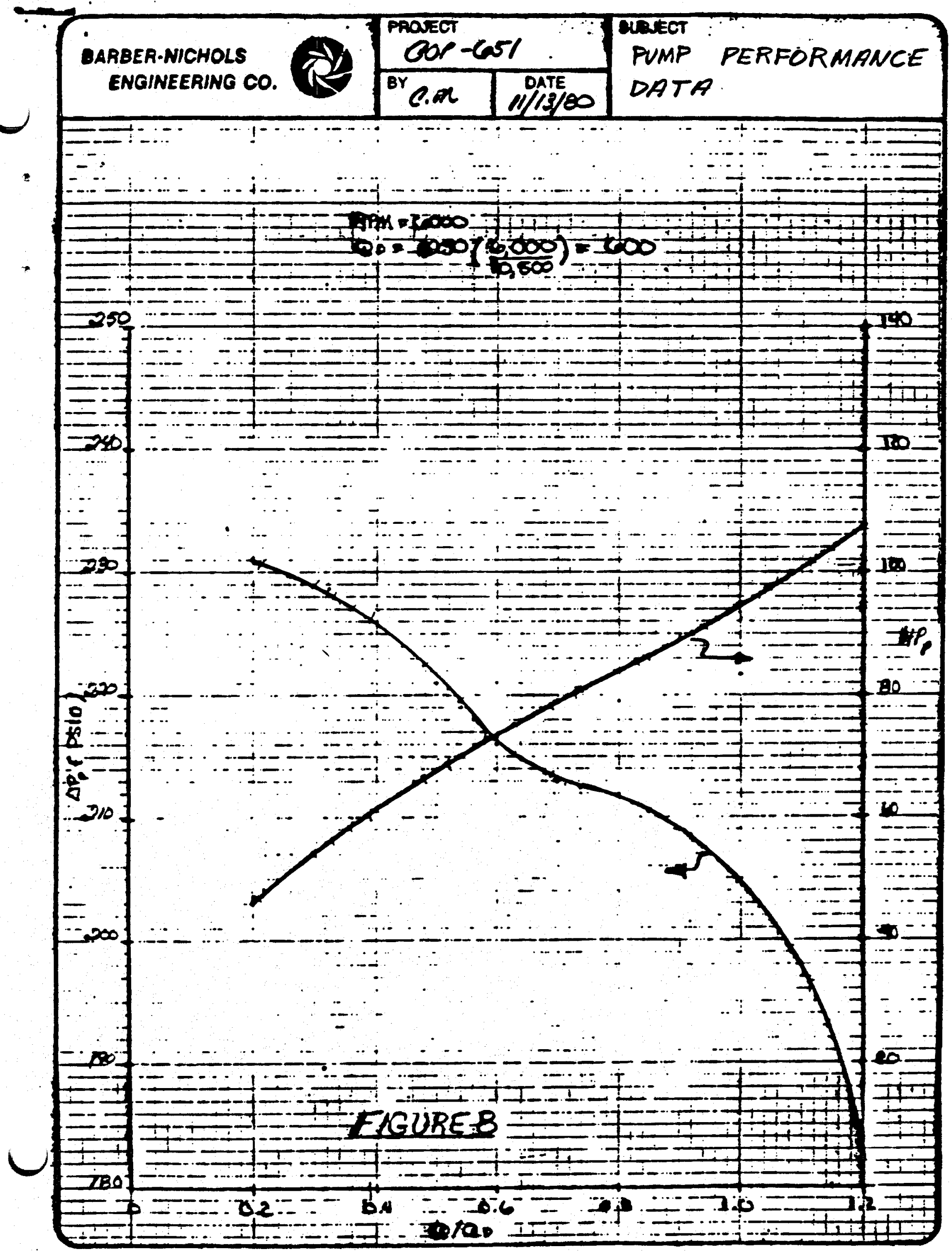




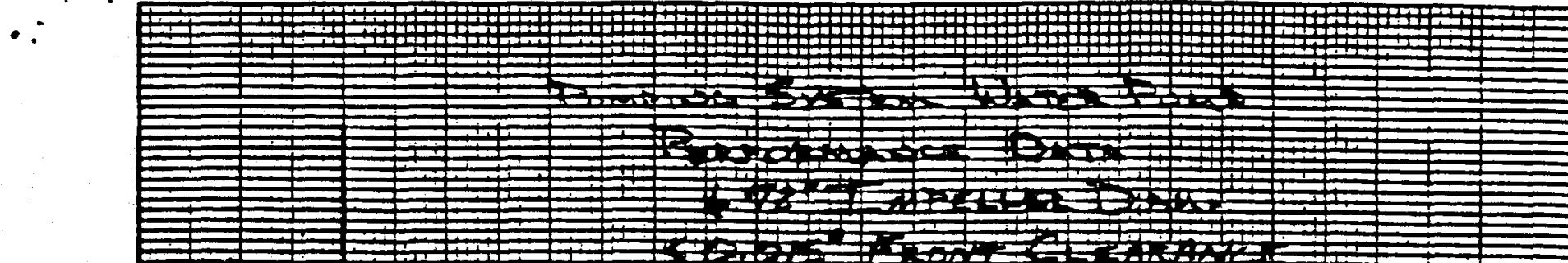
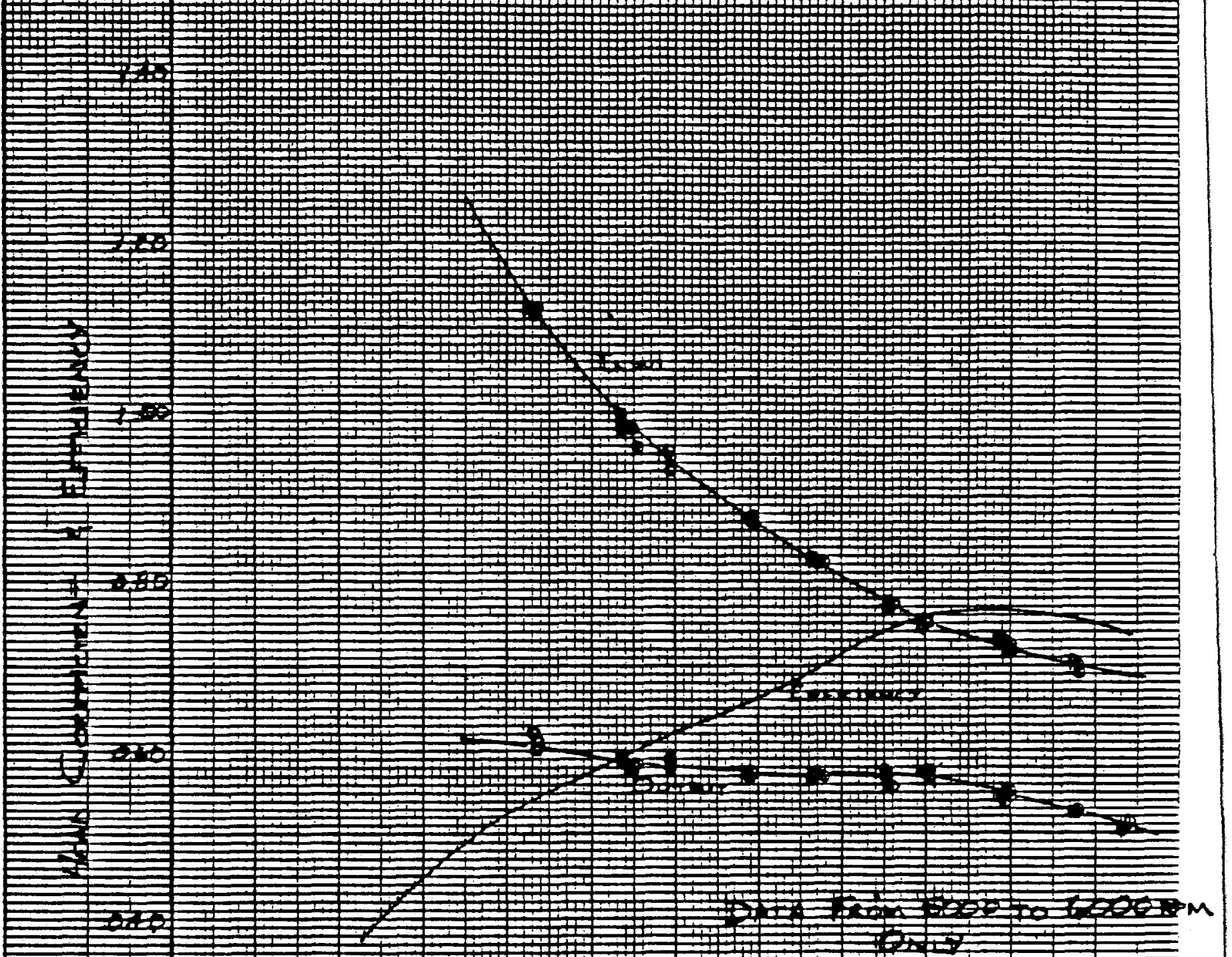
ORIFICE PLATES FOR THE SPERRY

STAND-ALONE PUMP SYSTEM

December 12, 1980

\section{SUMMARY:}

To maintain an all-liquid downcomer for the Sperry stand-alone pump system, a sequential set of thin-plate, square-edged orifice plates was Bized. Seven orifice plates are required to cover an R-114 flow range of 15 to 60 $1 \mathrm{bm} / \mathrm{sec}$. The operating ranges of consecutive orifices overlap by 5 percent. The size and operating range of each orifice is presented in Table 1.

DISCUSSION:

The useful operating range of each orifice is limited by the available surface pump pressure. The pump pressure required for a given flow rate and orifice size is determined by

$$
\Delta P_{P}=P_{O}+\Delta P_{O R F}+\Delta P_{f H X R}+\Delta P_{f F P}-\Delta P_{g F P}-\Delta P_{g H X R}-P_{S}
$$

where:

$$
\begin{aligned}
\Delta P_{P} & =\text { pressure rise in surface pump, psid } \\
P_{O} & =\text { turbine inlet pressure, psia } \\
\Delta P_{O R F} & =\text { pressure drop across orifice, psid } \\
\Delta P_{\text {fHXR }} & =\text { friction pressure drop in heat exchanger, psid } \\
\Delta P_{\mathrm{fFP}} & =\text { friction pressure drop in feed pump, psid } \\
\Delta \mathrm{P}_{\mathrm{gHXR}} & =\text { gravity pressure rise in heat exchanger } \\
\Delta \mathrm{P}_{\mathrm{gFP}} & =\text { gravity pressure rise in feed pipe } \\
\mathrm{P}_{\mathrm{S}} & =\text { inlet pump pressure. }
\end{aligned}
$$

The orifice pressure drop $\triangle P_{O R F}$ is determined by

$$
\triangle P_{\text {ORF }}=\frac{\mathrm{BO}^{2}}{2 \mathrm{BCPK} \mathrm{AO}^{2} 144}
$$

where: 
in $\quad=\mathrm{R}-114$ now rate, $\mathrm{lbm} / \mathrm{sec}$

$j$

gc = conversion factor, $32.17 \mathrm{lbm} / \mathrm{sec}$

$\mathrm{e}=$ upstream orifice density, $\mathrm{lbm} / \mathrm{Ft}^{3}$

$k \quad=$ velocity coefficient; $=\mathrm{CF}$, ratio

c = discharge coefficients, ratio

f $\quad$ velocity of a pproach factor; $\frac{1}{\sqrt{1-\beta^{4}}}$, ratio

$\beta=$ ratio of diameters; $=\frac{\mathbf{D}}{\mathrm{D}}$. ratio

d = orifice diameter, in.

D = pipe diameter, in:

Ao = orifice area, $\mathrm{Ft}^{2}$

Assuming insufficient length after the orifice to reestablish a fully developed velocity prof ile, a pressure recovery factor was not included in the orifice pressure drop equation. Discharge coefficients $C$ were obtained from ASME's Fluid Meters: Their Theory and Application, Part II.

The calculations were made assuming the following conditions:

1) Constant turbine inlet temperature of $330^{\circ} \mathrm{F}$;

2) 40 psia pump inlet pressure corresponding to a $90^{\circ} \mathrm{F}$ condensing temperature;

3) Constant gravity pressure rise of 892 and 18 psid in feed pipe and heat exchanger respectively; and

4) Constant upstream orifice density of $80.2 \mathrm{lbm} / \mathrm{Ft}^{3}$.

A summary of the results is presented in Table 1. 
TABLE 1

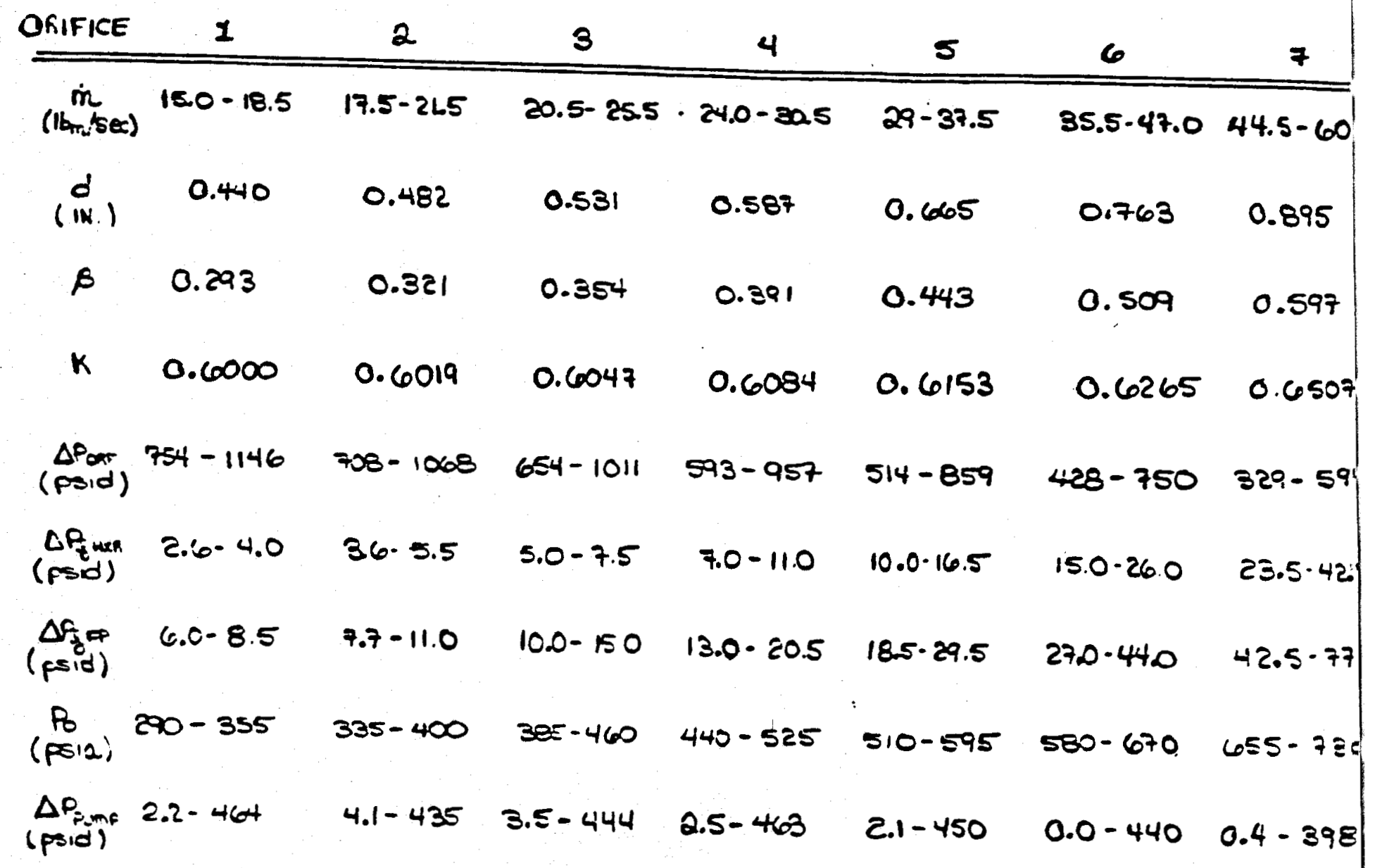




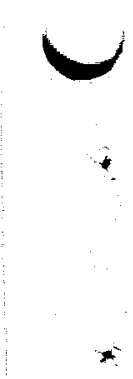

\section{APPENDIX E}

TURBINE-PUMP UNIT

TEST PROGRAMS 


\title{
BARBER-NICHOLS \\ ENGINEERING
}

\author{
GEOTHERMAL ORGANIC PUMP \\ COMPONENT TESTING \\ ALGLST 19, 1981
}

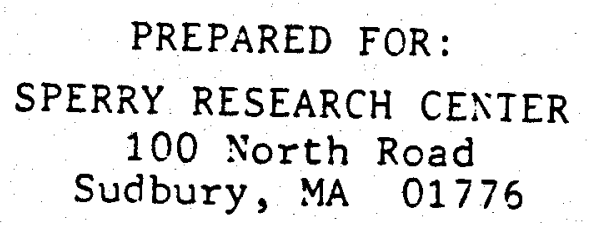




\subsection{INTRODUCIION}

The high reliability requirement of the stand-alone Geothermal Organic Pump (GOP) system mandates that thorough laboratory testing \$ of components be conducted. High confidence in the Turbo-Pump-Unit (TPU) performance must be established before it is subjected to downwell service, where there is no access for maintenance or repair.

A complete TPU test program was conducted at Barber-Nichols' facility from August 1979 to March 1981. The first of three phases of the program involved assembling critical subcomponents into special fixtures to test performance and to obtain data needed to finalize the designs. By testing separately, each subcomponent could be fully instrumented to obtain the data needed to map that component's performance. Hardware modification, if necessary, was simplified due to ease of access to components when they were tested separately. Tests were conducted on the following TPU subassemblies:

a) Ball bearings and lube system

b) Centrifugal pump section

c) Turbine section

d) Shaft seals

The second test phase involved performance mapping of the fully assembled TPU. A Rankine cycle facility was constructed at the Barber-Nichols plant for simulated downwell testing.

The final phase of TPU testing was a series of endurance runs designed to shake down the unit and to establish confidence in the system.

During commencement of the IPU test program another series of tests were conducted on a few other downwell components of the stand-alone system. A series of simulated well tests were conducted on the packer cups (which form the TPU-to-well seal). Also tested were the 4.5 inch sliding seal and the exhaust transition seal. The evaporative condensers which are to be used in the stand-alone system were tested to verify manufacturer's data.

Included in the report is a description of a test for two-phase flow pressure drop in an exhaust riser. 


\subsection{BALL BEARING TEST}

Bearing longevity is a crucial element of trouble-free downwell TPU operation. Maximizing the bearing life by experimentally optimizing bearing preload was the overlying goal of the bearing test program.

The fatigue life of a rolling element bearing varies inversely with the cube of the axial load, which is comprised of the applied load and the preload. Thus, the amount of preload on a bearing should be minimized in order to obtain maximum life. There exists a minimum preload, however, below which a "skidding" condition occurs due to loss of rolling contact between the balls and the raceways. Skidding is reported țo reduce drastically the life of a bearing. For optimum bearing life, preload should be set at the lowest level that insures adequate thrust for non-skidding operating conditions. The bearing test program was carried out to define experimentally the ball bearing skidding behavior unique to the IPU system and, thus, establish confidence in a safe minimum preload.

The test plan was to operate the bearings first at $80 \%$ of design speed, taking all data in increments ranging from high preload to very low preload, thus mapping a curve of retainer/race speed ratio versus preload. This procedure was then repeated for design speed and $20 \%$ over design speed.

\subsection{BALL BEARING TEST APPARATUS}

The test apparatus was designed to operate IPU bearings in an environment identical to that of the TPU, with the ability to vary preload while monitoring important parameters. Figure 2.1 is a layout of the ball bearing test $\mathrm{rig}$, and Figure 2.2 is a layout of the test stand. The rig was designed to accept swing-pad hydrodynamic bearings as well as ball bearings.

\subsection{BALL BEARING TEST INSTRUMENTAIION}

Preload thrust to the test bearing was supplied and measured by a strain gauge load bolt which exhibits varying electrical resistance proportional to the quantity of tension in its shank. Shaft rotational speed was measured with a magnetic pickup device. Rotational speed of the bearing retainer was measured with a proximity probe. The probe generates a magnetic field and reads interruptions in that field created by eleven steel screws set in the bronze retainer. Skidding 


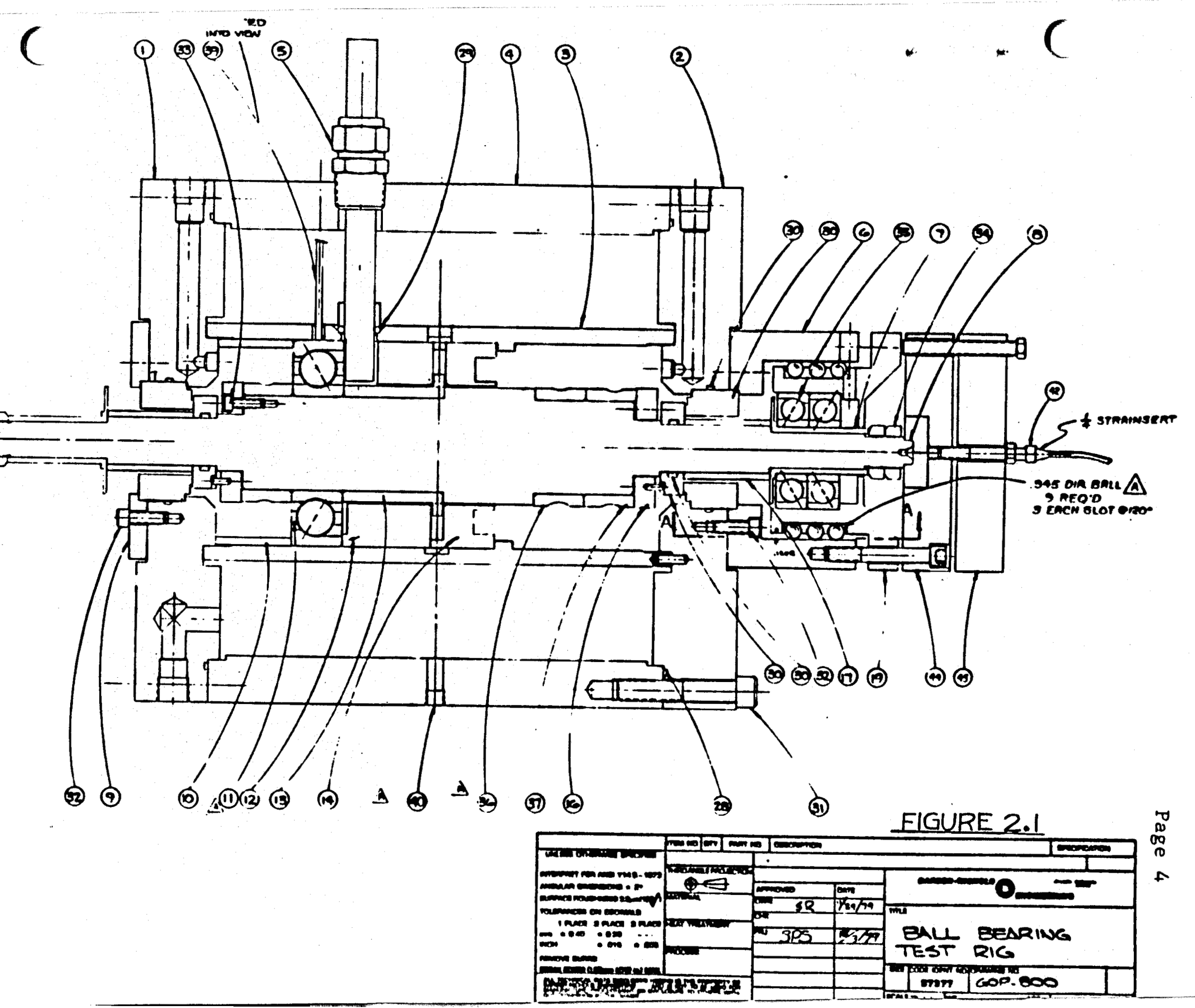



was detected by monitoring changes in the ratio between the retainer speed and the inner race (shaft) speed. Other parameters measured were: ofl temperature, race temperature, oil flow rate, oil inlet and outlet pressures, and shaft torque. These data provided additional information such as oll circulation pump performance and bearing power consumption.

\subsection{BALL BEARING TEST RESULTS}

The results of the skid test program are presented in Figure 2.3. Using the three skidding curves obtained, an empirical correlation between minimum safe preload and shaft speed was calculated to be:

$$
\text { Minimum preload (lbs) }=4.355\left(10^{-6}\right) \times \text { speed }^{2}(\mathrm{rpm})
$$

The above equation is very slightly arbitrary in the sense that there is no distinct knee in the skidding versus preload curve (Figure 2.3) to assign a value where "skidding occurs". The stars indicate where the minimum safe preloads calculated by the above equation occur on the curves. These points lie near the maximum value of speed ratio for each curve.

It should be noted on the curves in Figure 2.3 that the speed ratio increases with decreasing preload before it starts dropping. We believe this increase is due to slight straining of the bearing materials under high thrust loads which increases the contact angle. When thrust is reduced, the contact angle reduces and the speed ratio increases slightly.

Other correlations were obtained during testing. Figure 2.4 shows curves of retainer/race speed ratio versus hydraulic pressure of lubricating oil. It is seen from these curves that there is no significant change in skidding characteristics due to variations in pressure. The vertical displacement between the curves is due to differing bearing temperatures from test to test. After the oil pressure test above was completed, a test was conducted to determine the effect of temperature on the retainer/race speed ratio during no-skid conditions. It was found that this ratio increases with bearing temperature, probably due to changes in bearing contact angle with thermal growth. This behavior explains the non-closure of the curves in Figure 2.3, since the test bearing always heated up during the course of a test run. 


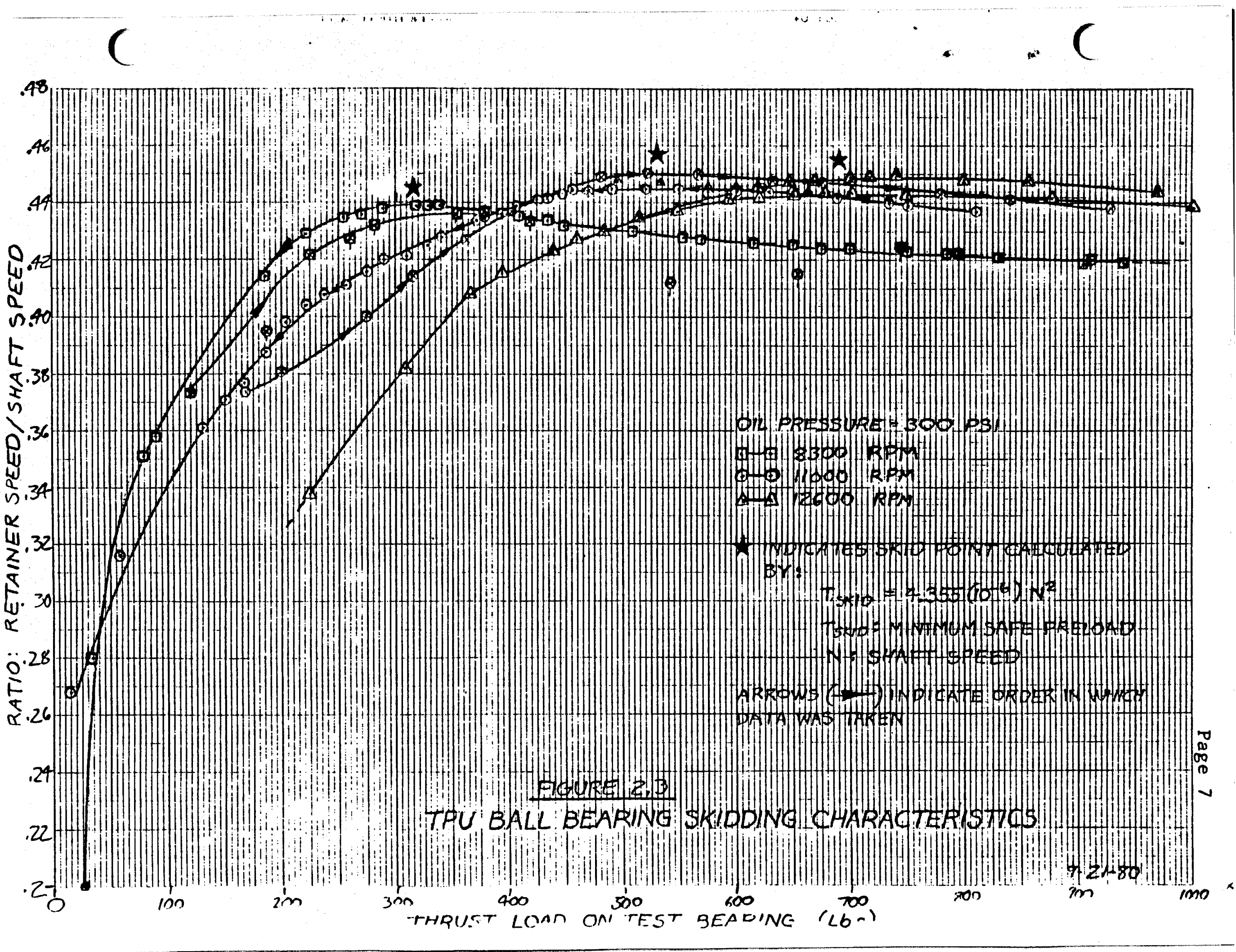




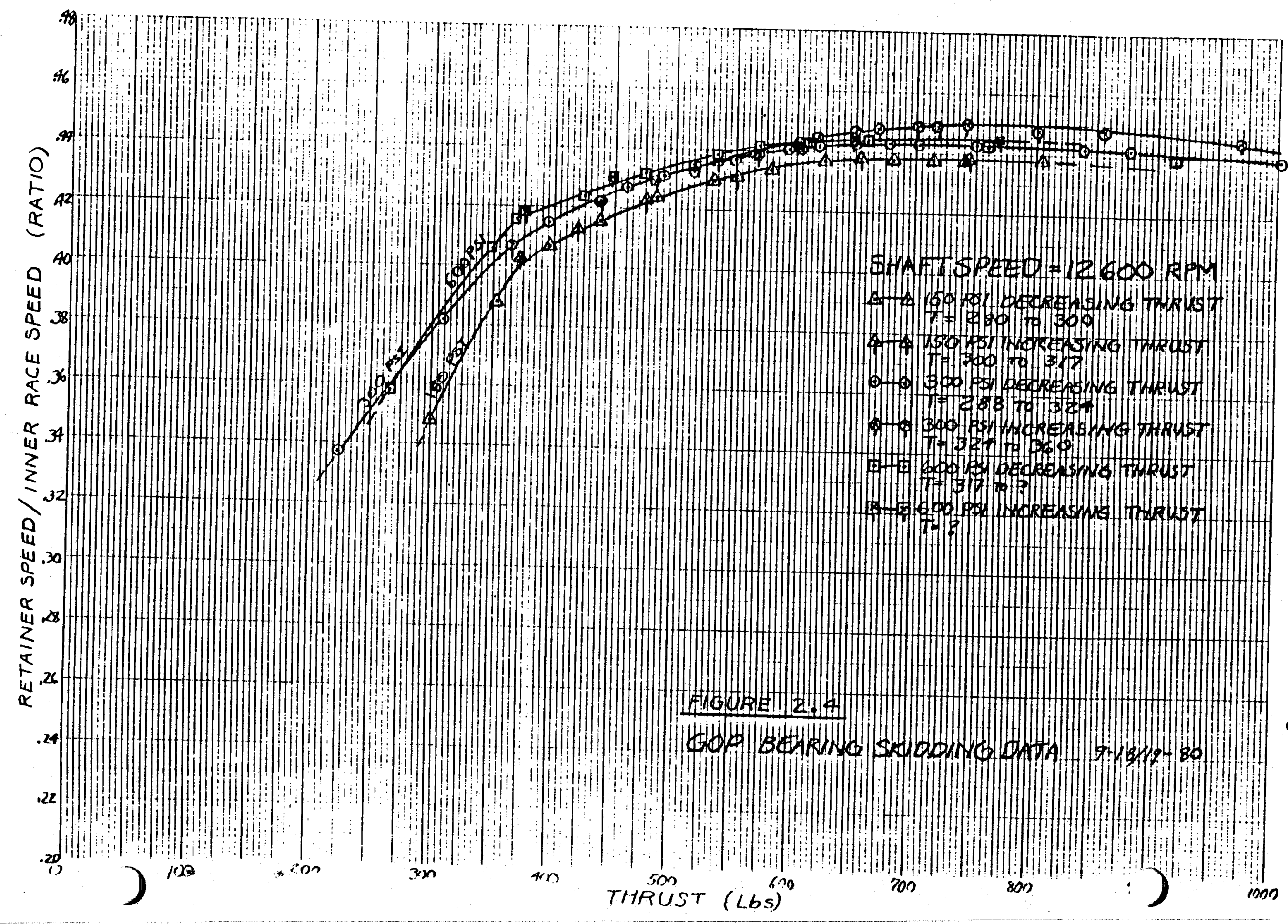


Before the data presented in this paper was generated, certain problems were encountered and corrected. For example, during one series of tests skidding rates were greatly affected by oil pressure. This test was halted by a failed shaft seal. When the seal was rẹplaced and the unit was back on line, testing showed no sensitivity of the skidding rates to oil pressure. It is our opinion that poor de-aeration of the oil was the cause of the sensitivity to pressure. This opinion is based on careful scrutiny of the test unit and an improved method in filling the machine with air-free oil after the seal fix. There has been no testing to date, however, to verify the cause of the pressure sensitivity.

\subsection{PLMP TEST}

The initial pump testing involved an investigation of the pump's performance characteristics and the thrust loads. Then a series of tests compared the performance of several different impeller configurations to achieve the optimum pump performance and to achieve thrust balance with the turbine. Impeller parameters that were varied during these tests included impeller diameter, impeller clearances, and pump-out vane diameter.

\subsection{PLMP TEST APPARATUS}

The TPL pump section components were designed into a test assembly as shown in Figure 3.1. The input power to the impeller was provided by a gasoline engine coupled to the pump through a step-up gearbox. The design input power to the pump is $485 \mathrm{Hp}$ at $10,500 \mathrm{rpm}$. However, since pump performance is correlated accurately over a wide range of conditions (by the dimensionless quantities of head coefficient and flow ratiol, the available engine power of $150 \mathrm{Hp}$ was sufficient to evaluate pump performance.

The pump end of the assembly mounted into a flow loop designed for it and for the IPU test. The flow loop (Figure 3.2) was designed to simulate well conditions. Water in the loop entered the pump suction at $350^{\circ} \mathrm{F}$ and $400 \mathrm{psig}$. At $10,500 \mathrm{rpm}$, the design pump flow rate is $1000 \mathrm{gpm}$, and the head rise is $1390 \mathrm{ft}(600 \mathrm{psid})$. Downstream of the pump discharge the flow was regulated by a hand-operated flow control valve, metered with an ASME orifice, and returned to the pump suction. Water temperature was maintained by bypassing some of the flow to a 300 ton cooling tower. The accumulator tank was half full of water and half full of pressurized nitrogen, which was 

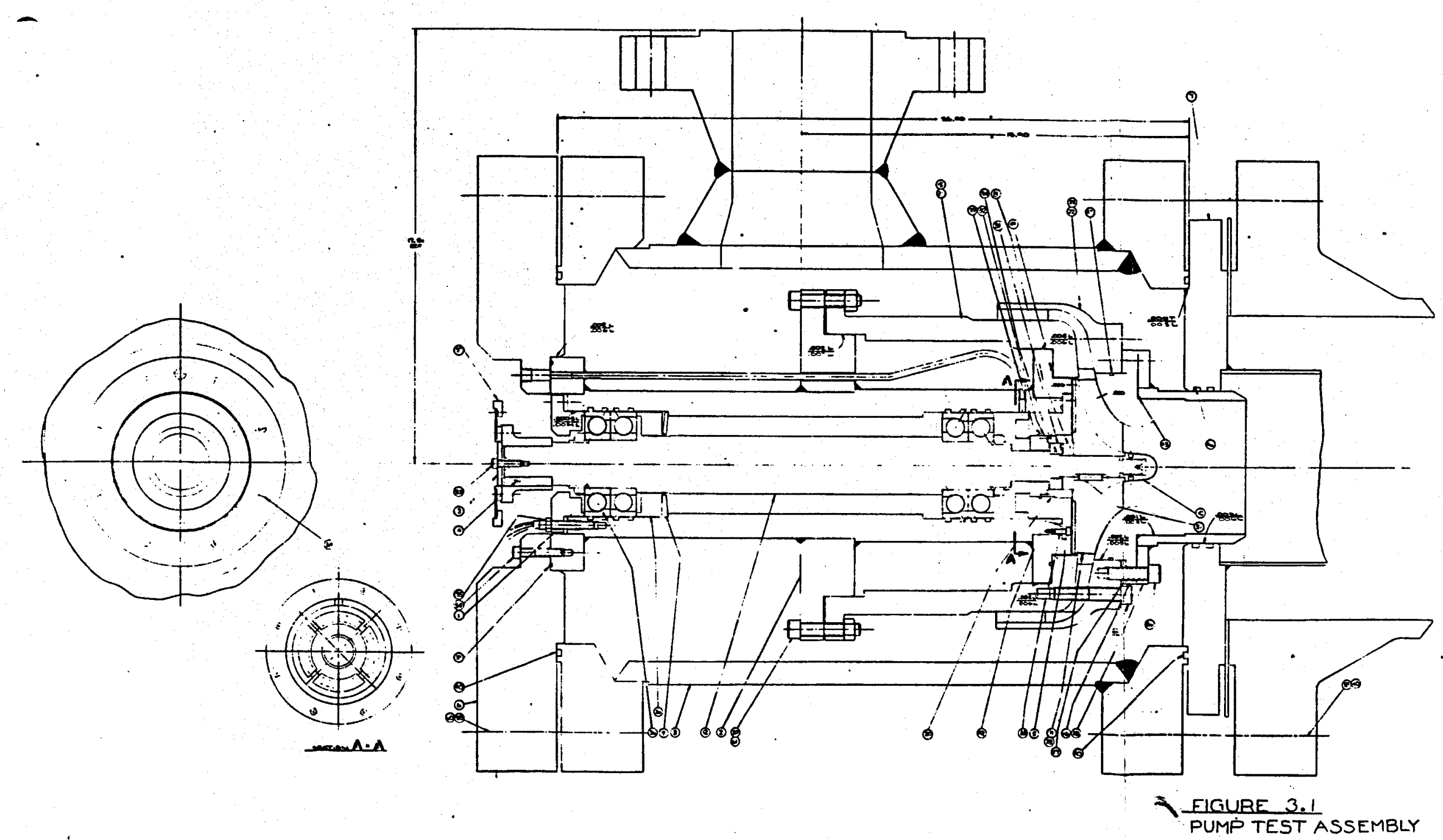


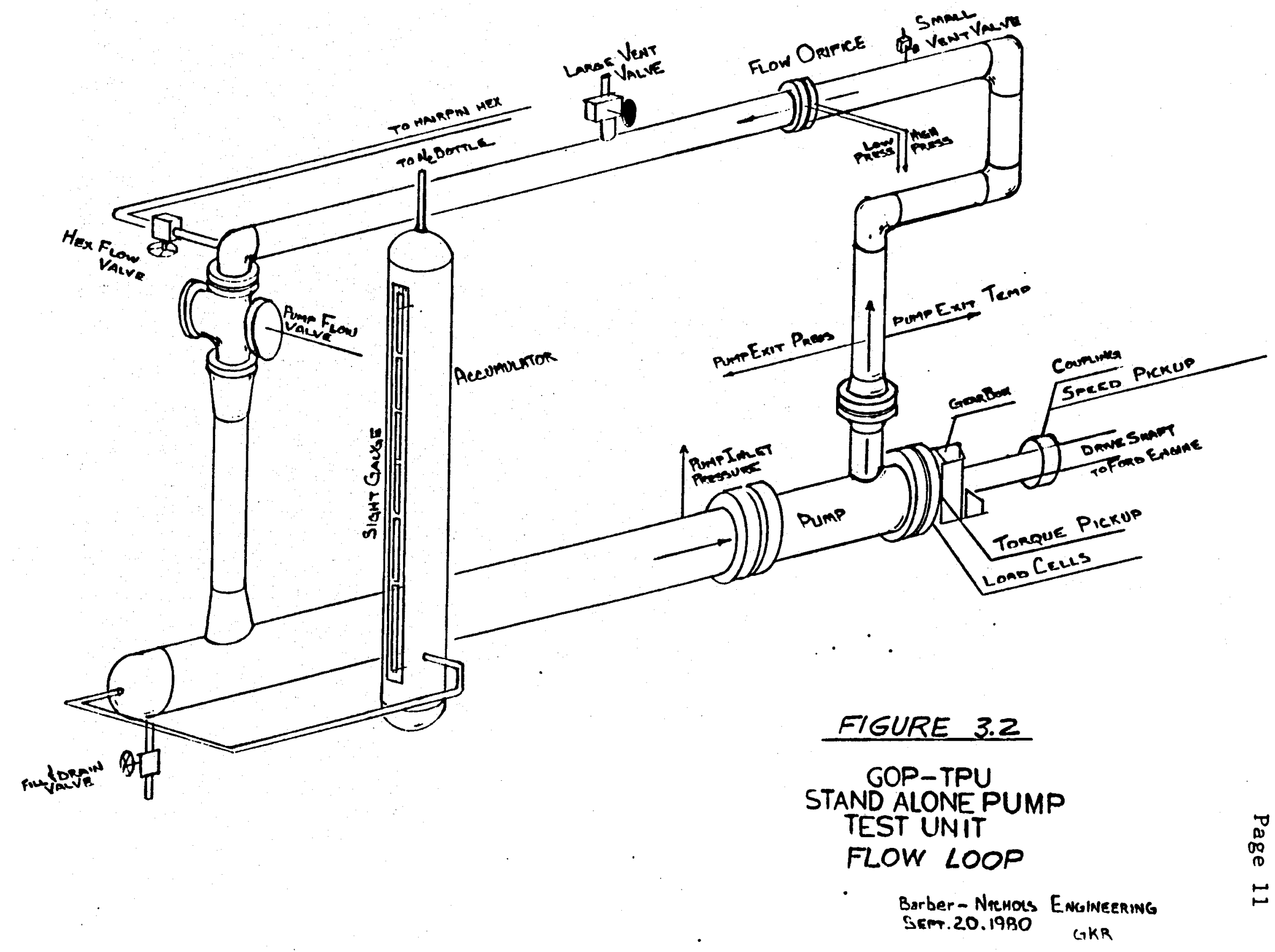


used for controlling the pump inlet pressure and providing expansion room for the heated water.

\subsection{PUMP TEST INSTRUMENTATION}

The pump test was instrumented to monitor pump inlet pressure, exit pressure, exit temperature, water flow rate, output speed and torque of the gasoline engine, and the axial thisust developed by the impeller. All pressure measurements were made with Bourdon tube pressure gauges calibrated using instruments traçeable to the National Bureau of Standards. Temperatures were measured with immersiontype bimetallic thermocouples. Water flow rate was measured as pressure drop across a square-edged orifice constructed and installed according to the ASME Power Piping Code. Shaft speed was monitored with a magnetic pickup device. A Stuska hydraulic torque meter measured the reaction force of the trunion-mounted gearbox housing for power calculations. The axial thrust load was measured using three strain gauge-type load cells calibrated statically in dead weight tests. 3.3: PUMP TEST RESULTS

Data for the selected pump design as tested separately and as part of the TPU is presented in Table 3.1. Comparison testing of several impeller diameters,pump-out vane configurations, and impeller clearances led to the selected pump impeller design. The selected impeller is 6.72 inches in diameter. Design pump impeller front clearance is 0.015 inch. Figure 3.3 shows performance versus flow rate.

Table 3.1 offers a point-by-point comparison of the predicted and measured pump performance. Since neither the pump test assembly nor the TPU test assembly were capable of producing the design turbine output power of $525 \mathrm{Hp}$, pump performance was reduced to a dimensionless quantity called flow ratio, which is the measured flow rate divided by measured speed over the ratio of design flow rate to design speed. Data presented in Table 3.1 is for the design flow ratio of 1.00 . An examination of the performance parameters yields the following results.

1. Input head coefficient, $\psi_{\text {in }}$ (defined in Figure 5.1) is slightly greater than predicted for both the individually tested pump and the pump tested in the TPU. The biggest part of this difference is due to impeller diameter, since $\psi_{\text {in }}$ varies inversely with diameter squared. Using an impeller diameter of 6.72 inches yields a $\psi_{\text {in }}$ of 0.717 versus the predicted 0.661 with $a 7.00$ inch 


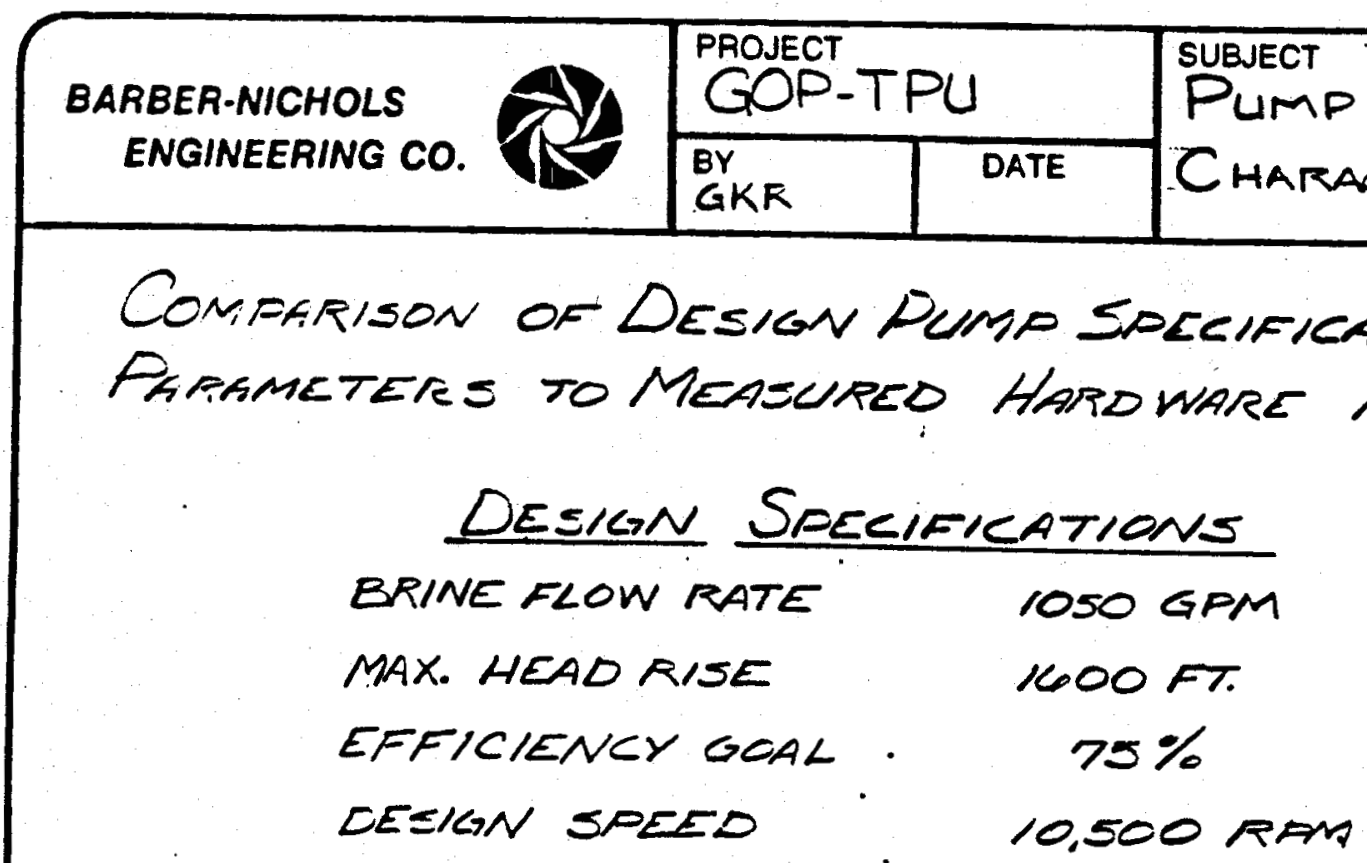

Parameters

PREDILTED ASTESTED ALTESTED PEFORMANCE INAIVIDUALLY. INTHE TPU

IMPELER DIAM.

EVE DIAMETER

HUE DIFIETER

SFEE

SUCT. SFECIFIC

SFEEL (GFN, UINITS)

NFSi-1

IVPUT PUMIF POWER

FLOW RATE

HEAL RISE

HEAL COEF HOWT

THRUST VANE LOES

EFFIEIEISY

HEA, COEF. H IN
7.00 in

$3.50 \mathrm{in}$

$1.25 \mathrm{in}$

$10,=00$ RPM

Eะ34

$767 \mathrm{RT}$

$485 \mathrm{HP}$

1050 crar

1600 FT

$0.50 E$

EI HF

$70 \%$

0.661
6.72 in

$5.50 \mathrm{rd}$

l. $2 \mathrm{es}$

6, 000 RPM

2 330

$292 F T=M$ M.

$104 \mathrm{Ht}$

GOOGPM

$520 \mathrm{FT}$

0.540

N.A.

$76.4 \%$

0.707
6.72 in

3.50 in

1. $5=$ in

5,000 RPM

N.A.

MER:=UREL

$325 \mathrm{Ht}$

900GPM

$1125 F T$

$0.52 \leq$

N.A.

$72.0 \%$

0.729

NOTE: DATA FRESENTED FOR COMPARISON $4 T$ A LEEILN FLOWTATIO (Q/QD) OF 1.00 . 
Page 13(a)

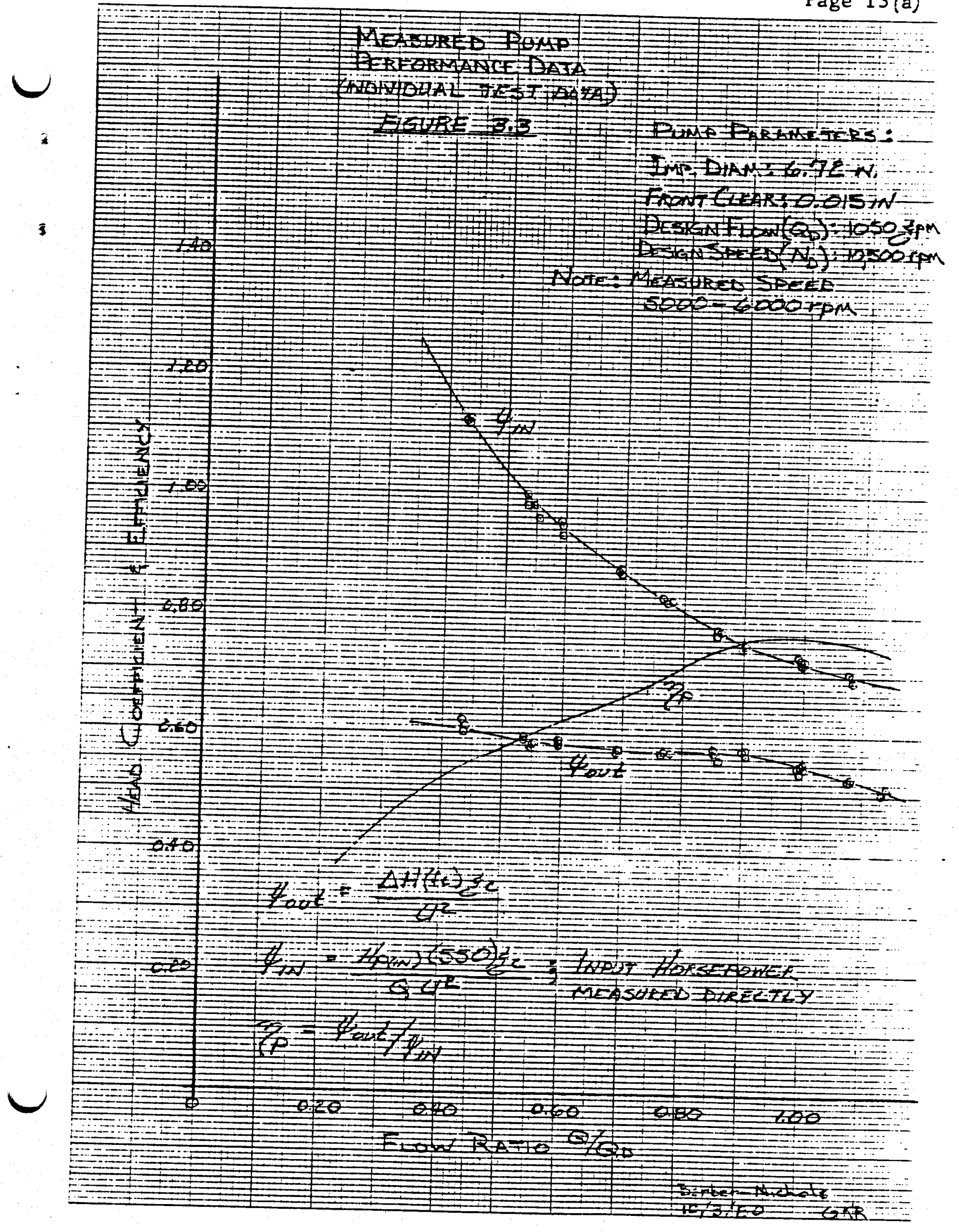


impeller diameter.

2. Output head coefficient, $\psi_{\text {out }}$, (defined in Figure 5.1) is also greater than predicted. Again, most of this difference is due

- to the change in impeller diameter. Head coefficient is also inversely proportional to impeller diameter. Reflecting this, the

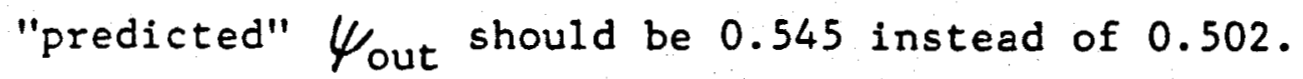

3. Pump efficiency, $\eta_{p}$, is defined as the ratio of output head coefficient to input head coefficient. The difference between the predicted efficiency and the efficiency measured in testing is not directly affected, by the change in pump diameter. However, the efficiency of the pump as tested separately is slightly greater than predicted because the input head coefficient is lower, resulting in a greater mass flow rate for a given input horsepower. The lower efficiency measured in TPU testing reflects an uncertainty in fluid density in the pump loop due to an unknown amount of entrained air in the system. The result is a lowering of the real fluid density as compared with the saturation density of water at measured pump inlet temperatures. Because of this uncertainty, downwell pump performance is expected to be slightly better than the measured performance.

4.0 TLRBINE TEST

Separate turbine testing concentrated on mapping the turbine performance over a wide range of operating conditions. There were no major modifications to the hardware as a result of these tests. As in the pump tests, turbine performance is correlated in terms of dimensionless parameters.

4.1 TLRBINE TEST APPARATUS

The turbine test assembly was designed to approximate closely actual IPU operating conditions while allowing full instrumentation and providing access to the turbine components for any necessary modifications. A layout of this assembly is shown in Figure 4.1. The turbine wheel was mounted on a common shaft with a water brake dynomometer shown on the left side of the figure. The IPU nozzle block and turbine housing were incorporated such that the turbine section details of the test assembly were identical to those of the TPU.

A binary Rankine cycle turbine test facility was constructed at the Barber-Nichols plant to provide $R-114$ vapor for the turbine. 


\section{Page 15}
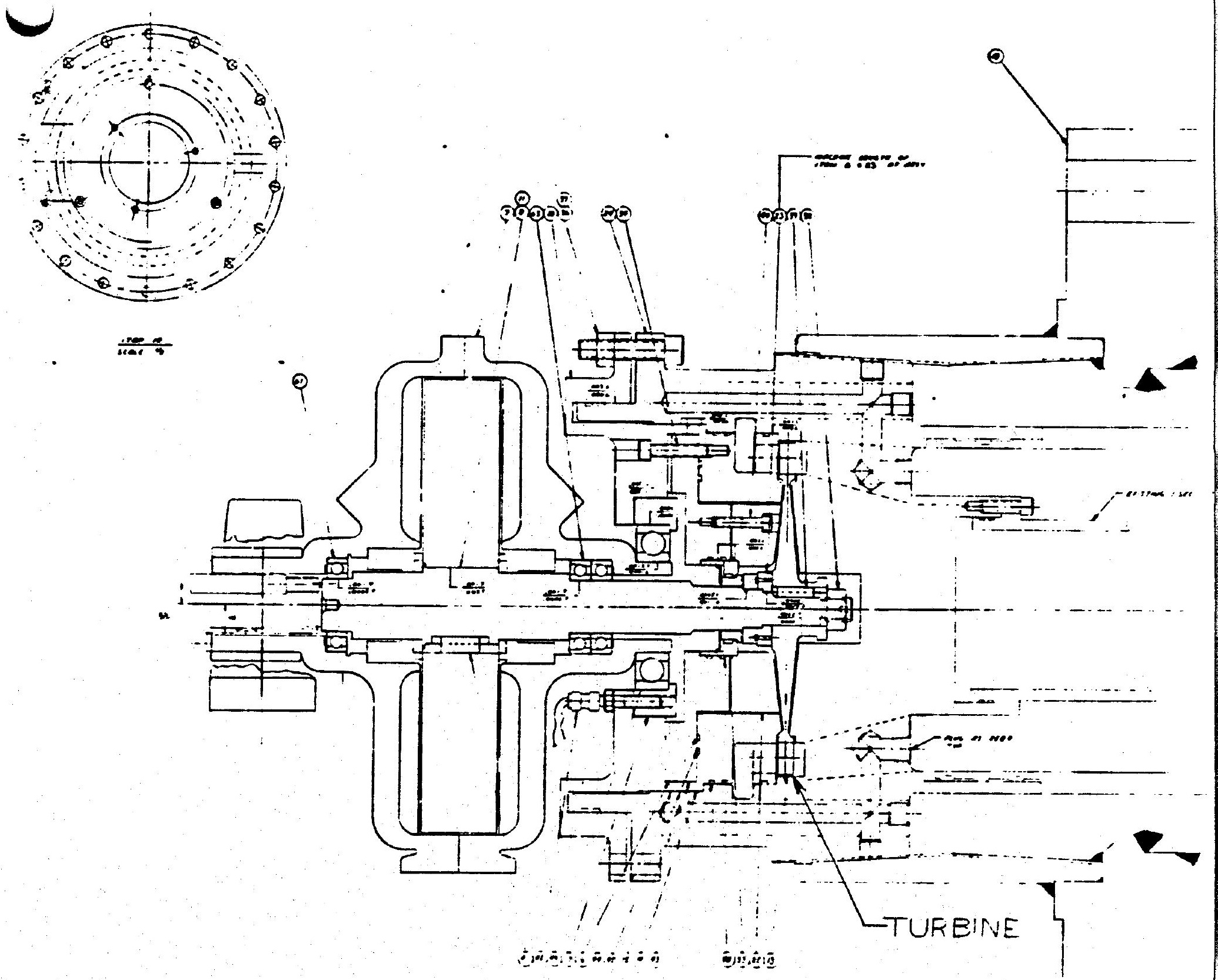

FIGIIRE 4.1

TURBINE TFST ASSEMBLY 
Figure 4.2 shows a schematic of the facility. The water side of the system starts from a holding tank from which the water is pumped to an oil-fired boiler. Saturated steam from the boiler flows through a flow control valve and into the main $R-114$ heat exchangers. The steam condensate exits these heaters as saturated liquid, then passes through a liquid level control tank and into a series of heat ex* changers that cool the water and preheat the R-114. The liquid level control tank assures that the heat exchangers are full of water in order for subcooling to take place. The water returns to the holding tank from the subcoolers.

On the $R-114$ side of the system, gravity feeds the refrigerant from the hotwell ( $R-114$ reservoir) into two centrifugal pumps which boost its pressure up to 1200 psig and provide a maximum flow of 200 gpm. Beyond the pump discharge, flow is controlled by a hand-operated plug valve and metered through an ASME orifice. Then the R-114 flows through the preheating heat exchangers (steam condensate subcoolers) and then through the main heat exchangers. The $R-114$ enters the turbine inlet (design temperature of $330^{\circ} \mathrm{F}$ and pressure of 450 psia), expands across the turbine, and then is condensed in an evaporative condenser. Liquid $\left(90^{\circ} \mathrm{F}\right) \mathrm{R}-114$ returns from the condenser to the hotwell.

Control of the turbine inlet temperature is achieved by adjusting the pressure of steam entering the main heat exchangers. The condensing pressure in the heat exchangers uniquely determines the condensing temperature of the steam, which in turn is related to the $R-114$ temperature leaving the heat exchangers. Turbine speed is controlled via adjustable water brake drag. Turbine inlet pressure and flow rate are controlled with a hand valve (HCVIO).

4.2 TURBINE TEST INSTRUMENTATION

The turbine test instrumentation measures turbine inlet fluid conditions (temperature, pressure and flow rate), turbine exit fluid conditions (temperature and pressures), turbine shaft speed, torque, and rotor axial thrust loads. The instruments are similar to those used on the pump test apparatus. The trunion-mounted water brake housing is instrumented with a hydraulic force gauge to provide a cross-check of turbine output power.

4.3 TURBINE TEST RESULTS

The turbine test results are presented in Table 4.1. The turbine 


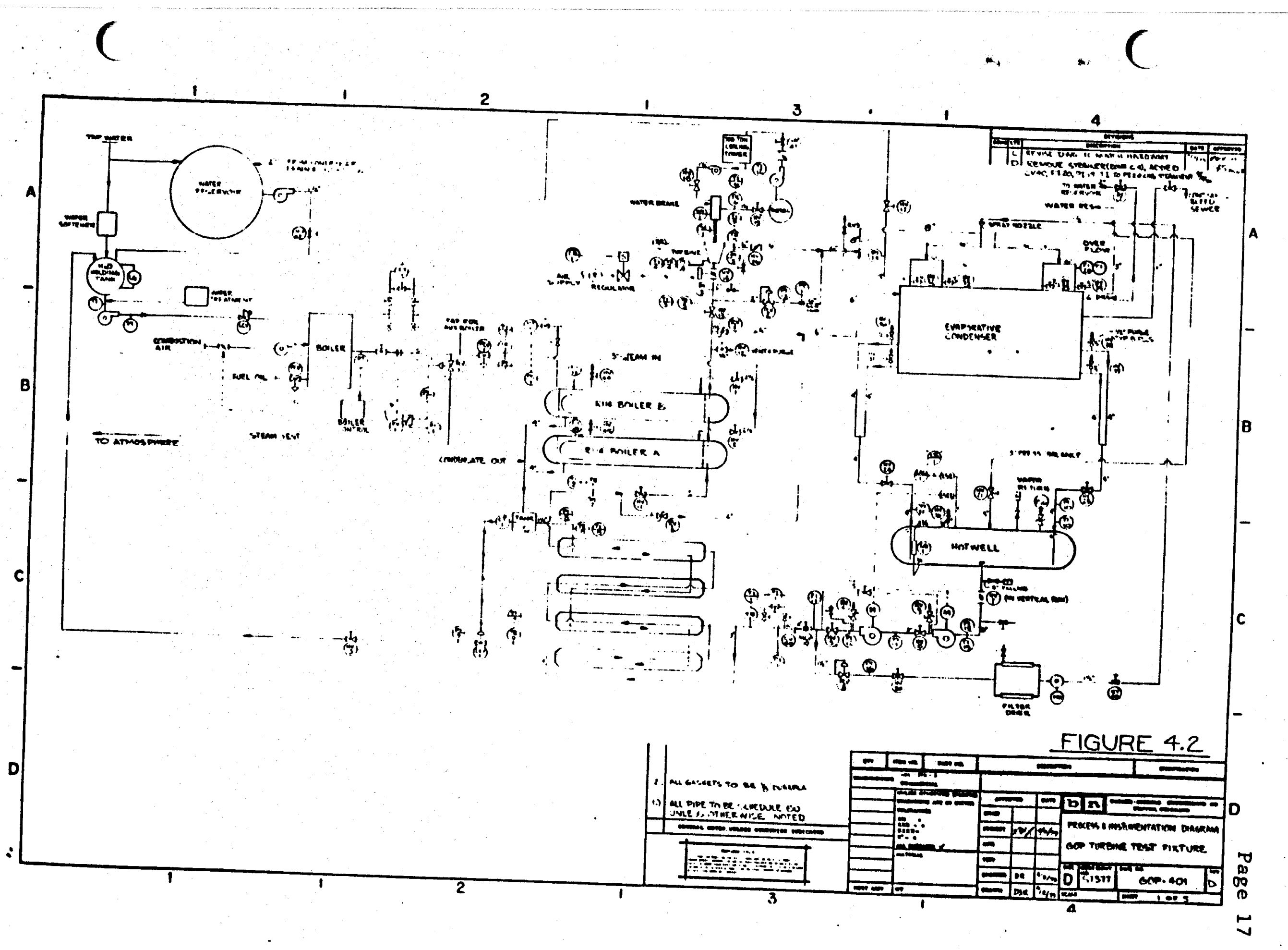




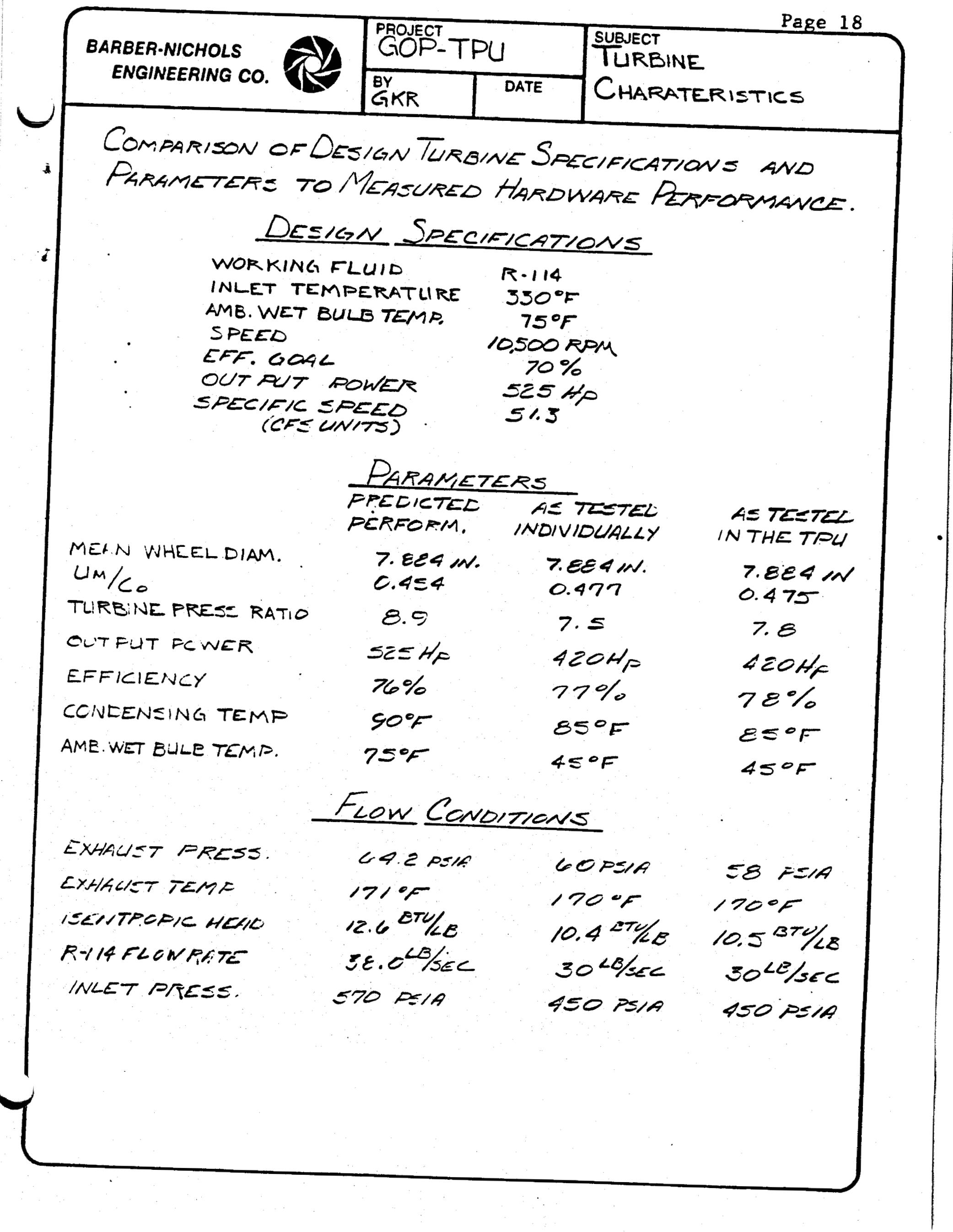


design was not altered from the original hardware configuration, so the only consideration in this comparison is the difference between measured and predicted performance.

i Turbine performance can be compared by using two methods, a comparison of output power at design pressure ratio or a comparison of efficiency at design velocity ratio. Turbine performance is

- presented as efficiency versus velocity ratio because design pressure ratio could not be achieved in the limits of the test apparatus. Examination of the pertinent parameters results in the following comparison.

Velocity ratio, $U_{m} / C_{0}$, is the ratio of the mean wheel diameter velocity, which is a function of turbine geometry, to the isentropic spouting velocity of the fluld. Since the measured $U_{m}$ is identical to the predicted, the measured $C_{0}$ is less than predicted. Isentropic velocity is directly proportional to the square root of isentropic head; therefore, for a given speed the measured isentropic head is less. Turbine efficiency, the ratio of actual turbine head to isentropic head, increases, so the turbine performance is slightly better than predicted. Figure 4.3 shows performance versus speed. 5.0 IPU PERFORMANCE TEST

Performance testing of the TPU spanned a range of operating conditions bounded by the limitations of the test assembly equipment. The common test plan for all runs was to set the turbine fluid inlet conditions (flow rate, temperature and pressure) and vary the speed of the turbine by changing pump flow ratio. The only parameters held during the tests were the pump inlet temperature and pressure and the turbine inlet temperature. These were maintained at $350^{\circ} \mathrm{F}, 400 \mathrm{psig}$ and $330^{\circ} \mathrm{F}$, respectively.

Turbine conditions were varied according to the following plan. R-114 vapor flow rate was varied from $81 \mathrm{bs} / \mathrm{sec}$ to $401 \mathrm{bs} / \mathrm{sec}$. Turbine inlet pressure, limited by the boller output capacity, ranged from 200 psig to 520 psig. Turbine speeds ranged from a maximum of 11,000 $\mathrm{rpm}$ down to $4500 \mathrm{rpm}$, at various input powers. A range of flow ratios from 0.2 to 1.8 was examined.

\subsection{TPU TEST APPARATUS}

The same Rankine cycle facility used for the turbine test was used for the TPU test. the facility was designed such that the turbine test assembly could be disconnected from the turbine inlet and exhaust 


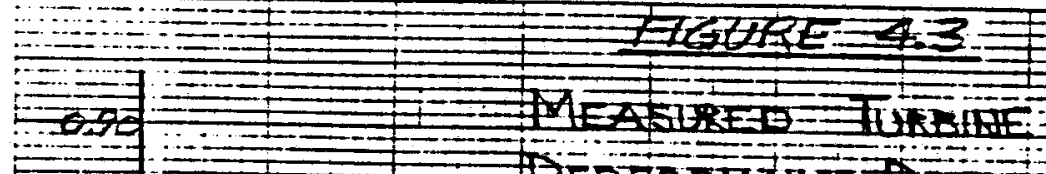

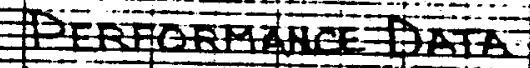
(HIOATAL TEST: DAFA:

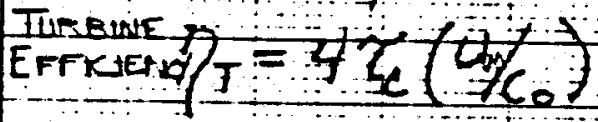
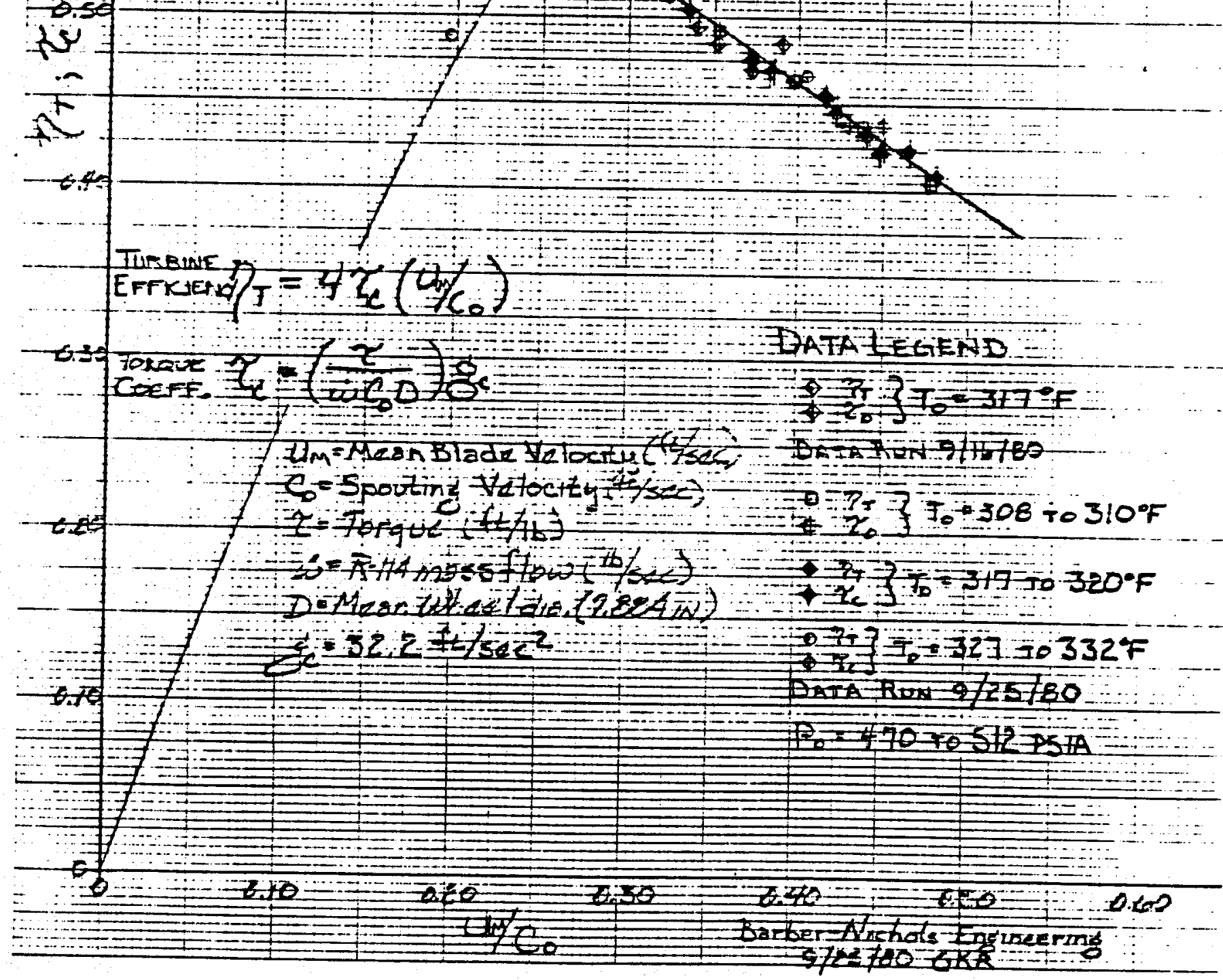
flanges, and the TPU could be connected in the same place.

The pump flow loop used for the pump test was also used for the TPU test. The TPU was totally immersed in water in a straight section of the loop to match closely the downwell environment.

A lubrication support system was incorporated into the TPU assembly. Oil was pumped out of the TPU by the internal, shaft-mounted centrifugal pump at a rate of 2 to $5 \mathrm{gpm}$ and a pressure of 20 to 40 psid: The oil flowed through an air-cooled heat exchanger which dropped the temperature by $50^{\circ} \mathrm{F}$, through a filter and a flow orifice, then back to the TPU.

During early testing, oil pressure was supplied by an air-driven, positive-displacement pump. Pressure was kept 50 psi higher than the pump inlet during testing. A later design change in the TPU allowed for automatic pressurization of the oil by tapping into pump pressure. A reservoir was added which contained half oil (on top) and half water. The oil side was tapped into the oil system and the water side was tapped into a section of the impeller backplate that was 50 psid higher pressure than the pump inlet. Thus the lube oil pressure was automatically controlled to 50 psi higher than the pump inlet pressure. The positive-displacement pump was used only for adding makeup oil.

\subsection{TPU TEST INSTRUMENTATION}

The test assembly was instrumented to measure turbine output shaft speed, turbine inlet temperature and pressure, turbine exhaust temperature and pressure, and R-114 feed pump exit temperature, pressure and flow rate. The pump/water loop had instrumentation to monitor pump inlet pressure, exit pressure, water temperature, flow rate, and the water level in the accumulator tank. The lube system was instrumented for pressure, temperature, flow rate, and leakage. The hardware used to instrument the IPU test was identical to that used on the pump and turbine tests.

\subsection{TPU PERFORMANCE TEST RESULTS}

Performance data for TPU testing is presented in Figures 5.1 and 5.2. These curves represent data taken during the last four hours of 368 hours of total running time. This test demonstrated that there was no degradation of performance with time or due to various TPU modifications. 
Page 21

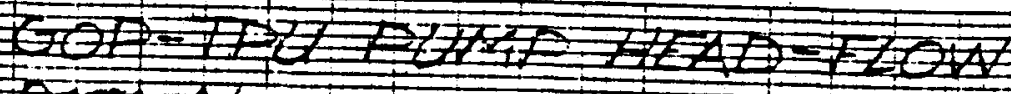

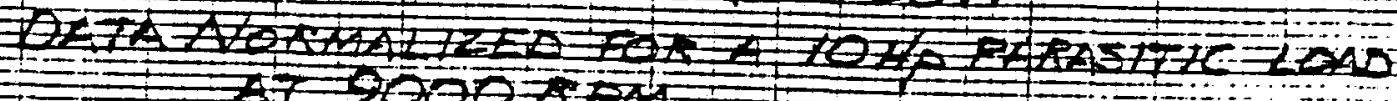

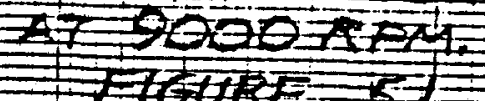

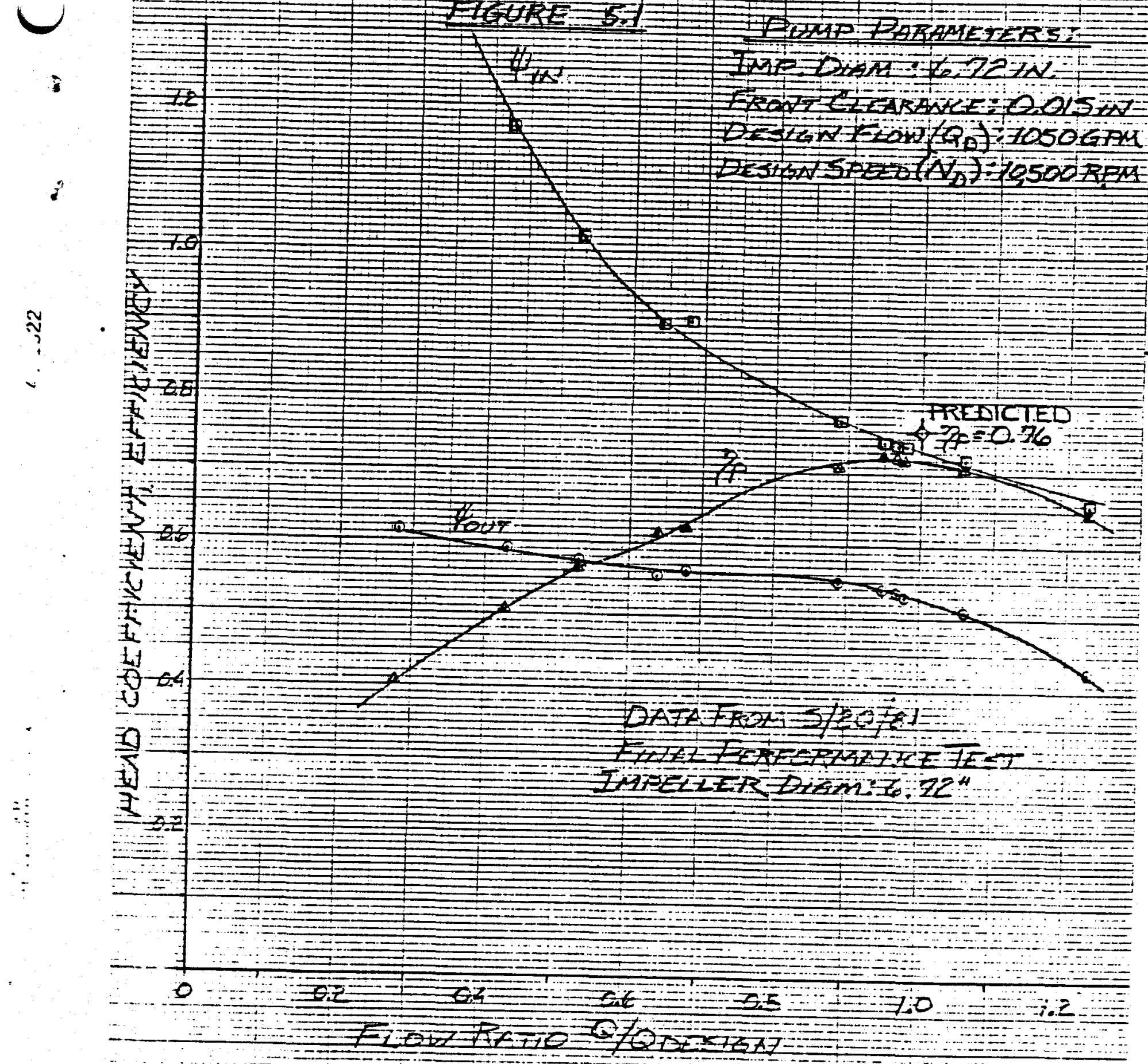




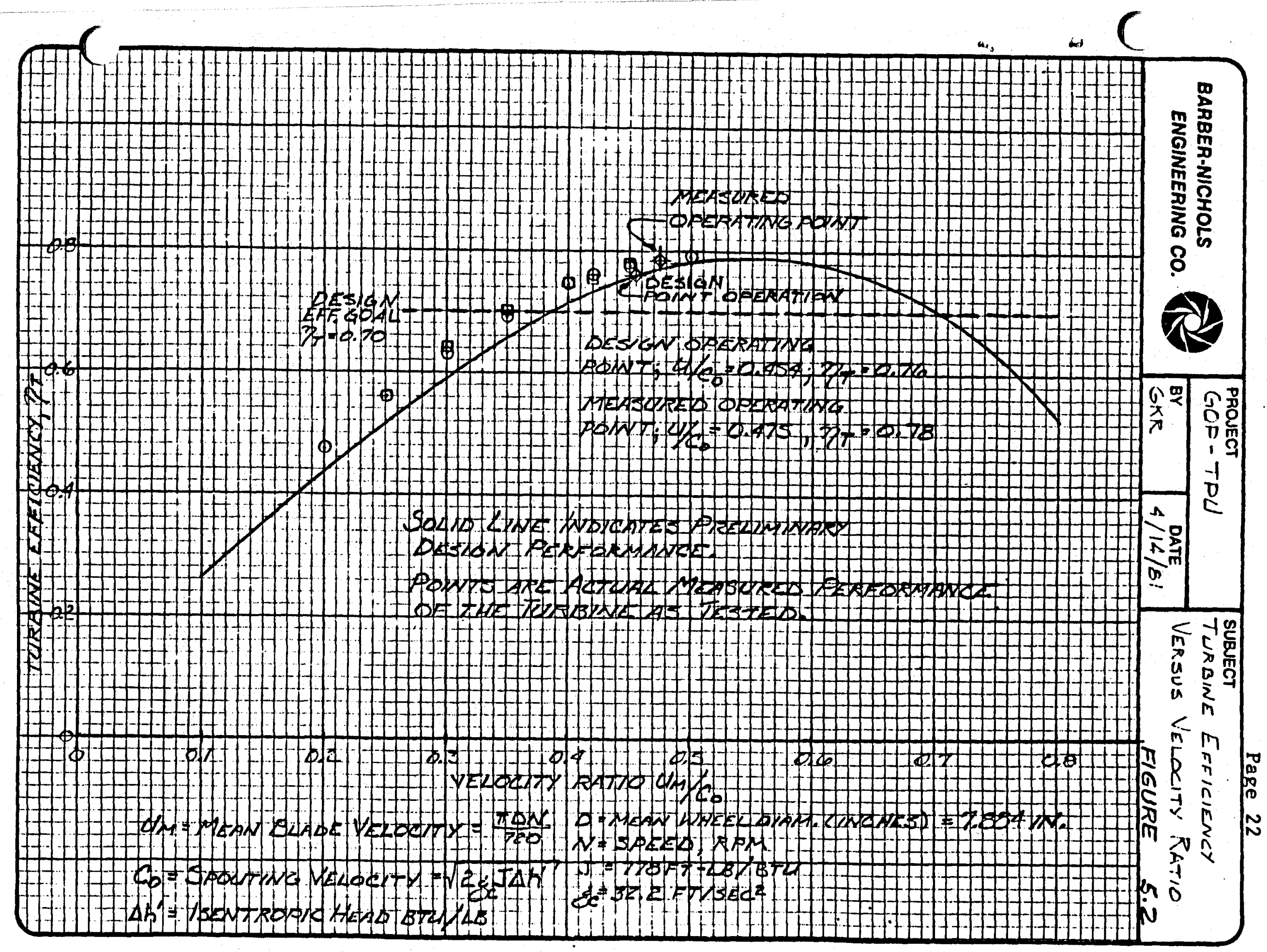


The performance curve for the pump as tested in the TPU is shown in Figure 5.1. The curve shows input and output head coefficients and pump efficiency plotted versus flow ratio. The maximum efficiency of 0.72 occurs at a flow ratio equal to 1.00 (design flow ratio). Design output head coefficient is 0.525 and design input head coefficient is 0.729 . Fig. 5.1, based on TPU losses, agrees closely with Fig. 3.3 .

The data plot can be used either to compare or to predict pump field performance, depending on how much data is available. If only pump speed and flow rate are known, all other pump performance parameters can be calculated using the plotted data by the method given in the following example.

Example 1 Given speed, $N_{m}$, rpm, and flow rate, $Q_{m}$, gpm, find flow ratio $=Q_{D} / N_{D}$ where $N_{D}=10,500 \mathrm{rpm}$, $Q_{D}=1050 \mathrm{rpm}$.

1. Graphically determine input and output head coefficient using flow ratio.

2. Knowing output head coefficient, find pump head rise in feet: $\mathrm{H}=\psi_{\text {out }} \times \mathrm{N}^{2} \times 2.67 \times 10^{-5}$

3. Knowing input head coefficient, calculate input horsepower required: $\mathrm{Hp}_{\text {in }}=\psi_{\text {in }} \mathrm{N}^{2} \mathrm{Q} F \times 1.08 \times 10^{-10}$; $C$ is the brine density at the pump inlet in $1 \mathrm{~b} / \mathrm{ft}^{3}$.

4. Knowing input power, the turbine output power can be calculated. Turbine output power is equal to pump input power plus the TPU parasitic losses. Assuming the parasitic losses vary linearly with speed and knowing the measured value of $10 \mathrm{hp}$ at $9000 \mathrm{rpm}$, the equation for turbine output horsepower is:

$$
\text { HP out }=H p_{\text {in }}+10 \times(9000 / \mathrm{N})
$$

The turbine characteristic curve, presented in Figure 5.2 can be used to verify turbine performance. If only speed and $R-114$ mass flow rate are known, the curve can be used in conjunction with turbine output power as calculated above to estimate efficiency, as in the following example. Fig. 5.2 agrees closely with Figure 4.3 .

Example 2 Given speed, $N$, and $R-114$ flow rate, in $1 \mathrm{~b} / \mathrm{sec}$, and knowing turbine output power, find the turbine efficiency.

1. Determine $\Delta H$, across the turbine in Btu/lb:

$$
\Delta H=\left(H_{\text {out }} \times 550\right) /(\dot{m} \times 778)
$$


2. Estimate isentropic head, $\Delta H^{\prime}=\Delta H / \eta_{T}$

3. Calculate mean wheel velocity,

$$
U_{m}=\frac{D N}{720}=0.034 \mathrm{~N}
$$

4. Using the estimated $\Delta \mathrm{H}^{\prime}$, find isentropic spouting velocity, $\mathrm{C}_{\mathrm{o}}=\sqrt{2 \mathrm{~g}_{\mathrm{C}} \Delta \mathrm{H}^{\prime} \times 778}=223.84 \Delta \mathrm{H}^{\prime}$

5. Graphically determine turbine efficiency using the velocity ratio $U_{m} / C_{0}$.

6. If $\eta_{T}$ as estimated does not match the turbine efficiency found above, use the graphically determined $\eta_{\mathrm{T}}$ and return to step 1 above. Continue iterating on turbine efficiency until satisfactory convergence is achieved, making result consisted with Figures 5.1 and 5.2.

\subsection{TPU - ENDURANCE TESTING}

The TPU endurance tests were designed to identify unforeseen problems and to evaluate reliability during long-term operation. They covered 344 hours of the total 368 hours of test time logged on the TPU. The tests were broken down into two 100-hour endurance runs, two 36-hour seal tests, two 24-hour seal/lube system tests, one 8-hour instrument checkout, and 16 hours of miscellaneous tests.

Several design modifications were made during the test program resulting from anomolies that occurred during operation.

A pump housing diffuser vane failed from fatigue early in the test program. The vanes on this (the first) diffuser housing were welded to the pump housing, and one of the welds partially sheared, leaving the vane to vibrate until fallure. The problem was solved when the failed housing was replaced with a production housing in which the vanes are integrally cast in place.

During a physical inspection of the IPU after the first 100 hour run, it was found that the bearing outer races had "walked" around in the bearing housing during operation. This relative motion between race and sleeve left visible marks in the sleeve. If the observed wear is projected over 20,000 hours of operation, it is conceivable that enough clearance could develop to allow detrimental shaft vibration. A design change was therefore made which added tool steel inserts (Rockwell-C50) to the bearing housing where the bearing races are located. Subsequent inspections revealed no signs of wear in this location. 
A clogged oil filter caused a low lubrication flow rate which led to an overheat condition in the TPU during one test. The routine teardown inspection which followed this test showed no significant damage. The heat coloration of the steel indicated that the areas around the seal housings were exposed to the highest temperature. As a preventative measure, modifications to the seal housings were made to improve cooling in the event of a similar overheat in service.

Unusual vibration forced a shutdown late in the endurance testing program. Inspection exposed a hairline crack along a fillet near the pump end of the shaft. A stress concentration at the fillet yielded the material with fatigue over $75 \%$ of the cross-section of the shaft. A stress analysis was conducted and a new shaft was fabricated with appropriately conservative fillet radii to lower the stress concentrations. 


\subsection{SHAFT SEAL TESTS}

At the conceptual stages of the TPU program, it was intended that either Dyna-Seal or Borg-Warner shaft seals would be designed into the TPU. Before TPU testing began, Dyna-Seals were installed in the bearing test rig to facilitate the bearing tests. The seal cartridges failed under pressure so Dyna-Seals were dropped from further consideration. Although Borg-Warner seals successfully passed a test program at the Sperry Research Center, there were two drawbacks. First, the package size of the cartridge assembly was too large for installing them in tandem in the envelope constraints of the IPU. Secondly, there was low confidence in the reliability of reverse pressure sealing.

With this background, Barber-Nichols entered a program in mid1980 to design a set of shaft seals for the IPU. The areas that were addressed are as follows:

a) Materials

b) Face design

c) Pressure balancing

d) Spring loading

e) Secondary seal design

f) Cooling

The $B / N$ seals are a radial face design in which the nose is static and is spring-loaded against a mating ring which rotates with the shaft.

The original test approach was to install seal prototypes into the TPU and monitor leakage while conducting other TPU tests. After two incidents of seal failure, a new approach was undertaken in which seals were tested in a fixture that featured quick setup and disassembly and allowed closer observation of the seals during operation. Typically, promising seal designs that were proven in these tests were then installed into the TPU for testing. 


\subsection{SEAL TEST APPARATUS}

Two different devices were used for testing and determining performance of the shaft seal designs. Besides using the TPU as a test bed, the bearing test rig (described in Section 2.1) was set up to test Barber-Nichols' seals. Only single seals could be tested in the bearing test rig. This unit provided pressurized, temperature-controlled ofl to the inboard sides of the seals. The outboard sides, however, were exposed to room temperature air. The bearing test rig provided a good test bed for general seal development in which parts could be changed out quickly.

\subsection{SEAL TEST INSTRUMENTATION}

A number of instrumentation devices were added to the TPU and to the bearing test rig to facilltate data collection of shaft seal parameters. Devices were added to the bearing test rig for collecting oil that has leaked past the seals. This effluent is directed into graduated cylinders for measurement.

A pressure tap was added to the pump back-plate of the TPU for measuring brine pressure outboard of the pump side shaft seal. Bimetal thermocouples were installed in the lubrication lines such that oil temperature could be measured immediately in and out of the TPU housing, thus giving an indication of seal temperature.

Two methods were used to monitor shaft seal leakage in the

TPU. Early in the test program, makeup oil was pumped into the IPU from an accumulator with a positive displacement hydraulic pump. By keeping the system pressure constant by adding oil, the oil lost through the seals was equally offset by oll pumped out of the accumulator. Thus, monitoring the accumulator level gave a measurement of oil lost through seals. Later in the program, an oil pressurization system identical to the downwell accumulator was installed. With this system a dual fluid, oil over brine, accumulator automatically kept the oil pressure 50 psi higher than the brine pressure. 011 leakage was indicated by measuring the level change of the line between the oil and the brine through the sightglass in the accumulator.

\subsection{SEAL PROGRAM RESULTS}

All of the seals tested use silicon carbide for both the seal nose and mating ring. An Invar ring was added to the OD of the mating ring to improve the tensile strength under centrifugal loading. 
A mechanical design change was made after an October 1980 failure in which a spacer pinched a mating ring from hydraulic pressure. The change added a snap ring to captivate the spacer.

A number of iterations of secondary seal design were experienced. At first, standard $O$-ring seals and glands were used. Common materials such as Viton, Buna-N, and ethylene propylene were disregarded as a result of SRC tests showing incompatability with one or more of the TPU fluids. An early material tested in $\mathrm{B} / \mathrm{N}$ seals was Kalrez. During a November test, a mating ring fractured due to swelling of the elastomer. Also tried were teflon-coated Viton 0 -rings. These seals failed when the teflon coating separated from the Viton and extruded: out of the gland.

The remainder of secondary seal development centered around spring-energized seals made of fiber-reinforced teflon. Initially Bal-Seals were tried. These performed satisfactorily, but have some drawbacks. First, the reliability is questioned, since manufacturing tolerances are a significant percentage of the dimensions of the small cross-section seals. this is a problem in all springenergized seals of the same small cross-section (which is dictated by IPU package design constraints). Secondly, the wire spring used by Bal-Seal has a very small footprint on the teflon material, which can "Brinell" into the plastic. During one shaft seal test an overtemperature to $450^{\circ} \mathrm{F}$ had just that result, i.e. the spring pushed into the plastic. It is possible that a flat ribbon spring may not have yielded the teflon in that case. Another brand, Omni-Seal, which has ribbon springs, was tested.

It was difficult to determine the performance of springenergized seals because it is difficult to distinguish whether leakage observed in a test is from the primary seal, the secondaries, or both. Some major design requirements, however, were verified which will improve the rellability. One is the surface finish of the gland. It must be below 16 microinches, and preferably under 8. Another requirement is freedom of installation. The seals should not be bent of bowed on installation. A design change was carried through on the TPU shaft seal assembly to eliminate having to bend the secondary seals for installing in ID grooves of the seal nose secondary. 
Seal face design and testing covered three basic areas: 1) face width; 2) wear pads; and 3) pressure balancing. Three face widths were tested. They were $0.050 \mathrm{inch}, 0.068 \mathrm{inch}$, and

* 0.100 inch. Three bearing rig tests of the $0.050 \mathrm{inch}$, pressurebalanced, face-seal style (December 1980), of 18, 15, and 2 hours each, had dynamic leak rates of $0.6,0.3$, and $1.5 \mathrm{cc} / \mathrm{hr}$, respec* tively. these seals were also tested in the TPU for 11.5 hours with undetectable leakage. In February, a bearing rig test of over 400 hours was run with a 0.100 inch face seal partially balanced on top, and a 0.068 inch.face, unbalanced seal, on the bottom. The average leakage was $1.5 \mathrm{cc} / \mathrm{hr}$ on top and $9 \mathrm{cc} / \mathrm{hr}$ on the bottom. It is evident from these and other tests that narrower, balanced face designs seal more effectively than wider unbalanced designs. The disadvantage of narrower faces, such as the 0.050 inch design, is that they have higher wear rates than the wider faces, such as the 0.100 inch design. Also, the narrower faces are more susceptible to failure from chipping or other damage to the face.

An early seal design utilized wear pads. When tested, this seal leaked in excess of $100 \mathrm{cc} / \mathrm{hr}$ due to hydrodynamic lifting of the pads. Rather than enter a series of development tests to. optimize the wear pads, all further design approaches utilized no pads.

The wear rate of non-wear-pad seal faces was brought up to an acceptable level by reducing the preload spring force to 15 pounds, from 25 pounds. Also, a design change made on the TPU to improve oil cooling passages to the seal cavities resulted in an improved seal wear rate, presumably due to lowered operating temperature of the seals. After an 840 hour test run on the bearing test rig, the 0.068 inch face design had less than 10 microinches of wear.

TPU testing during the first four months of 1981 showed erratic shaft seal leakage rates while running, but very low leakage when static. In May it was discovered that the IPU shaft had been slowly failing by fatigue. It was judged that high speed irbalance of the cracked shaft was causing the seal problems. 
The defect in the shaft was corrected and an 11-hour TPU test was run with the same seal configurations as had been previously used. The total leakage for both sets of seals was an acceptable $5 \mathrm{cc} / \mathrm{hr}$.

The IPU was shipped to Mustang Engineering Company. All seals in the unit are of the 0.050 inch face design with 15 pound preload springs, except the outer pump-side set, which are the 0.100 inch face design with a 25 pound preload spring. The wider face is used on the outer pump side due to possible abrasion from brine contaminants. 


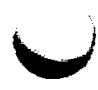

z

APPENDIX F

GRAVITY HEAD TURBINE-PUMP UNIT

SIZING STUDY 


\title{
BARBER-NICHOLS
}

MEMORAN DUM

\author{
July 30,1980 \\ TC: $\quad$ K. E. Nichols \\ FRONI: \\ H. Johnson $y_{i}^{\prime}$.
}

SUBJECT: Gravity Head TPU Sizing Study

OBJECTIVE: The objectives of this study were to determine the optimum speed match of the turbine and pump with respect to the combined efficiency and to compare the required turbine and pump diameters to the space available. These were to be done for two operating conditions: with and without brine reinjection pressure ( $w / \triangle P-R E I J$ and $w / O \triangle P-R E I J)$ supplied by the downhole pump.

APPROACH: A thorough study of commercial "turbine" type pumps was made to determine a reasonable expected efficiency as a function of specific speed. Pumps were chosen as near the design capacity as possible and scaled to the design flow rate. Data from Stepanoff - "Centrifugal and Axial Flow Pumps" was also included to determine the final efficiency curve. An efficiency curve for Francis Turbines as a function of specific speed was constructed by scaling down from data in Daugherty-Franzini - "Fluid Mechanics with Engineering Applications." The Francis type turbine offered the highest potential efficiency at the level of specific speeds examined in the study. Thermodynamic cycle calculations were carried out far enough to determine the properties through the turbine and pump for the calculation of specific speeds. The thermodynamic cycle computer program has been in a state of development so the calculations for this study have been updated from time to time accordingly.

RESULTS: The turbine and pump efficiency curves are shown on Curve Sheet $2 \cdot$ The specific speed has been computed using volume rate of flow in $\mathrm{ft}^{3} \cdot \mathrm{s}^{-1}$ in both cases.

The thermodynamic data for the turbine follows: 
w/ODP-REIJ

$T_{t \text { in }}$

$\mathrm{m}_{\mathrm{R} 114}$

$\mathrm{P}_{\mathrm{t} \text { in }}$

$\Delta \mathrm{h}_{\mathrm{t}}$

$\left(h_{t \text { in }}-h_{\text {out's }}\right) \cdot 748 \mathrm{Btu} \cdot \mathrm{lbm}^{-1}$

$P_{\text {out }}$ 686. lbf $^{\circ}$ in $^{-2}$

$\mathrm{H}_{\mathrm{S}} \quad 582 \mathrm{ft}$.

The pump data follows:

\begin{tabular}{|c|c|c|c|c|}
\hline 7 & $1000 \mathrm{gal}^{\circ} \mathrm{min}^{-1}$ & 1000 & 1000 & 1000 \\
\hline $\mathrm{H}$ & 1270. $\mathrm{ft}$ & 1270 & 2500 & 2500 . \\
\hline in & $55.6 \mathrm{lbm} \cdot \mathrm{ft}^{-3}$ & 55.6 & 55.6 & 55.6 \\
\hline
\end{tabular}

The efficiency, size, speed data is tabulated below and shown on Curve Sheet 1. Specific Speed $\mathrm{N}_{S}=\frac{N \sqrt{\psi}}{N^{.55}}$ where $N$ is the rotational speed in rev' $\mathrm{min}^{-1}, \forall$ is the turbine discharge or pump inlet volume rate of flow in $\mathrm{ft}^{3} \cdot \mathrm{s}^{-1}$, and $\mathrm{H}$ is the turbine isentropic head or the pump discharge head in $\mathrm{ft}$.

$\underline{w} / \mathrm{O} \triangle \mathrm{P}-\mathrm{REIJ}$

\begin{tabular}{|c|c|c|c|c|c|}
\hline$N$ & $N_{S_{T}}$ & 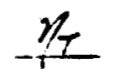 & $N_{s p}$ & $\eta_{p}$ & $\underline{Y}_{T \times P}$ \\
\hline 6000 & 160 & .820 & 42.1 & .698 & .572 \\
\hline 7000 & 186 & .817 & 49.1 & .718 & .587 \\
\hline 8000 & 213 & .811 & 56.2 & .734 & .595 \\
\hline 10000 & 266 & .792 & 70.2 & .757 & .600 \\
\hline \multicolumn{6}{|c|}{$\mathrm{w} / \triangle \mathrm{P}-\mathrm{REIJ}$} \\
\hline 6000 & 107. & .810 & 25.3 & $.60 ?$ & $.49 ?$ \\
\hline 7000 & 125 & .816 & 29.6 & $.63 ?$ & $.51 ?$ \\
\hline 8000 & 143 & .8195 & 33.8 & .663 & .543 \\
\hline 10000 & 178. & .8185 & 42.2 & .698 & .571 \\
\hline
\end{tabular}

330. $\quad 320$.

$493 . \quad 523$.

$900 . \quad 900$.

$1.176 \quad 1.109$

$1.470 \quad 1.386$

$503 . \quad 504$.

$549 . \quad 1144.1079$. w/ $/ \triangle P-R E I J$ 
ANALYSIS: The efficiency product $\eta_{\tau} \times \eta_{p} w / 0 \Delta \mathrm{P}-\mathrm{REIJ}$ peaks at a level of 0.60 at a speed of $10,000 \mathrm{rpm}$ whereas the same speed results in an efficiency product of $.57 \mathrm{w} / \triangle \mathrm{P}-\mathrm{REIJ}$ but is still increasing with increasing speed. This is shown on Curve Sheet 1. The basic reason for the efficiency variation is shown on Curve Sheet 2 where $T$ and $P$ component efficiencies are shown as a function of specific speed $N s$ with the 10,000 speed points spotted in. The pump requirements force low Ns operation unless the rotational speed is relatively high. If the speed is increased to improve pump efficiency, the turbine specific speed goes to the high end where the turbine efficiency decreases. For these reasons, the speed of $10,000 \mathrm{rpm}$ splits the opposing turbine and pump optimum specific speed effects quite well for the case $w / 0 \triangle P$-REIJ. There is also considerable incentive to use a speed of 10,000 rpm because the Stand-Alone pump has been developed for that speed and would only require minor trimming to be used for the Gravity Head TPU.

There would be an expected increase in TPU life by using a lower speed. A $40 \%$ reduction to $6000 \mathrm{rpm}$ would cost 3 product efficiency points or approximately 5\%. This speed however would force the pump to operate at a lower specific speed where the efficiency is lower and not as certain.

The design of the pump $w / \triangle P$-REIJ would indicate a rotational speed requirement greater than $\overline{10,000 \mathrm{rpm}}$ in order to obtain a more acceptable product efficiency by raising the pump specific speed. This would require a turbine specific speed which might be approaching too high a level for satisfactory Francis design. Providing the reinjection pressure with the downhole TPU also has the disadvantage that a major function is located downhole which does not have to be downhole.

TIP DIAMETERS of the rotors are shown on Curve Sheet 1. There is no problem in packaging the TPU to meet the well-hole size limitation until the speed is lowered to the $6000 \mathrm{rpm}$ range for the design $\mathrm{w} / \triangle \mathrm{P}-\mathrm{REIJ}$.

cc: Jim Lobach

Bob Langley

Hugh Matthews, Sperry

Barna Toekes, Sperry

Warren McBee, Sperry 
BARBER-NICHOLS

ENGINEERING CO.

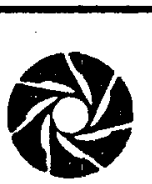

PROJECT

\begin{tabular}{|c|c|} 
GOP 656 \\
\hline BY $21 !$ & $\begin{array}{c}\text { DATE } \\
7-28-80\end{array}$ \\
\hline
\end{tabular}

SUBJECT

Gravity Head TPIS

Efficiency Situdy

$\leqslant$

1

㟧

Li 10

$\sum$

4

E

Q 5

0

0

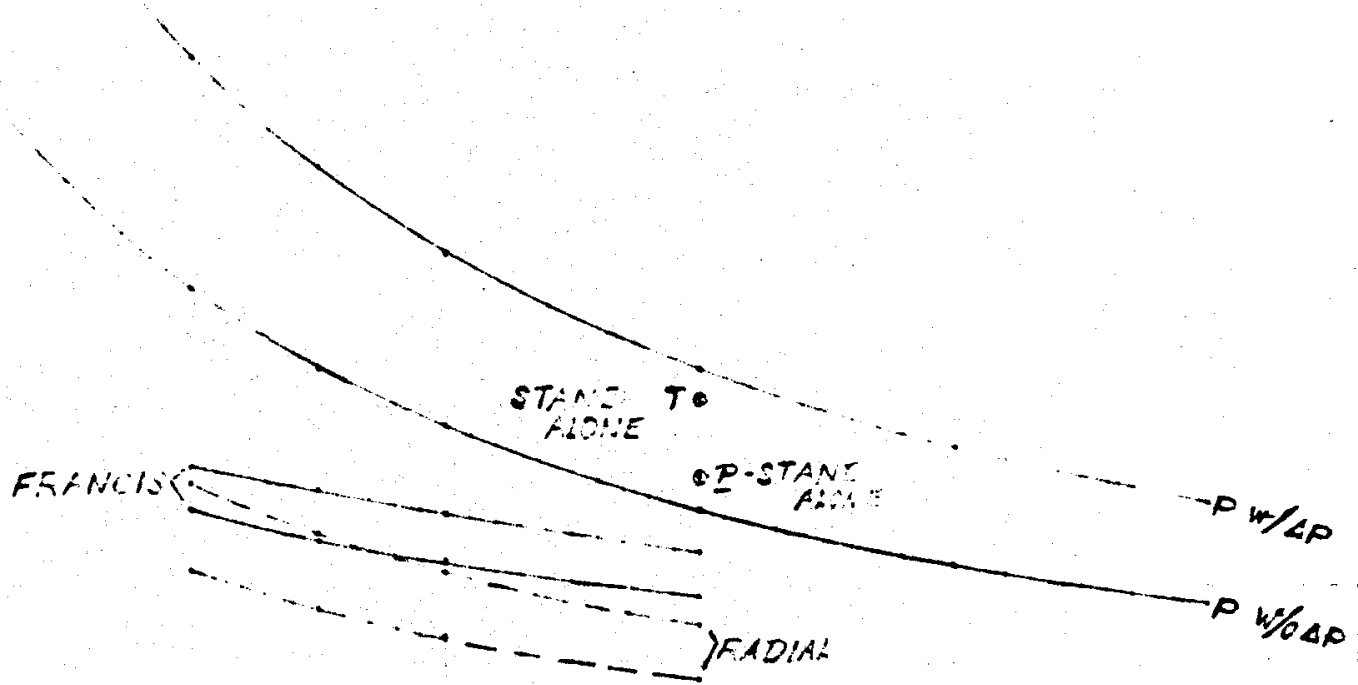




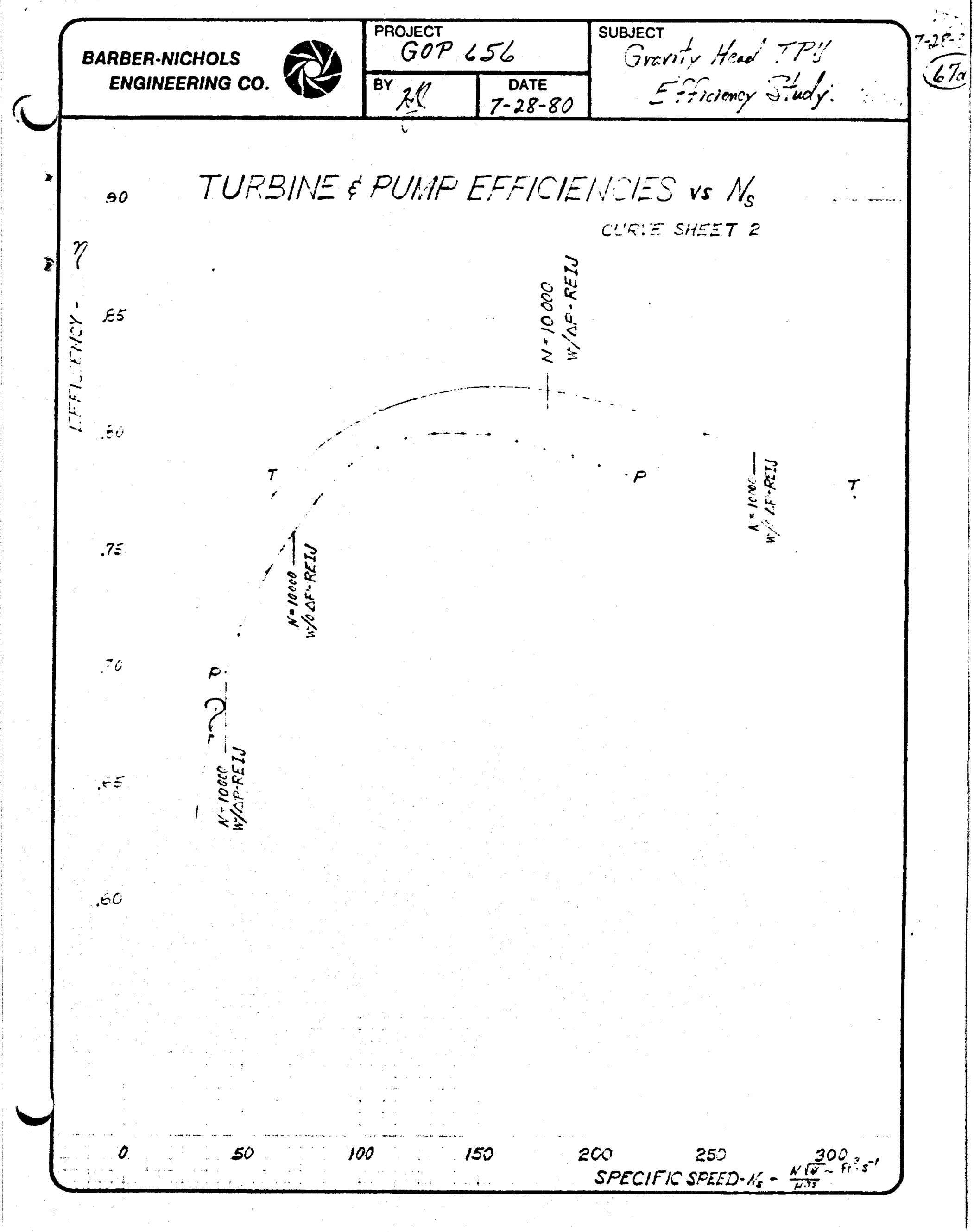




\section{APPENDIX G}

MICRO MOTION MASS FLOW METER 
MICRO MOTION MASS FLOW METER

\section{General Information}

The Micro Motion mass flow meter is a non-intrusive meter designed to measure the mass flow rate of any fluid, liquid, gas or slurry. It measures actual mass flow rate ( $1 \mathrm{bs} / \mathrm{min}, \mathrm{gms} / \mathrm{sec}$, etc.) independent of density, viscosity, temperature, pressure or other flow parameters.

The sensor is a rigid " $U$ " shaped tube that is magnetically vibrated about an axis passing through the open end of the " $U$ ". The " $U$ " tube is excited and forced to oscillate at its natural frequency (approx. $5 \mathrm{OHz}$ ) depending upon the size of the tube and the density of the material within the tube. Although the natural frequency of the " $U$ " tube changes as the density of the material is varied, the mass flow measurement is not determined by measuring this frequency.

Flow in the sensor tube causes a coriolis/gyroscopic twist that is measured optically using two photo transistors. The mass flow rate is determined by measuring the " $U$ " tube twist angle on the downward vibration stroke and by comparing this twist angle to that of the upward stroke. In a no-flow condition the twist angle will be constant for both the upward and downward vibration strokes. If flow exists in the sensor tube, the tube will twist in opposite directions during the upward and downward vibration strokes. It is this difference angle that is measured optically and can be shown to be a linear measurement of mass flow rate. This mass flow rate measurement is unaffected by two-phase flow or by changes in the effective tube diameter due to flow material deposition.

*ASME Paper 77-WA/FM-4 dated August, 1977 
The mass flow meter offers the user excellent reliability since there are no electrodes to wear out, no bearings to deteriorate, no critical flow stream geometry and no requirement with respect to upstream/downstream piping.

The meter operates from either 115v AC or 18-30v DC and incorporates a slide switch to change input modes. The output of the meter is provided in either or both of two output formats (1) analog output current or (2) a frequency output proportional to flow rate. The analog output is compatible with any 4-20 (0-20)ma control system and the frequency output has been designed to be compatible with any type of logic.

As an additional output, the meter provides the user with a square wave output signal at the pipe vibration frequency. Should the user desire to monitor the relative density of the flowing fluid, he may do so by monitoring the period of this square wave frequency. 


\section{Mass Flow \\ Measurement by Micro Motion}

Physical

\section{Characteristics}

The flow sensor consists of a U-shaped tube which is vibrated at its natural frequency. The angular velocity of the vibrating tube in combination with the mass velocity of the flowing fluid causes the tube to twist. The amount of twist is measured with magnetic position detectors, producing a linear signal which is proportional to the mass flow rate of every particle passing through the U-shaped tube. The output of the meter is linearly proportional to mass flow rate and virtually unaffected by variations in fluid properties.

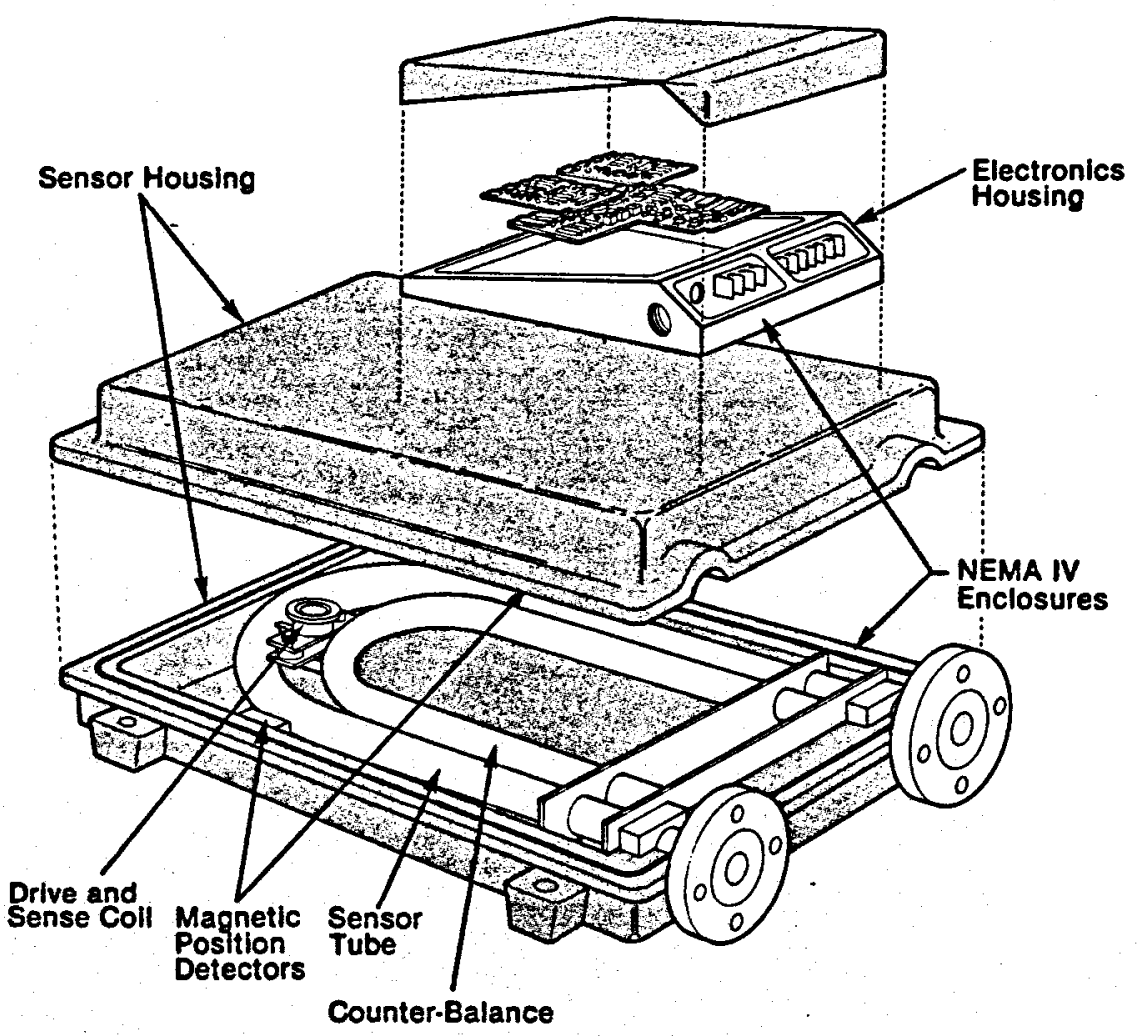

\section{Remote} Flow Indicator D10.RT

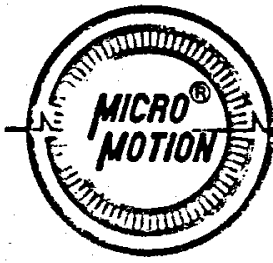

The Micro Motion Model D10-RT is a digital flow indicator designed for use with Micro Motion Model C mass flow meters.

It converts the frequency of the meter output to a 4-digit flow rate indication, and a resettable, 7-digit totalizer displays the total flow. This compact and rugged instrument has a NEMA IV enclosure and can be operated on either AC or DC power.

It may be set on a table top, mounted on a wall, or installed in a panel.

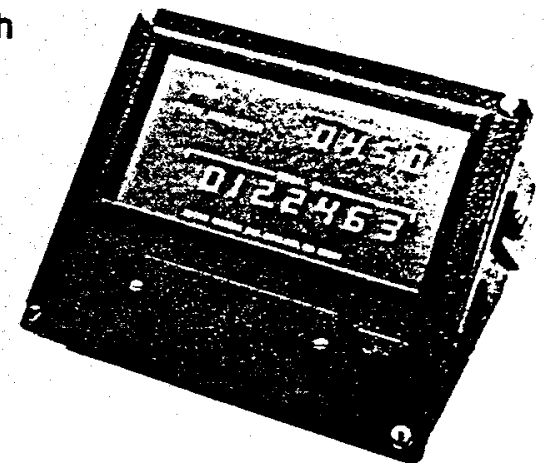




\section{General}

Specifications

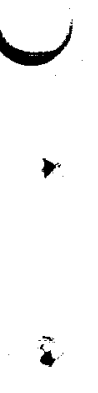

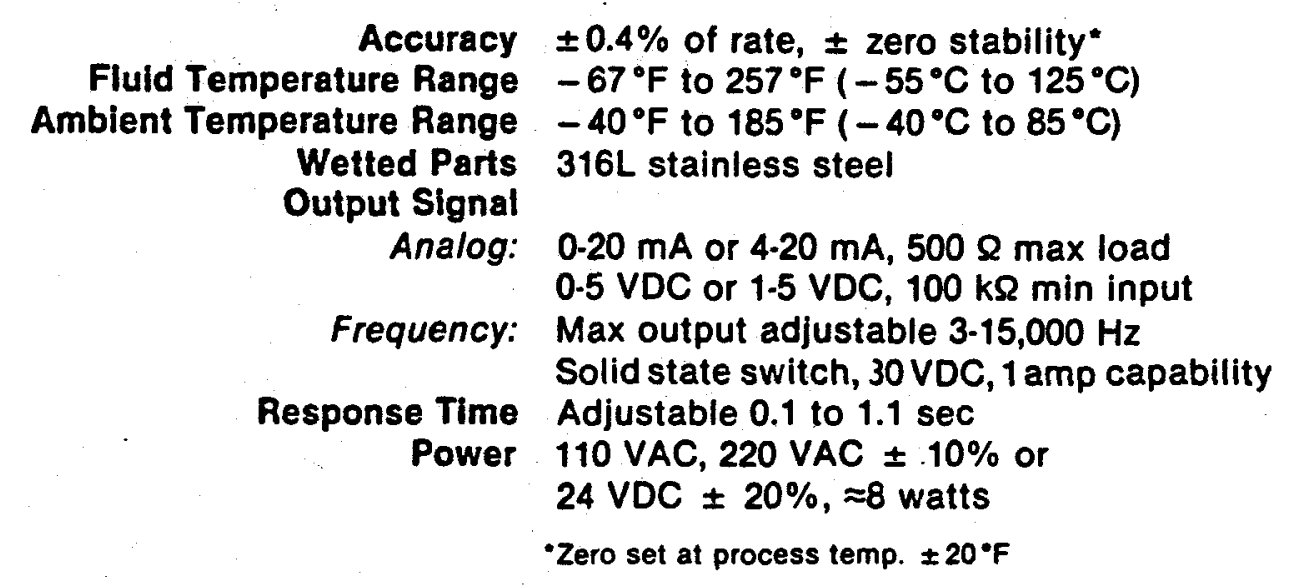

\section{Detail} Specifications

Model C6

Model C12

Model C25

Model C50

Model C100

Model C150

0.2020
(0.916).

Model C200

$\begin{array}{ll}0.3200 & .3 \\ (0-1450) & (.14)\end{array}$

\section{Flow Range lb/min (kg/min)}

$0-2.2$

$(0-1.0)$

$0-13.5$

(0-6.1)

$$
.002
$$

(.0009)

.01

$$
\begin{aligned}
& 0.90 \\
& (0-41)
\end{aligned}
$$

(.0045)

0.440
$(0-200)$

.05
$(.02)$

$0-1600$

(0-726)

.15

(.07)

.2

(.14)

$\begin{array}{lll} & \text { Shipping } & \text { Case } \\ \text { Process } & \text { Weight } & \text { Dimensions } \\ \text { Connections } & 10(\mathrm{~kg}) & \text { in }(\mathrm{mm})\end{array}$

$1 / 4$ "FNPT 11

(5)

1/4" FNPT 11

(5)

(138)

1000

$1 / 4$ " FNPT

11

(5)
Models C6. C12 and C25 $8.63(219) L$. .8 .0 (203) $W$ 3.48 (88) $H$
(69)

$$
\begin{aligned}
1 / 2^{\prime \prime} \text { Flange* } & 53 \\
& (24) \\
1 \text { " Flange* } & 53 \\
& (24)
\end{aligned}
$$

53
$(24)$

Models
C50 and C100
$19.5(495) L$
$15.0(381) W$
$6.3(100) H$

(103)

$11 / 2$ " Flange* 175

(79)

1500
$(103)$

Models

C150 and $\mathrm{C200}$ $31.0(787) \mathrm{L}$ $21.5(546) W$ $8.28(210) H$

-Flanges are ASA $150 \mathrm{lb}$ raised face slip ring

Consult your local representative for information about the following options:

Expanded temperature range

Remote electronics

Corrosion resistant tubes

Abrasion resistant tubes

Expanded pressure ratings

Other process fittings

Intrinsically safe design, C6 - C200

(UL-Approved Models C12 - C200) 


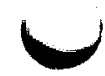

$\checkmark$

APPENDIX H

$\div$

DOUBLE TUBESHEET LEAK TESTS 


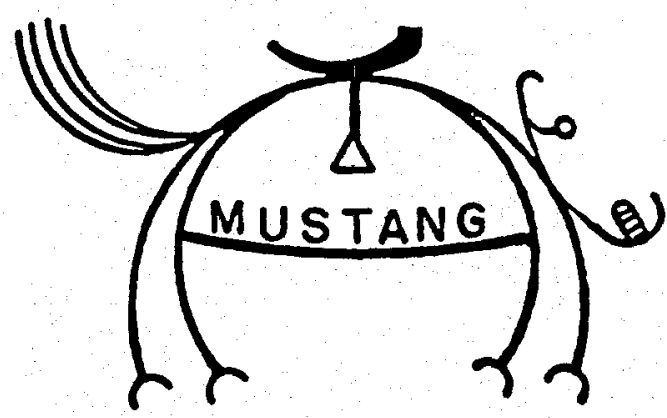

MUSTANG ENGINEERING COMPANY 13230 CAMBRIDGE STREET SANTA FE SPRINGS, CALIFORNIA 90670 JULY 25,1980 
DOUBLE TUBESHEET TEST FIXTURES

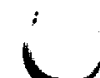

PAGE

$\checkmark$

I. ABSTRACT

2

II. OBJECTIVE

4

III. APPARATUS

4

IV. PROCEDURE

4

V. RESULTS

7

VI. DISCUSSION

8

VII. APPENDICES

APPENDIX A: DOUBLE TUBESHEET LEAK TEST ASSEMBLY PROCEDURE 9

B: PHOTOGRAPHS 14

C: WIRING DIAGRAM FOR HEATERS 15

D: RAW DATA 16 
ABSTRACT

DOUBLE TUBESHEET SEAL EVALUATION

ROLLED TUBES: Of all the tubes expanded by rolling none leaked when tested by a Halogen Leak Tester or by Hydraulic Testing at a minimum of 1500 psig with cold water before torturing.

WELDED TUBES: No leaks were found.

FLARED TUBES: These tubes were prepared as deliberate leakers. All leaked on Halogen Test.

EPOXY SEALED FLARED TUBES: One test unit epoxy coated and clamped did not leak on Halogen Test, but would not stand hydraulic pressure.

One test unit where epoxy was injected did not leak under repeated temperature cycling from ambient to $350^{\circ} \mathrm{F}$ and pressuring with hot water to a minimum of 1500 psi.

FURMANITE SEALED TUBES: Three units were sealed with Furmanite injected hot and under pressure (5000 psig).

(a) One fixture with rolled tubes which had withstood the Halogen and Hydro Test failed on pressure and temperature cycling. Furmanite and steam issued from the injection holes, at at least 3000 psig.

(b) The second fixture with rolled tubes showed no water (steam) leak at 3000 plus pressure, but furmanite extruded through injection holes.

(c) A third fixture (flared tubes) with deliberate leakers were sealed with Furmanite and withstood the pressure and temperature cycle torture test. Furmanite was extruded through the injection holes.

\section{CONCLUSION}

Either material epoxy (Scotch-Weld \$2214) or Furmanites EPDM (F79E) will seal leaking tubes. Epoxy can be made to surround the tube in the tubesheet more completely than Furmanite, but Furmanite does penetrate the annular space to some degree.

Apparently Furmanite's compound expands more with temperature as it extruded back out the injection holes on heating. These holes would be plugged in the actual exchanger. The compounding of one Furmanite sample was bad (crumbly) and had to be expelled.

Epoxy (Scotch Weld \#2214) did not adhere to the tubesheets as advertised, but these sheets were not degreased. The Furmanite did not adhere to the steel. 
Provided proper procedures are used as regards tubesheet spacing, cleanliness, curing and injection either material may be selected. Epoxy has an advantage of lower overall cost. The flexibility and coefficient of expansion of the Furmanite may be of advantage. If Fumanite is used better quality control of the compound is required.

For minimum cost and maximum reliability, standard fit holes and grooves should be used for the tubesheets in the actual exchanger. The tubes should be welded to the tubesheets and then rolled. 


\section{OBJECTIVE}

The objective of this test was to determine the best method of attaching the heat exchanger tubes to the tubesheets for the unit to be used in the Geothermal Project. By fabricating small test fixtures, each with a different tube to tubesheet joint, and testing them for leaks, the most suitable configuration could be selected. Another objective was to determine whether Furmanite or epoxy could be used to seal the tubesheet joints if necessary.

APPARATUS

1) Test Fixtures (see Appendix A)

2) Imperial Eastman System Analyzer - used for charging and pressure testing with R-22.

3) Allied Chemical refrigerant $R-22$, 15非

4) TIF Model 5000 Automatic Halogen Leak Detector, 3 PPM sensitivity features audible beeper to detect R-22 leaks

5) Air Driven Sprague Water Pump for pressurizing test fixtures to 1500 psi.

6) Chromalox Model Series 3804 temperature controller - temperature range 0-4000F; used with contactor and heater to cure Furmanite and epoxy, also for torture testing.

7) Furnas magnetic contactor, catalog 非1NB308F

8) Chromalox tubular band heater, Catalog 排BT-75, 240V, 1275W, 7 1/2" barrel diameter

9) Furmanite EPDM F79-E Leak Sealing Compound - injected into some of the test fixtures to seal leaks.

10) Scotch - Weld Structural Adhesive 非214 - one part epoxy also used to seal leaks in test fixtures.

PROCEDURE

1. Eight (8) test fixtures were prepared according to procedures given in Appendix A.

2. The rolled tube fixtures were pressure tested with R-22 using the system analyzer connected to two fixtures simultaneously. Each unit was tested for a minimum of eight hours. The halogen leak detector was used to check for leaks. The flared tube fixtures (deliberate leakers) were also tested briefly as a check.

3. The rolled tube fixtures were filled with water, pressurized to 1500 psi, and checked for external water leakage or pressure loss. 
4. Fumanite compound was injected between the tubesheets of those fixtures which had leaked in the previous tests, except for \#6 and \#7, which required epoxy. Fixture \#2, which had not leaked, was also injected. The injection was done by furmanite personnel using their own high pressure injection equipment. Before injecting, the test fixtures, Furmanite and injection unit were preheated to $300^{\circ} \mathrm{F}$ in an electric kiln. The Furmanite was injected at a pressure of about 5000 psi, then cured for one hour at 3000F (Fixture \#2 cured overnight at 2500F) using the electric band heaters.

5. Epoxy was injected in fixture 非 using a hand screw type tool, then cured overnight at $250^{\circ} \mathrm{F}$ using the electric band heaters.

6. Epoxy was applied between the tubesheets of Fixture $\$ 6$, then clamped together and cured for 20 minutes at $300 \mathrm{~F}^{\mathrm{F}}$ in the electric kiln. No ring was used.

7. All sealed units were retested (R-22 and high pressure hydrostatic) and checked for leaks.

8. Sealed units $(2,4-1,4-2,7)$ were torture tested as follows:

Fixture \#2: (a) It was filled with water, pressurized to 1500 psi, then heated to $350^{\circ} \mathrm{F}$. The tubes were vibrated by striking with a hammer handle and the unit checked for leaks. It was then allowed to cool to room temperature.

(b) It was heated to $350^{\circ} \mathrm{F}$ while maintaining a pressure of 1500 psi (bleeding off excess). The tubes were vibrated as in part (a) and the unit checked for leaks. It was then allowed to cool to room temperature.

(c) Part (b) was repeated.

Fixture 4-1 \& 7: (a) They were filled with water, heated to 3500F, then pressurized to $1500 \mathrm{psi}$. The tubes were vibrated by striking with a hammer handle and the units checked for leaks. They were then allowed to cool to room temperature.

(b) They were pressurized to $1500 \mathrm{psi}$, then heated to $350^{\circ} \mathrm{F}$. The tubes were vibrated as in part (a) and the units checked for leaks. They were allowed to cool to room temperature.

Fixture 4-1 \& 7 (c) The units were heated to $350^{\circ} \mathrm{F}$ while maintaining a pressure of $1500 \mathrm{psi}$ (bleeding off excess). The tubes were vibrated as in parts (a) and (b) and the units checked for leaks. They were allowed to cool to room temperature. 
Fixture 4-2:

1 .

$+$

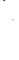

(a) It was filled with water, pressurized to 1500 psi, then heated to $350^{\circ} \mathrm{F}$. The tubes were vibrated by striking with a hammer handle and the unit checked for leaks. It was then allowed to cool.

(b) It was heated to $350^{\circ} \mathrm{F}$ while maintaining a pressure of 1500 psi (bleeding off excess). The tubes were vibrated as in part (a) and the unit checked for leaks. It was then allowed to cool to room temperature.

(c) Part (b) was repeated.

9. A comparison was made between the inside diameters of the tubes which were rolled, then welded, and those which were welded, then rolled.

10. The sealed units were cut with a bandsaw between the tubesheets in order to observe penetration of the sealant. 
DOUBLE TUBESHEET LEAK TESTS

BEFORE SEALING

FREON HYORO FREON

TEST TEST RETEST
AFTER SEALING

HYDRO TORTURE

RETEST TEST
2 (std. fit holes, rolled tubes) ${ }^{1}$

3 (close fit holes, rolled tubes)

4-1 (std. fit \& grooved, OK

OK rolled tubes) ${ }^{l}$

4-2 (std. fit \& grooved, LEAKS NONE flared tubes) ${ }^{l}$

4-3 (std. fit \& grooved, OK OK welded \& rolled tubes)

5 (combination holes, OK OK rolled tubes)

6 (std. fit \& counterbored, flared tubes $)^{2}$

LEAKS NONE

OK

LEAKS

NONE

7 (std. fit, counterLEAKS NONE

OK

OK

OK

OK

NONE

bored \& grooved holes, flared tubes) ${ }^{3}$

1: Injected with Furmanite

2: Epoxy Applied Between Tubesheets

3: Injected with Epoxy

*Furmanite Extruded from Filler Holes 


\section{DISCUSSION}

Epoxy appears to be very effective when injected, although it is unsatisfactory when merely applied between tubesheets and clamped. When injected, it fills gaps and voids, and upon curing becomes a hard, homogeneous solid. However, being inelastic, there is the possibility of it separating from the tubesheets under repeated thermal stress. Inspection of the cut open tubesheets revealed that the epoxy did not adhere well the the uncleaned metal; this problem may be minimized if the tubesheets are thoroughly cleaned prior to injecting the epoxy.

Furmanite has the advantage of being elastic. However, in the tests, some problems were noted. The two fixtures which were subjected to pressures of $3000 \mathrm{psi}$ or more while hot experienced extrusion of the Furmanite from the filler holes. From inspection of the cut open tubesheets, the furmanite loss did not appear to cause any leaks. However, upon subsequent reheating of those test fixtures at 1500 psi Furmanite continued to extrude. In addition, it was observed that the Furmanite adhered poorly to the tubesheets. This was expected as Furmanite is not intended to be an adhesive.

Either standard or close fit holes will produce a leakproof joint with rolled tubes; however, standard holes pose fewer problems in assembly. Grooving the holes will provide an extra measure of safety and they are easily made. The same applies to welding the ends of the tubes to the tubesheet.

Concerning procedure \#9, it was found that for standard fit holes, there was no significant difference in I.D. for tubes that were first rolled, then welded and those that were welded, then rolled. For close fit holes, rolling, then welding produced a significantly larger I.D. than with the reverse procedure. Also, it was observed that welding followed by rolling produced a neater joint. 
DOUBLE TUBESHEET ASSEMBLY PROCEDURE

1. Make eight test devices.

2. Use 2" 600 非 ANSI flanges for tubesheets with seven $1 / 2$ " tubes each.

3. Drill six types of holes:

a. Standard fit, $0.510+0.002-0.004$ without grooves.

b. Close fit, $0.503 \pm 0.002$ without grooves.

c. Standard fit with standard grooves

d. Close fit with standard grooves

e. Standard fit with counterbore, $0.573^{\prime \prime}$ dia. $\times 0.1875^{\prime \prime}$ deep without grooves.

f. Standard fit with counterbore and standard grooves.

4. Drill tubesheets as follows:

a. One all close fit holes (Tubes to be rolled). Fixture 非

b. One all standard fit holes (Tubes to be rolled). Fixture 非

c. Three all standard fit and grooved (Tubes to be rolled on one, flared on one, and welded, then rolled on one). Fixture \#4-1, 4-2, 4-3

d. One with four standard fit holes and three close fit holes, two of each grooved (Tubes to be rolled). Fixture \#5

e. One all standard fit and counterbored holes (Tubes to be be flared, secondary tubesheet to be left loose, epoxy to be applied, and tubesheets to be clamped). Fixture \#6

f. One all standard fit, counterbored and grooved holes (Tubes to be flared and epoxy to be injected). Fixture \#7

5. Prepare 56 tubes, 0.5"O.D. $\times$ 0.402" I.D. $\times$ 3'0" long. Material spec. SA-214. Plug weld one end shut all tubes. Flare ends of 21 tubes.

6. Roll 28 tubes to $7 \%$ - $8 \%$ wall reduction with a torque limiting air motor. Measure deformation with dial internal calipers. Determine torque required. Roll additional 7 tubes to the same after welding them to tubesheet. Do not roll flared-end tubes. Test tubes, after rolling, with tubesheet leak tester under full vacuum.

7. Assemble three tubesheets with all flared tubes (see 4.c, 4.e, and 4.f). Assemble all other tubesheets with rolled tubes, but one with welding prior to rolling. 


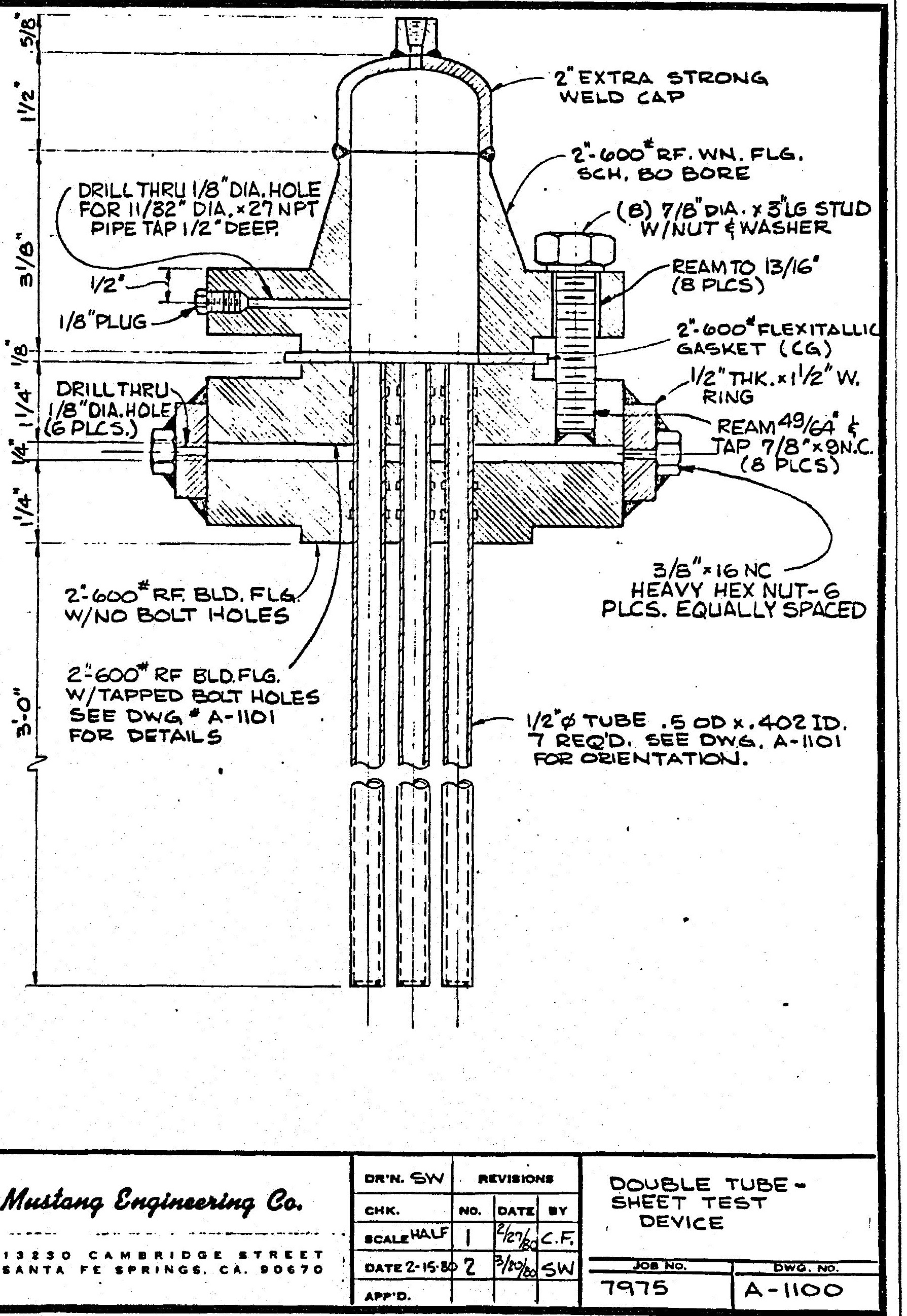




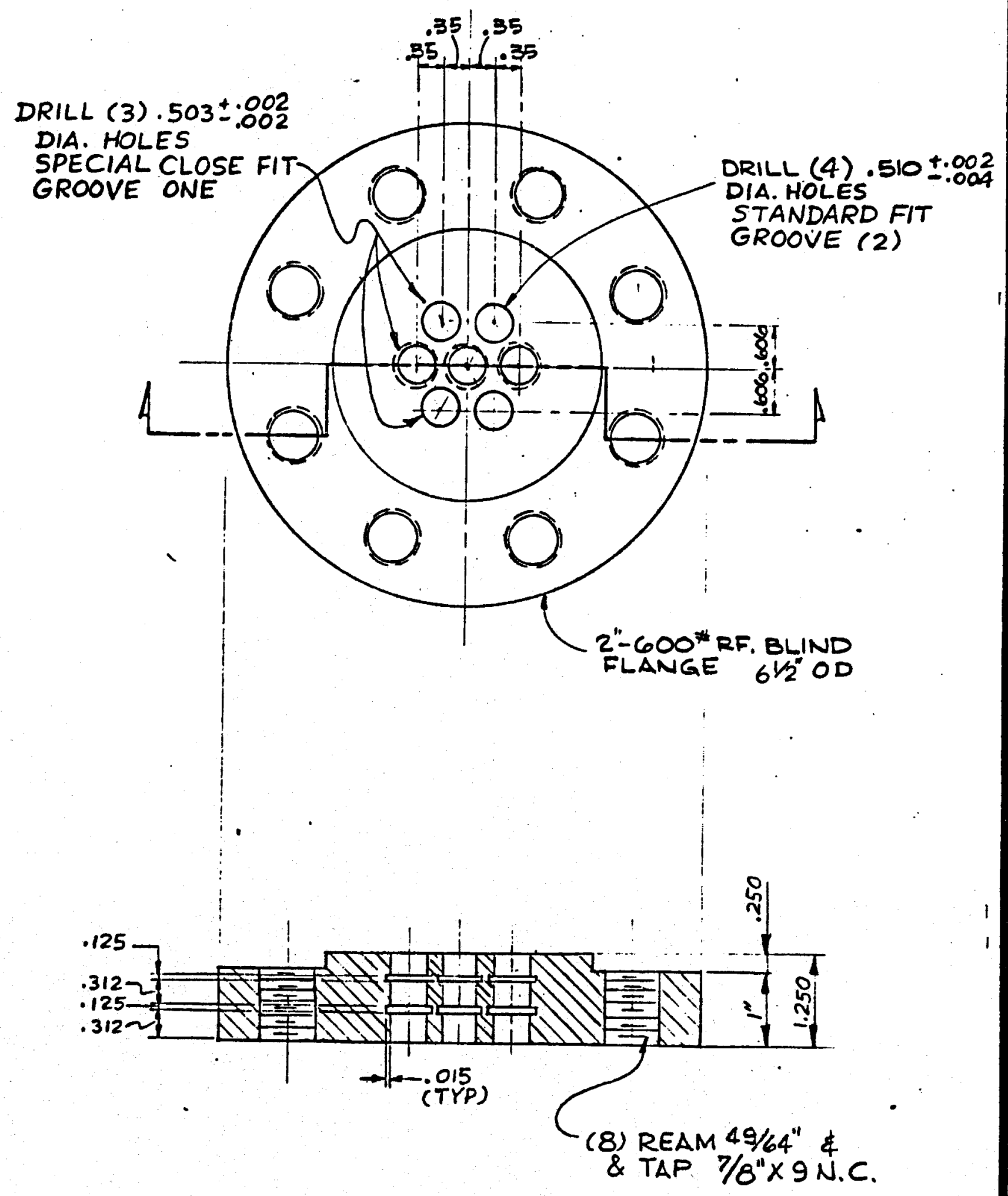

\begin{tabular}{|c|c|c|c|c|c|}
\hline \multirow{5}{*}{$\begin{array}{l}\text { Mustang Enginesering Ca. } \\
\text { I3230 CAMERIDGE STREET } \\
\text { SANTA FE PRINGS. CA. OOSTO }\end{array}$} & \multirow{3}{*}{$\begin{array}{l}\text { DN'N. QPL } \\
\text { CHK. } \\
\text { PALF } \\
\text { PCALE }\end{array}$} & \multicolumn{3}{|c|}{ mevielons } & \multirow{3}{*}{$\begin{array}{l}\text { DOUBLE TUBE- } \\
\text { SHEET TEST DEVICE } \\
\text { DRILLING PATTERN }\end{array}$} \\
\hline & & no. & \multicolumn{2}{|c|}{$\because 9$} & \\
\hline & & 1 & $3 / 2 \%$ & SW & \\
\hline & DATE & & & & DWC.NO. \\
\hline & Aprid. & & & & $A-1101$ \\
\hline
\end{tabular}




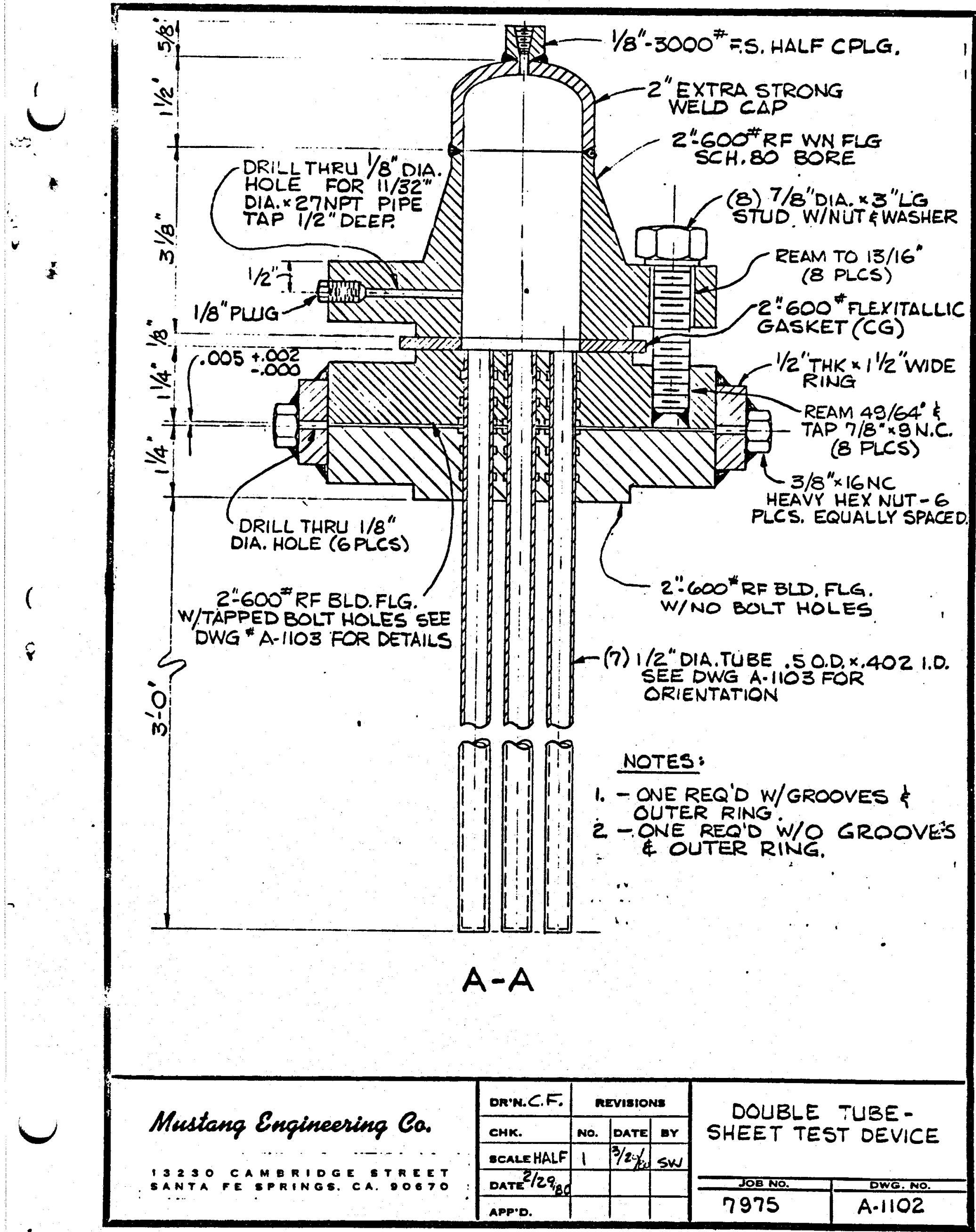



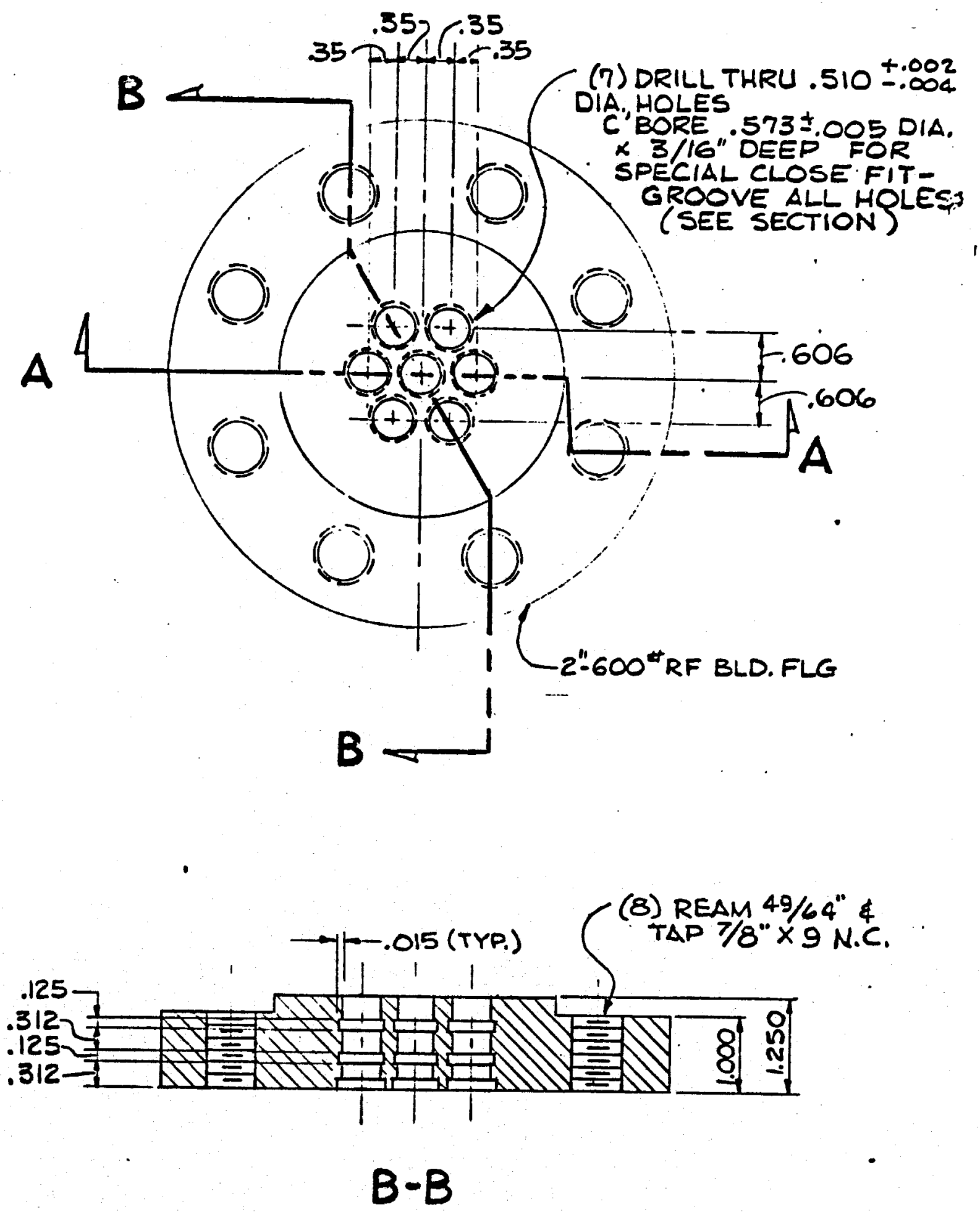

Mustang Engineering Ca.

I3230 CAMERIDGE STREET

SANTA FE SPRINGS. CA. DOGTO

\begin{tabular}{|c|c|c|c|c|}
\hline on'N.C.F. & \multicolumn{3}{|c|}{ Revisions } & \multirow{3}{*}{$\begin{array}{l}\text { DOUBLE TUBE- } \\
\text { SSHEET TEST DEVICE } \\
\text { DRILLING PATTERN }\end{array}$} \\
\hline CHK. & No. & DATE & or & \\
\hline scaleHaLF & 1 & $3 / 20 / 80$ & sw & \\
\hline DATE2/29/80 & & & & JOB NO. \\
\hline APP:D. & & & & $A \cdot 1103$ \\
\hline
\end{tabular}




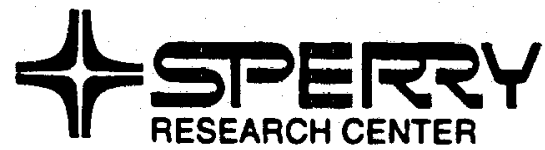

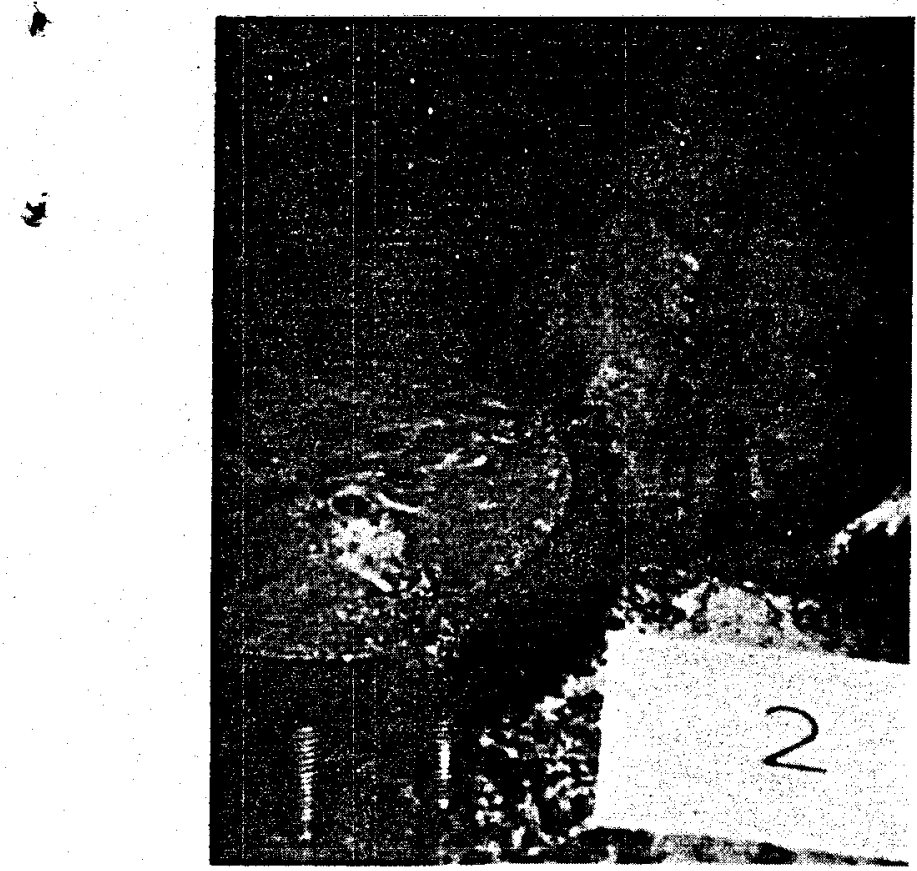

Furmanite Injected Tubesheet

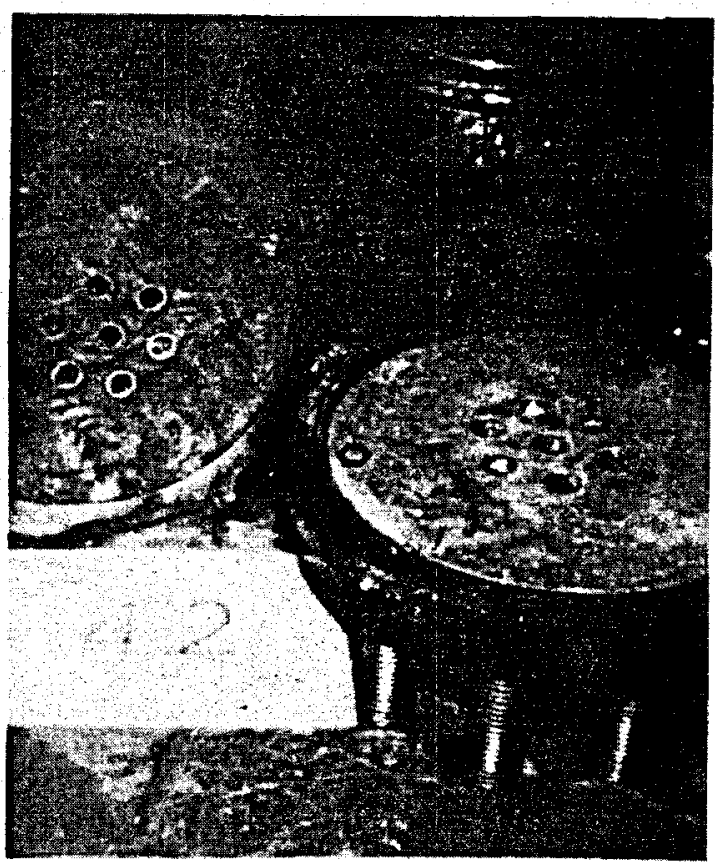

Furmanite Injected Tubesheet

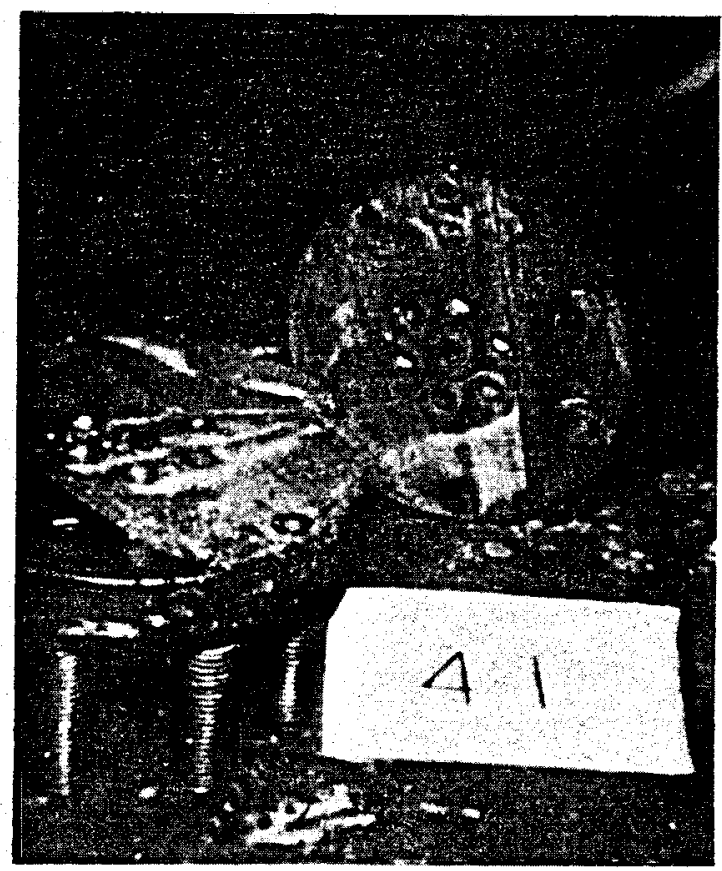

Furmanite Injected Tubesheet

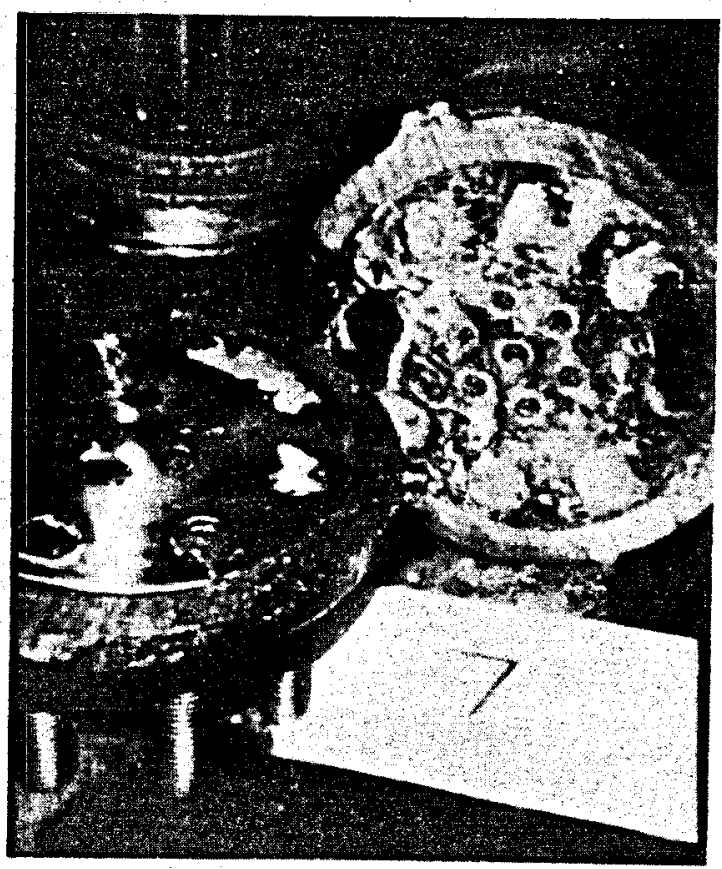

Epoxy Injected Tubesheet 


\section{t)}
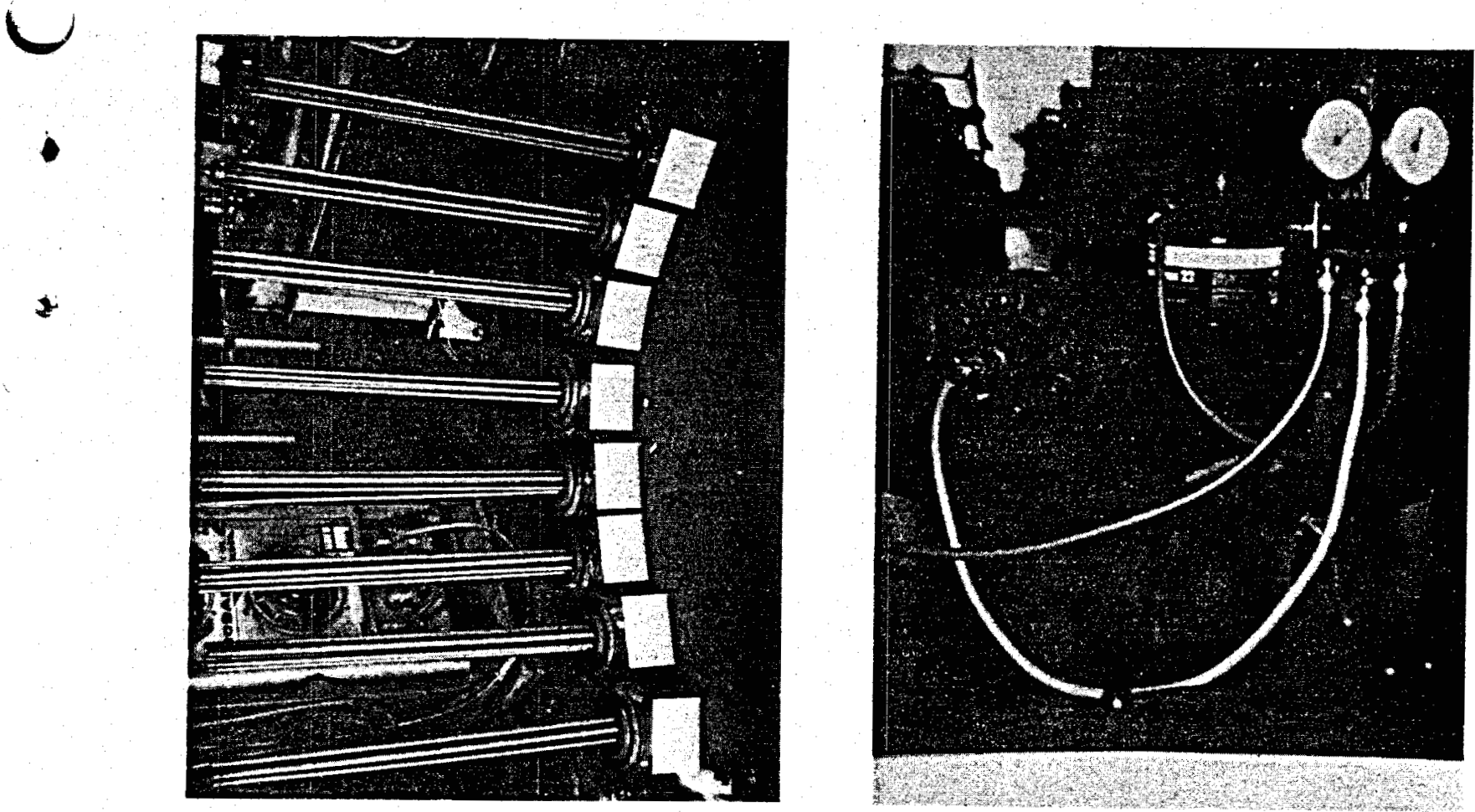

Freon Test Setup
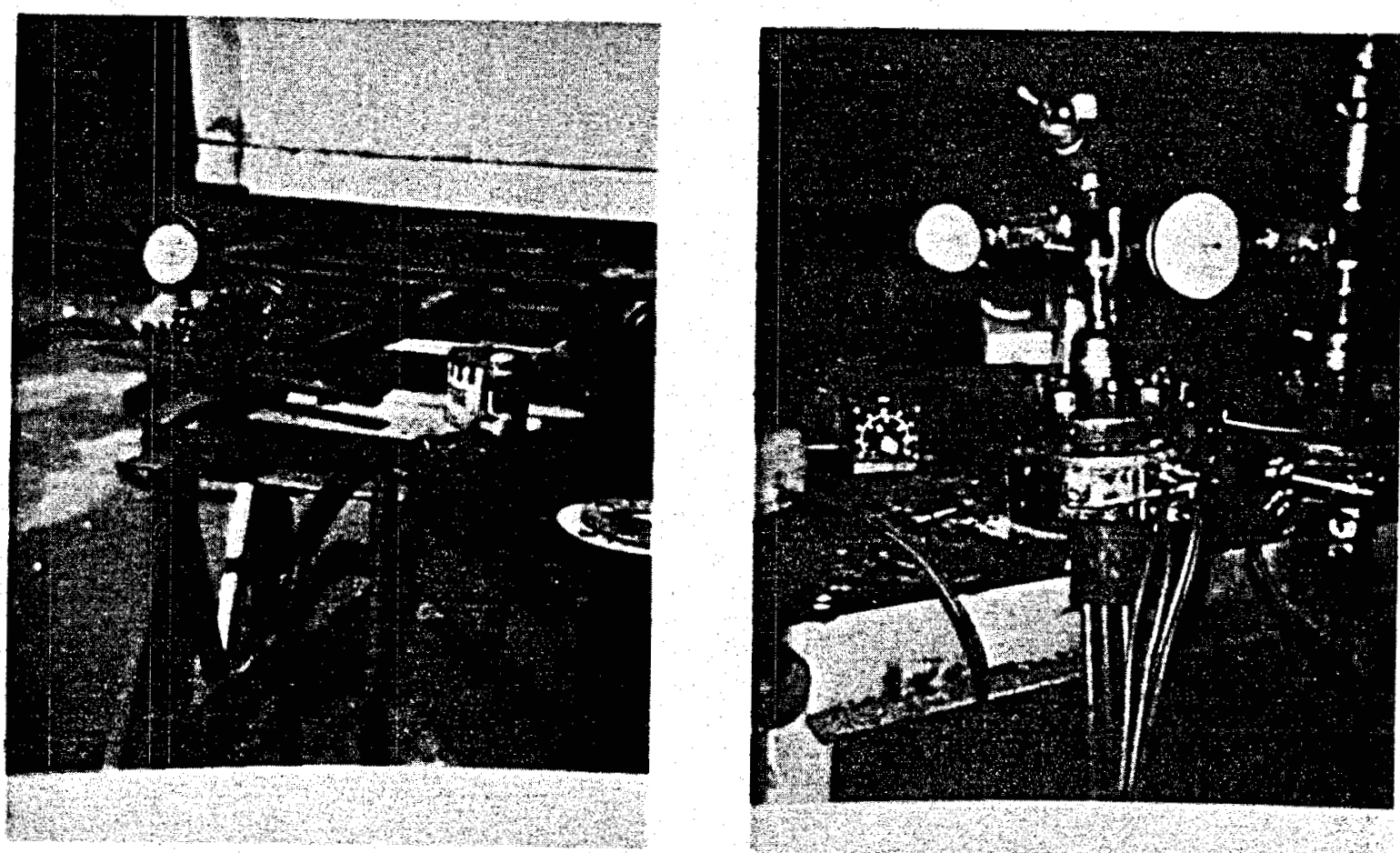

Hydrostatic Test Setup

Torture Test Setup 
June 19, 1980

FIXTURES

2

3

$4-1$

$4-2$

$4-3$

5

6

7

\section{FREON TEST}

No leaks (Rolled)

10:50 AM

No leaks (Rolled)

10:45 AM

No leaks (Rolled)

10:35 AM

Leaks at Tube to Tubesheet Joints and Injection Holes (Flared Only) $1: 30 \mathrm{PM}$

No leaks' (Rolled)

10:40 AM

No leaks (Rolled)

$1: 25 \mathrm{PM}$

Leaks at Tube to Tubesheet Joints and Injection Holes (Flared)

$1: 35$ PM

Leaks at Tubes to Tubesheet Joints and Injection Holes (Flared)

$1: 40$ PM 


\section{FIXTURE}

$2(6 / 23 / 80)$

$3 \quad(6 / 23 / 80)$

$4-1 \quad(6 / 20 / 80)$

$4-3(6 / 23 / 80)$

$5 \quad(6 / 24 / 80)$
HYDRO TEST - 1500 PSI

No Leaks (15 Minutes)

No Leaks (15 Minutes)

No Leaks (20 Minutes)

No Leaks (45 Minutes)

No Leaks (20 Minutes) 
June 20,1980

\section{FREON TEST}

FIXTURE

FIXTURE

IIME 2 (Std. fit holes, rolled tubes) 3 (Close fit holes, rolled tubes)

9:45 AM

No Leaks

No Leaks

No Leaks

No Leaks

10:45 AM

No Leaks

No Leaks

11:15 AM

No Leaks

No Leaks

$11: 45$ AM

No Leaks

No Leaks

12:45 PM

No Leaks

No Leaks

1:45 PM

No Leaks

No Leaks

2:45 PM

No Leaks

No Leaks

3:45 PM

No Leaks

No Leaks

5:00 PM

No Leaks

No Leaks

$8: 00$ AM $(6 / 23)$

No Leaks

No Leaks 
June 23, 1980

\section{FREON TEST}

\section{FIXTURE}

IIME 4-1 (Std. fit \& grooved holes, rolled tubes)

$\begin{array}{ll}\text { 10:30 AM } & \text { No Leaks } \\ 11.00 \mathrm{AM} & \text { No Leaks } \\ 11: 30 \mathrm{AM} & \text { No Leaks } \\ 12: 00 \mathrm{PM} & \text { No Leaks } \\ \text { 1:00 PM } & \text { No Leaks } \\ \text { 2:00 PM } & \text { No Leaks } \\ \text { 3:00 PM } & \text { No Leaks } \\ \text { 4:00 PM } & \text { No Leaks } \\ \text { 5:00 PM } & \text { No Leaks } \\ \text { 8:00 AM (6/24) } & \text { No Leaks }\end{array}$

FIXTURE

5 (Comb. holes, rolled tubes)

No Leaks

No Leaks

No Leaks

No Leaks

No Leaks

No Leaks

No Leaks

No Leaks

No Leaks

No Leaks 
June 24,1980

\section{FREON TEST}

\section{FIXTURE}

TIME

4 - 3 (Std. fit \& grooved holes, tubes welded \& rolled)

$\begin{array}{ll}\text { 8:15 AM } & \text { No Leaks } \\ \text { 8:45 AM } & \text { No Leaks } \\ \text { 9:15 AM } & \text { No Leaks } \\ \text { 9:45 AM } & \text { No Leaks } \\ \text { 10:15 AM } & \text { No Leaks } \\ \text { 10:45 AM } & \text { No Leaks } \\ 11: 15 \text { AM } & \text { No Leaks } \\ 11: 45 \text { AM } & \text { No Leaks } \\ 1: 00 \text { PM } & \text { No Leaks } \\ \text { 2:00 PM } & \text { No Leaks } \\ \text { 3:00 PM } & \text { No Leaks } \\ \text { 4:00 PM } & \text { No Leaks } \\ \text { 5:00 PM } & \text { No Leaks } \\ \text { 8:00 AM (6/25) } & \text { No Leaks }\end{array}$




\section{FREON RETEST (EPOXY APPLIED)}

\section{FIXTURE}

TIME

\#6 (Std. fit \& counterbored holes, flared tubes)

Tubesheets epoxied together (Scotch Weld 2214)

Cured for 20 Minutes at $300^{\circ} \mathrm{F}$ in electric kiln.

$8: 30$ AM $(6 / 25)$

No Leaks

9:00 AM

No Leaks

$9: 30 \mathrm{AM}$

No Leaks

10:00 AM

No Leaks

10:30 AM

No Leaks

11:00 AM

No Leaks

$11: 30 \mathrm{AM}$

No Leaks

12:00 PM

No Leaks

1:00 PM

No Leaks

2:00 PM

No Leaks

3:00 PM

No Leaks

4:00 PM

No Leaks

5:00 PM

No Leaks

$8: 00$ AM $(6 / 26)$

No Leaks

Hydro Retest (Epoxy Applied)

June 26,1980

800 PSI loss in one minute

water Leaks at tube to tubesheet joint and between tubesheets. 
June 26,1980

FIXTURE

TIME

5:00 PM

$8: 15$ AM $(6 / 27)$

No Leaks

No Leaks

4-1 (rolled tubes)

FREON RETEST (FURMANITE INJECTED)

June 27, 1980

(6/30) No Leaks

HYDRO RETEST (FURMANITE INJECTED)

FREON RETEST (EPOXY INJECTED)

TIME

10:30 AM

11:00 AM

$11: 30$ AM

12:00 PM

$8: 00$ AM $(6 / 30)$

June 27, 1980

FIXTURE \#7

No Leaks

No Leaks

No Leaks

No Leaks

No Leaks
FIXTURE

4-2 (Std. fit \& grooved holes, flared tubes)
Water Leaks at Tube to

Tubesheet Joint, 100 PSI

Drop in 10 Minutes
No Leaks

No Leaks 
June 30,1980

\section{FREON RETEST (FURMANITE INJECTED) \\ FIXTURE}

TIME

\#2 (Std. fit holes, rolled tubes)

2:00 PM

No Leaks

2:30 PM

No Leaks

3:00 PM

No Leaks

3:30 PM

No Leaks

4:00 PM

No Leaks

4:30 PM

No Leaks

5:00 PM

No Leaks

8:00 AM (7/1)

No Leaks

HYDRO RETEST (FURMANITE INJECTED)

FIXTURE \#2

FIXTURE \#17

$(7 / 1 / 80)$

No Leaks

No Leaks 
Fixtures $4-1 \& 7(6 / 30 / 80-7 / 1 / 80)$

$2 \& 4-2(7 / 2 / 80)$

a

4-1 a) No leaks

b) Excessive Pressure (Over 3000 psi) caused some extrusion of Furmanite

c) No leaks

7: a) No leaks

b) No leaks

c) No leaks

2: a) Excessive pressure (over 3000 psi) caused extrusion of Furmanite from filler holes and some loss of steam

b) No leaks - some extrusion of Furmanite

c) No leaks

4-2 a) Excessive pressure (over 3000 psi) caused some extrusion of Furmanite

b) No leaks - some extrusion of Furmanite

c) No leaks 
July 3, 1980

Tubes rolled, then welded

close fit holes

.449 I.D.

std. fit holes

.418 I.D.

Tubes welded, then rolled

close fit hole

$.412-.413$ I.D.

sto. fit holes

$.419-.420$ I.D. 